\title{
THE IMPACT OF ELECTRIC VEHICLES ON THE SOUTHERN CALIFORNIA EDISON SYSTEM
}

Final Report

Prepared for the

California Institute for Energy Efficiency

\author{
by \\ Andrew Ford \\ Institute of Safety and Systems Management \\ University of Southern California \\ Los Angeles, CA
}

July 1992 


\section{GENERAL ACKNOWLEDGEMENTS}

The research reported here was made possible by funding from the California Institute for Energy Efficiency (CIEE). I appreciate the financial support of the CIEE and the assistance in organizing and guiding the project from Ed Vine and Jim Cole of the CIEE staff.

This report is one of several interim reports from a team of researchers at the University of Southern California and the University of California at Davis. The technical lead on the project is Dan Sperling from the University of California at Davis. I appreciate Dan's efforts in organizing and co-ordinating the research project. The project has also benefited from many suggestions from the advisory committee whose members are listed on the next page.

Several planners and engineers from the Southern California Edison Company worked with me on this study. They provided useful sources of information, helped with the selection of scenarios, and performed the production costing calculations explained in Chapter 6. I wish to acknowledge the time and effort invested in this project by Richard Schweinberg, Michael Kaiser and Raymond Haug of the Research Division and by Margaret Cheng, Karen Koyano and Jonathan Rubin of Electric System Planning.

I also wish to acknowledge the assistance from other researchers who explained the details of their electric vehicle studies to me. I particularly appreciate the interesting discussions with Lamont Hempel from The Claremont Graduate School and with Glenn Ducat of the Southern California Edison Company. 
Mike Batham

Calif. Energy Commission

1516 Ninth St, MS 43

Sacramento, CA 95814-5512

Nancy Deller

Calif. Energy Commission

1516 Ninth St, MS 43

Sacramento, CA 95814-5512

Mike Eaves

Southern California Gas Co.

818 South Flower Street

Los Angeles, CA 90017

Jerry Enzenauer

Dept. of Water and Power

PO Box 111, Room 1106

Los Angeles, CA 90051

Steve Gauthier

Gas Research Institute

8600 West Byrn Mawr Av

Chicago, IL 60630

Phil Heirigs

Mobil Source Division

Air Resources Boaxd

9528 Telstar Avenue

El Monte, CA 91731

Jeff Horne

Southern Calif. Gas Company

810 South Flower Street

Los Angeles, CA 90017

Rod Lighthipe

San Diego Gas \& Electric

New Products Development

P.O. Box 1831

San Diego, CA 92112-4150

Allan Lloyd

South Coast AQMD

21865 E. Copley DI

Diamond Bar, CA 91765-4182

Dwight MacCurdy

Sacramento Municipal

Utilities District

PO BOX 15830, MS73

Sacramento, CA 95852-1830
Gary Occhuizzo

Calif. Energy Commission

1516 Ninth St, MS 22

Sacramento, CA 95814-5512

Larry o'Conne 11

Electric Power Research

Institute

P.O. Box 10412

Palo Alco, CA 94303

Roland Risser

Pacific Gas Electric Co. 3400 Crow Canyon Road

San Ramon, CA 94583

Don Schultz

Public Utilities Commission

1107 Ninth St, Room 710

Sacramento, CA 95814

Richard Schweinberg

Southern California Edison

P.O. Box 800

Rosemead, CA 91770

Don Siglex

Dept. of water \& Power

PO BOX 111, Room 1106

Los Angeles, CA 90051

Brian Stokes

Pacific Gas Electric Co

3400 Crow Canyon Road

San Ramon, CA 94583

Paul Wuebben

South Coast AQMD

21865 E. Copley DI

Diamond Bar, CA 91765-4182

Beth Young

General Motors Electric Vehicle Group

5869 Devon Drive

Rocklin, CA 95677 


\section{ACRONYMS AND ABBRJVIATIONS}






\section{TABLE OF CONTENTS}

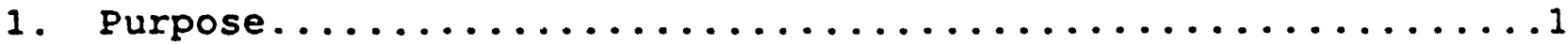

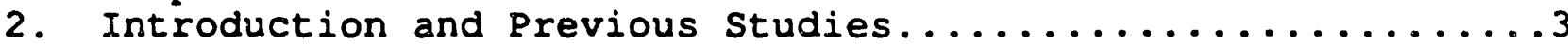

2.1. Introduction

2.2. General Review

2.3. Southern California Scenario Studies

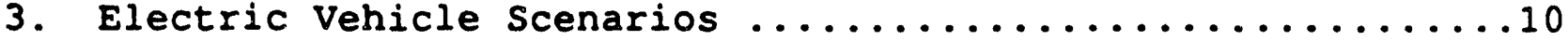

3.1. Nature of Scenario Studies

3.2. Summary of Eight EV Scenarios

3.3. The SCE System

4. Growth in Electric Vehicle Use in Southern California.....15

4.1. Introduction

4.2. Two Million EVs in the SCE Area

4.3. One Million EVs in the SCE Area

4.4. Discussion

5. Electricity Demand from Electric Vehicles...............25

5.1. Electricity Demand from Simple Examples

5.2. Night Time Charging Assumptions

5.3. Day Time Charging Assumptions

5.4. 1st Scenario: Charging at Customer Convenience

5.5. 2nd Scenario: Charging with a "10pm Incentive"

5.6. 3rd Scenario: Charging with "Smart Control"

5.7. 4th Scenario: Charging with Less Advanced Batteries

5.8. 5th \& 6th Scenarios: Demand from One Million EVs

5.9. 7th \& 8th Scenarios: Demand in the Year 2000

5.10. Discussion: Daily, Weekly and Seasonal Cycles

6. Impact of EVs on Utility production Costs.............52

6.1. Introduction

6.2. Electric Generation to Serve the EV Load

6.3. EVs' Impact on the Cost to Operate the System

6.4. The Role of PURPA QES

6.5. Are Extra Resources Needed to Serve the EV Load?

6.6. EVs' Impact on the Average Electric Rate

7. Electric Vehicles and Emission of Air Pollutants........66

7.1. Avoiding Emissions from Conventional Vehicles

7.2. Monetary Value of Avoided Emissions

7.3. Discussion of Upstream Effects

7.4. NOx Emissions from Two Million EVS

7.5. NOx Emissions from In Basin Comparisons

7.6. Discussion

8. Airshed Modeling and Peak Ozone Concentrations ........78

8.1. Introduction

8.2. Summary of Previous Projections

8.3. Discussion

8.4. Interpolating from Previous Projections

9. Summary of Important Findings..................86

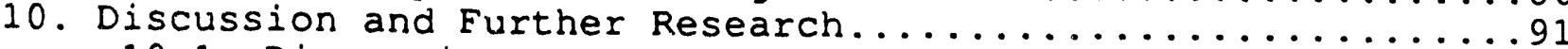
10.1. Discussion

10.2. Further Research

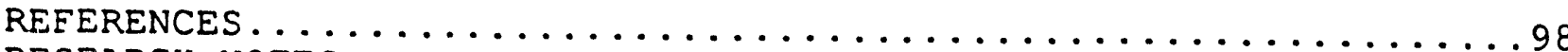

RESEARCH NOTES 


\section{IIST OF TABLES AND EIGURES}

Table I. Electric Vehicle Scenarios

Table II. Day Time Charging Assumptions

Eig. 1. Comparison of EV Scenarios for the South Coast

Eig. 2. Position of EV Scenarios $\$ 1, \$ 2$ and $\$ 3$

Fig. 3. Market Share Assumptions for EV Scenario 1.

Fig. 4. Comparison of Market Shares with CARB Requirements.

Fig. 5. Population of EVs Operating in Scenarios 1-4.

Fig. 6. Comparison of Market Shares with CARB Requirements.

Fig. 7. Comparison of Market Shares with Two Ways to Comply with the CARB Requirements.

Fig. 8. Electric Demand from one Million Large Vans

Fig. 9. Electric Demand from One Million Large Vans

Fig. 10. Electric Demand from One Million Large Vans

Fig. 11. Electric Demand in the 1st Scenario

Fig. 12. Electric Demand in the 2nd Scenario

Fig. 13. Electric Demand from Two Million EVs with "Blind Control"

Fig. 14. Electric Demand in the 3rd Scenario

Fig. 15. Comparison of 3rd Scenario Profile with a Flat Profile

Fig. 16. Electric Demands in the First Four Scenarios

Fig. 17. Electric Demand in the 5 th and 6 th Scenarios

Fig. 18. Electric Demand in the 7 th and 8 th Scenarios

Fig. 19. Avoided Hydrocarbon Emissions from Sale of EVs in 1993

Fig. 20. Avoided Hydrocarbon and NOx Emissions Sale of EVs

Fig. 21. Monetary Value of Avoided Emissions from Sale of EVs

Fig. 22. Ratio of NOx Emissions from a CV and a Power Plant

Fig. 23. Comparison of Peak Ozone Projections

Fig. 24. Comparison of Peak Ozone Projections

Fig. 25. Comparison of Peak Ozone Projections

Fig. 26. Peak Ozone Projections in SCE Airshed Modeling 


\section{Chapter 1. Purpose of the Report}

This report describes the results of the first phase of an investigation of the impacts of electric vehicles (EVs) in southern California. Readers interested in a short summary should skip to Chapter 9 which summarizes the important findings in the report.

The investigation focuses on the Southern California Edison Company (SCE) which provides electric service for approximately $60 \%$ of southern California. The report is one of several reports completed in collaborative research by faculty from the University of California at Davis (UCD) and the University of Southern California (USC). The project is supported by the "Air Quality Impacts of Energy Efficiency" Program of the California Institute for Energy Efficiency (CIEE). The first phase of the research is organized around how EVs might be viewed by customers, vehicle manufacturers and electric utility companies. The customers' view is examined in a preliminary report on the "Market Potential of Electric and Natural Gas Vehicles" by sperling, Turrentine and Kurani (1991) from the Institute of Transportation Studies at UCD. A final version of the market potential study is scheduled for completion early in 1992. The vehicle manufacturers' view has been studied with special emphasis on the role of marketable permit systems. The preliminary findings are reported in "Economic Incentives to Introduce Electric and Natural Gas Vehicles and Reduce Mobile Source Emissions" by Kling, Sperling and Wang (1991). $A$ final version of the incentives study is also scheduled for completion early in 1992 .

The utilities' view of EVs is the subject of this report. It begins with a general introduction and a short review of previous EV studies in Chapter 2. The review is particularly important as several case studies of EVs in southern California have been conducted in recent years. Chapter 3 explains the "scenarios" approach and summarizes the key features of the eight EV scenarios adopted for the study. The dynamics of a growing population of EVs is explained in Chapter 4. Chapter 5 explains a simple method of deriving the electricity demands which could result from the operation of EVs in southern California. The method is demonstrated for several simple examples and then used to find the demands associated with each of the eight EV scenarios. Chapter 6 reports the impacts on SCE operations from the new demands for electricity. Impacts are summarized in terms of system operating costs, reliability of service, and changes in the utility's average electric rate. For readers interested primarily in utility operations, Chapters 5 and 6 constitute the heart of the report. 
Chapter 7 turns to the emissions of air pollutants released by the operation of EVs, conventional vehicles (CVs) and power plants. The air pollution benefits of EVs are summarized in terms of tons/year of avoided emissions and in dollars per EV. Chapter 8 takes the air pollution analysis one step further by examining the possible reduction in ambient ozone concentration in southern California. I use simple interpolation from previous ozone modeling studies, and I explain why such a simple approach turns out to be useful.

Chapter 9 summarizes the important findings from the first phase of the research and may be viewed as an executive summary of the report.

Chapter 10 is reserved for a discussion of interesting issues which were not addressed in the first phase of the research. The plans for the next phase of the research are explained.

Detailed research notes are included in the appendix to the report. The notes are organized in a series of spread sheets which document the calculations and information sources used in the analysis. The sheets are included to allow other researchers to follow the analysis in a step by step fashion. 


\section{Chapter 2. Introduction and Previous Studies}

\subsection{Introduction}

As the United States entered the 20th Century, the largest selling car was not powered by the internal combustion engine. The largest seller was the "steamer", a steam-powered vehicle that carried its own water and fuel to operate the boiler. The steamers dominated the market from 1899 to 1901. Interestingly, their nearest competition was not powered by internal combustion engines. Rather, the second best selling vehicle of that time was powered by electric motors. The EVs of 1900 were viewed as quiet and reliable, but their heavy batteries limited their speed and range. Internal combustion engine vehicles (ICEVs) occupied third place in the market for new cars. They were difficult to start, noisy and mechanically complicated. According to Col. Albert Pope, the largest automobile manufacturer at the turn of the century, the internal combustion engine had a bleak future because "you can't get people to sit over an explosion" (Volti 1990, p. 42). Less than two decades later, however, the vast majority of cars manufactured in the United States were ICEVs.

The early history of EVs and their competition with ICEVs is told in Rudi Volti's (1990) answer to the fundamental technological question of US auto manufacturing: "Why Internal Combustion?" Volti explains how the greater speed, acceleration, and range of the ICEVs won out in the competition with steamers and EVs. ICEVs were also aided along the way by the development of an electric battery to replace the crank starter. EVs, on the other hand, were hampered by limited speed and acceleration. Volti also explains that EVs were less popular because the electric utility companies were not as aggressive as the oil companies in setting up charging stations to deliver their fuel.

This report explains that extensive use of EVs in southern California can benefit the SCE system while contributing to improvement in southern California's air pollution problem. Chapter 6 shows that over a million EVs could be accommodated with SCE's existing resource plan, and the improvement in efficiency of SCE operations could result in reductions in the company's average electric rate. Such benefits have prompted many planners to ask whether utility companies should actively promote the sale and use of EVs. Promotional options include (1) research and demonstration programs, (2) provision of supporting infrastructure, (3) offering low electric rates for night-time charging and (4) provision of direct financial incentives to lower the initial purchase price of the vehicle. Volti's account of how EVs lost their position at the start of the century is instructive for planners studying the 
possible ascendancy of EVs at the end of the century. Many of the research questions of today were raised in somewhat different form at the start of the century. Volti (1990, p. 46) notes, for example, that Thomas Edison suggested that power stations go into the garage business to stimulate the demand for electric vehicles.

\subsection{General Review}

In a review of the "modern history of electric vehicles," Deluchi (1989, p. 255) observes that interest in EVs has peaked three times in the past few decades. The first peak occurred in the mid-1960s; it coincided with a growing concern over urban air pollution. The second peak arrived in the late 1970 s as a reaction to the nation's problems from oil imports. The third surge is said to have started in the mid-1980s, and it continues to the present day. This current surge is attributed to a combination of concerns over energy security and urban air pollution.

My review begins with reports prepared at the end of the 1970 s during the second surge of interest. Several reports provide useful information despite the major changes in EV technology since the 1970s. These include the extensive study by Mathtech (1978) on "The Impact of Electric Passenger Automobiles on Utility System Loads, 1985-2000" conducted for the Electric Power Research Institute (EPRI) and Hamilton's (1980) description of Electric Automobiles. Hamilton's (1982) assessment of the "Social and Environmental Impacts of Electric Hybrid Vehicles" also proved useful.

As one would expect, the most useful studies have been conducted in the late 1980 s during the third surge of interest in EVs. For a national perspective, the most useful publications have been produced by researchers from the Institute for Transportation Studies at UCD. These include an assessment of the "Emission Impacts of Electric Vehicles" (Wang 1990) and a "Comparison of Primary Energy Consumption by Gasoline Internal Combustion Engine Vehicles and Electric Vehicles" (Wang and Deluchi 1991). The most detailed and comprehensive publication is Deluchi's (1989) "Electric Vehicles: Performance, Life Cycle Costs, Emissions and Recharging Requirements."

One of the most recent EV studies is Diane Fisher's (1991) assessment of the relative potential for "Reducing Greenhouse Gas Emissions With Alternative Transportation Fuels." EVs are compared along side of vehicles fueled by methanol, ethanol, and compressed natural gas (CNG) to learn which combination of vehicles (and fuel supply) will lead to the largest reduction in greenhouse gases over the vehicle lifecycle. 
Several studies are proceeding in parallel with my
investigation, and some reports have been released while my research was underway. The Southern California Association of Government (SCAG) has released Phase I and II reports on their assessment of the regional mobility benefits and the air pollution benefits of "Highway Electrification and Automation Technologies" (SCAG 1991). The SCAG reports document the initial steps in a three-year investigation of regional impacts from implementing advanced highway technologies in the greater Los Angeles area. Another ongoing study is funded by the California Air Resources Board (CARB). The CARB has contracted with Bevilacqua-Knight, Inc. to produce a "1990 Electric Vehicle Systems Update" (Knight 1991) to complement CARB's previous assessment of electric vehicle technologies conducted in 1985 (CARB 1985). The CARB report is particularly important as many planners view the initial market for EVs as driven by the CARB requirements for Zero Emission Vehicles (ZEVS). The CARB update is especially relevant to this report because the authors were willing to speculate about the likely characteristics of EVs operating in California over 15 years into the future. The characteristics of their "nominal EVs" are used directly in the Chapter 5 portrayal of the electricity demand from each of eight EV scenarios. A third, ongoing study is supported by the Northeast States for Coordinated Air Use Management (NESCAUM). In a preliminary report to NESCAUM, Michael Tennis (1991) estimates the air pollution benefits if the ZEV provisions of the CARB program were implemented in the northeast states. Theodure Barry \& Associates has recently completed a comparative analysis of electric vehicles and other clean fuel vehicles which finds that EVs are "the most environmentally sound of all clean fuel vehicle options in Southern California" (TB\&A 1991, p. 2). And finally, the California Energy Commission (CEC) staff has just completed an interesting "Analysis of the potential Electricity Demand, Electricity Supply and Emissions Imracts of Electric Vehicles" (CEC 1992).

\subsection{Review of Southern California Scenario Studies}

Because of its serious air pollution problems, southern California is a focal point for interest in EVs. During the past few years, six different assessments of EVs have been reported that are directly relevant to my investigation. The first three are especially helpful because EVs are their primary focus:

The Claremont Report: The Claremont Graduate School report on "Curbing Air Pollution in Southern California: The Role of Electric Vehicles" (Hempel 1989) was produced by Professor Lamont Hempel and his students at the Center for Politics and Policy. The report is organized around "Steady Advance" and "Breakthrough" scenarios for EV penetration in the South coast region. The report 
includes a (1) broad analysis of EV characteristics, (2)

estimates of changes in air emissions, and (3) projections of peak ozone levels using the airshed model developed by Science Applications, Inc (SAI). It concludes with an informative discussion of public policy considerations.

Ducat's Study: In his 1989 report from the Electric System Planning Division of the SCE, Glenn Ducat analyzed the extent of EV penetration that could be accommodated on the SCE system by the year 2008 without deploying additional generating capacity over and above that which would be required without EVs. Ducat's report concentrates on utility planning and operational implications of EVs by analyzing a "deployment scenario" in which 600,000 large electric vans could be accommodated if vehicle recharging were restricted to off- peak hours.

The RFF Study: The Resources for the Future (RFE 1990) study on "Electric Vehicles and the Environment: Consequences for Emissions and Air Quality in ios Angeles and U.S. Regions" was supported by EPRI and the South Coast Air Quality Management District (SCAQMD). The study was organized around scenarios involving both EVs and methanol vehicles. The scenarios were constructed with "modest but realistic penetration rates" that "are designed to bound the changes in emissions and ozone concentrations likely to accompany EV penetration." Iike the Claremont study which preceded it, the RFF analysis projected changes in ozone concentrations in the south coast region. This analysis used the airshed model developed by Carnegie Melion University and the California Institute of Technology.

The remaining studies were conducted by the California Energy Commission (CEC) and the South Coast Air Quality Management District (SCAQMD). These studies include EV scenarios and EV impacts along side of a wide range of other measures that could be taken to improve air quality in southern California.

SCAQMD 1989 Plan: In March of 1989, the SCAQMD and the Southern California Association of Governments (SCAG) issued the Final 1989 Air Quality Management Plan. The plan is comprised of many different reports. The report which touches on EVs is Appendix IV-B entitled "Tier III Control Strategy: Energy Future" whose primary objective is to identify the emission reduction potential from large scale electrification.

SCAQMD 1991 Revision: In May of 1991, the SCAQMD and the SCAG issued the draft final 1991 Air Quality Management 
Plan. The revised plan has the same overall strategy and targets as the 1989 plan, but the modeling and data behind the plan have been improved, and there have been several changes in control measures. As far as energy issues are concerned, the revised plan is said to achieve "much higher level of consensus on energy impacts" ( $p$. ES-15) because of the findings from an energy working group. Information on EVs is reported in draft Appendix IV-D on "Energy Conservation Measures and Energy Analysis for Control Strategies."

CEC Scenarios Project: Working with analysts from the SCAQMD, analysts from the CEC completed an "Air Quality Scenarios Project" in November of 1990. The purpose of the project was to develop a better analytic understanding of the energy and emissions consequences of the three major elements of the 1989 Air Quality Marlagement Plan issued by the SCAQMD and the SCAG. The study was organized around a base line scenario and six scenarios which were analyzed for reduction in emissions. Patrick Mcauliffe's analysis of "Electric Generation and Emissions" is particularly relevant to EVs.

Figure 1 arranges the EV scenarios appearing in the six studies for convenient comparison with one another. Each of these scenarios was developed at the end of a twenty year planning period, so they correspond to conditions envisioned for the time period around 2008 to 2010. Since each scenario was assembled in a somewhat different manner, the Eigure 1 comparison required some digging and extra calculations. (The details are reported in Spread Sheet \#1 in the Appendix.) Each scenario is located on the horizontal axis by the number of EVs and on the vertical axis by the annual sales of electric energy to fuel the EVs. The three rays in Eigure 1 allow one to also position the scenarios relative to their daily energy requirement. Notice, for example, that both the "breakthrough" and "steady advance" scenarios in the claremont study envision EVs using $20 \mathrm{kwh} /$ day. This daily usage is the result of a daily travel assumption of 33 miles and a vehicle efficiency of 1.66 miles/kwh. The "breakthrough" scenario envisions 5 million EVs which would amount to nearly half of the vehicles operating in the South Coast region. Claremont's "steady advance" scenario envisions $2.8 \mathrm{million}$ vehicles which is roughly $25 \%$ of the vehicle population.

The three scenarios from the CEC and the SCAQMD may be viewed as a group since the two agencies have co-ordinated their analyses. The CEC's "High EV" scenario has the largest number of vehicles, nearly 7 million or around two-thirds of the vehicle population. These vehicles are limited to $28 \mathrm{miles} / d a y$ of travel, and they operate with an efficiency of $2.5 \mathrm{miles} / \mathrm{kwh}$. Thus, their energy requirement is only $11.2 \mathrm{kwh} /$ day. The SCAQMD assumptions in their 1989 Plan and the 1991 Revision is around 2 million vehicles. The 


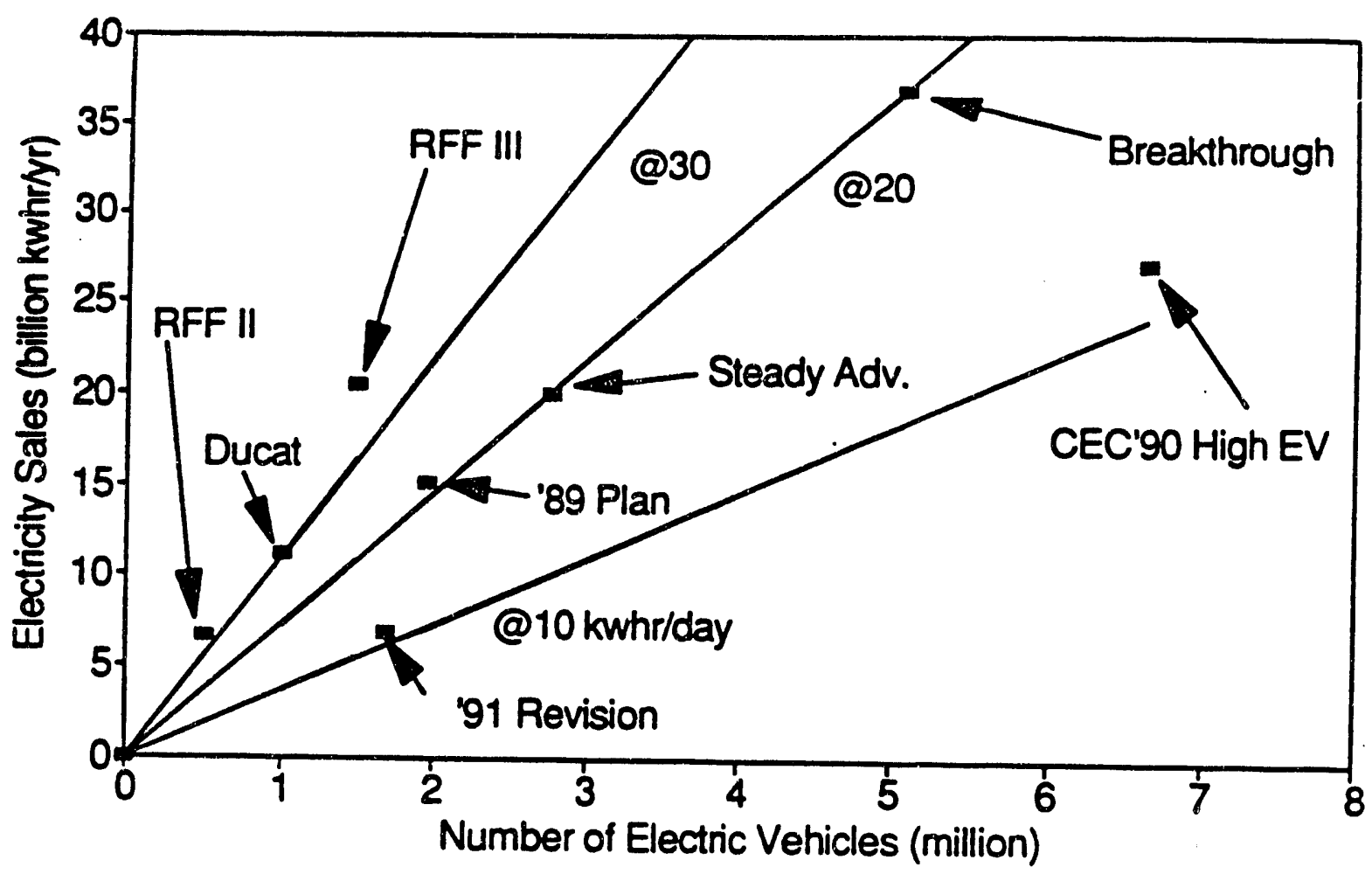

Figure 1. Comparison of EV Scenarios for the South Coast.

$20 \mathrm{kwh} /$ day energy requirement in the $1989 \mathrm{plan}$ appears to be the result of a $28 \mathrm{miles} /$ day travel assumption and an efficiency of. .33 miles/kwh. With the 1991 Revision, however, each vehicle is assumed to require only $11.2 \mathrm{kwh} /$ day. This energy requirement is the same as the CEC's "High EV" scenario and it appears to come from the same combination of assumptions $(28$ miles/day e 1.33 miles/(hwh).

The two RFF scenarios and Glenn Ducat's deployment scenario may be viewed as the final group in Figure 1 because of their interesting position in the left side of the diagram. Each of these scenarios envisions electricity demands exceeding $30 \mathrm{kwh} / \mathrm{day}$ per vehicle. In Ducat's case, the high usage stems from his decision to use the Griffon electric van as the typical Ev. The Griffon was selected because its energy requirements and charging profiles are well known. Ducat's combination of assumptions lead to the average Griffon traveling around $44 \mathrm{miles} /$ day and operating at an efficiency of $1.42 \mathrm{miles} / \mathrm{kwh}$ for an energy requirement of around $31 \mathrm{kwh} /$ day. The two RFF scenarios are also based on vans, but they selected the TEVan with a Nickel Iron (Ni/Fe) battery and an overall efficiency of 2.14 miles/kwh. The RFF (1990, p. 2-4) scenarios envision that each EV would travel $80 \mathrm{miles} / \mathrm{day}$, an assumption which was adopted to "create a scenario where in-basin 
existing generation capacity would be exceeded while still hoiding penetration rates to a realistic $15 \%$ of the stock of passenger vehicles and light duty trucks."

Three main lessons may be drawn from the separate analyses of the EV scenarios spread across Figure 1. The first and most covious lesson is that investigators may arrive at substantially different characterizations of the future of EVs. These differences arise from inevitable uncertainty in EV penetration, daily travel, and characteristics of EVs. But, more importantly, they arise from important differences in the focus of each study. The large differences in daily travel is an example. The SCAQMD and CEC scenarios limit EV travel to $28 \mathrm{miles} /$ day due, in part, to the travel restrictions to be implemented as part of the plan. The RFF, on the other hand, sets travel at $80 \mathrm{miles} /$ day as a means of increasing total electric demand (while keeping EV penetration to "realistic" levels).

Another major difference involves the number of EVs envisioned for twenty years in the future. In the Claremont study, Hempel and his students purposely created a "breakthrough" scenario with almost half the vehicle population as EVs. Their goal was to learn more about the factors that will influence the development of clean fuel technologies in the Los Angeles region (Hempel 1989, p. 37). The RFF scenarios and Ducat's deployment scenario, on the other hand, were created with a more specific goal in mind. These investigators were interested in the level of $\mathrm{EV}$ penetration that might be accommodated with the generating resources expected to be operating over the next two decades with the utilities' existing expansion plans. Ducat's scenario focuses directly on the maximum deployment level, and the RFF scenarios were created to land below and above their estimate of the deployment level.

Despite the wide differences apparent in Figure 1, the scenario studies arrive at some common conclusions. The most important conclusion is that a major fraction of the electric energy needed to fuel EVs will be provided by natural gas-fired generating units. Thus, a southern California EV scenario quickly translates into a natural gas scenario. The studies also draw some common conclusions about the impact of EVs on emission of key air pollutants. As a group, they lead one to conclude that displacing conventional gasoline fueled vehicles with EVs will lead to major reductions in Reactive Organic Gasses (ROG) and Carbon Monoxide (CO). And depending on the relative efficiency of new conventional vehicles and gas burning power plants, EVs would lead to important reductions in emissions of Nitrogen Oxides (NOx). Four of the studies conduct airshed modeling to arrive at how EV penetration can reduce peak ozone concentrations. Common conclusions from the airshed modeling are discussed later in Chapter 8 of this report. 


\section{Chapter 3. Electric Vehicle Scenarios}

\subsection{Nature of Scenario Studies}

Each of the EV studies represented in Figure 1 is described as a scenario study or a scenario analysis. The term "scenario" originated in the field of drama and was then borrowed for war gaming and large-scale simulations (Turban 1988, p. 47). Scenario analyses are becoming widely used in the energy field as planners search for more effective means to plan for a highly uncertain future (Wack 1985; SCE 1986,1988; BPA 1988; Hadfield 1991): A recent scenario study by the Puget Sound Power and Light Company (1989, p. 29) defines scenario analysis as a way to

stimulate thinking about the future and to add context to the way the Company deals with uncertainties.

A report from the Bonneville Power Administration (BPA 1988, p. 1) describes scenario planning as

a strategic planning tool that acknowledges the unpredictability of the future, allows for the eventuality of several different plausible futures, and focuses on the development--and :ehearsal--of responses that most efficiently meet the challenges and opportunities inherent in each scenario.

A review of past applications of scenario analyses by energy planners is given in recent report to the BPA (Geinzer, Cranna and Ford 1991). The review shows great diversity in the approaches taken and concludes that there is no "right or wrong" way to conduct a scenario study. Preparing a scenario is much like writing a script for a play; a good scenario analysis is an internally consistent account of what it would be like if the scenario were actually to happen. The purpose is to help planners identify problems and opportunities and, as the Bonnevilie report has noted, to rehearse a response.

The scenario analysis reported here has a similar purpose. The goal is to identify the likely problems or opportunities arising from extensive use of EVs in southern California. Like the investigators who have conducted the previous EV scenario studies, I caution the reader to avoid focusing on these scenarios as forecasts of what is likely to happen in the future. The point of focus should be the conclusions drawn from the scenario analysis. These conclusions are summarized in Chapter 9. 


\subsection{Summary of Eight Scenarios}

Eight scenarios were selected for examination. The scenarios differ in terms of the total number of vehicles, the batteries used to power the vehicle, the range from an overnight charge, the pattern of night time charging and the need for day time charging. These differences are summarized in Table I as follows:

Number of Vehicles: In the spirit of scenario analysis, I have selected easily remembered numbers: 2 mililion, 1 million, and million. When the 2 million EVs in the SCE service area is expanded to the south Coast, one would envision around 3.3 million EVs by the year 2010; every third vehicle would be an EV. The population of EVs is broken down into five classes (large vans, small vans, large cars, small cars, and light trucks) before assigning batteries and efficiencies.

Year: The year 2010 is selected for six of the scenarios. This corresponds to the end of the long term planning period for SCE, and it is sufficiently far in the future that advanced, high performance EVs may be ready for commercial use. The $7 \mathrm{th}$ and 8 th scenarios look at the year 2000 which is midway through SCE's planning interval. The near-term scenarios assume that less advanced batteries will be available.

Night Time Charging: The timing of night time charging depends on the charging profile and when the charger begins drawing power. Table I notes that night time charging in the eight scenarios is instigated at the convenience of the vehicle owner, is instigated at the customer's convenience subject to a financial incentive to delay charging until $10 \mathrm{pm}$, or is subject to so-called "smart control" by SCE.

Day time Charging: Table I reports that battery charging during day time hours is "minimal" in the five scenarios with the EVs" ranges set at 250 miles. "Some" day time charging is assumed in the long-term scenario with EVs' ranges set at 150 miles. "More" day time charging is assumed in the two scenarios for the year 2000 .

Advanced Batteries: EV scenarios $\# 1,2,3$ and $\# 4,5$ assume that all five classes of EVs will be powered by Sodium Sulfur (Na/S) batteries. These are advanced, high temperature batteries which some forecasters expect will be available by the year 2010. They are capable of a 250 mile range from a single overnight charge, so the need for day time charging is "minimal." The efficiency of EVs is reported in miles/kwh (to be analogous to miles/gallon 
for a conventional vehicle). The efficiencies for $\mathrm{Na} / \mathrm{S}$ EVs range from a low of $1.67 \mathrm{miles} / \mathrm{kwh}$ for the large vans to a high of $4.17 \mathrm{miles} / \mathrm{kwh}$ for small cars.

Near Term Batteries: EV scenarios $\$ 7,8$ apply to the year 2000, and the EVs are assumed to be powered by less advanced batteries. The 4 th scenario envisions that less advanced batteries will still dominate iri the year 2010 . These scenarios assume that cars will operate with sealed, lead acid (Pb/acid) batteries with a range of 150 miles and efficiencies of $2.45 \mathrm{miles} / \mathrm{kwh}$ (large car) and $4.17 \mathrm{miles} / \mathrm{kwh}$ (small car). They assume that vans and trucks will operate with Nickel Iron (Ni/Fe) batteries with a $150 \mathrm{mile}$ range and efficiencies of $1.11 \mathrm{miles} / \mathrm{kwh}$ (large van and light truck) and $1.67 \mathrm{miles} / \mathrm{kwh}$ (small van).

Table I. Electric Vehicle Scenarios.

\begin{tabular}{|c|c|c|c|c|c|}
\hline 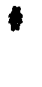 & $\begin{array}{l}\text { Number } \\
\text { of EVs }\end{array}$ & Year & $\begin{array}{l}\text { Night time } \\
\text { Charging }\end{array}$ & $\begin{array}{l}\text { Day time } \\
\text { Charging }\end{array}$ & $\begin{array}{l}\text { Batteries, Range and } \\
\text { small car efficiency }\end{array}$ \\
\hline 1 & 2 million & 2010 & $\begin{array}{l}\text { customer } \\
\text { convenience }\end{array}$ & minimal & $\begin{array}{l}\text { Na/S, } 250 \mathrm{miles} \\
4.17 \mathrm{miles} / \mathrm{kwh}\end{array}$ \\
\hline 2. & 2 million & 2010 & $\begin{array}{l}\text { customer } \\
\text { incentive }\end{array}$ & minimal & $\begin{array}{l}\text { Na/S, } 250 \text { miles } \\
4.17 \text { miles/kwh }\end{array}$ \\
\hline 3 & 2 million & 2010 & $\begin{array}{l}\text { smart } \\
\text { control }\end{array}$ & minimal & $\begin{array}{l}\text { Na/S, } 250 \mathrm{miles} \\
4.17 \mathrm{miles} / \mathrm{kwh}\end{array}$ \\
\hline 4 & 2 million & 2010 & $\begin{array}{l}\text { customer } \\
\text { convenience }\end{array}$ & some & $\begin{array}{l}\mathrm{Ni} / \mathrm{Fe} \text { and } \mathrm{Pb} / \mathrm{acid} \\
150 \mathrm{miles} \\
4.17 \mathrm{miles} / \mathrm{kwhr}\end{array}$ \\
\hline 5 & 1 million & 2010 & $\begin{array}{l}\text { customer } \\
\text { convenience }\end{array}$ & minimal & $\begin{array}{l}\text { Na/S, } 250 \mathrm{miles} \\
4.17 \mathrm{miles} / \mathrm{kwh}\end{array}$ \\
\hline 6 & 1 million & 2010 & $\begin{array}{l}\text { smart } \\
\text { control }\end{array}$ & minimal & $\begin{array}{l}\text { Na/S, } 250 \text { miles } \\
4.17 \text { miles/kwh }\end{array}$ \\
\hline 7 & $\begin{array}{l}50 \\
\text { thousand }\end{array}$ & 2000 & $\begin{array}{l}\text { customer } \\
\text { convenience }\end{array}$ & more & $\begin{array}{l}\mathrm{Ni} / \mathrm{Fe} \text { and } \mathrm{Pb} / \mathrm{acid} \\
150 \mathrm{miles} \\
4.17 \mathrm{miles} / \mathrm{kwh}\end{array}$ \\
\hline$B$ & $\begin{array}{l}500 \\
\text { thousand }\end{array}$ & 2000 & $\begin{array}{l}\text { customex } \\
\text { convenience }\end{array}$ & more & $\begin{array}{l}\mathrm{Ni} / \mathrm{Fe} \text { and } \mathrm{Pb} / \mathrm{acid} \\
150 \mathrm{miles} \\
4.17 \mathrm{miles} / \mathrm{kwh}\end{array}$ \\
\hline
\end{tabular}

The two million EV scenarios in Table I were selected in the same spirit as the scenarios from the claremont study. That is, planners do not necessarily expect that there will be two million EVs in the SCE service territory in the year 2010. Nevertheless, it is useful explore the implications of such extensive use of EVs. 
Three versions of the two million vehicle scenario were selected to test the importance of changes in the night time charging strategy. The fourth scenario with 2 million EVs was included to learn the importance of changes in the batteries used to power the EVs. The likely impacts from the 2 million EV scenarios may be anticipated by comparison with previous scenario studies. Figure 2 helps one make this comparison by locating the position of the three scenarios relative to the studies summarized in Eigure 1. The horizontal position is set at 3.3 million to correspond to the total number of EVs which are envisioned to be used in the South Coast in the year 2010. The vertical position is based on total electricity sales to EVs which would be around $20 \mathrm{billion} \mathrm{kwh} /$ year spread over the South Coast. Figure 2 reveals

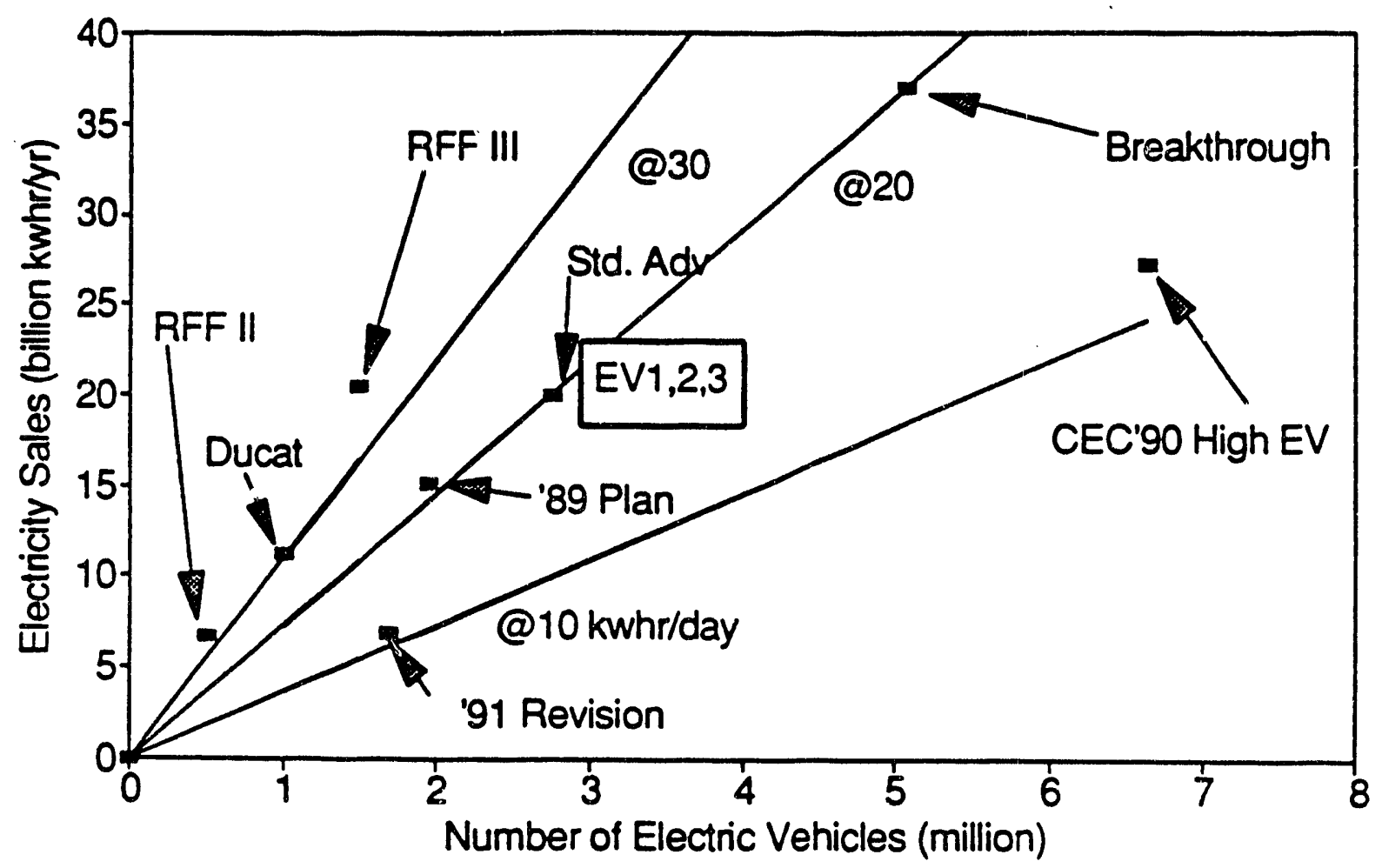

Eigure 2. Position of the EV Scenarios 1, $2 \& 3$.

that the nearest scenario from a previous study is the "steady advance" example from the claremont study. When looking strictly at electricity sales, Figure 2 shows that the first three scenarios are similar to the RFE III scenario and well above Ducat's "deployment" scenario. This position is intentional. The idea was to include at least one scenario with electricity sales that exceed the sales that previous researchers found could be accommodated with existing resource plans. Based on the previous findings, the reader may anticipate that the 2 million EVs assumed in the first three scenarios would require SCE to include additional resources in its long term plan. 
Scenarios 5,6 envision one million EVS in the SCE service area. These examples were selected to study the impacts of scenarios closer to the 1991 revision in the SCAQMD plan. If one expands the one million vehicles to cover the south coast, for example, there would be 1.7 million EVs in the South Coast

(see sheet 1 in the Appendix for the SCAOMD values). The 1 million EV scenarios were adopted to include examples which planners anticipate could be easily accommodated with SCE's existing resource plan. The 1 million EV examples were created strictly as scenarios and not as forecasts of the likely use of EVs in southern California. Chapter 4 explains, however, that 1 million EVs is similar to the number of EVs forecasted to be in use in the year 2011 by utility planners at SCE and the CEC.

The final two scenarios in Table I were selected to shift attention from the end point to the midway point of SCE's planning interval. Both scenarios assume that EVs will operate with either $\mathrm{Ni} / \mathrm{Fe}$ or $\mathrm{Pb} /$ acid batteries with ranges of 150 miles. The 50,000 vehicle scenario was selected as approximately the number of EVs that would be operating in the year 2000 if the EV population were climbing toward the one million level by the year 2010 . Thus, scenarios $\$ 5$ and $\$ 7$ may be viewed together. Scenario 77 provides a snap shot of conditions in the year 2000 ; scenario $\$ 5$ gives a second snap shot of the conditions in the year 2010. Taken together, they demonstrate how rapidly conditions could change over time. The 8th scenario was added to the list at a time when various news releases revealed the possibility that EV sales could increase more rapidly than portrayed in any of the other scenarios. The final scenario was included as a possible "near term surprise" that might present resource planning problems to SCE. The number of EVs was set at $1 / 2$ million, over ten times higher than in the previous scenario.

\subsection{The SCE System}

Each of the scenarios is examined in the context of SCE, an investor-owned electric system serving around 4 million customers spread over a 50,000 square mile service territory. The customers and their demands comprise approximately $60 \%$ of the south Coast. SCE uses a variety of resources including nuclear, coal, gas-fired units, hydro-electric units, imports from other utilities, demand side management programs and purchases from Qualifying Facilities (QFS). The QFs, in turn, employ a variety of generating technologies including cogeneration, wind, biomass, geothermal, and solar. The crucial features of the SCE system for this analysis are a heavy dependence on existing, gas-fired units and the attractiveness of new, combined cycle, gas-fired units in the long term resource plan (Ducat 1989, p. 27). Also, the large role of QFS will turn out to be a key feature of the SCE system which will shape the results of the EV analysis. 


\section{Chapter 4. Growth in Electric Vehicle Use in Southern California}

\subsection{Introduction}

Southern Californians operated over $8 \mathrm{million}$ vehicles during the year 1990. According to the SCAQMD projections, the need for vehicles will grow to over 10 million by the year 2010 (see sheet \#2 in the Appendix). EVs can penetrate this large market through retrofitting of conventional vehicles (CVs) or through the sale of newly manufactured EVs. The scenarios examined in this report ignore retrofits and concentrate on the EV' share of annual sales of manufactured vehicles.

Annual sales of new vehicles can fluctuate significantly from year to year. For example, national vehicle sales peaked at almost 13 million in the year 1978; but only two years later, vehicle sales were just over 8 million (MVMA 1990, p. 6). The volatile "ups and downs" in vehicle sales that may be associated with fluctuations in the nation's economy or in the world oil market are ignored in this analysis. Annual sales in southern California are assumed to grow in a somewhat regular pattern over the next two decades. More specifically, annual vehicle sales are dependent on the existing population of venicles, their likely retirements over time, and the southern Californians" growing "need" for vehicles over time.

The "need" for vehicles is based on the SCAQMD projection explained in sheet \#2. A total requirement of 10.4 million is comprised of separate requirements for five classes of vehicles: large vans, small vans, large cars, small cars and light trucks. The need for light duty autos, for example is set a constant $72 \%$ of the total requirement. Autos are further divided into $30 \%$ small cars and $70 \%$ large cars. These shares are fixed over time, and they lead to the expectation that southern Californians will require around 2.2 milition small cars and 5.2 million large cars in the year 2010. The need for each of the five classes of vehicles is also fixed from one scenario to another. For example, 2.2 million small cars are required in the year 2010 . This requirement can be met by any combination of CVs and EVs. The possibility that a particularly attractive EV designed for the small car market could end up creating a larger requirement for small cars in the minds of southern Californians is not considered in the analysis.

Sheet \#2 shows that vans comprise an extremely small share of the total vehicle population. The spread sheet notes a requirement for only 55 thousand small vans and 111 thousand large vans by the year 2010. Despite their small numbers, vans appear explicitly in 
the analysis because they are viewed by many planners as the prime candidate for the first "economic niche" for EVs. The general expectations from planners interviewed in my research is that EVs will first penetrate the fleet van market because the fleet managers are most likely to appreciate their benefits of long life times, low operating costs and low maintenance costs. EVs would then be in a better position to compete in the market for private vans. Success in van sales is assumed "to pave the way" for electric cars.

As previous researchers have done, I use a "vintaging model" to keep track of the growth in EV and CV populations over time. The model may be viewed as an accumulator which keeps track of the combined effect of sales of new vehicles, the aging of vehicles, and the eventual retirement of vehicles. The age structure of both the EV and the CV populations is represented by tracking the number of vehicles in each of ten age groups. The average life time of a CV is set at 10 years. EVs, on the other hand, are expected to operate considerably longer due to fewer moving parts and less need for maintenance. Deluchi (1989, p. 23) expects the useful life of an EV to be anywhere from 258 to $100 \%$ longer than the corresponding life of a CV. The vintaging calculations assume the average EV will operate for 15 years.

The vintaging calculations are organized for the South coast as a whole. The scenarios assume that the SCE service area is roughly 608 of the South Coast. Thus, the EV scenarios in Table I with 2 million vehicles correspond to $3.3 \mathrm{milli}$ on EVs in the South Coast. With this level of aggregation, the possibility that EVs sales (and EV charging) may not be evenly distributed across the south Coast is ignored. Some planners worry about the possibility that EVs will be owned disproportionately by households living in the SCE area but working downtown in the area served by the Los Angeles Department of Water and Power (LADWP). They are concerned that SCE would experience the night time charging loads whereas LADWP would experience the day time charging loads. Their concerns are not addressed in this report.

\subsection{Two Million EVs in the SCE Area}

Figure 3 shows one set of assumptions with sufficiently large EV penetration of the new vehicle market to build the population of EVs in southern California to $3.3 \mathrm{milli}$ on by the year 2010 . The van market assumptions are that EVs will penetrate the market for van sales in the late 1990s, achieve $75 \%$ penetration by the year 2000 and eventually saturate at $90 \%$ of new van sales. The success in vans is followed by success in the small car market 4 to 5 years 


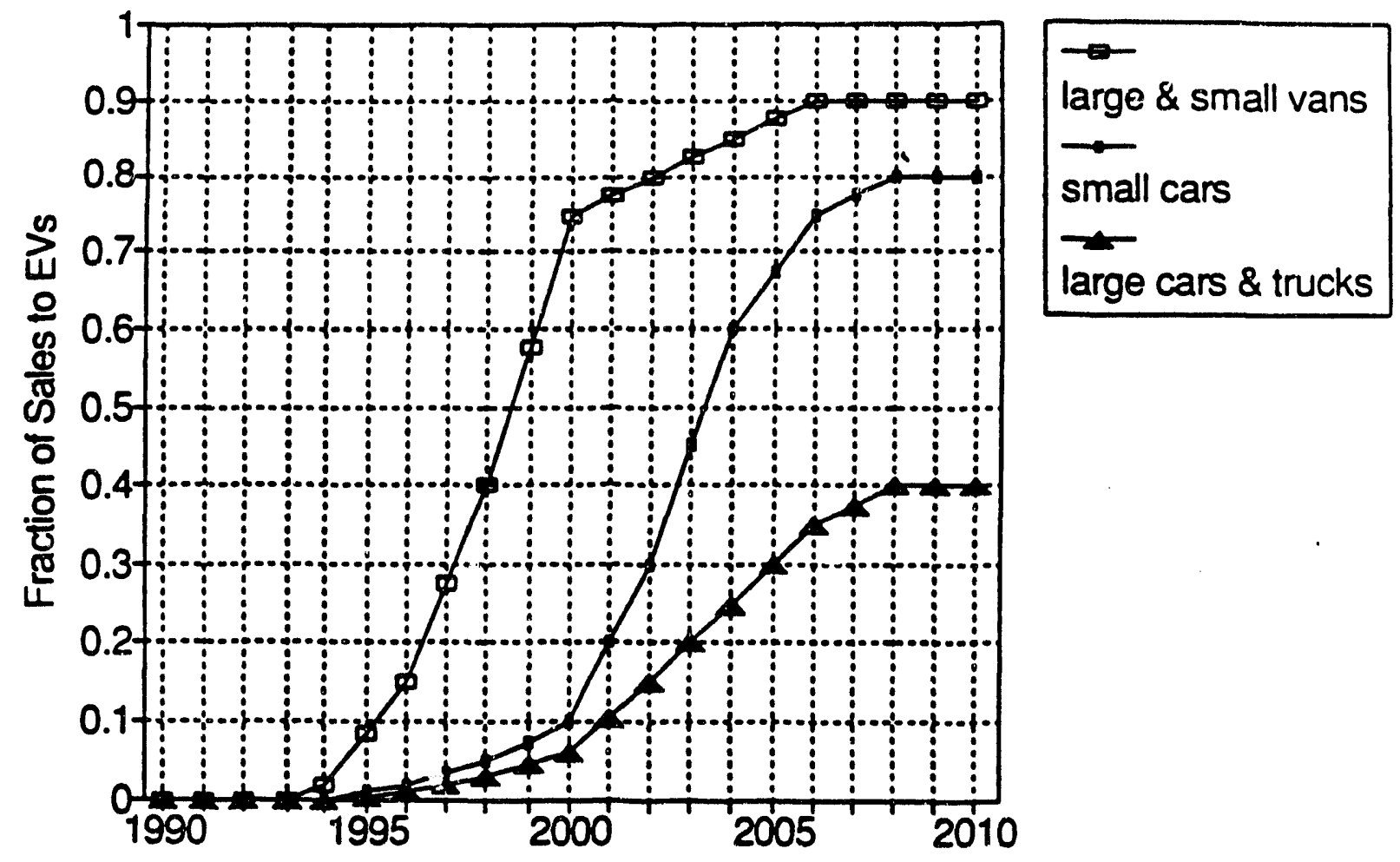

Figure 3. Market Share Assumptions for EV Scenario \#1.

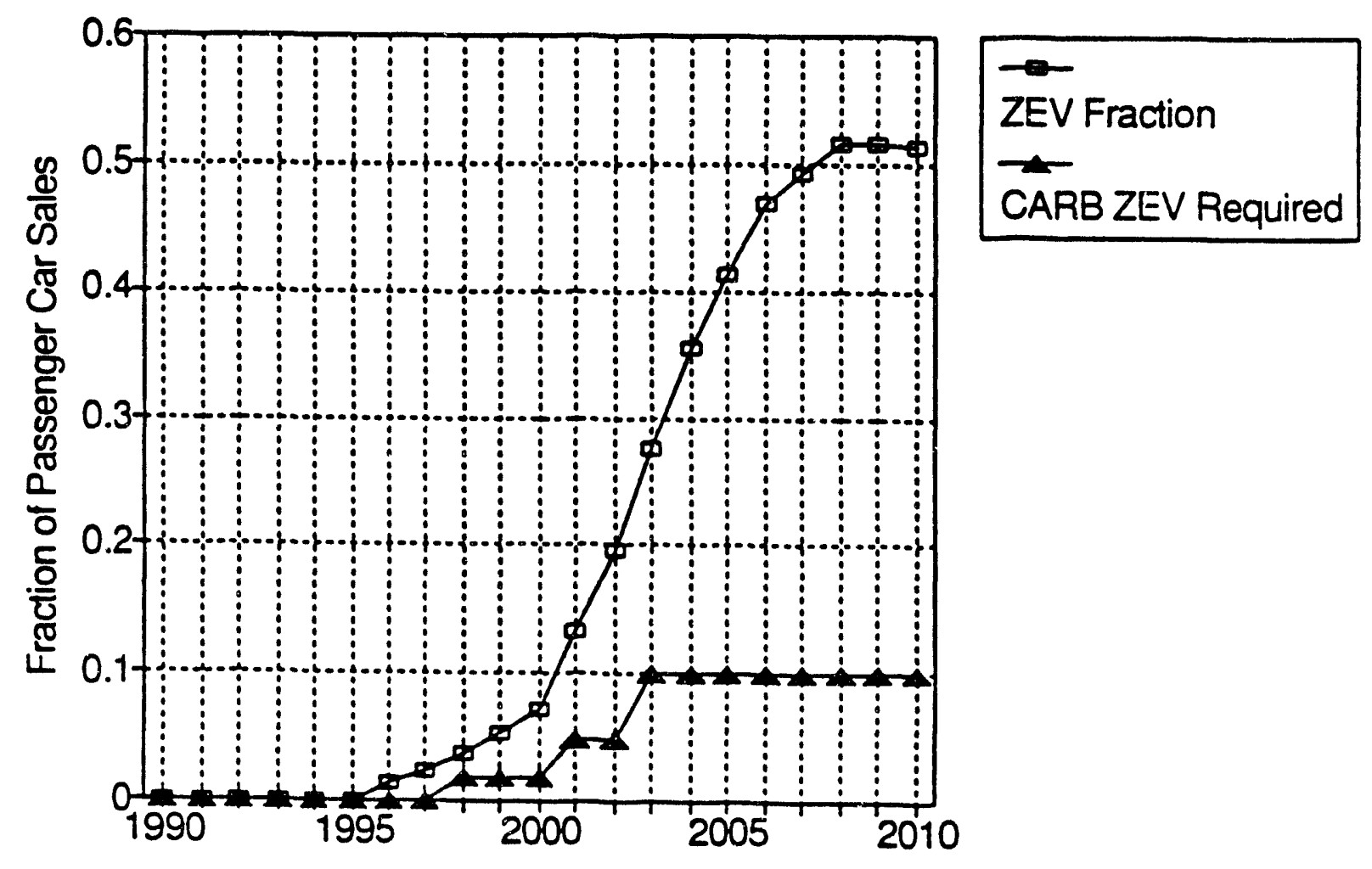

Figure 4. Comparison of Market Share Assumptions with the CARB ZEV Requirement. 
later. EVs capture around $50 \%$ of small car sales by the year 2003, and their market share saturates at 808 by the year 2008 . The large car market is set at the third position (in the sequence from van to small cars to large cars). EVs are expected to penetrate the large car market only after demonstrating their usefulness in vans and small cars. The lagged position of the large car market is based on the view that many large cars serve single vehicle households and are the vehicle used for long trips (Deluchi 1989, p. 272). According to the 1983 National Personal Transportation Survey, long trips (defined as 75 miles or longer) tend to be for social and recreational purposes, and they involve an occupancy of 2.6, over twice the occupancy for shorter trips (NPTS 1986, p.721,9-3). EVs are assumed to operate at a disadvantage in this third market because of their range limitation. The third curve in Figure 3 shows EVs share of large car sales set to lag behind small car market share by two to three years. EVs are assumed to capture around 308 of sales by the year 2005, and their market share saturates at 408 by the year 2008 .

Figure 4 rearranges the Figure 3 assumptions by showing EVs share of combined sales of small and large cars versus the CARB requirement for ZEVs or "zero emission vehicles." By 1998, CARB requires that $2 \%$ of passenger car sales be ZEVs. With technologies developing toward use by 1998, the only way to comply with the ZEV requirement is through EVs. Figure 4 shows that EV Scenario \#1 would be well ahead of the 1998 CARB target. The CARB target steps up to 5\% in 2001 and to 108 in 2003. But Figure 4 shows EVs capturing a far greater share of passenger car sales during this time frame. By the end of the planning interval, over 50 of passenger car sales are EVs.

Figure 5 displays the total population of EVs in operation in southern California over the 20 year planning period. As intended, the total population grows to 3.3 million by the year 2010. The population crosses the one million level around the year 2004 . In the year 2000, the total EV population is just over 150 thousand. The Figure 5 scenario envisions that EVs will eventually comprise one third of the vehicle population. This ambitious scenario goes well beyond the market potential assessments appearing in recent EV studies. In her greenhouse gas study, for example, Fisher (1991, P. 42) limits EVs use to 178 of vehicle miles of travel based on their limited range. In "A Near Term Constraints Analysis" of the EV market place, Nesbitt (1991) argues that the EV market will be limited by a combination of factors including home ownership, access to a secure garage, ownership of more than one vehicle and range considerations. Based on national household data, Nesbitt estimates that $28 \%$ of the 1985 households would qualify as the near term EV market. If roughly 608 of the households own two or more vehicles, the $28 \%$ share of the household population translates into about $17 \%$ of the vehicle population. If a 178 constraint were applied to southern California 20 years in the future, one would envision the EV market limited at around 


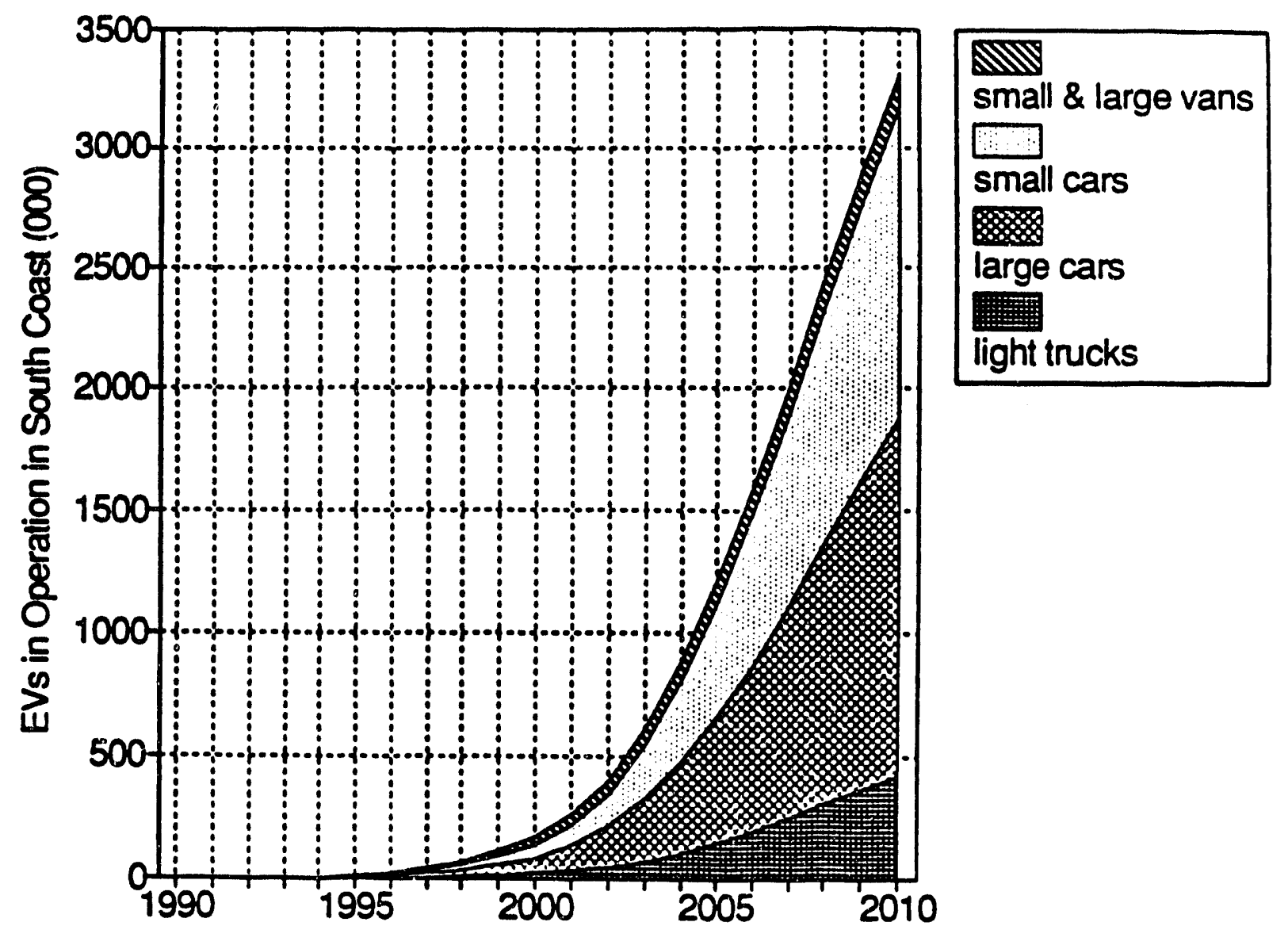

Figure 5. Population of EVs Operating in Southern California in EV Scenarios 1-4.

1.8 million vehicles. Figure 5 shows that EV Scenario \#1 satisfies this initial EV market by the year 2008. Two years later, the EV population is twice as large as the maximum value apparent from an assessment of near term constraints. This scenario assumes that an extremely long range and the demonstrated use of the EVs over the interval from 1998 to 2008 will allow EVs to succeed beyond the 178 limit from the Fisher (1991) and Nesbitt (1991) studies.

Figure 5 shows an extremely rapid growth in EV population. From a utility planning perspective, the important feature is how rapidly the EV population can grow during the interval normally required to acquire new generating resources. During the 1970s, resource acquisition could take 10 to 15 years due to long delays in acquiring sites, completing construction, and certifying that new generating units could operate in a safe manner. Utility planners have turned away from the extremely long lead time options during the late 1970 s and 1980s, and the total lead time is now in the range from 5 to 10 years. The exact lead time depends on the generating resource and whether the utility builds new generating units or goes out to bid. If you examine the Figure 5 scenario with a 10 year lead time in mind, the rapid growth in EVs is 
dramatic. Over the interval from the year 2000 to 2010 , for example, the number of EVs in the south Coast increases 20 fold-from around 150 thousant to over 3 million.

The vintaging model reveals the likely age structure of the population of EVs and CVs. In the Figure 5 scenario, the EV population is dominated by younger vehicles; the CV population is slanted toward older vehicles. By the year 2010, for example, almost 708 of the small car EV population would be 6 years old or younger. Thus, one should envision that 708 of the small car EVs in operation in the year 2010 will have been manufactured between the interval from 2004 to 2010. From a utility planning perspective, the rapid growth and "youth" of the EV population presents an interesting problem. Place yourself in a planner's position in the year 2000, for example. If you were operating with 10 year lead times on acquiring new generating resources, you would be looking to the year 2010 wondering about the number of EVs and their likely characteristics. According to the Figure 5 scenario, the number of EVs is likely to increase 20 fold during your planning interval. And according to the age structure information, 70 of the EVs that you would serve in the year 2010 would not be manufactured until the year 2004 or thereafter. Obviously, the utility's planning problems could be quite challenging. The severity of the challenge will depend on the lead time for utility acquisition of generating units relative to the lead time faced by EV manufacturers.

\subsection{One Million EVs in the SCE Area}

Table I notes that EV scenarios 5,6 involve 1 million EVs in the SCE area. One would envision 1.67 million EVs in the South Coast. At this level, the EV population would just about fill the 178 market segment identified in the studies by Fisher (1991) and Nesbitt (1991). The total of 1.67 million EVs was obtained by assuming the same general pattern of EV sales as shown in Figure 3. EVs are assumed to penetrate the van market first, reaching 758 of annual sales by the year 2000 and saturating at 858 by the year 2005. EVs penetrate the small car market next, but this scenario assumes that a longer interval of success is required than in the first scenario. EVs capture $25 \%$ of small car sales by the year 2003, $50 \%$ by 2006, and saturate at $60 \%$ of sales by 2008 . This scenario assumes that EVs achieve only limited penetration of the large car/light truck market. EV sales saturate at $13 \%$ of vehicle sales in this final niche by the year 2007 .

The vintaging model demonstrates that this collection of assumptions are sufficient to build the population to 1.67 million by the year 2010. As in the previous scenario with 3.3 million EVs in the South coast, the EV population is dominated by younger vehicles. The new scenario envisions that small car EVs are a more 

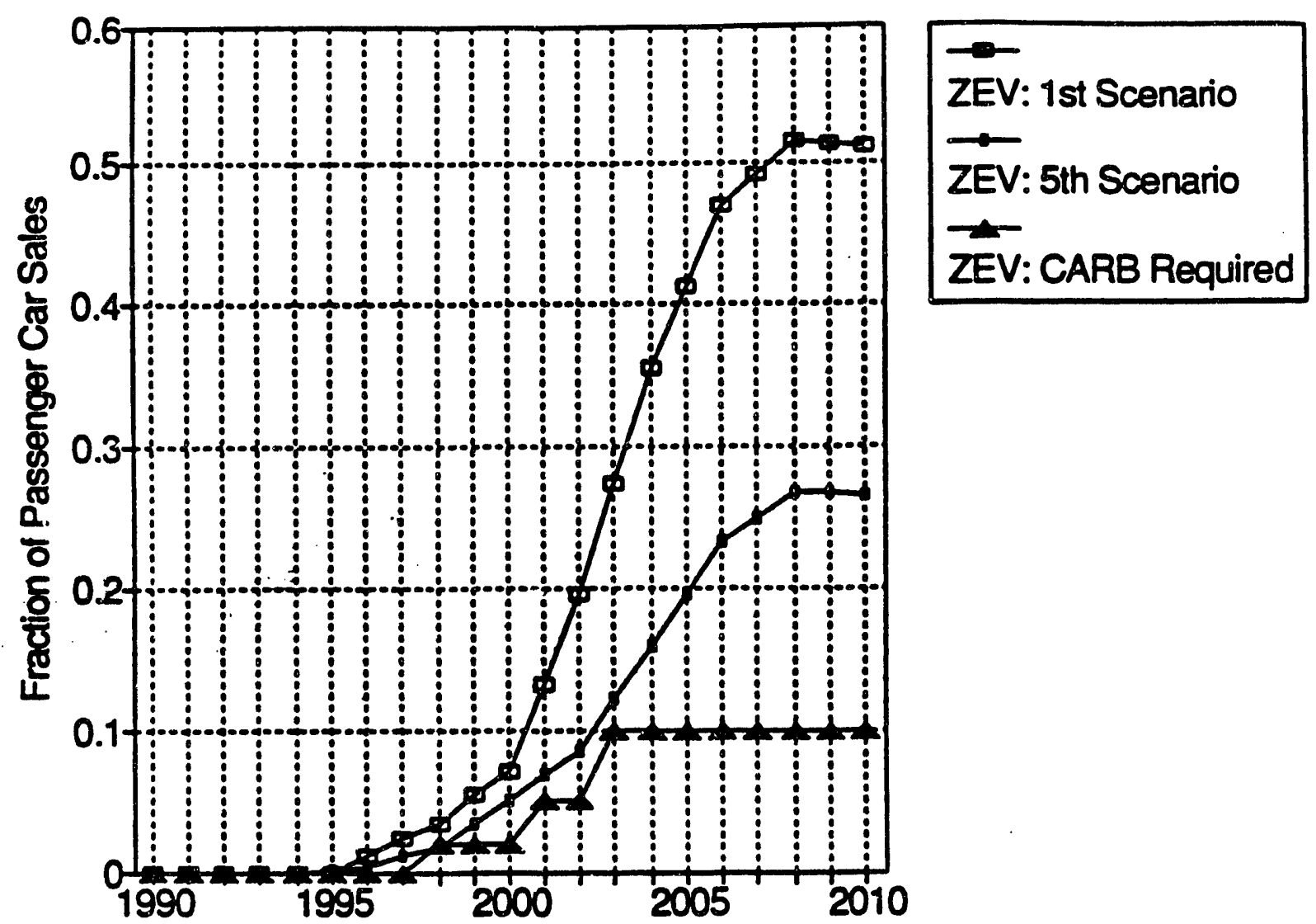

\section{Figure 6. Comparison of Market Share Assumptions with the CARB ZEV Requirement.}

important part of the population mix. They account for over half of the EVs in the year 2010.

Figure 6 puts market share assumptions for the two scenarios into perspective by comparing the EV penetration of the passenger car market with the CARB ZEV requirement. This comparison shows that EV Scenario $\$ 5$ envisions compliance with the CARB requirement in the year 1998, the first year when ZEVs are required. After the initial year, the scenario envisions that EV manufacturers will surpass the CARB requirements with EV sales eventually saturating at over $25 \%$ of annual vehicle sales.

\subsection{Discussion of EV Scenarios}

The 1 or 2 million EVs envisioned in these scenarios are not to be viewed as forecasts. These numbers are merely an initial step in the scenario analysis. The number may be viewed as part of a script in which the goal is to help utility planners anticipate problems and opportunities and to rehearse appropriate responses. 
But many readers will be interested to learn what level of EVs have been projected by utility planners who are responsible for forecasting the future demand for electricity. This is a new responsibility since EVs have only recently been included in the formal forecasting procedures in California. In fact, electricity demand from EVs appeared for the first time in the electricity report (ER) process in preparations for the CEC 1992 report (CEC 1991A, P. I-13). The initial forecasts for EVs in the SCE area turn out to be quite close to the one million level assumed in EV scenarios 5,6 . In forecasts for the year 2011 , for example, the CEC staff anticipated 1.008 million EVs while planners for SCE anticipated .93 million. The forecasts were presented in CEC testimony available after my work was in progress, so the close match is rather coincidental. Also, the rationale for the CEC and SCE forecasts is different than my reasoning shown in Figure 6 . My one million EV scenario envisions that manufacturers would first comply with and then surpass the CARB requirements. But the forecasts explained in the CEC discussion paper (1991, p. I-14) assume that manufacturers will comply with the CARB requirements and go no further. The forecasters then assume that EV sales will be concentrated predominantly in southern California rather than spread evenly across the state. With even distribution of EVs, around 45-50\% of EV sales would occur in the South Coast. But the CEC staff forecast assumes 1008 of EV sales concentrated in the South Coast; the SCE forecast assimes 758 concentration. The concentration in southern California is based on manufacturers building up a concentrated collection of dealers to sell and service the EVs. Concentrating sales in southern California is also viewed as logical since the air pollution benefits of EVs is much higher in the south coast. These arguments have their appeal, but one should remember that SCAQMD encouragement for alternative fueled vehicles is "fuel neutral" (Nazemi 1991). Also, when discussing the likely impact of their requirements, CARB planners discount the view that manufacturers will concentrate EV sales solely in the South Coast (Santoro 1991). Speaking from a forecasting perspective, the CEC staff admits that "the allocation of future EV sales across the various service area is perplexing at this time" (CEC 1991A, P. I-17), and they go on to recommend that $85 \%$ of EV sales be concentrated in the South Coast.

Figure 7 expands on the CARB comparison by allowing for two interpretations of how EV sales will be distributed across the state. The fraction of annual sales of small and large cars captured by EVs in EV Scenarios \#1 and \#5 are arranged against two versions of the CARB requirement. If $E V$ sales turn out to be distributed evenly across the state, CARB's $10 \%$ ZEV rule translates into a 108 share of South Coast sales. Since South Coast sales are around 45-50\% of state sales, the concentrated implementation of CARB rules could lead to twice as many $Z E V$ sales in the south Coast. Figure 7 shows that my EV scenario \#5 corresponds approximately to the concentrated interpretation of the CARB 

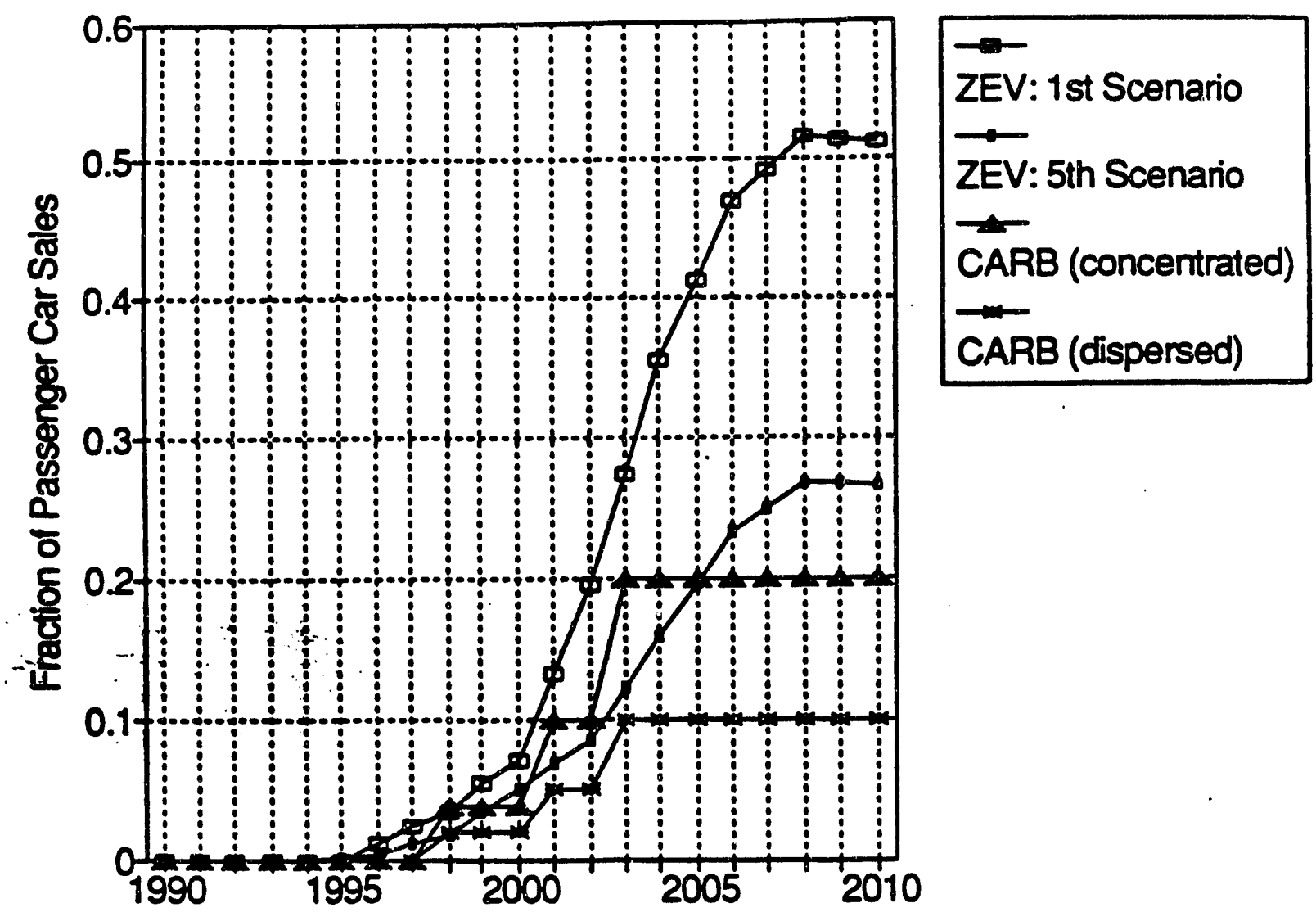

Figure 7. Comparison of Market Share Assumptions with Two Ways of Complying with CARB's ZEV rules.

requirement until around the year 2005. After 2005, the CARB rule is constant at $20 \%$ of (concentrated) sales, whereas my scenario envisions that EVs will succeed in capturing around $25 \%$ of the passenger car sales in southern California.

One final feature of the EV scenarios deserves attention, especially since scenario studies are meant to identify unanticipated problems and opportunities. One feature of the vehicle population projections that was entirely unanticipated at the outset of the study involves an EV-induced decline in annual vehicle sales. Recall that the vintaging calculations were designed on the assumption that annual sales will grow in a regular manner over time. (They would be immune from the volatility of the nation's economy and the world oil market.) But the vintaging model shows a drop in total sales of both EVs and CVs in all the scenarios where EVs capture a major share of the market. The drop in sales arises from the gradual shift in the vehicle population from CVs with 10 year average life times to EVs with an expected life of 15 years. Total sales are based on the need to counter retirements as well as serve a growing "need" for vehicles (defined in Sheet 21 . When EVs begin to dominate the population, however, one should expect a decline in the rate of retirements and a subsequent decline in annual sales. Thus, one should expect the 
penetration of EVs during the early years of the planning period to depress new vehicle sales later in the planning period. This dynamic is represented automatically as the vintaging model keeps track of the aging and retirements of the EV and CV populations. The vintaging calculations show that the EV-induced decline in sales is limited to $15 \%$ or less. As an example, small car sales in EV scenario 1 (with two million EVs in the SCE area) are depressed by $15 \%$ around the year 2010 due to large number of longer lifetime EVs in operation at the end of the planning period. one would expect, the induced decline in vehicle sales is small in the scenarios 


\section{Chapter 5. Electricity Demand \\ from Electric Vehicles}

To analyze the utility impacts of EVs, one must either assume or estimate the likely timing of the EV demands over a typical 24 hour period. Most of the previous analyses simply adopt an assumed charging profile. The less common approach is to estimate the profile based on a step-by-step calculation for each EV, its individual charring profile and the vehicle owner's decision on when to start night time charging. An example of the step by step approach appears in Appendix 2 of Ducat's (1989) study. He calculated a "composite EV demand profile" for a mix of Griffon Vans with a daily travel distribution of $20 \%$ at 20 miles/day, $20 \%$ at $40 \mathrm{miles} / \mathrm{day}$ and 608 at $60 \mathrm{miles} /$ day. Data from a Spiegel/Lucas Chloride charger was to specify the charging profile for each of the three types of vans. Ducat then folded in assumptions about the fraction of vans in operation and the extent of opportunity charging during the day time hours. The end result of this calculation was a composite EV demand profile which was then multiplied by the number of vans under study.

To assist in the analysis of many EV scenarios, I developed a spread sheet software to automate Ducat's approach for interactive analysis on a personal computer. The program is called "The Stacker" since it is designed to stack EV electricity demands on top of the regular demand for electricity in the SCE area. The Stacker is designed for up to five classes of EVs. Each class may have a different number of vehicles and different miles/day of travel. Each class may be subject to different night time charging decisions by the vehicle owner and may be equipped with a different battery/charger. The chargers may be one or two step chargers, with energy delivered on each step at approximately constant power. Further details on The Stacker are provided in a Technical Memo (Ford 1991A). The Stacker's calculations are best illustrated here with several, simple examples in which the electricity demands from EVs are easy to visualize.

\subsection{Electricity Demand from Simple Examples}

Figure 8 shows the electricity demand for a simple example based on Ducat's data on the Griffon Van with a Spiegel/Lucas Chloride charger. This charger is a two step charger with a high power rating of $5.5 \mathrm{kw}$ and a low power rating of $3.2 \mathrm{kw}$. (The second, lower power rating is needed to control the gasses that may accumulate near the end of the charging cycle.) With daily travel of 30 miles, the recharging profile is approximately 3 hrs at high power and 2 hours at low power. The total energy need is $22.9 \mathrm{kwh}$ for an overall efficiency of $1.3 \mathrm{miles} / \mathrm{kwh}$. Figure 8 portrays the 
electricity demand from one million Griffon Vans with these characteristics. Figure 8 assumes that each and every van is driven 30 miles per day; every van begins night time charging at midnight; and there is no charging during the day time hours. Figure 8 shows the expected demand of $5.5 \mathrm{GW}$ for the three hour period when all one million Griffon Vans are charging at the high rate. The demand falls to $3.2 \mathrm{GW}$ at 3 am when all the vans switch to the low power setting. Demand remains at the lower level for two hours and drops to zero by 5 am. The lower chart in Figure 8 stacks the EV demand on top of SCE's other electricity demands that are projected for a peak day in August in the year 2010. The method for specifying the shape of SCE's other demands is explained in a Technical Memo (Ford 1991B).

Figure 9 shows The Stacker's results with a different example from Ducat's data on the Griffon Van. In this example, the one million vans are driven 60 miles/day. The charging profile is approximately 5 hours at the high charge rate of $5.5 \mathrm{kw}$. The charger would then step down to the low rate of $3.2 \mathrm{kw}$ for 4 hours of finishing charge. Total energy is $40.3 \mathrm{kwh}$ for an overall efficiency of $1.48 \mathrm{miles} / \mathrm{kwh}$. Figure 9 shows the electricity demand from one million vans if all of the vans begin the charging cycle exactly at $11 \mathrm{pm}$. (The start time is shifted from $12 \mathrm{pm}$ to $11 \mathrm{pm}$ to allow charging to be completed by 7 am in the morning.) Figure 9 shows the expected result: $5.5 \mathrm{GW}$ of demand over the 5 hour period followed by 3.2 GW for a 4 hour period.

Figure 10 shows The Stacker's projections from a $50 / 50 \mathrm{mix}$ of the previous two examples. One half million vans are driven 60 miles/day; the other half million travel $30 \mathrm{miles} /$ day. The charger profiles are identical to the previous two examples, but I eliminate the abrupt assumption that $100 \%$ of the charging begins immediately at 11 or $12 \mathrm{pm}$. The assumption for this third illustration is that 258 of the vans start charging at $8 \mathrm{pm} ; 25 \%$ at $9 \mathrm{pm} ; 25 \%$ at $10 \mathrm{pm} ;$ and the final $25 \%$ at $11 \mathrm{pm}$. The top chart reports the total EV demand from this combination of assumptions, and the lower chart stacks the EV demand on top of SCE's regular demands for the peak summer day.

These three simple examples are for illustrative purposes only. The first two examples are extreme cases which allow one to check the program's operation in a simple, visual manner. The third example illustrates how quickly the characteristics of the charging profile for an individual vehicle becomes lost in the final picture of EV demands from a mix of vehicles. These examples illustrate how the stacker might be used to reveal how the electricity demands may change with changes in EV assumptions.

I turn now to the electricity demands to be expected from EV scenarios \#1-4 which envision two million EVs operating in the SCE service area. The exact $\mathrm{mix}$ of EVs is obtained by scaling the Figure 5 results by $60 \%$ to obtain: 

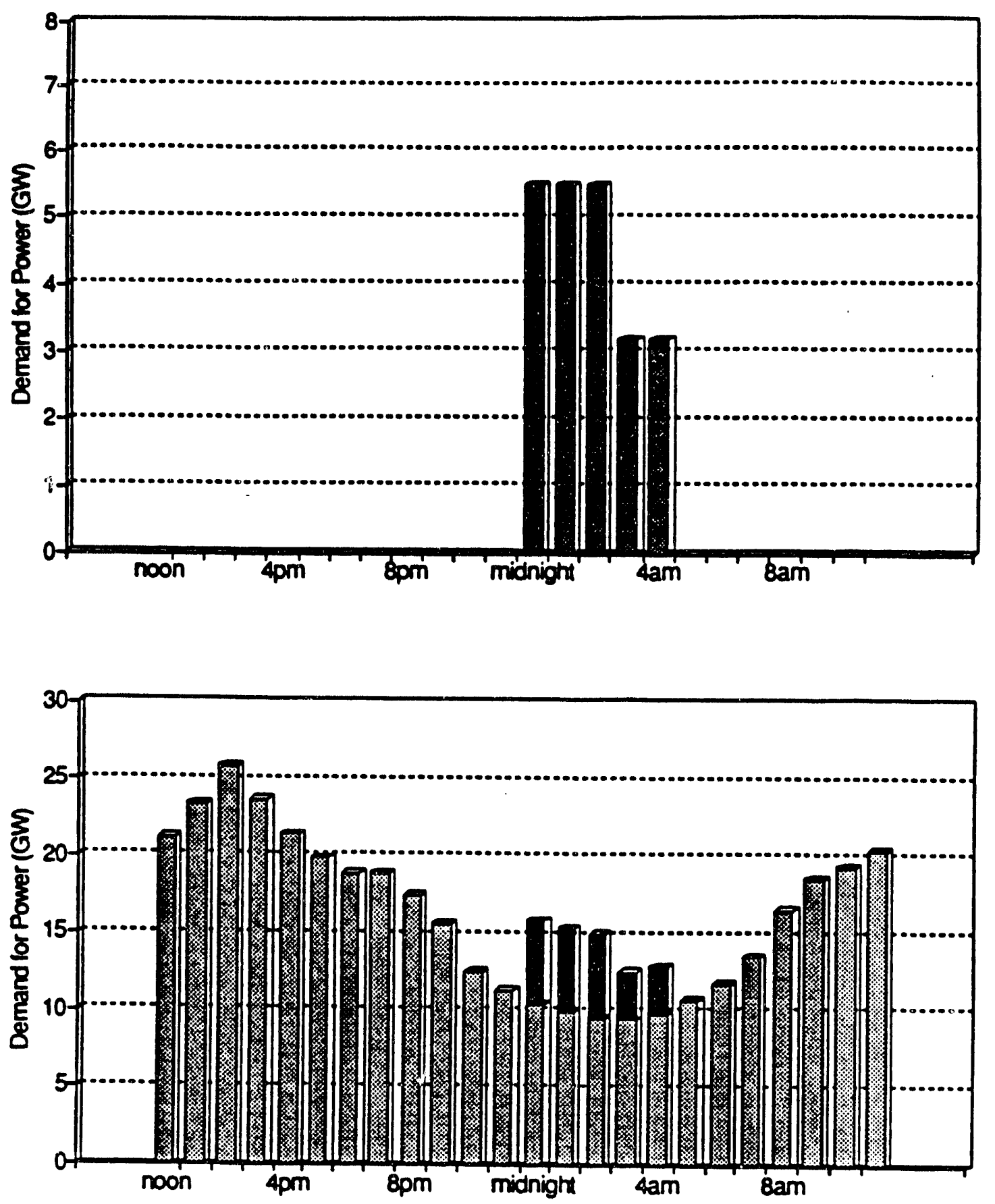

Demand without EVs Demand from EVs

Figure 8. Electric Demand from One Million Large Vans

The top chart shows the electricity demand from one million large vans which are used to travel $30 \mathrm{miles} / \mathrm{day}$. Each van uses $22.9 \mathrm{kwhrs} / \mathrm{day}$ and recharging starts exactly at midnight. The charging profile for each van is $5.5 \mathrm{kw}$ for 3 hours followed by $3.2 \mathrm{kw}$ for 2 hours. The lower chart, 3 tacks the EV demand on top of the regular SCE demand for a peak day in August for the year 2010. 

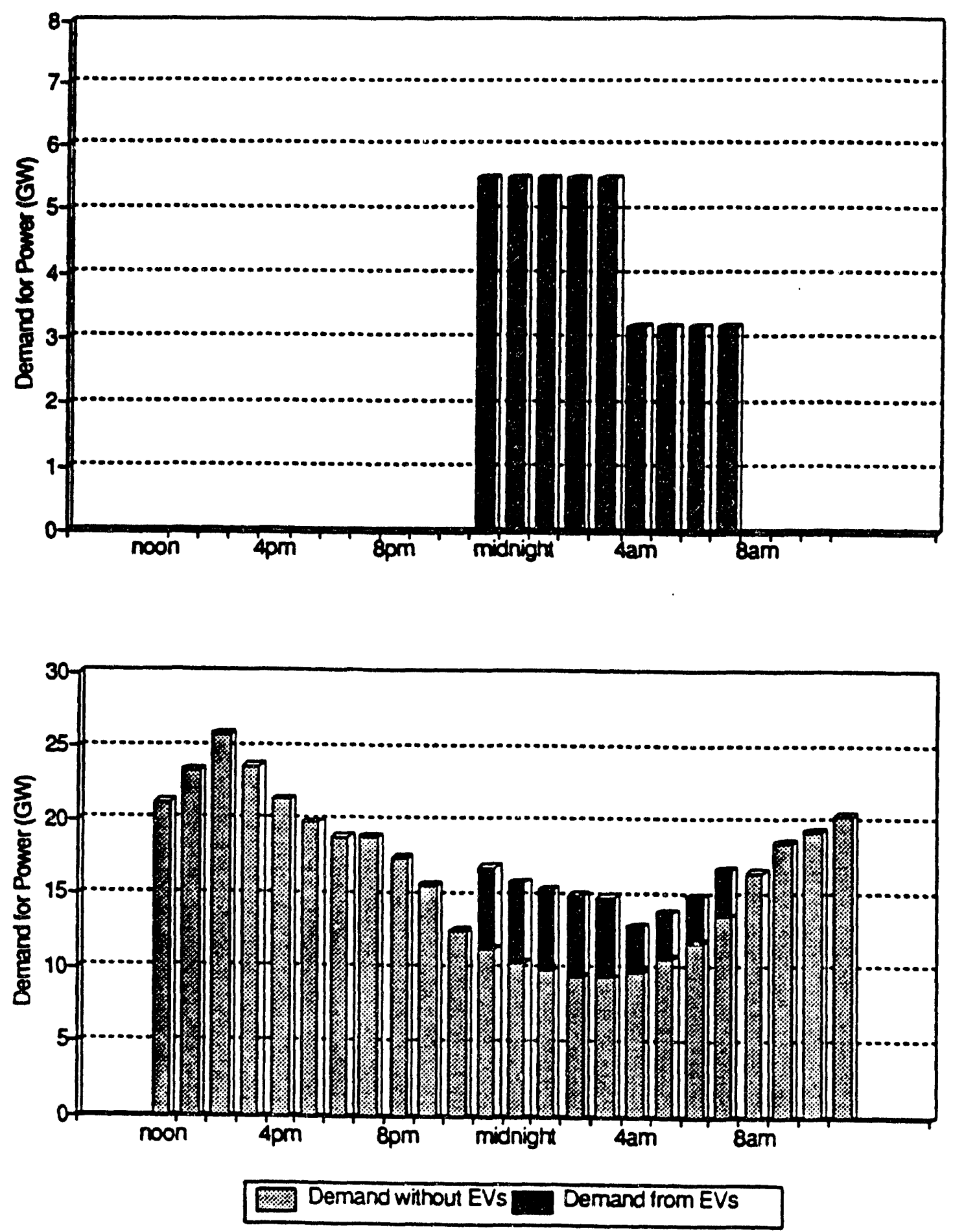

Figure 9. Electric Demand from One Million Large Vans

The top chart shows the electricity demand from one million large vans which are used to travel $60 \mathrm{miles} / \mathrm{day}$. Each van uses $40.3 \mathrm{kwh} / \mathrm{day}$. Recharging starts exactly at $11 \mathrm{pm}$. The charging profile for each van is $5.5 \mathrm{kw}$ for 5 hours followed by $3.2 \mathrm{kw}$ for 4 hours. The lower chart stacks the EV demand on top of the regular SCE demand for a peak day in August for the year 2010 . 

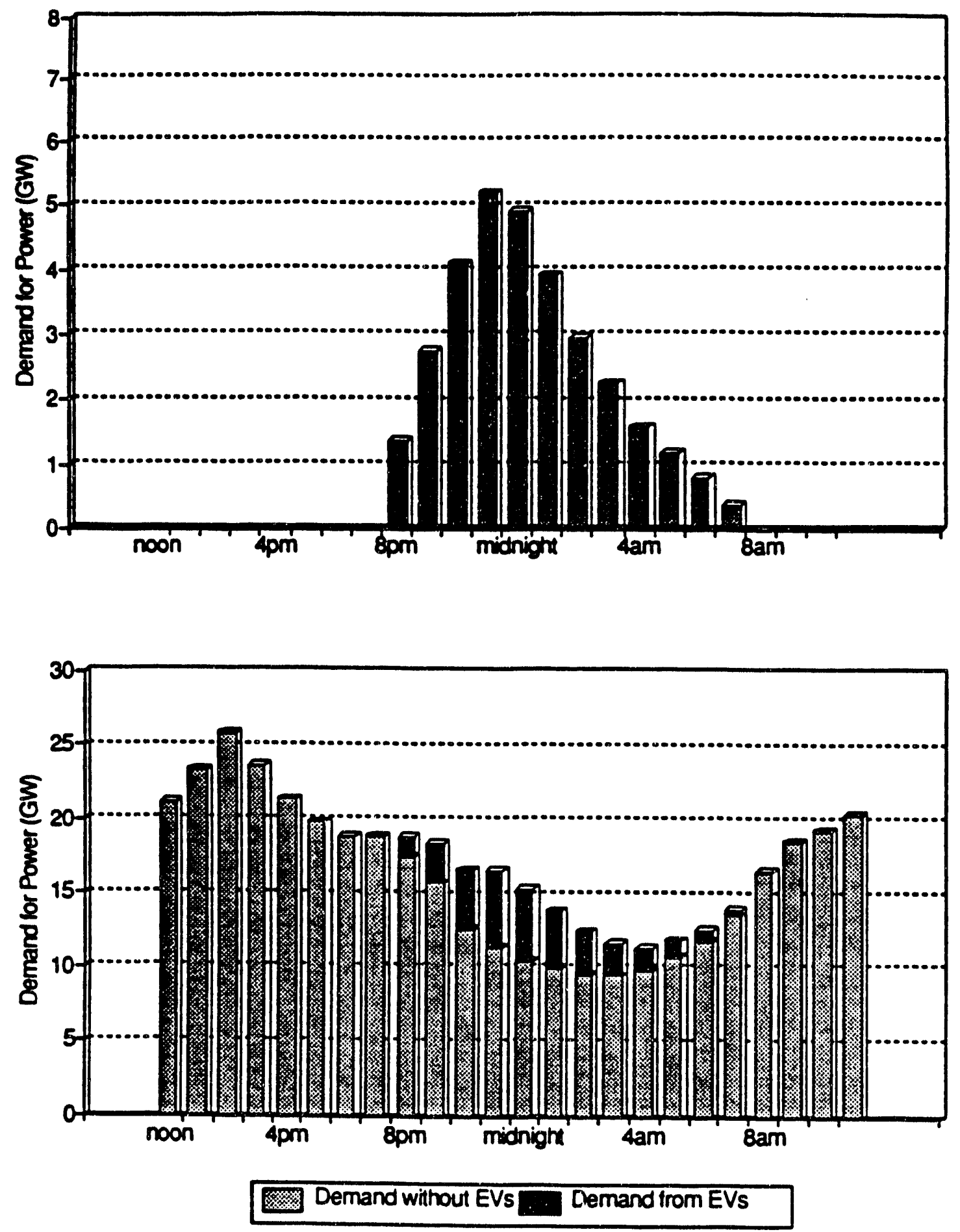

Figure 10. Electric Demand from One Million Large Vans

The top chart shows electricity demands from a combination of $1 / 2$ million large vans at $30 \mathrm{miles} / \mathrm{day}$ and another $1 / 2 \mathrm{million}$ at $60 \mathrm{miles} / \mathrm{day}$. Charging profiles are the same as Eigs. 8\& 9. Recharging is assumed to start evenly over the time interval from 8 to $11 \mathrm{pm}$. The lower chart stacks the EV demand on top of the regular SCE demand for a peak day in August for the year 2010 . 


56,000 large vans
28,000 small vans
878,000 large cars
767,000 small cars, and
251,000 light trucks.

The bulk of the energy for these vehicles will be supplied during the night time hours. The exact shape of the night time demands depends on the characteristics of each vehicle as well as the vehicle owners' decisions on daily travel and on when to begin night time charging.

\subsection{Night Time Charging Assumptions}

The vast majority of the EVs in scenarios 1-4 will have been manufactured after the year 2004. Assigning characteristics to such vehicles requires one to speculate about the type of vehicles and batteries that manufacturers will produce 15 years in the future. Previous investigators have assigned characteristics based on vehicles that are already in operation or in development. Ducat's study, for example, is based on the Griffon Van, an existing, fully tested vehicle. The RFF study was based on the TEVan with a $\mathrm{Ni} / \mathrm{Fe}$ battery since the investigators wanted "to use an efficiency of a battery currently being demonstrated rather than a more technologically speculative battery" (RFF 1990, p 2-4).

The scenarios examined in this report turn toward the future. Given the rapid pace of battery development (Deluchi 1989, Guy 1991), it is useful to speculate on characteristics of advanced EVs that might be sufficiently attractive to achieve the massive use shown in Figure 5. The best information available to aid in this speculation is provided in an ongoing study for the California Air Resources Board (1990). The CARB study describes the batteries, ranges, and efficiencies for "nominal EVs" in the near term (the year 2000) and for the longer term (the year 2010). The CARB "nominal EVs" come in four classes: large vans, small vans, 2 seat passenger cars, and 4 seat passenger cars. The CARB study suggests that electric vans will be first to enter the market. The investigators argue that electric cars will require a much larger investment to put into production, so manufacturers are likely to wait until vans have demonstrated that EVs perform in a reliable manner. Their near term vans are based on figures for the Chrysler's TEVan with a Ni/Fe battery. Both small and large vans would have a working range of 100 miles; the large van would get $1.11 \mathrm{miles} / \mathrm{kwh}$, while the small van would get $1.67 \mathrm{miles} / \mathrm{kwh}$. By the year 2010, the CARB nominal EV vans would be equipped with sodium sulfur (NA/S) batteries and designed with improved tires, aerodynamics and power trains. These improvements would extend the working range to 250 miles and improve the efficiencies to 1.67 miles/kwh for the large van and $2.5 \mathrm{miles} / \mathrm{kwh}$ for the small van. 
The CARB study envisions that the passenger car EVs will enter the market several years after electric vans. When they do appear, electric cars are expected to be manufactured in dedicated facilities and designed from the ground up to take advantage of technologies that have proved effective in vans. The CARB study views a near term electric car operating with a sealed $\mathrm{Pb} / \mathrm{F} \epsilon$ battery with a working range of 150 miles. The 4 seater would get $4.17 \mathrm{miles} / \mathrm{kwh}$, and the 2 seater would get $5.55 \mathrm{miles} / \mathrm{kwh}$. By the year 2010, the electric cars would operate with advanced Na/S batteries, a working range of 250 miles, and the same efficiencies as in the near term (CARB 1990, p. 2-33; Knight 1991).

With some minor modifications to account for differences in size of vehicles, the characteristics of the "nominal EVs" in the CARB study are adopted for the analysis. Starting with the long term, both the vans and cars use Na/S batteries. Since these batteries do not present the gaseous problems associated with $\mathrm{Pb} / \mathrm{acid}$ batteries. I do not have to deal with a two step charging profile. (Deluca's (1990) report on the Argonne performance evaluations of advanced battery technologies gives examples of possible charging methods.) Rather, chargers designed to work with $\mathrm{Na} / \mathrm{S}$ batteries will deliver the necessary energy at approximately constant power. Vehicle manufacturers and utility companies are now working with one another to learn if "standard" power settings on chargers can be agreed upon (Janasik 1991). An agreement has not been announced during the time of my analysis. Lacking "standard power settings," the analysis proceeded with power levels selected to fall within a reasonable range and to provide the correct amount of electric energy over an integral number of hours (Ford 1991A).

The summary of previous EV studies given in sheet 1 show estimates of daily travel ranging from a low of $28 \mathrm{miles} /$ day to a high of $80 \mathrm{miles} /$ day. The $28 \mathrm{mile} /$ day estimate is based on travel restrictions envisioned in the SCAQMD 1989 Plan and the idea that EV use would be similar to CV use. But many planners have suggested that EV owners will use their EVs much more extensively than a CV. The argument for higher use can be made from the lower cost to operate an maintain an EV. Deluchi (1989, p. 267), for example, estimates the cost of energy for a CV at 3.77 cents/mile and the corresponding cost for an EV to range form 1.48 to 2.11 cents/mile. And with advanced Na/S batteries with a working range of 250 miles, EVs could be used more extensively without encountering range limitations. On the other hand, one might well envision that EVs would not end up with higher daily travel if their performance characteristics (ie, acceleration) falls short of a CV. From an electric utility perspective, planners must realize that many years will pass before customer's attitudes toward their EVs become clear. Utility planners will probably want to "stay on top" of EV owners attitudes by direct monitoring of some EVs' daily travel. Meanwhile, for the purposes of this analysis, I adopt the "conservative" assumption that EVs will be used much more extensively than CVs. The high daily travel 
assumption is "conservative" in the sense that I wish to learn if SCE can accommodate the electricity demands from two million EVs which end up being used much more extensively than the average CV. Rather than the 28-33 miles/day which is typical of a CV (see sheet 1 and NPTS 1986, P. 4-22), I set the travel for electric cars at $40 \mathrm{miles} / \mathrm{day}$. And since conventional vans are used somewhat more extensively than cars (NPTS 1986, P. 4-22), I assume that an electric van would be used even more extensively.

The previous collection of assumptions that govern night time charging may be reiterated as follows:

The small car EV travels 40 miles/day with an efficiency of $4.17 \mathrm{miles} / \mathrm{kwh}$ based on the 4 seater passenger car in the CARB study. The net result is an energy requirement of $9.6 \mathrm{kwh}$ per day. This energy would be provided at constant power charge of $4.8 \mathrm{kw}$ over a 2 hour interval.

The large car also travels $40 \mathrm{miles} / d a y$. The efficiency is set at $2.45 \mathrm{miles} / \mathrm{kwh}$ based on a somewhat heavier version of the 4 seater car in the CARB study. The net result is an energy requirement of $16.3 \mathrm{kwh} /$ day. This energy would be provided at $5.44 \mathrm{kw}$ over a 3 hour interval.

The small van travels $70 \mathrm{miles} /$ day with an efficiency of $2.5 \mathrm{miles} / \mathrm{kwh}$ for an energy requirement of $28 \mathrm{kwh} / \mathrm{day}$. The energy is provided at a constant power of $9.33 \mathrm{kw}$ over a 3 hour period.

The large van travels 55 miles/day with an efficiency of $1.67 \mathrm{miles} / \mathrm{kwh}$ for an energy requirement of $33 \mathrm{kwh} /$ day. This energy is provided with a constant charge of $11 \mathrm{kw}$ over a 3 hour period.

Light trucks are the final class of vehicles included in the demand analysis. Information on their characteristics was lacking, and the default assumption was to assign them the same characteristics as the large vans. Thus, light trucks are assumed to draw power at $11 \mathrm{kw}$ over a 3 hour interval to provide $33 \mathrm{kwh} / \mathrm{day}$.

The next step in organizing The stacker calculations is to specify the time at which each class of vehicle will begin its regular night time charging cycle. EV scenario \#1 from Table I adopts the assumption that night time charging will proceed at the convenience of the vehicle owner. Some owners may turn their chargers on around 5 or $6 \mathrm{pm}$, immediately after returning home from work. Many owners may turn on the chargers around 9 or $10 \mathrm{pm}$ after they are done using the vehicles for the day. And still others may wait until early in the morning before starting the charging cycle. EV scenario \#2 allows for a different pattern due to a financial incentive to delay charging until after $10 \mathrm{pm}$. EV scenario \#3 
allows for the possibility that the utility would control when the EVs begin night time charging.

\subsection{Day time Charging Arsumptions}

Utility planners are concerned over the possibility that EV owners may need to supplement the night time charging with extra energy during the day. Day time charging is sometimes called "opportunity charging" because the owner may take the opportunity to obtain extra energy in order to extend the miles/day of travel. Day time charging may be popular if charging stations are located conveniently around the South Coast. Indeed, some planners argue that massive use of EVs will simply not be possible unless day time charging is made convenient. Unfortunately, day time charging will contribute to the utilities' peak load and make the system more expensive to operate.

The need for supplemental energy will depend on the daily travel requirements of the EV owners and the range of their vehicles. Sheet $\$ 3$ in the Appendix shows how supplemental energy might vary with variation in the vehicles' range. The spread sheet begins with a 60 mile range which is available with current technology (Sperling 1990, p. 257; Deluchi 1989, p. 257). The spread sheet quits at a range of 240 miles per charge since this range is sufficient to reduce supplemental energy to zero. The first four columns of sheet 3 show an assumed probability distribution on daily travel per vehicle. The grey column contains the inputs to the spread sheet. It is unfortunate that these inputs are not directly available from previous studies and surveys. (The most extensive information on vehicle travel is given in the National Personal Transportation Surveys (NPTS). But these data are reported in miles/trip rather than in miles/day (NPTS 1986, p. E-23). Moreover, the NPTS trips/day data suggest that converting from a distribution on miles/trip to a corresponding distribution on miles/day is not straightforward.) Sheet $\$ 3$ is based on indirect use of the NPTS data and a desire to yield a mean travel of 30 miles/day as well as a good match with SCAG projections for travel in southern California. More specifically, $95 \%$ of trips involve less than 80 miles/day of travel, and 988 of all trips involve less than $140 \mathrm{miles} /$ day. Sheet \#3 shows the mean of the distribution at the desired value of 30 miles/day per vehicle. Sheet $\$ 3$ also shows that the cumulative probability distribution closely matches a scaled version of the trip distributions projected in the recent SCAG study of highway electrification. The SCAG researchers employed detailed models of the South coast network of roads and freeways to project possible trip distributions in the year 2025. Their study focuses on EVs that can supplement their night time energy by traveling on electrified roadways during the day time. Looking at the SCAG estimates of the fraction of trips that could be 
completed without the use of supplemental energy, one can obtain a cumulative probability based on a "derated" battery range running from $20 \mathrm{miles} / \mathrm{charge}$ to $60 \mathrm{miles} / \mathrm{charge.} \mathrm{The} \mathrm{"derated"} \mathrm{ranges} \mathrm{from}$ the SCAG study were multiplied by a scale factor of two as if each vehicle in their scenarios were to make one round trip per day. The resulting probability distribution in the fourth column provides a second plausibility check on the information in the grey column.

The right side of Sheet 3 portrays the possible consequences of EVs with different ranges. Consider the $60 \mathrm{mile} / \mathrm{day}$ column which shows the consequences of vehicles with an extremely limited range. Even with this limitation, EVs could cover 93\% of all trips. If the EVs were sold to individuals who planned to seldom drive the vehicle beyond $60 \mathrm{miles} / \mathrm{day}$, the daily travel would end up at $23.3 \mathrm{miles} / \mathrm{day}$, and there would be no need for supplemental energy. If, on the other hand, the EVs were sold to individuals whose travel plans were unchanged by the EV, some supplemental energy would be needed. To reach the mean value of $30 \mathrm{miles} /$ day, the supplemental energy would have to fuel the vehicle for an extra $6.7 \mathrm{miles} / \mathrm{day}$. If the supplemental energy were provided with the same efficiency as the night time energy, one could conclude that supplemental energy would account for 228 of the total energy requirement.

The 228 estimate is the highest value in sheet 3 . It should be interpreted as but one of many plausible estimates of the supplemental energy requirement for vehicles with the low range of 60 miles per charge. (The 228 estimate happens to be similar to a CEC. EV scenario which was designed to show the impact of extensive opportunity charging. The CEC recharging profile (CEC 1990A Vol. II, Part B, P. 24) assumes that $24 \%$ of the energy is provided during the interval from $9 \mathrm{am}$ to $8 \mathrm{pm}$.$) Unfortunately, it$ is difficult to assign high confidence to the 228 estimate. It is also difficult to judge whether the estimate may be viewed as a lower or upper bound. For example, one might envision that EVs would be sold predominantly to households whose daily travel plans do not exceed the range of the vehicle. With such behavior, the supplemental energy would be minimal, and the daily travel would be $23.3 \mathrm{miles} / \mathrm{day}$. On the other hand, one might envision that the low operating cost of EVs might induce the owners to use them more extensively than a CV, and supplemental energy would end up greater than portrayed in sheet 3 .

The day time charging assumptions in the eight EV scenarios in Table I were specified after discussions with planners at SCE. Given the great uncertainty on EV owner behavior, I decided to simply specify the fraction of the EV population that would be drawing an opportunity charge during the hours from 8 am to $5 \mathrm{pm}$. With EV scenario \#1, for example, the opportunity charging is limited to a "minimal" fraction of the venicle population. I set the fraction at $1 \%$, and The stacker calculations show that this 
Table II. Day Time Charging Assumptions.

\begin{tabular}{|c|c|c|c|c|}
\hline 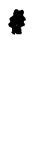 & $\begin{array}{l}\text { Number } \\
\text { of EVs, } \\
\text { Year }\end{array}$ & $\begin{array}{l}\text { Batteries } \\
\text { and Range }\end{array}$ & $\begin{array}{l}\text { EVs } \\
\text { drawing } \\
\text { power in } \\
\text { day time }\end{array}$ & $\begin{array}{l}\text { Supplemental } \\
\text { Energy as a } \\
\text { of rotal } \\
\text { Energy }\end{array}$ \\
\hline $\begin{array}{l}1 \\
2 \\
3\end{array}$ & $\begin{array}{l}2 \text { million } \\
\text { in } \\
2010\end{array}$ & $\begin{array}{l}\mathrm{Na} / \mathrm{S} \\
250 \text { miles }\end{array}$ & 18 & 48 \\
\hline $\begin{array}{l}5 \\
6\end{array}$ & $\begin{array}{l}\text { million } \\
\text { in } \\
2010\end{array}$ & $\begin{array}{l}\mathrm{Na} / \mathrm{s} \\
250 \mathrm{miles}\end{array}$ & 18 & 48 \\
\hline 4 & $\begin{array}{l}2 \text { million } \\
\text { in } \\
2010\end{array}$ & $\begin{array}{l}\mathrm{Pb} / \mathrm{Acid} \text { and } \\
\mathrm{Ni} / \mathrm{Ee} \\
150 \mathrm{miles}\end{array}$ & 38 & 108 \\
\hline $\begin{array}{l}7 \\
8\end{array}$ & $\begin{array}{l}50,000 \\
500,000 \\
\text { in } 2000\end{array}$ & $\begin{array}{l}\mathrm{Pb} / \mathrm{Acid} \text { and } \\
\mathrm{Ni} / \mathrm{Fe} \\
150 \text { miles }\end{array}$ & 58 & 158 \\
\hline
\end{tabular}

assumption leads to 48 of the energy occurring during the day time hours. Sheet 3 shows that there would be no need for supplemental energy given the $250 \mathrm{mile}$ range, so the reader may attribute the minimal amount of day time charging to other reasons (ie, some EV owners may simply forget to charge their vehicle the night before). Table II notes that the same day time assumptions apply to EV scenarios $\$ 1,2,3,5,6$ since all of these envision the use of $\mathrm{Na} / \mathrm{S}$ batteries with the extremely long range of $250 \mathrm{miles} / \mathrm{charge}$.

EV scenario 4 was specified to check the impact of vehicles similar to the "near term" nominal EVs in the CARB study. The vans in this scenario would operate with $\mathrm{Ni} / \mathrm{Fe}$ batteries while the cars would have sealed $\mathrm{Pb} / \mathrm{Acid}$ batteries, and all vehicles would have a range of $150 \mathrm{miles}$. Because of the lower range, the fraction of EVs drawing opportunity charge is increased to $3 \%$ of the vehicle population. This assumption causes $10 \%$ of the total energy to come during day time hours. Checking sheet \$3 shows that $10 \%$ supplemental energy is approximately what one would expect with a range of $140 \mathrm{miles} / \mathrm{charge.} \mathrm{The} \mathrm{final} \mathrm{two} \mathrm{scenarios} \mathrm{listed} \mathrm{in} \mathrm{Table}$ I apply to the year 2000 and assume that EVs can deliver $150 \mathrm{miles}$ per charge. After discussions with planners at SCE, I decided that opportunity charging could be more extensive in the near term because vehicle owners may still be "unsure" of the EV performance. I assumed that 58 of the EVs would be drawing opportunity charge during the interval from $8 \mathrm{am}$ to $5 \mathrm{pm}$, and The stacker shows that this assumption would cause $15 \%$ of the energy to arrive during the day time hours. 


\subsection{Ist Scenario: Charging at Customer Convenience}

This collection of assumptions is sufficient to allow one to project the electricity demand at each of 24 hours in a typical day in the year 2010. Both "Summer and Winter days" have been analyzed in the research (Ford 1991A,B), and both sets of results are of interest to utility planners. The Winter results are interesting because there is less room for the $E V$ demands in the night time valleys (Ford 1991A,B; Ducat 1989, p. A2-5). The Summer results are interesting because SCE's peak occurs in the Summer. The results shown in this report concentrate on the summer, but the impacts across all seasons are included in the analysis.

Figure 11 shows The Stacker results for EV scenario 1 . This scenario assumes that night time charging is begun at the customers' convenience over the hours from $6 \mathrm{pm}$ to $1 \mathrm{am}$ with $9 \mathrm{pm}$ with $10 \mathrm{pm}$ assumed to be the most popular times to start charging. This scenario envisions that $95 \%$ of the chargers being the nightly cycle by midnight (Ford 1991A, p. 8). The total demand for electric energy is estimated at around $34 \mathrm{GWh}$ per day. When spread evenly over the 365 days in a year, the EVs would demand 12.3 billion knh in the year 2010. Expressed relative to the number of EVs, the demand is $17.3 \mathrm{kwh} /$ day per vehicle, so one would "locate" this scenario just below the $20 \mathrm{kwh} /$ day ray in Figure 2. The peak EV demand is $6.1 \mathrm{GW}$, and the peak occurs at $10 \mathrm{pm}$. When stacked on top of the regular SCE demands for an August day in the year 2010 , the EVs cause the $2 \mathrm{pm}$ peak to increase by $121 \mathrm{MW}$. The $121 \mathrm{MW}$ arises from the 18 of the EVs which are drawing opportunity power at $2 \mathrm{pm}$ in the afternoon. The top chart in Figure 11 shows that the EV demands lead to a second peak in the daily demand profile at $9 \mathrm{pm}$ in the evening. The top chart also shows that very little of the EV demand falls in the early morning hours when the regular SCE demand is at the lowest values. The absence of demands in the early morning hours arises from a combination of two assumptions. First, recharging is assumed to start relatively eariy in the evening hours at the customer's convenience. Second, the duration of charging is rather short since all vehicles complete their night time charge in 3 hours or less. The short charging intervals, in turn, are a logical consequence of the relatively short daily travel (ie 40 miles/day) compared to the 250 mile range.

\subsection{2nd Scenario: Charging with a "10 pm Incentive"}

The 2 nd and 3 rd scenarios in Table I were created to study the effect of different charging strategies. The goal is to learn what might be done to avoid a second peak in demand and to place more of the EV demand into the deep valley available in the early morning hours. Figure 12 shows the impact of a financial incentive to encourage customers to wait until $10 \mathrm{pm}$ before turning on their chargers. The change in customer behavior is represented in a very simple manner: all customers that would have turned the chargers 

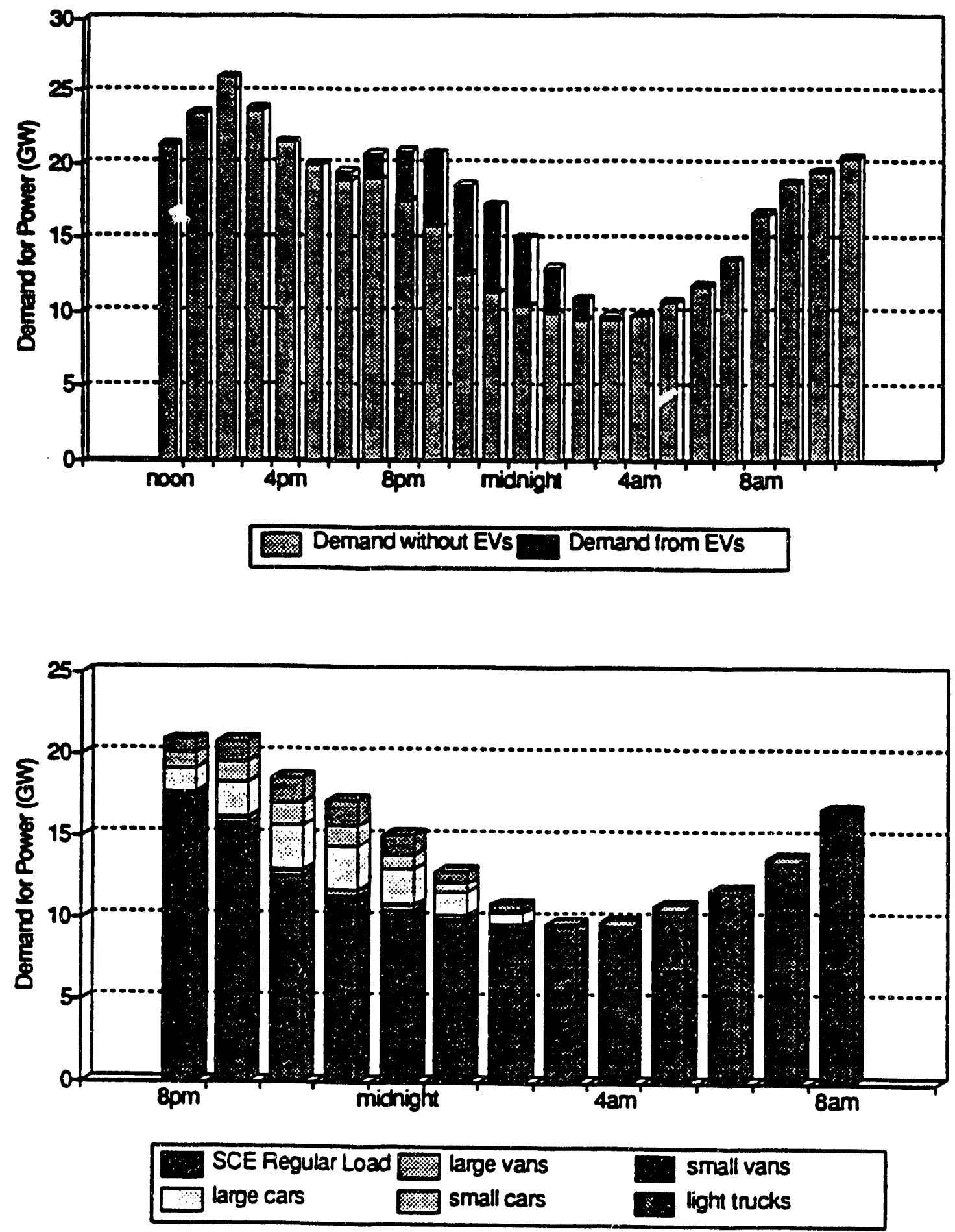

Figure 11. Electricity Demand in the 1st Scenario.

Two million EVs with advanced batteries on the SCE system in the year 2010 . The night time charging occurs at the customers' convenience. 
on prior to $10 \mathrm{pm}$ in the 1 st scenario are assumed to wait until 10 $\mathrm{pm}$ in the 2nd scenario. The remaining customers are assumed to behave as in the 1 st scenario.

Figure 12 show that the "10 pm incentive" would lead to a large, second peak in SCE demand around $11 \mathrm{pm}$. The large peak is the inevitable result of the large number of $\mathrm{EV}$ owners who are waiting until 10pm to turn on their chargers. Figure 12 also shows that the "10 pm incentive" does little to place the EV demand into the early morning valley. This result is a logical consequence of the short charging interval and the assumption that $95 \%$ of the EV owners will turn on their night time chargers by midnight. The "10 pm incentive" tested here is admittedly an extremely simple version of a financial incentive. More sophisticated incentives might be designed, but utility planners will always wonder whether greater sophistication will lead to an improved electricity demand or to confusion on the part of the customer. If incentives prove difficult to design, the utility might turn to direct control of EV charging.

Figure 13 reports the electricity demands from the two million EVs if the utility does take control of when chargers begin their night time charging. The utility might adopt direct control in which signals are sent to each EV charger to instigate charging. Alternatively, the utility might use preprogrammed clocks which are designed to start charging at a particular time in the evening or early morning. The Figure 13 results were obtained by simply experimenting with different starting distributions for each of the five classes of EVs. The idea was to use The stacker in an interactive fashion to search for a relatively flat profile. The results in Figure 13 are labeled "blind control" because the search for a flat demand profile is limited by an important constraint. The key restriction arises from the assumption that the utility can send information to the each of the two million chargers, but the utility does not have information on the status of each vehicle. With this one way communication, the utility must devise a control strategy in the absence of information about the depth of discharge and the likely duration of night time charging of each vehicle. Given the typical design target of an 8 hour charging time (when the vehicle is driven at full range), the utility would probably wish to start all vehicles no later than $11 \mathrm{pm}$ in the evening. The $11 \mathrm{pm}$ restriction would ensure that all vehicles are ready by 7 am the next morning.

Figure 13 shows one of the better demand profiles which complies with the $11 \mathrm{pm}$ restriction on instigating charging. A fundamental problem with "blind control" is readily apparent from the top chart: the $11 \mathrm{pm}$ restriction prevents a significant portion of the EV demand from landing in the deep valley available during the early morning hours. These disappointing results suggest that the utility could do better if a control system were implemented that did not suffer from the $11 \mathrm{pm}$ restriction. 

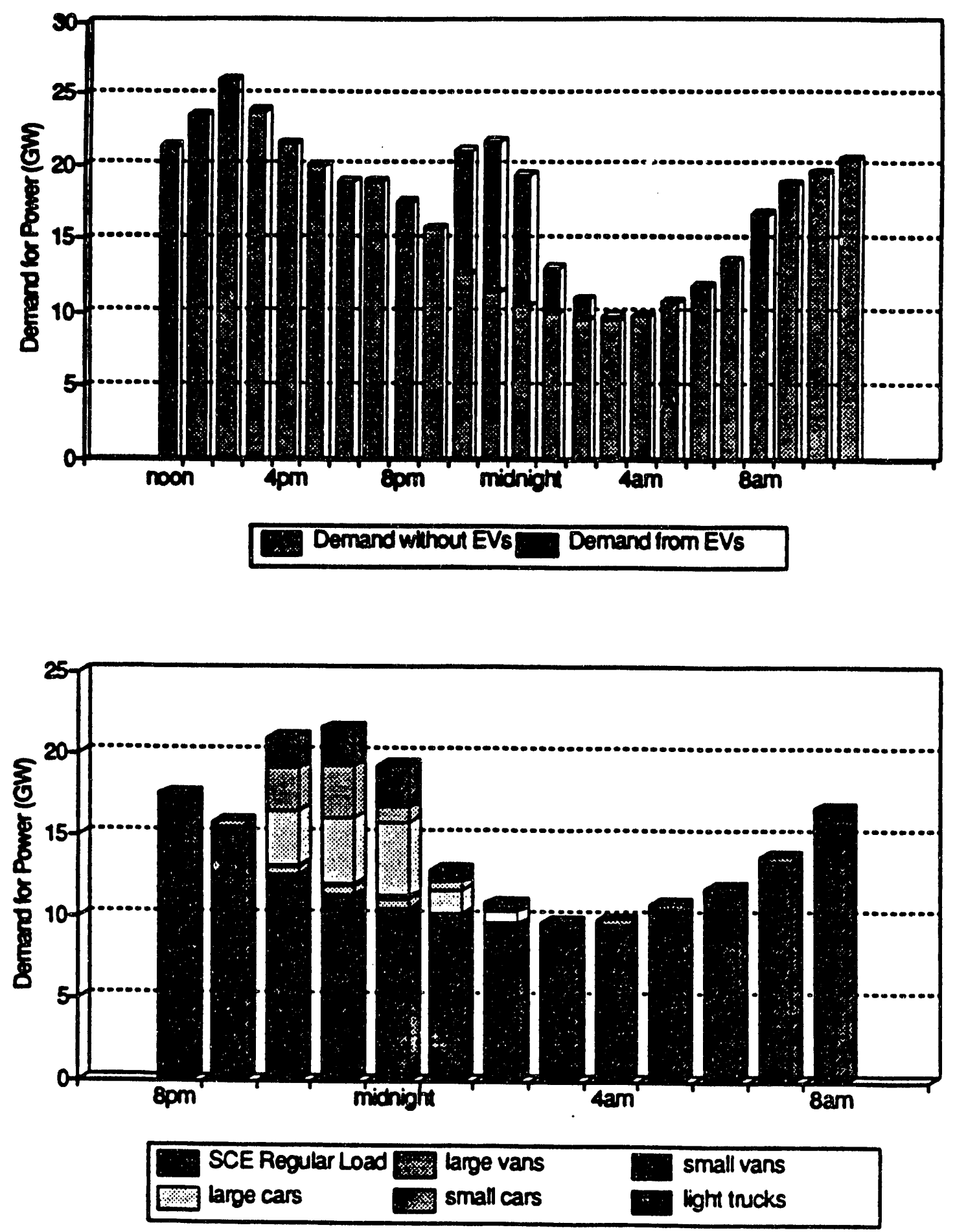

Figure 12. Electricity Demand in the 2nd Scenario.

Two million EVs with advanced batteries on the SCE system in the year 2010 . The night time charging is influenced by a "10 pm incentive." 

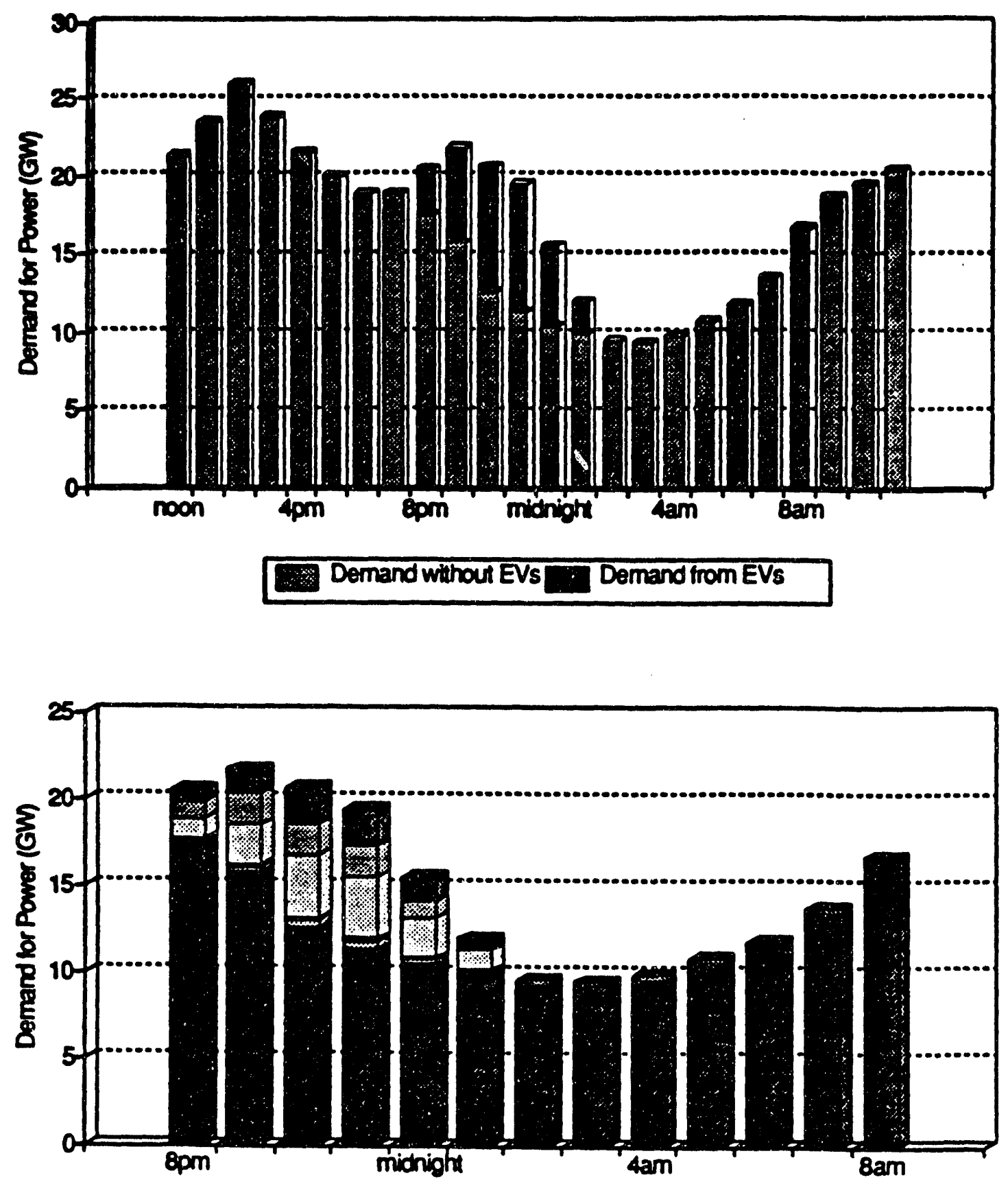

\begin{tabular}{|l|l|}
\hline SCE Regular Load & small vans \\
large cars & light tncks vans \\
\hline
\end{tabular}

Figure 13. Electricity Demand from 2 million EVs under "Blind Control." 


\subsection{3rd Scenario: Charging with "Smart Control"}

Figure 14 shows EV demands with a utility "smart control" assumption in which the utility has two way communication with the charger. Smart control assumes that the utility control center can read the status of the battery and estimate the duration of charging. If, for example, the control center learns that a particular vehicle requires only 2 hours of charging, the signal to instigate charging might be delayed until 3 or 4 am in the morning to help fill the deep valley. An EV "smart control" system might be interwoven with the equipment and systems envisioned as part of a "smart house" (EPRI 1991). Proponents of "modernizing" the pricing and metering practices of electric utilities might envision an EV control system as part of the "revolution" in the utility industry (Sioshansi 1991, p. 294, 306). For example, smart control of EVs could be implemented by expanding the role of the "NetComm" system under consideration at SCE. (NetComm is described in an SCE newsletter (1990) as an advanced communication system based on a network of packet radios which would interface with electrical distribution devices for monitoring and automation.)

The particular method used to implement "smart control" of night time EV charging is not part of the scenario analysis. What is of interest is the extent to which such a system can lead to $a$ flat load profile. Figure 14 shows one of the better load profiles obtained after multiple, visual experiments with The Stacker. The $11 \mathrm{pm}$ restriction from the "blind control" experiments was replaced by less severe constraints on the control system. For example, all night time charging must be completed by 7 am to permit EV owners to begin their morning commute. Next, night time charging is delayed until $11 \mathrm{pm}$ or later to allow EV owners the use of their vehicles during the evening hours.

The top chart in Figure 14 shows one of the flatter profiles that could be found under these restrictions. EV demand peaks at $6.1 \mathrm{GW}$, the same as in the first scenario. But with smart control, the peak occurs at $3 \mathrm{am}$ (and $4 \mathrm{am}$ ) in the morning. When stacked on top of SCE's other demands, the controlled EV demands lead to a major improvement in the daily profile for this typical day in August of 2010. Close study of Figure 14 shows that the total demand is not flat during the early morning hours. Rather, it increases gradually once the EVs begin charging around $11 \mathrm{pm}$ and reaches a peak just above $15 \mathrm{GW}$ at 4 am in the morning.

Figure 15 demonstrates that the new 4 am peak from smart control can be attributed to the restriction that night time EV demand are confined to the interval from $11 \mathrm{pm}$ to $7 \mathrm{am}$. This diagram shows the regular SCE load (with no EVs) along with the total demand when the two miliion EVs are subject to smart control. The diagram makes it clear that there is no night time EV demand until after $11 \mathrm{pm}$. Also, it is clear that EV demand returns to zero by 


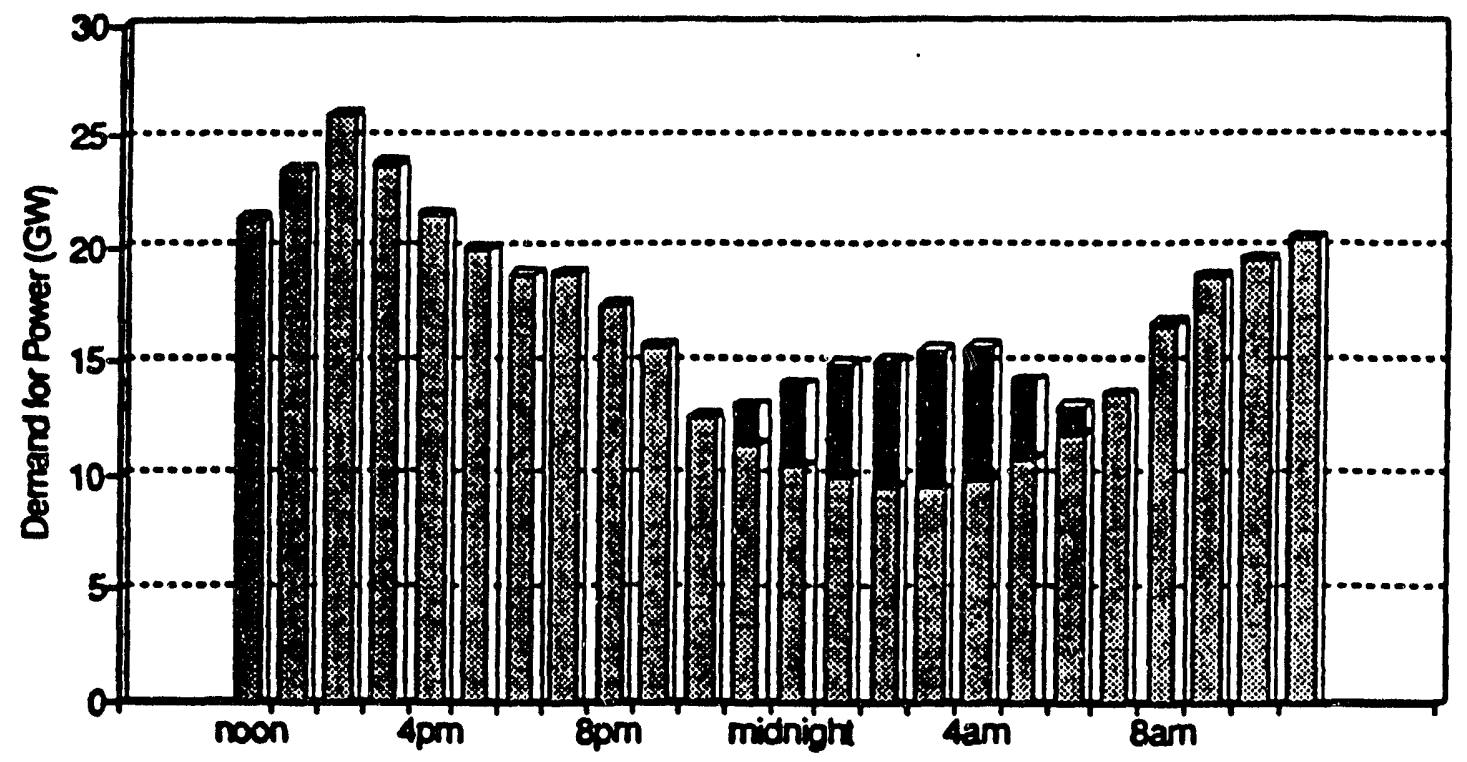

Demand without EVs Demand from EVs

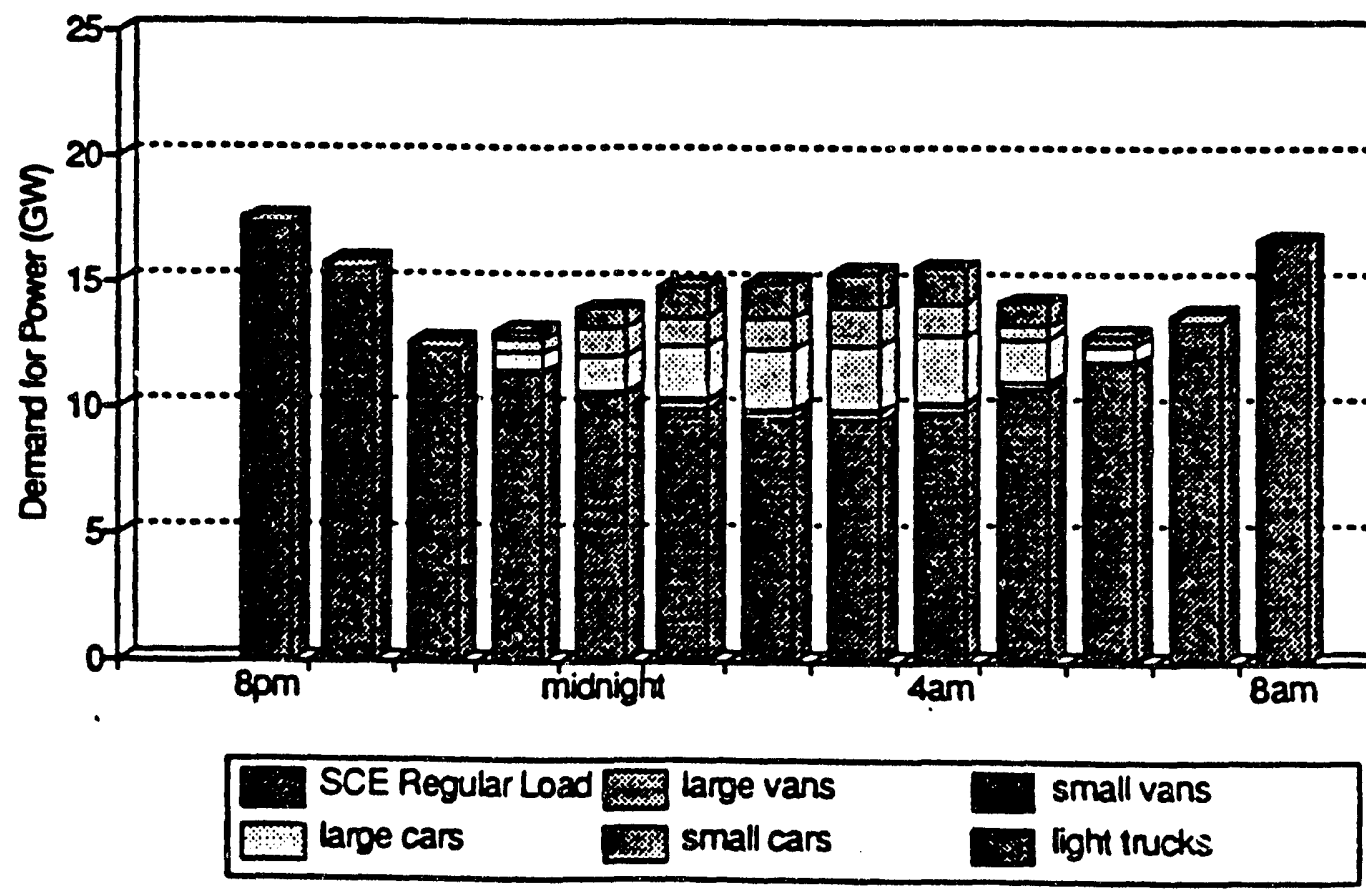

Figure 14. Electricity Demand in the 3rd Scenario.

Two million EVs with advanced batteries on the sCE system in the year 2010. The night time charging is subject to smart control by the utility. This example shows smart control implemented for a peak day in August. 

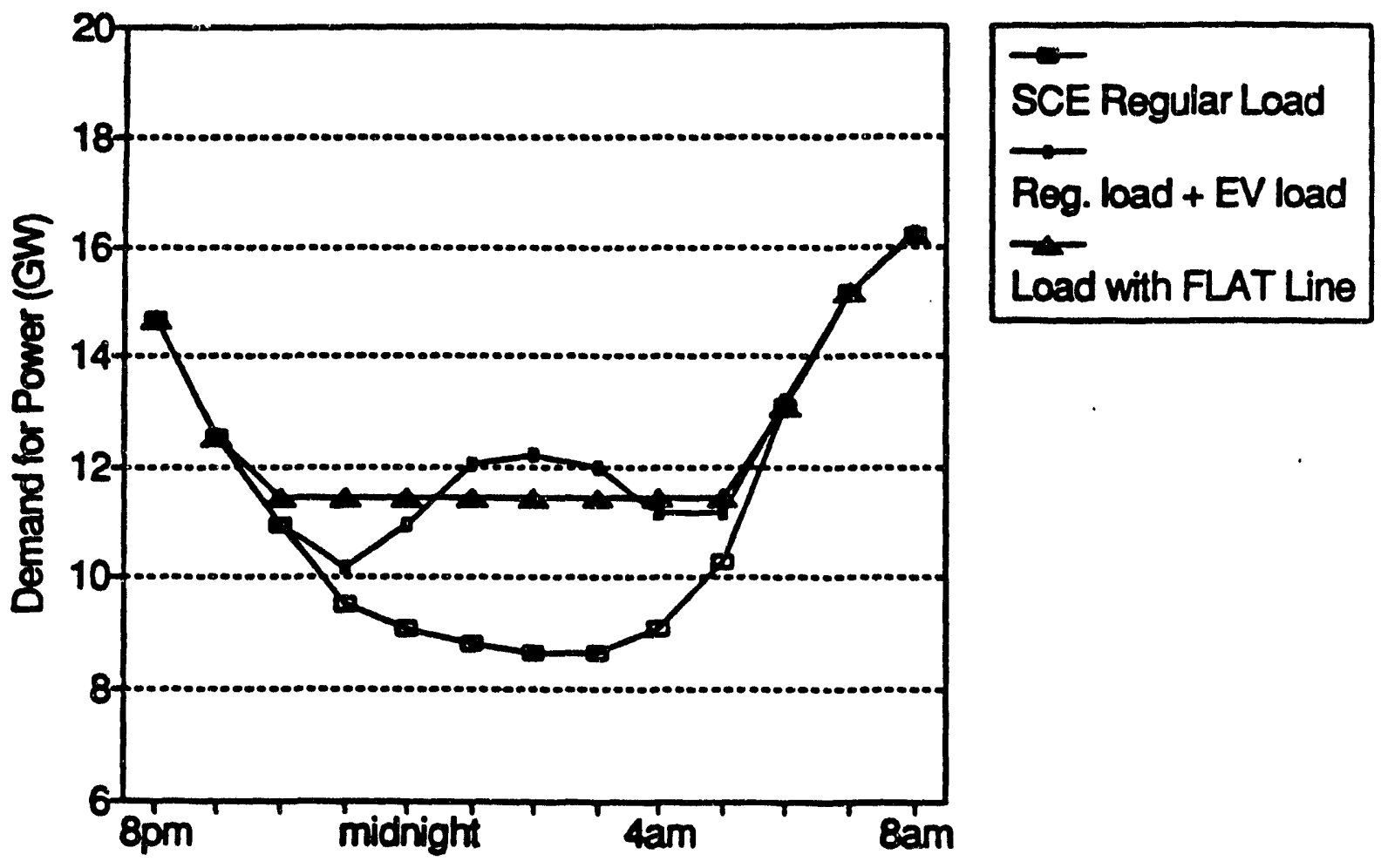

Figure 15. Comparison of the August Electricity Demand under Smart Control with a Flat Demand Profile.

7 am in time for the morning commute. The "flat line" is located in Figure 15 such that the area between SCE's regular demand profile and the flat line is equal to the total electric energy needed for the two million EVs. The position of the flat line demonstrates that a flatter profile could be obtained, but only if some vehicle owners were willing to permit charging to begin as early as $10 \mathrm{pm}$ in the evening or to continue as late as 7 am in the morning.

The smart control results in Figures 14 and 15 depend on the attributes of the two million EVs and the shape of SCE's other demands expected for a peak August day in the year 2010. Since smart control works to blend the EV demands with the other demands, the timing of the EV demands will change with changes in the regular SCE profile. This variability requires that a smart control system be reexamined in different months of the year to determine how the EV demands might change. A separate Technical Memo on the project (Ford 1991B) explains that the 7 months of April-october are likely to show a peak demand at $1 \mathrm{pm}$ or $2 \mathrm{pm}$. These months are similar in their base demand profile to the August shape shown in Figure 14, so The stacker results for August have been assigned to each of the months with afternoon peaks. The five winter months, November - March, on the other hand, are likely to exhibit a "dinner time peak" around $5 \mathrm{pm}$ or $6 \mathrm{pm}$. Their base profiles are sufficiently different that The Stacker search for a 
relatively flat profile must be repeated. The new search is based on January as typical of the five months with a "dinner time" peak. The January results are explained in a Technical Memo on the project (Ford 1991A).

\subsection{4th Scenario: Charging with Iess Advanced Batteries}

The fourth scenario assumes two million EVs in the SCE area with the EV owners turning on the night time chargers at their convenience. Thus, one should expect EV demands in the 4 th scenario to be quite similar to demands in the 1st scenario. The key difference between the scenarios involves the batteries, their ranges and the need for day time charging. Table II notes that the 4 th scenario limits the EV ranges to $150 \mathrm{miles} / \mathrm{ch} a \mathrm{rge}$ and assumes a greater need for supplemental energy. The electric cars are equipped with $\mathrm{Pb} / \mathrm{acid}$ batteries with a two step charging profile. The vans and light trucks are assumed to operate with $\mathrm{Ni} / \mathrm{Fe}$ batteries and to receive their night time charge at approximately constant power. The constant power assumption is based on the profile reported by the RFF researchers $(1990, p .2-34)$ who used a TEVan with a Ni/Fe battery in their study. (Their information, in turn, was obtained via a private communication from staff at Peritastar Electronics, Inc.. Chrysler's subsidiary in charge of testing the $\mathrm{Ni} / \mathrm{Fe}$ battery.)

This new collection of assumptions was entered in The Stacker, and the final result was a total demand for energy quite similar to the 1st scenario. Total electricity sales to EVs increased from 12.3 to 12.6 billion $\mathrm{kwh} / \mathrm{year}$, and the average use per vehicle increased from $17: 1$ to $17.5 \mathrm{kwh} /$ day. This similarity arises from the fact that scenarios 1 and $\$ 4$ adopt the same assumptions on numbers of EVs, their miles/day of travel and their miles/kwh efficiency. Also, since both scenarios assume night time charging at the "customer's convenience," the shape of the night time demand for power is quite similar. The key difference is in the day time demand. The 4th scenario shows $358 \mathrm{MW}$ of demand during SCE's afternoon peak as compared to only $121 \mathrm{MW}$ in the 1 st scenario. The three fold increase is a logical consequence of the three fold increase in the number of vehicles drawing opportunity charge during the day time hours.

The similarity between the 1 st and 4 th scenario is evident from Figure 16 which arranges electricity demands from the first four scenarios in one chart. This comparison shows the two "customer convenience" scenarios with demands peaking around $11 \mathrm{pm}$. The 2nd scenario stands out from the rest because of the dramatic effect of the "10 pm incentive." The incentive leads to zero demand until after $10 \mathrm{pm}$; then demand peaks at over $10 \mathrm{GW}$ at $11 \mathrm{pm}$ when a large fraction of EV owners turn on their chargers. 


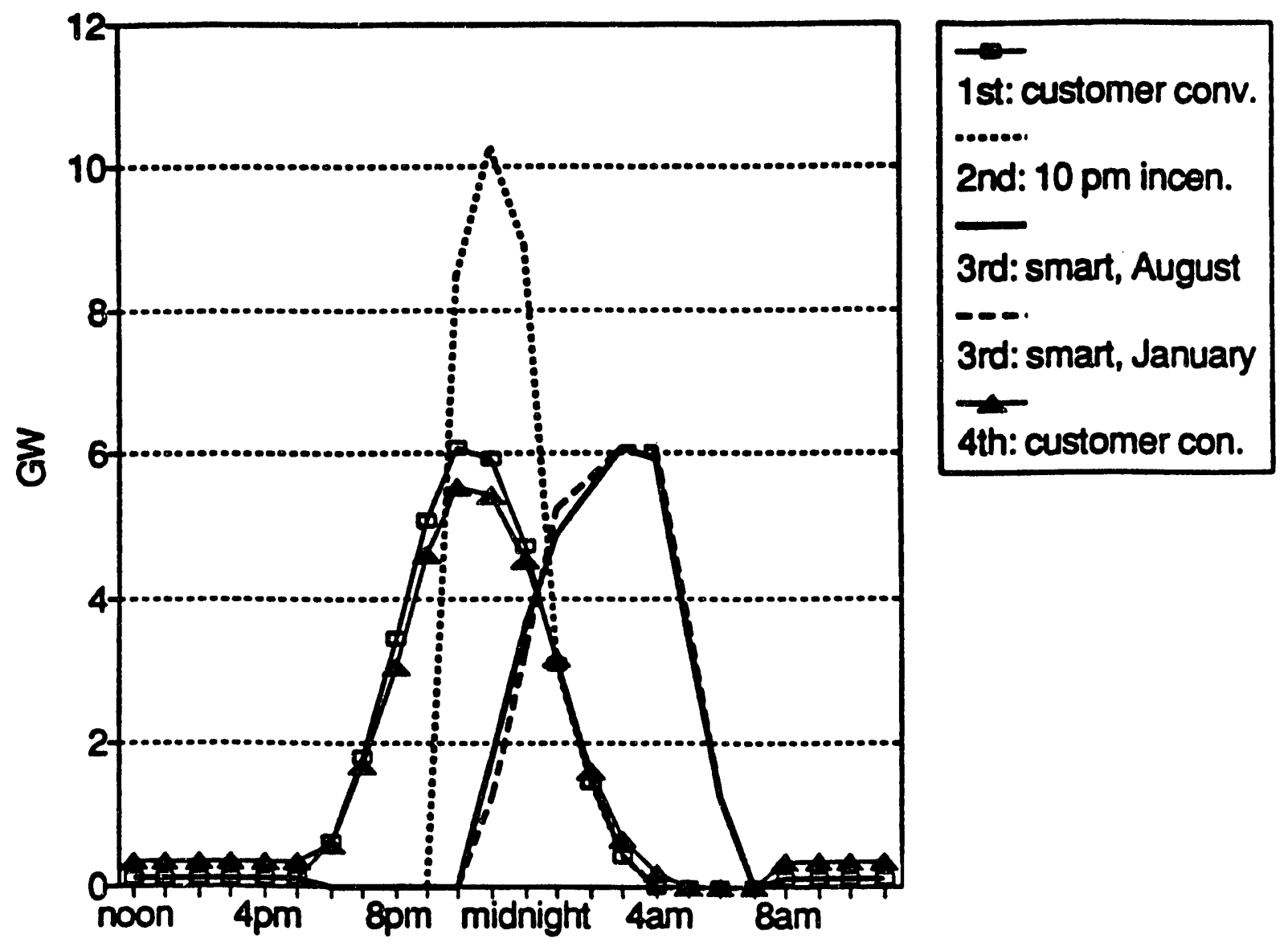

Figure 16. Electricity Demands in the First Four Scenarios.

The final two curves in Figure 16 show the demand in the third scenario with "smart control." One curve shows the demand profile that blends well with SCE's regular demands expected for a typical August day in the year 2010. The second curve applies to a typical day in January. The two curves show that EV demand peaks at around $6 \mathrm{GW}$ (similar to the 1st scenario), and the peak occurs around $4 \mathrm{am}$ in the morning. The small differences between the August and January demand profiles suggests that the scenario analysis may proceed without a month by month analysis of smart control. 


\subsection{5th and 6th scenarios: Damand from One Mil110n IVa}

Figure 17 shows the electricity demands in the two scenarios with one million EVs in the SCE service area by the year 2010. The exact mix of vehicles was based on the Chapter 4 vintaging results scaled back by 608 to obtain:

$$
\begin{aligned}
& 55,000 \text { large vans } \\
& 28,000 \text { small vans } \\
& 316,000 \text { large cars } \\
& 516,000 \text { small cars } \\
& 91,000 \text { light trucks }
\end{aligned}
$$

These scenarios assume approximately the same number of electric vans as in the previous scenarios and about two-thirds as many electric small cars. The big difference shows up in the large car and light truck categories where the new scenarios assume only about a third as many EVs as in the previous examples. Overall, the mix of vehicles is slanted more heavily toward smaller vehicles
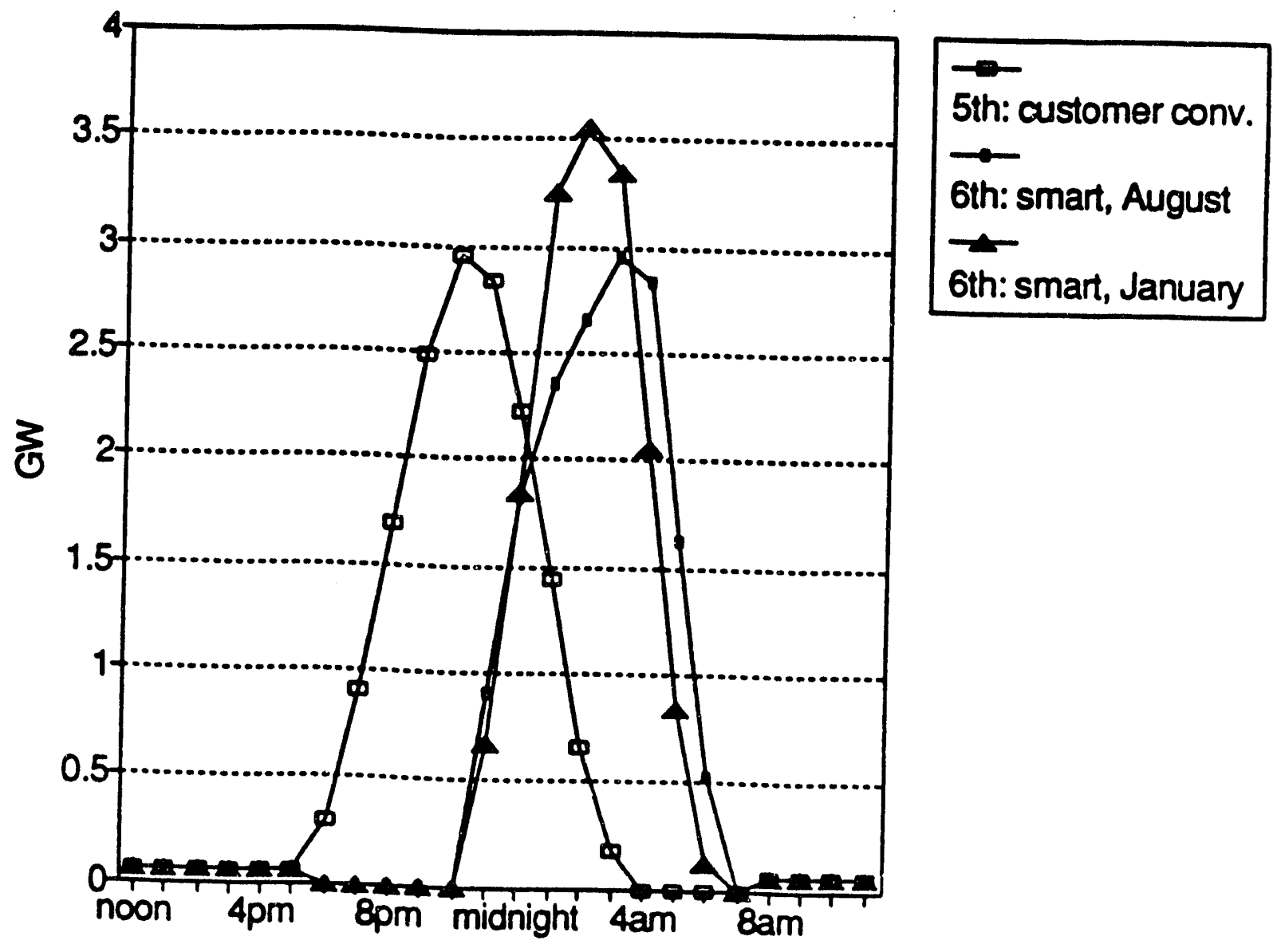

Figure 17. Electricity Demands in EV Scenarios $\$ 5,6$ 
which are expected to travel with greater efficiency (measured in miles/kwh).

The one million EVs are assigned the same $\mathrm{Na} / \mathrm{S}$ batteries used in the first three scenarios, so the night time and day time assumptions are similar to the previous scenarios. Electricity demands in the 5 th scenario are based on the customer convenience assumption. Demands in the $6 \mathrm{th}$ scenario are based on smart control. As before, he smart control demands are found by interactive search which is constrained to allow EV owners to use their vehicles until $11 \mathrm{pm}$ and to be ready to use them again at $7 \mathrm{am}$ the next morning.

Figure 17 shows the same pattern observed in the scenarios with two million EVs. That is, leaving night time charging to the convenience of the customers leads to peak demands around $11 \mathrm{pm}$. Putting night time charging under the smart control of the utility shifts the demand to the early morning hours. The stacker shows total demand of around $16.3 \mathrm{GWh} /$ day or $6.0 \mathrm{billion} \mathrm{kwh} / \mathrm{year}$. When compared to the number of vehicles, the weighted average usage turns out to be $16.2 \mathrm{kwh} /$ day per vehicle. (The new figure is somewhat lower than the $17.1 \mathrm{kwh} /$ day in the first scenario because the population of EVs is comprised of a larger share of small cars.) The two curves for summer and winter smart control show that seasonal differences are somewhat more important in these scenarios than in the scenarios with two million EVs. These larger differences probably arise from the greater share of small vehicles (and their shorter charging interval) in the EV population.

\subsection{7th and 8th Scenarios: Demand in the Year 2000}

Figure 18 shows the demands from the final two scenarios which apply to the year 2000, the mid-point of the SCE long term planning interval. The 7th scenario envisions 50,000 EVs in the SCE area, approximately the number found in a vintaging calculation that leads to one million EVs by the year 2010. The mix of vans, cars and trucks are scaled back by $60 \%$ and used in The Stacker program to find electricity demands. The vehicies are assigned the same set of batteries (Pb/acid for the cars, Ni/Fe for the vans) used in the 4th scenario, and the opportunity charging is set at $5 \%$ during the hours from 8 am to $5 \mathrm{pm}$. The Stacker calculations show a weighted average electricity use of $24.1 \mathrm{kwh} /$ day per vehicle. This figure is higher than the weighted averages in all previous scenarios because the vans comprise a larger share of the EV population in the year 2000. Total electricity demand for the year 2000 turns out to be around 0.5 billion $\mathrm{kwh}$.

The 8th scenario is designed as a "near term surprise." It would lead to 500,000 EVs in the SCE area or 833,000 EVs in the South Coast by the year 2000. Simulations from the vintager show 


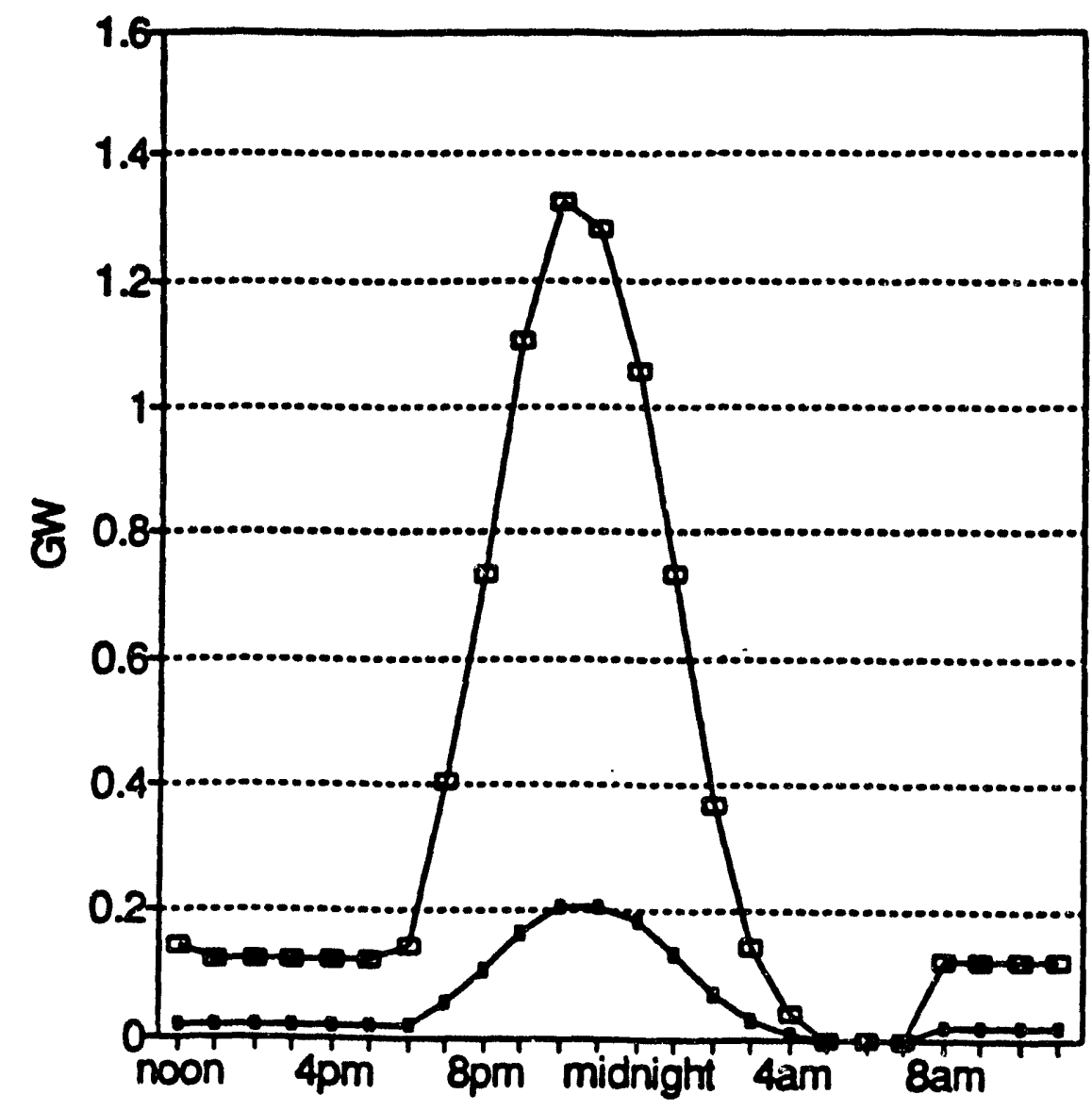

8th $1 / 2$ million EVs 7th 50,000 EVs

Figure 18. Electricity Demands from EVs in Scenarios 17,8 .

how quickly EVs must capture a major portion of new vehicle sales for this "surprise" to arrive by the year 2000. In the year 1998, for example, the 8th scenario requires that EVs capture 50 of van sales, almost 408 of small car sales, and 158 of large car and light truck sales. These assumptions translate into EVs capturing over 208 of passenger car sales by the year 1998. By the year 2000 , EVs would have to capture 358 of passenger car sales. The total population of EVs hits the 833,000 level in the year 2000 and continues to grow in the following decade. By the year 2010, the total population would reach 4.8 million. Thus, the 8 th scenario ends up with roughly half the vehicles in southern California running on electricity by the end of the planning interval. The vintager's projection of vehicles in the year 2000 are scaled back by 608 and assigned the same $\mathrm{Pb} / \mathrm{acid}$ and $\mathrm{Ni} / \mathrm{Fe}$ batteries used in the previous scenario. Night time charging is performed at the "customer's convenience." The Stacker calculations show a total electricity demand of 3.1 billion $\mathrm{kwh} / \mathrm{year}$ and a weighted average use of $17.4 \mathrm{kwh} /$ day per vehicle. 
Figure 18 compares the electricity demands from the final two scenarios. As one would expect, the demands have the same shape because both scenarios assume that night time charging is instigated at the convenience of the vehicle owners. Naturally the demand in the scenario with 500,000 vehicles is much higher than the demand with 50,000 vehicles. But the ratio of the two demands is considerably lower than the ten to one ratio in the number of vehicles because vans comprise a larger share of the EV population in the 50,000 vehicle scenario.

\subsection{Discussion: Daily, Heekly and Seasonal Cycles}

The set of eight electricity demands are used in Chapter 6 to determine the impact of EVs on the SCE system. Before turning to the impact analysis, I discuss three assumptions which were adopted to keep the Chapter 6 analysis as simple as possible. These assumptions involve daily, weekly and seasonal variations in the EV' ${ }^{\prime}$ demand for electric power.

\section{Daily Cycles:}

The EV demands in Figures 11-18 are based on the simplifying assumption that each EV draws a night time charge each and every night of the week. But with a 250 mile range and daily travel of around 40 miles/day, many EV owners might choose to skip the night time charging from time to time. Some EV owners might choose to charge every other night, and others may choose to skip the night time charge for several nights in a row. Two factors may contribute to deviations from the once-a-night pattern: convenience and (2) battery maintenance.

The convenience factor involves the ease of charging and the EV owners' competing uses for garage space. On many nights, the EV may simply be left outside to allow the household an alternate use of the garage. The maintenance factor involves the possibility that some batteries will perform better over the long run if they are fully discharged from time to time. (This feature is sometimes called a hysteresis effect or a "memory effect" because one is left with the impression that the battery "forgets" its full capability when it is not discharged extensively from time to time.) But scientists at the Argonne National Laboratory suggest that such "memory" effects are only likely for Nickel-Cadmium batteries (for which they are said to pose only a small problem.) As far as the long term performance of $\mathrm{Na} / \mathrm{S}$ batteries are concerned, Argonne engineers suggest that EV owners would want to recharge frequently to avoid a deeply discharged state (Deluca 1991). Based on the Argonne findings, one would expect convenience considerations to dominate considerations of battery maintenance. Thus, the EV owner's decision making on regular, night time charging might be heavily influenced by competition for use of the garage space. 
The possibility for skipping the regular night time charge raises yet another source of uncertainty for utility planners. Based on how planners describe demands from other electric equipment, a so-called "diversity factor" might be assigned to EVs. A 508 diversity factor, for example, would represent the average EV owner plugging in the vehicle every other night. With this behavior, the demand for power from EVs would be cut in half, and the charging intervals would be twice as long as I have assumed in each of the eight scenarios. The longer charging intervals, in turn, would greatly change the patterns shown in Figure 11 . For example, longer charging intervals would cause much more of the electricity demand (in the customer convenience scenarios) to fall into the early morning hours. Were this to happen, the utility would feel less need to implement a smart control system.

\section{Weekly Cycles:}

The previous demand calculations assume that EVs exhibit the same electricity demands for each day of the week. But EV owners may deviate from this regular pattern, both in terms of miles/day of travel and in the timing of night time charging. The deviations are likely to show up on the weekends. First, miles/day of EV travel may differ for weekends because there are fewer trips on the weekends, and these trips may be less suitable for EVs. The NPTS (1986, p. 5-8) data for 1983 show 248 of trips occur on the weekends (versus 28.68 if trips were spread evenly over the seven days in a week). The NPTS reports that social, educational, recreational and religious purposes dominate the weekend travel. The survey also reports that these purposes are heavily linked to long trips (NPTS 1986, p. 9-3). Since EVs are not likely to be suitable for these long trips, one might envision some reduction in the miles/day of EV use on weekends. Next, one might imagine the charging patterns would differ on the weekends. For example, night time charging at the customers' convenience might begin later on Friday and Saturday evenings. Also, EV owners may well tolerate charging past 7 am on Saturday and Sunday mornings.

Another factor leading to different weekend demands arises in the two scenarios with a smart control system. It involves the utilities' choice of when to instigate night time charging in order to obtain the best stacking of EV demands on top of the regular demands. Since the utilities' regular weekend demands are different from the weekday demands, one might envision that a control center operator would send out a different sequence of signals on weekend nights.

Seasonal Cycles:

Except for the smart control scenarios, the demand analysis assumes that EV demands are the same for each month of the year. (With smart control, one set of demands is assigned to 7 "summer months" while another set is assigned to the 5 "winter months.") 
One might wonder, however, whether EV use will be distributed evenly over the 12 months in a year. The NPTS national survey suggests that vehicle miles of travel were distributed rather evenly over the four seasons of the year (1986, p. 5-22). But the NPTS data on long trips shows a greater concentration in the summer months (1986, p. 9-15). Since EVs are not likely to be suitable for the long trips, one might suspect that EV use to be somewhat lower in the summer months.

The importance of some of these simplifying assumptions may be determined by repeating the Chapter 6 impact analysis with changes in the daily, weekly, or seasonal cycles. Priorities for further analysis are reported in the Chapter 10 discussion of further research. It is especially important to reexamine the EV demands with a relaxation in the assumption that EV owners will choose to recharge their vehicle each and every night of the week. Results from the new tests will be described in a future report to the CIEE. 


\section{Chapter 6. Impact of Electric Vehicles on Otility Production Costs}

\subsection{Introduction}

EV impacts on utility system operations have been analyzed in three different ways by previous investigators. Ducat's (1989) analysis was the most extensive. He estimated the energy required to serve the 600,000 Griffon Vans in a "deployment scenario," and used the PROMOD and PROSCREEN models to assess which generating resources would supply the extra energy. PROMOD is a proprietary computer model for detailed production costing calculations. PROSCREEN is a proprietary model for more aggregated production calculations said to be suitable for "screening" studies. Ducat's production cost calculations were grounded in the 1987 SCE resource plan. The resource plan contains a mix of resources expected to come on line during the first decade of the planning interval. The resources scheduled for the second decade are dominated by gasfired combined cycle units. Ducat's principal finding was that 908 of the extra energy would come from natural gas-fired units and $10 \%$ from economy purchases from utilities in the southwest. He calculated that two-thirds of the gas-fired generation would come from company owned gas units. The other third was expected to come from so-called "generic combined cycle" units which he suggested would probably be owned by third parties. Ducat did not ieal with the emissions from utility and third party electricity generation, but he did estimate the changes in SCE's fuel and purchased power budget and in average system costs. He found that the EVs would increase total electricity sales by 6.88 and increase the annual fuel and purchase power budget by $9.6 \%$. Average system cost, was estimated to decline by just over 3.58 (Ducat 1989, p. 31).

The RFE (1990) study focused on power plant emissions in the South Coast area. The production calculations were based on a simplified dispatching procedure that allowed for a careful calculation of emissions but that eliminated the need to specify the characteristics of all the generating units. They assumed that natural gas units will supply the energy for EVs during those days when ozone concentration is most severe in the South coast. Their final results are reported by listing emissions of the five criteria pollutants as well as carbon dioxide.

The CEC (1990A) scenarios study is similar to my approach, so a careful review of both their methods and their findings is instructive. The CEC staff used the ELFIN model for the production cost calculations. ELFIN is a computer simulation model for analysis of utility operations and financing. It was originally developed by the Environmental Defense Fund (EDF) and has been used extensively by staff at the CEC as well as the California public 
Utilities Commission (CPUC). ELFIN is explained in several reports available from the EDF (1985, 1988, 1990A, 1990B). It's key features are summarized below:

Reference Demand: The peak demand and the demand for electric energy are specified for the year in question. The user also defines a reference shape by specifying the demand for power for a "typical week." (There are 12 typical weeks in a year; each week requires 168 values of the demand for power.) ELFIN scales the reference shape to the year in question using simple algorithms that preserve the reference shape and meet the specified values for peak demand and energy demand. Further information on the scaling algorithm is given in a Technical Memo (Ford 1991B).

Load Modifiers: ELFIN permits modification of the load to account for demand-side programs. Modifiers may be specified in a general manner (such as variations in peak and average power) or as hour-by-hour changes in the demand in each of the 12 weeks.

Scheduled Outages: ELFIN allows for endogenous scheduling of planned maintenance. The maintenance is spread over the 12 months to even out the reserve margin remaining after scheduled outages. Since EV demands are likely to be similar from month to month, the ELFIN scheduling of planning outages should not be affected in a significant manner by the introduction of EVs.

Must Run Units: The user specifies four types of resources that must be scheduled early in the dispatch order due to four general types of constraints: (1) local voltage, (2) physical, (3) contractual and (4) hydro flows. The fifth resource category to be dispatched early in the sequence is the so called "MC" resources. These are plants whose output is priced at the short run marginal cost.

Remaining Dispatch order: The remaining plants are dispatched in economic order based on the product of their fuel cost and their incremental heat rate. At a highly aggregated level, the SCE economic dispatch order includes (1) nuclear units, (2) coal units, (3) new gasfired combined cycle units, (4) repowered gas-fired units, and (5) the older gas-fired units. ELFIN dispatches the pumped hydro units in the midst of the thermal units by finding a segment under the equivalent load duration curve whose area matches the energy available from the unit. A similar approach is used for hydro storage units. This approach is said to be equivalent to "peak-shaving dispatch." 
Baleriaux-Booth Method: ELFIN uses the "equivalent remaining load duration curve" method to simulate generating unit dispatch in each of the 12 typical weeks in a year. This method is often called the "BaleriauxBooth" method (Booth 1972, Stremel 1982). For additional detail, each week may be broken down into subperiods. For example, five subperiods were found useful in a published calibration exercise (EDF 1985, p. 4). Still more detail may be included by breaking generating units down into resource blocks. ELFIN employs numerical methods for the convolution - deconvolution calculations, and the equivalent load duration curve is approximated by a piece wise linear curve with 201 points. (Ad hoc adjustments are used to ensure that the area under the approximated curve is equal to the demand for energy.) The results of the probabilistic dispatch may be viewed in graphical form using the "ELfink" program (EDF 1990A, Figure VI-3).

Unserved Energy: ELFIN reports the expected value of unserved energy as well as the loss of load probability (LOLP) for each subperiod. The expected value of the unserved energy is found by finding the area under the equivalent load duration curve after all units have been dispatched. (This area may be viewed as the final, "vertical sliver" in "Elfink" charts for each subperiod.) LOIP is the probability that there is any remaining load after all units have been dispatched. (The LOLP may be viewed as the width of the final, "vertical sliver" in "Elfink" charts for a subperiod.) Planners at SCE warn that the ELFIN projections of LOLP are often unreliable (Cheng 1991). They suggest that the LOLP projections be verified by simulations from a more detailed model such as POLL, a Probability of Loss of Load model. POLL is used at SCE to determine target values for unserved energy and target reserve margins (CPUC 1991, $\mathrm{P} . \mathrm{X}-1$ ).

The high EV scenario examined in the CEC study envisioned 6-7 million EVs in the South Coast (see Figure 1). These vehicles impose demands far beyond what could be served with the utilities' regular resource plans. Consequently, it was necessary for the CEC staff to add extra generating resources to the base case resource plan. This step was performed "using judgement rather than an explicit capacity expansion procedure" (CEC 1990A, Vol. I, p. 12). The extra generating resources were added in an incremental fashion, and the CEC warned that the incremental approach may lead to unusually large additions:

Of considerable interest in this case is the need to add thousands of megawatts of new resources, even though the great majority of recharging occurs in the off peak period... 2,888 MW of generic resources located within 
the South Coast were added in this case. Arguably, if we had been able to expand these systems from existing and committed resources, fewer power plants might have been adequate in this case.

(CEC 1990A, Vol. II, Part B, P. 20)

The CEC (1990A, p. 20) staff also warned that some judgement must be applied regarding commit targets to avoid an unusually large requirement for additional generating capacity:

In constructing a resource plan for this case and others that included electric vehicles, we increased the commit target in ELFIN. Without this adjustment, we found excessive amounts of unserved energy, even when it appeared that an adequate quantity of resources had been added to the ELFIN data set.

The CEC study reports total electricity demand, changes in electricity generation and the emissions of five criteria pollutants and carbon dioxide.

For my purposes, the key finding from the CEC analysis arises from their "High EV" scenario shown to the far right side of Figure 1. The ELFIN projections suggested that 808 of the electric energy for EVs would be supplied in fossil units inside the basin. (These would be fired by natural gas if it were available.) Their generation numbers suggest that the 808 is comprised of 508 from new generating units and 308 from more extensive use of existing, gas-fired units in the basin. The remaining $20 \%$ is expected to come from a variety of sources including fossil units outside the basin and electricity purchases from other utilities. The CEC projections show no change in the amount of energy from Qualifying Facilities (QFS). The CEC staff did not choose to show EV impacts on the annual costs to operate the utility systems.

My approach is similar to the CEC approach. After discussions with planners at SCE, it was decided to employ the ELFIN model used in resource planning at SCE. Planners from the Electric system Planning group set up a base case simulation with a somewhat modified version of the SCE resource plan described in the CEC' $s$ 1990 Electricity Report. This resource plan is sometimes called "ER'90 Resource Plan." According to CEC staff, the mix of resources in the plan was determined by an iterative procedure which CEC staff used to arrive at a "least cost" plan for each utility. ELFIN projections for the "ER'90" provide a point of comparison with eight separate projections which include the effect of the EV demands. The demands for electricity from EVs were specified as hour-by-hour load modifiers using the demand shapes shown in Chapter 5. The shapes were applied to all 12 "typical weeks" when night time charging occurred under customer control. 
With smart control of EV night time charging, separate load modifiers were used for the summer months (April-october) and the winter months (November - March).

A key assumption in the analysis is that absolutely no changes will be made in the resource plan in any of the EV scenarios. The idea is to learn the impacts on the SCE system if the utility were to not add any new generating units to serve the additional load. Also, we assume that the utility does not attempt to change the $\mathrm{mix}$ of various resources to take advantage of the additional load. This simple approach was adopted (1) to allow the arialysis to be completed on schedule, (2) to avoid the unusual problems that have been encountered when expanding the resource plan, (3) to keep the results simple to interpret and (4) to learn if the EV demands could be accommodated without the need for additional generating resources.

\subsection{Electric Generation to Serve the EV Load}

ELFIN's regular printouts have been rearranged for easier interpretation in sheets $4-20$ in the Appendix. The sheets provide a direct comparison between simulations with EVs and the base case simulation without EVs. The EV impacts are recorded in both absolute and in percentage terms. Many of the sheets include a totals check to help one verify that the projected impacts are internally consistent.

Sheets \#-7 show the sources of electric energy needed to meet the extra load imposed by EVs. These summary tables provide the first important conclusion on utility impacts:

The bulk of the extra energy needed for EVs will come from natural gas-fired units.

Sheet \#4 shows the that gas-fired units would provide 12,345 GWh or 918 of the extra energy needed to serve the EV load. The $91 \%$ is comprised of $60 \%$ from new or repowered units and $30 \%$ from the existing units. This conclusion is similar to Ducat's finding that $90 \%$ of the extra generation for EVs would come from natural gas.

Sheets \#4,5 show that the dependence on gas-fired units varies somewhat across the four scenarios with two million EVs. The $91 \%$ dependence occurs in the 1 st and 4 th scenarios with night time charging at the customers' convenience. The 3 rd scenario leads to somewhat less use of natural gas and somewhat greater use of coal when night time charging is subject to smart control. The 2nd scenario (with the "lopm incentive") shows less use of gas-fired units due, in part, to a greater amount of unserved energy. Sheet \#6 shows the sources of electric generation in the two scenarios with one million EVs. Gas-fired units provide $87 \%$ of the 6,434 GWh 
needed to serve the EV load in scenario 5 when night time charging is left to the customers' convenience. This figure drops to $75 \%$ in scenario 6 when the night time loads are under smart control. Sheet 6 shows that the reduced dependence on gas-fired units would be made up by predominantly by increased use of coal and increased purchases of energy from utilities in the Pacific Northwest. Sheet \$ 7 shows the ELFIN results when the two near term EV scenarios are compared against a base case projection in the year 2000 . EV scenario $\$ 7$ shows only 551 GWh of EV load (since there are only 50,000 EVs), and gas-fired units are projected to provide 698 of the extra load. EV scenario 8 with 500,000 EVs imposes a load of $3,403 \mathrm{GWh}$, and 798 of this is generated in gas-burning units.

Sheets \$4-7 break the gas-fired generation down into generation from existing units and from new or repowered units. This distinction is important because the new/repowered units tend to be more efficient, and they emit less Nox. The new/repowered units provide $58 \%$ of the EV load in the first scenario. Because of smart control, the new/repowered units' contribution increases to $68 \%$ in the third scenario.

Sheet $\$ 8$ provides a closer look at some of the SCE units fired by gas in the first four scenarios with two million EVs. The gasfired capacity is comprised of four repowered stations (representing projects at Units 3,4 at Huntington Beach, Units 1,2 at the Alamitos Station, etc). New gas-fired units are represented by CCSIMI, a hypothetical, combined cycle unit with 2,800 MW capacity. All existing gas-fired units are represented by single entries in sheet 8 . The tabulation for the first scenario shows that existing units provide 348 of the extra gasfired generation to serve the EV load. Repowered units provide 298, and the hypothetical combined cycle unit provides $38 \%$. If the night time demands are under smart control, however, the existing gas-fired units would only provide 208 of the extra gas-fired generation. The new combined cycle unit's share of the extra gasfired generation would increase from $38 \%$ to $40 \%$. The biggest change appears with the repowered units whose share of extra gasfired generation would increase from $29 \%$ to $41 \%$ due to smart control.

A general conclusion from the ELFIN results in sheets $\$ 4-7$ is that natural gas will end up providing around $80-908$ of the energy needed to fuel EVs. This finding is consistent with previous studies of EVs in southern California. Thus, utility planners should realize that EV scenarios in the South Coast quickly become "natural gas scenarios." The heavy dependence on natural gas raises important questions about the ability of the gas utilities to supply the extra gas needed in EV scenarios. If the gas utility were forced to curtail deliveries to power plants, the electric utilities would probably fire the units with fuel oil. The results shown in this report ignore gas curtailments on the SCE system. If curtailments were to occur, the switch to fuel oil would lead 
to appreciably higher emissions from $\mathrm{SCE}^{\prime} \mathrm{s}$ dual fuel plants (CEC 1990A, Vol II, Part B, P. 39).

The second general conclusion from the ELFIN generation results concerns the electric resources that will supplement the gas-fired units in providing the extra energy needed for EVs. The supplemental sources are a mix of coal generation and economy purchases from utilities in the Pacific Northwest (PNW) and in the Pacific Southwest (PSW). Coal's share of the EV energy depends on the night time charging strategy. EV scenario 1 shows the coal units providing only 28 of the EV load when customers charge at their convenience. Coal's contribution is doubled to 48 in scenario 3 when night time charging is subject to smart control. A similar pattern appears in Sheet $\$ 6$ which shows scenarios $\$ 5,6$ with one million EVs. Coal units contribute 48 of the EV load with customer convenience and 98 with smart control. Economy PNW purchases' contribution is also dependent on the night time charging strategy. EV scenario 5 shows $5 \%$ of the EV load from PNW purchases with charging at customers' convenience. But with the smart control in EV scenario \$6. PNW purchases provide 98 of the EV load. Purchases from the PSW provide a minor share of the EV energy in the long term (around 28 in EV scenarios $1-6$ ). But PSW purchases are a somewhat larger contributor in the year 2000 . (Sheet $\$ 7$ shows their contribution at 88 in EV scenario \#8.) The short term PSW results are consistent with Ducat's (1989 p. 21) findings that PSW purchases would be the primary source of EV energy after the gas-fired units. The longer term Psw results are somewhat lower than one would expect from Ducat's analysis and somewhat lower than expected by ELFIN's primary developer (Kirshner 1991). The PSW results are controlled by the exogenously specified constraints on economy energy. (These particular inputs have been found to be a "dominating" feature in attempts to calibrate ELFIN against more detailed production costing models (EDF 1985).)

A third general conclusion from sheets $\# 4-7$ involves the resources that are NOT used to supply energy for the EVs. Nuclear, hydro, cogenerators with energy to sell to the utility (QFs), cogenerators who self generate, and demand side management (DSM) programs fall into this category. The nuclear units do not contribute to the EV load because they are already heavily used in the base case. The hydro, QFs and DSM resources do not end up contributing because they are represented as load modifiers in ELFIN.

A final conclusion from the generation results involves units that are used IESS frequently due to the EV loads. These are SCE's pumped storage units... Sheet \#4 shows that the pumpers are projected to provide 138 GWh of energy in the base case as the water flows "down hill" to generate electricity during peak intervals. ELFIN projects that SCE would reduce pumped storage operations in all the EV scenarios. The "down hill" energy would be reduced to $73 \mathrm{GWh}$ in EV scenario \#1 with customer convenience 
and to only $11 \mathrm{GWh}$ in EV scenario 3 with smart control. The reduced usefulness of pumped storage is a logical result of the timing of the EV loads. The reduction also suggests that the cost effectiveness of SCE's "load shifting" DSM programs should be reexamined in scenarios with EVs demands, especially if those demands are subject to smart control.

\subsection{IVs Impact on the Cost to Operate the System}

Sheets $\$ 9$ and 10 report the annual production cost along with the purchased power budget estimated for the base case and the EV scenarios. The sheets report costs in million dollars per year, and the differences in costs are reported in both dollax amounts and as a percentage of extra costs required to serve the EV loads. The base column in Sheet 9 shows that gas-fired units cost around $\$ 4.2$ billion out of an annual cost of $\$ 8.6$ billion. They are roughly 508 of the annual cost to operate the system. The payments to QFs amount to around $\$ 3.2$ billion which is 378 of the annual costs. The remainder of the costs are attributed primarily to coal-fired generation (5\%), PNW economy purchases (4.68), and nuclear generation (28).

Sheet 9 shows that EVs cause the annual cost to increase from around $\$ 8.6$ to 10.5 billion in first scenario. The change in costs is around $\$ 1.9$ billion. Similar cost increases are shown in each of the four scenarios with two million EVs.

Sheet 10 arranges the production cost results from the final four scenarios for direct comparison. The top half of the table shows EV scenarios $\$ 5,6$ with one million EVs. The extra cost to serve the EV load is projected at $\$ 871$ million with customer convenience and at $\$ 936$ million with smart control. These results are surprising since one would normally expect lower production costs with smart control. Sheet 10 does reveal that the flatter load profile would allow SCE to increase the use of coal units and reduce the need for expensive, gas-fired generation. For example, the total cost for natural gas is reduced from $\$ 659$ million in scenario $\$ 5$ to $\$ 565$ million in scenario $\$ 6$. This benefit is overshadowed, however, by an increase in the QF payments with smart control. - The QF row in sheet 10 is highlighted to draw your attention to this pivotal factor.

\subsection{The Role of PURPA QTS}

QFs are projected to account for $\$ 3.2$ billion out of the total costs of $\$ 8.6$ billion in the base case simulation. At this level, they contribute $37 \%$ of the annual cost to operate the system--the single largest entry in sheet $\$ 9$. When one million EVs appear on the system, payments to QFs are projected to increase by $\$ 169$ 
million in the $5 \mathrm{th}$ scenario and by $\$ 298$ million in the 6 th scenario. The higher cost of QF payments in the 6th scenario is especially significant. It accounts for 328 of the estimated cost increase to serve the EV load, and it ends up erasing the benefits utility planners might expect from a smart control system.

The pivotal role of QFs is explored in greater detail in sheets 11-15. Sheets 11-12 help explain ELFIN's endogenous calculation of the marginal costs in each scenario. Sheets 13-15 provide a closer look at the individual QFs included in the ELFIN projections.

The base case column in sheet 11 shows a marginal cost of $86.2 \mathrm{mills} / \mathrm{kwh}$. This cost is a weighted combination of the costs to operate any of the dozen resources that might "spend some time" on the margin. This calculation is dominated by cost of the new/repowered gas-fired units and the cost of PNW purchases. The new/repowered gas units account for about $26 \%$ of the marginal resource while the PNW purchases account for $23 \%$. Nuclear units are used at full availability, so they do not appear on the margin. The cheapest resource on the margin is coal-fired generation. Coal units account for $8 \%$ of the marginal resource in the base case simulation.

Sheet 11 shows that the marginal cost increases to around 97$100 \mathrm{mills} / \mathrm{kwh}$ in the four scenarios with two million EVs. The highest marginal cost is $99.6 \mathrm{mills} / \mathrm{kwh}$ in the 3 rd scenario with smart control. The 3rd scenario exhibits the highest marginal cost because smart control makes it possible for much greater use of coal-fired units, and they practically "disappear" from the margin. The final two scenarios in sheet Il envision one million EVs. The EV load drives the marginal cost up to $92.3 \mathrm{mills} / \mathrm{kwh}$ with charging at customers' convenience and to $96.8 \mathrm{mills} / \mathrm{kwh}$ with smart control. The higher cost with smart control may be attributed to coal units spending less time on the margin ( 18 versus 4.68 ) and an increased appearance of the PNW purchases on the margin (28\% versus $20.5 \%$ ).

Sheets 13-15 provide a closer look at the QFs and self generators by singling out the individual resources and sorting them by the size of the annual payments. Sheet 13 tabulates the QEs as simulated in the base case; sheet \#14 shows EV scenario \#5; and sheet \#15 shows EV scenario \#6. These tabulations allow one to check that the unit cost of QF energy (reported in mills/kwh in the final column) is approximately the same as the marginal cost shown in the grey row of sheet 11 . The largest QF resource is designated as CGNVCP. It provides 16,311 GWh in the base case at a cost of $86.2 \mathrm{mills} / \mathrm{kwh}$. Since this is a marginal cost resource, the same energy costs $92.2 \mathrm{mills} / \mathrm{kwh}$ in the $5 \mathrm{th}$ scenario and 96.8 mills/kwh in the 6 th scenario. Similar changes are shown in the other seven $Q F$ resources with marginal cost contracts. 
Sheet 16 gathers the QE information for a comparison across all six, long term scenarios. This tabulation reports total energy provided by QFs and self generators and the total cost of the energy to SCE. The unit cost is defined as total payments divided by the energy. Sheet 16 shows that the presence of EV loads increases the unit cost by around 10-118 in the four scenarios with two million EVs. Unit costs are driven up by 5-98 in the two scenarios with one million EVs. The final rows in sheet 16 show the annual payments if there were no change in the unit cost to SCE. These entries allow for a sensitivity test later in the report to learn the impact of EVs if the cost of QF energy were not allowed to change due to EV loads.

\subsection{Ire Ixtra Resouxces Needed to Serve the iv Load?}

Utility impacts for all eight scenarios are summarized in sheet 17 which address the question of whether SCE would have to expand the resource plan to accommodate the extra EV loads. The top rows in sheet 17 summarize the key assumptions of each scenario and the EV's contribution to peak load. A comparison of peak load with peak capacity gives the reserve margin, one of the first indicators used to gauge whether generating resources are sufficient. The base case simulation shows a reserve margin of 22.68. The reserve margin drops to 22.08 in EV scenarios $1-3$ due to the $131 \mathrm{MW}$ of $\mathrm{EV}$ load appearing during the day time peak. EV scenario *4 shiws the reserve margin declining to 20.88 due to the 387 MW of EV load appearing on peak. The near term impacts show a base case reserve margin of $26.5 \%$ in the year 2000 . This would drop to 26.48 with 50,000 EVs and to 25.78 with 500,000 EVs.

Sheet 17 also shows SCE's projected operating reserve margin. This indicator runs from 9.18 in the base case to a low of 7.68 in EV scenario 4 . Operating reserves are measured by eliminating around $3,300 \mathrm{MW}$ of capacity classified as non firm and comparing the remaining, firm capacity to SCE's peak load. Taken by themselves, the two sets of reserve margin results in sheet 17 do not suggest that SCE would have difficulty accommodating the EV loads in any of the scenarios. For example, all ten of the reserve margins are comfortably above the 168 "reserve margin targets" adopted in the CEC's 1990 Electricity Report (p. 2-17).

The reserve margin results show whether EVs exacerbate the SCE peak load situation; they do not indicate whether SCE would have trouble serving the bulk of the EV demands which occur during night time hours. A better measure of the overall ability of SCE to accommodate the entire range of $\mathrm{EV}$ demands is provided by ELFIN's projection of the unserved energy and the LOLP. The unserved energy is measured in GWh and is estimated as the area remaining under the equivalent load duration curve after all of SCE's units have been dispatched. The base case shows only 0.07 GWh of unserved energy; this amount increases to $.35 \mathrm{GWh}$ in EV scenario 
$\$ 3$ with smart control. The LOLP is estimated by finding the probability of unserved energy. (The probability corresponds to the width of the "vertical sliver" remaining in the ELFink charts after all units are dispatched.) The LOLP in the base case shows the probability of unserved energy is extremely low--approximately 30 chances in a million. When multiplied by the 365 days in a year, the base case LOLP may be reported as 0.01 "days/year."

Sheet 17 shows the LOLP increasing to 0.971 days/year in the first scenario due to the loads from two million EVs charged at the customer' convenience. Were the loads subject to smart control, the LOLP would only be 0.044 days/year. Planners often set the target LOLP at "one day in ten years". (Kahn 1988, p. 83; EPRI 1978, p. X-5; CEC 1986, p. 2-18). Also, a target of "one day in twenty years" was mentioned in my discussions with SCE system planners (Cheng 1991). The final two rows of Sheet 17 answer the question of whether the SCE resource plan would be sufficient to meet these goals. The results are the same, regardless of which goal is selected:

1. The existing resource plan is sufficient to accommodate two million EVs, but only if they are subject to smart control (scenarios $1-3$ ).

2. The existing resource plan is sufficient to accommodate one million EVs, reqardless of whether night time charging is at the customers' onvenience or subject to smart control (scenarios $(5-6)$.

3. The existing resource plan is sufficient to accommodate the EVs in the short term, even with the "surprise" example of one half million EVs appearing by the year 2000 and charced at the customers' convenience (scenarios $\$ 7-8$ ).

The results from sheet 17 suggest that the "deployment level" for the SCE resource plan is around two million EVs. This number is dramatically different from the 0.6 million EVs in Ducat's (1989) report. But the two findings are not necessarily inconsistent with one another. First of all, the two analyses employ quite different assumptions about the daily energy requirement for a typical EV. As noted in Figure 2, Ducat's EVs use around $30 \mathrm{kwh} / \mathrm{day}$, and the weighted average in my first three scenarios is less than $20 \mathrm{kwh} /$ day. A more useful measure of the "deployment level" is total electricity sales. But Figure 2 shows the first three scenarios with electricity sales well above the sales in Ducat's study. The higher "deployment level" found in my third scenario is caused by a combination of factors. One obvious factor is the imposition of smart control. The next important feature is the extremely long range of the EVs $(250 \mathrm{miles})$ which leads to the assumption that opportunity charging will be limited to only 1 of of the vehicles during day time hours. A third factor is the high degree of reliability in the base case resource plan. Sheet $\# 17$ notes an LOLP of 0.01 or one day in one hundred years 
without any EVs. This high degree of reliability provides, in effect, an extra "cushion" which allows a greater deployment of EVs before additional resources are required for reliability purposes. (The "cushion" may be attributed to the iterative procedure used to arrive at a "least cost" resource plan. Such a plan may arrive at somewhat higher reserve margins if additional generating resources prove useful in reducing total system costs.)

\subsection{IVs Impact on the Arerage Electric Rate}

A useful way to conclude the analysis of utility impacts is to focus how EVs might change the average electric rate. Recall that Ducat estimated that 600,000 GVans would allow for a $3.5 \%$ reduction in SCE's average system cost (1989, p. 31). I show somewhat lower benefits in sheets 18-19. Sheet 18 shows the estimated change in the long term electric rate for EV scenarios $\$ 3,5,6$, the three scenarios in which additional generating resources would not be required to meet customary reliability targets. Sheet 19 shows the corresponding rate calculation for the two short term scenarios. Both sheets begin with the ELFIN projections of fuel and purchases costs reported previously. These variable costs are combined with "other costs" to obtain a total revenue requirement. The key assumption is that SCE's "other costs" are not changed by the EV loads. More specifically, one should bare in mind that this simple calculation assumes that

(1) SCE will not acquire additional resources beyond the existing plan,

(2) costs associated with the transmission and distribution system may be ignored,

(3) costs associated with EV infrastructure (such as smart control systems) may be ignored, and

(4) SCE costs associated with EV RED, with EV monitoring or the possible promotion of EVs may be ignored.

Furthermore, the simple calculation assumes that the financial community (i.e., Moody's) will not consider the presence of millions of EVs as a significant factor in their evaluations.

The average electric rate is calculated by comparing the total revenue requirements to total electricity sales. Expressed in nominal dollars, the base case electric rate is estimated at 197.1 mills/kwh for the year 2009. With two million EVs subject to smart control, the average electric rate could be reduced to 191.5 $\mathrm{mills} / \mathrm{kwhr}$, a reduction of 2.98 . With one million EVs, the average electric rate could be reduced by 1.58 (with charging at customers' conveniencel or by $1.2 \%$ with smart control. 
Sheet 19 turns to the near term impact on SCE's average electric rate. Without EVs, the average rate is expected to be $134.4 \mathrm{mills} / \mathrm{kwh}$ expressed in nominal dollars. The $50,000 \mathrm{EVs}$ in EV scenario $\$ 7$ would lower the average electric rate by only 0.48 . But with the 500,000 EVs in the 8 th scenario, the average electric rate would be lowered by 1.98 .

These rate impacts are somewhat smaller than one would have expected from the $3.5 \%$ reduction from Ducat's study. I attribute the smaller rate impacts to the increase in QF payments caused by EV loads. The overall impact of the changes in marginal cost payments to QFs may be seen in sheet 20 . This spread sheet repeats the estimate of the long term electric rate with the assunption that QF payments would not be changed by the appearance of EV loads. The footnotes in sheet 20 note that this assumption would reduce SCE's payments to QFs by $\$ 371$ million in the 3rd scenario, by $\$ 166$ million in the 5 th scenario and by $\$ 291$ million in the 6th scenario. These savings lead to results more in line with Ducat's study. With two million EVs subject to smart control, the sensitivity test shows a 4.68 reduction in the average electric rate. With one million EVs, the reduction would be $2.3 \%$ (customer convenience) or 2.68 (with smart control).

The rate impacts shown in sheet 18 (with one millior. EVs) are unusual and unexpected. This calculation suggests that SCE might be better off to let the EV owners charge their vehicles at their convenience. Apparently, a smart control system would lead to greater benefits for QFs but to higher rates to SCE's customers. This unusual result prompts many planners to ask the question:

"What's wrong with smart control?"

followed by:

"What's wrong with marginal cost payments to QEs?"

The appropriate answer may well be that there is nothing wrong with imposing a smart control system to obtain a flatter load profile. Furthermore, there may be nothing wrong with the marginal cost pricing for QFS. What is unusual is the restriction that SCE's long term resource plan would not be altered in the slightest even after miliions of EVs have appeared on the system. Although this restriction allows for a clear portrayal of the number of Evs that can be "accommodated" with the existing plan, it is not likely to represent what SCE would actually do once EVs achieve high penetration. A more realistic response is to experiment with different mixes of generating resources to find a better plan in light of the larger (and flatter) loads. The new resource plan would probably show a greater dependence on resources suitable to "base load operation" and a smaller dependence on resources with high operating costs. (This possibility is mentioned in the Chapter 10 discussion how the entire west coast electric system 
might react to large EV loads in southern California.) It is quite possible that tailoring the new resource plan to the flatter loads would eliminate the unusual results in the two scenarios with one million EVs.

The average rate impacts explained in this chapter may be taken as the final, summary indicator of the overall impact of EVs on the SCE system. This is an important measure of the overall benefits of EVs because a significant reduction in the average electric rate indicates that the utility has some "room to act" in support of EVs. One logical action is to distribute some of the benefits in the form of a special rate to EV owners which is considerably lower than the average electric rate. Other logical actions include utility spending on $R \& D$ and on supporting infrastructure. And finally, the utility might consider whether some of the potential rate benefits might be used to promote EV sales by direct financial incentives. The impacts of these actions are the subject of future research on this project. 


\section{Chapter 7. Electric Vehicles and the Emission of Air Pollutants}

Planners in southern California are looking to alternative fueled vehicles to help the region meet air quality standards and to reduce the health and environmental impact of air pollution. The alternatives include EVs, methanol vehicles, compressed natural gas vehicles and vehicles running on reformulated gasoline. Previous researchers have found that EVs stand out from this list as the most promising option for decreasing the smog in southern California (RFF 1990, Hempel 1989, Fisher 1991, TB\&A 1991). I examine the benefits from EVs by estimating the emissions that would be avoided when EVs displace CVs in southern California. I then discuss how the comparison would be altered when one looks upstream to the refineries and power plants that provide the fuel for the vehicles.

\subsection{Avoiding Emissions from Conventional vehicles}

A pure EV produces no emissions. It may be viewed as a "zero emissions vehicle" or a ZEV. Thus, the emission benefits of EVs are dominated by the description of the conventional vehicle (CV) that is displaced.

My estimates of emission benefits for EVs are reported in sheet \$21 for hydro carbons (HC), sheet \$22 for nitrogen oxides (NOX) and sheet 23 for carbon monoxide (CO). These calculations consider a simple example in which one million EVs are sold in the year 1993 and operated over a 15 year life. I assume that the first 10 years of the EV life displaces a CV sold in 1993. The last 5 years of the EV's life displace what the CARB refers to as a "low emission vehicle" (LEV). The calculations are similar for all three pollutants, so I focus my explanation on HC emissions.

Sheet \#21 assumes that CVs sold before 1994 would have to achieve 0.39 grams/mile (CARB 1990, p. 24,29). CARB plans to tighten the HC standards over time by requiring a greater share of vehicles that meet stricter standards. In the year 1994, for example, CARB expects $80 \%$ of the $C V$ sales to achieve" 0.25 grams/mile while. the other $20 \%$ may be a mix of cleaner and dirtier cars. loverall, the 1994 fleet average requirement would be 0.25 grams/mile.) The CARB implementation schedule would lead to a gradual reduction in the fleet average emission rate (CARB 1990, p. 24). To simplify the calculations, I ignore the CARB provisions for mixing of different vehicle types and thereby sidestep the interesting question of whether all EVs will really lead to reduced emissions. With a fleet average standard, manufacturers might push EVs sales past the ZEV requirement in order to permit greater sales of dirtier vehicles. In this situation, the benefits of the additional EVs does not translate into lower emissions but into 
greater flexibility and lower cost of compliance. This important issue is addressed in detail in Kling's (1991) report from our research project. Meanwhile, the simplifying assumptions used in this study (see sheet 121 ) are that:

CVs sold before 1994

CVs sold from 1994-1998

must certify to 0.390 grams/mile;

CVs sold after 1998

must certify to 0.250 grams/mile; and

must certify to 0.075 grams/mile.

These standards are quite strict when compared, for example, to the 4.1 grams/mile for cars first subjected to controls (1968-1971) and the precontrol emission rate of $10.6 \mathrm{grams} / \mathrm{mile}$ (MVMA 1990, $\mathrm{p}$. 88).

The CARB requirements are called "certification standards" since the manufacturers must certify that vehicles meet the emission standard after $50,000 \mathrm{miles}$ of travel. Sheet 21 includes an odometer reading and an "emissions age factor" to clarify my assumptions on the likely changes in emissions over the life of the vehicle. Notice that by the 4 th year, the displaced $C V$ would have traveled 49,300 miles. The emissions age factor is set at 1.0, and the emissions rate meets the required value of 0.39 grams/mile. An emissions factor of 0.55 is assigned to the first year. This initial value is sometimes called a "safety factor" since it denotes a margin of safety that manufacturers achieve to ensure successful certification after 50,000 miles. The emissions age factors shown in sheet $\$ 21$ are consistent with the "zero mile emissions factor" and the "deterioration rates" in a CARB working paper (Heirigs 1991).

A "travel factor" appears in sheet $\$ 21$ to represent the likely changes in travel over the life of the displaced CV. The general assumption is that young cars are used more; older cars are used less. The average travel is $30 \mathrm{miles} / \mathrm{day}, \mathrm{a}$ value considerably below than the $40 \mathrm{miles} / \mathrm{day}$ assumed for the EV demand calculations in chapter 5. I limit CV travel to a more familiar value to avoid the appearance of exaggerating the emissions benefits of EVs. The travel factors cause the travel to vary from year to year over the course of the 15 year calculation. The specific travel factors shown in sheet \#2I were selected as a simplified representation of national trends reported in the NPTS 1983 survey (1986, p.4-21).

Sheet \#21 combines the different assumptions on travel and emissions to arrive at avoided emissions in tons/day achieved by the sale of one million EVs. These results are portrayed in Figure 19. The variations over the 1993-2002 interval reflect the changing performance and use of the displaced CVs. (The year 1996 may be taken as a"nominal" year since both the travel factor and the emissions factor are 1.0 during the 4 th year of the displaced vehicle's life.) Avoided emissions decline abruptly in the year 


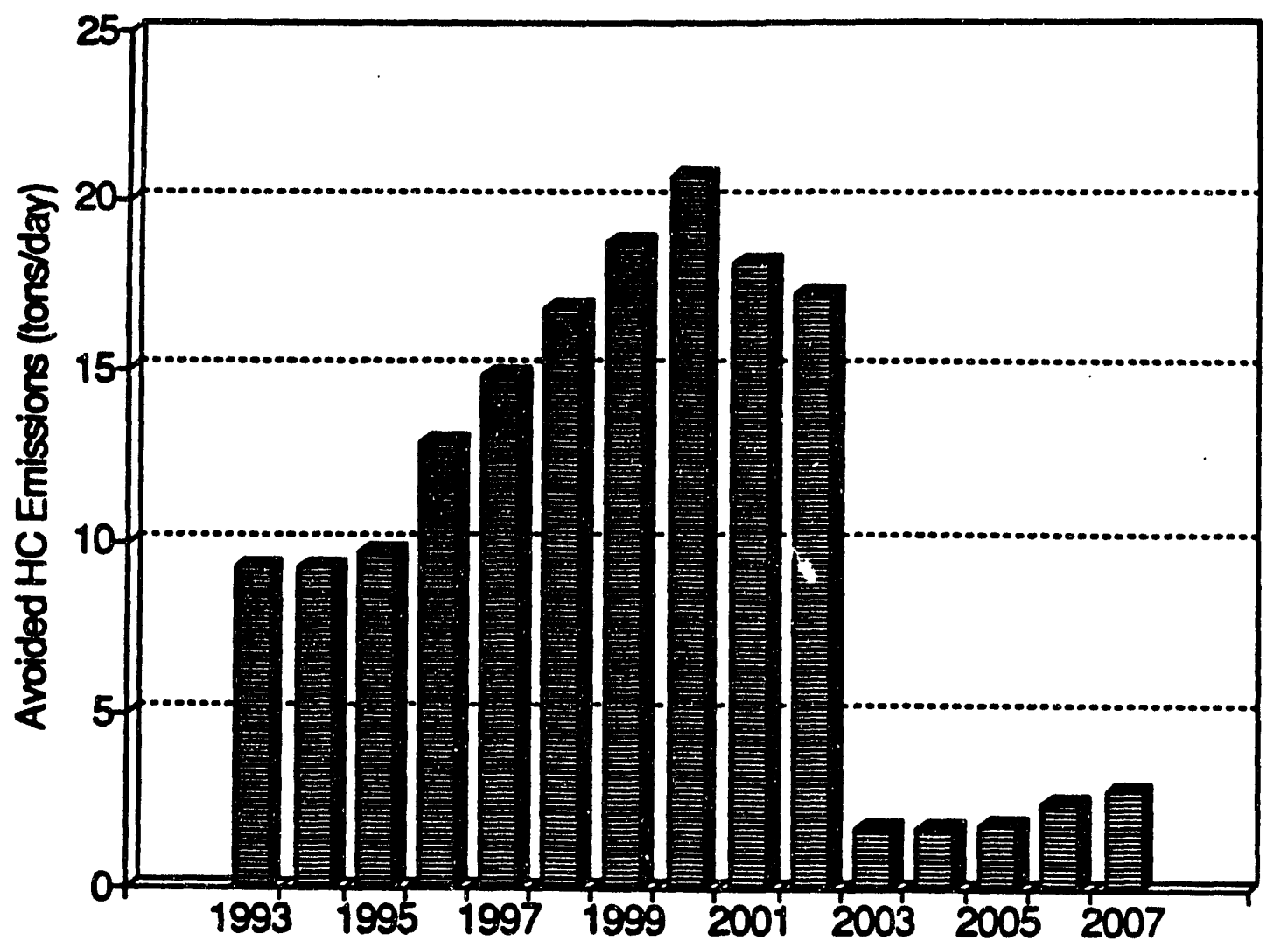

Figure 19. Tons/Day of Avoided HC Emissions from the Sale of One Million EVs in the Year 1993.

2003 when the $C V$ is replaced by an LEV that is designed to meet the 0.075 grams $/ \mathrm{mile}$ standard after $50,000 \mathrm{miles}$ of travel.

The lower section of sheet $\$ 21$ accumulates the avoided emissions to arrive at the highlighted finding that each EV sold in the year 1993 would end up eliminating 115 pounds of HC emissions. Sheet 22 shows a similar calculation for NOx emissions. In this example, the applicable CARB standards are set at 0.4 grams mile until 1998 and to 0.2 grams/mile thereafter. An EV sold in the year 1993 is estimated to eliminate 133 lbs of Nox. Sheet 23 shows the $C O$ calculation in which the applicable standard is fixed at 3.4 grams/mile. An EV sold in 1993 is estimated to eliminate 1,346 pounds of $\mathrm{CO}$.

Sheet 24 reports the avoided emissions for all three pollutants when the calculations from the previous three sheets are repeated for different values of the $\mathrm{EV}$ sale year. Since the CO standard is fixed at 3.4 grams/mile, avoided $C O$ emissions are shown at 1,346 pounds vehicle, regardless of the year of sale. Avoided HC emissions are found to be 115 pounds for EVs sold in 1991-1993, 96 pounds for EVs sold in 1994-1998, and 36 pounds thereafter. 


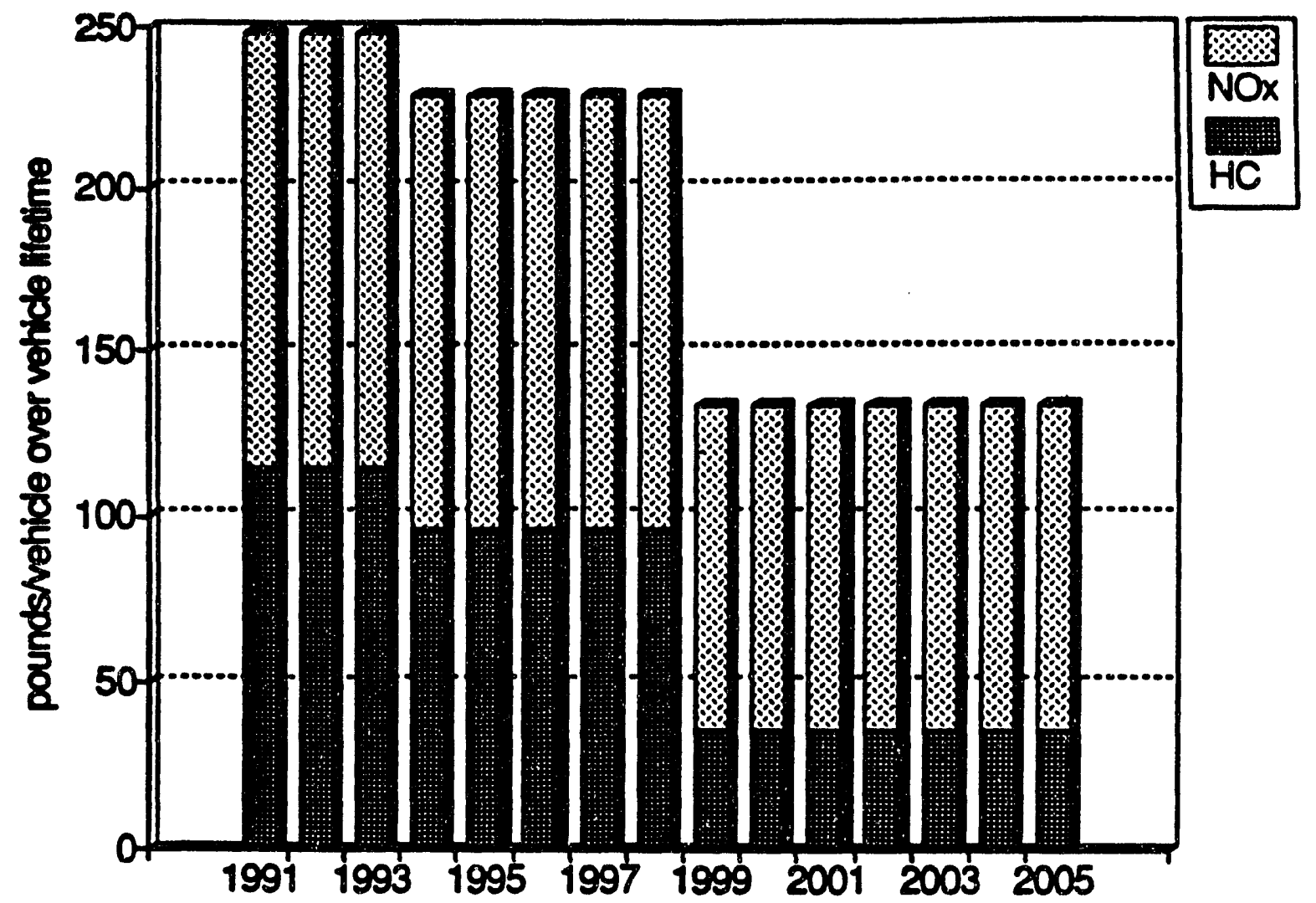

Eigure 20. Avoided HC and NOx Emissions from EVs Sold in Different Years.

Avoided NOx emissions are estimated at 133 pounds/vehicle for EVs sold from 1991-1998 and 97 pounds/vehicle thereafter. The time varying results for $H C$ and NOx, the precursors of ozone, are displayed in stacked form in Figure 20 .

\subsection{Nonetary Value of Aroided Iniseions}

The importance of reducing emissions of aix pollutants is sometimes gauged by assigning a monetary value to each ton of $H C$, NOx or CO that will be eliminated. Such dollar assignments can be "slippery; using them as a measure is like using a ruler with inch marks that stretch or contract with inflation or interest rates" (Meadows 1991). But even slippery monetary values can be instructive if they provide a "ball park economic value" of the emission reductions from EVs.

The various approaches to assigning monetary values to environmental impacts are reviewed by kirlin (1990), by the Tellus Institute (1990) and by Chernick and Caverhild (1991). The most ambitious method is to estimate how reduced emissions translate 
into improved air quality; estimate the reduced health effects and damages due to improved air quality; and then assign a dollar value to these improvements. The most recent example of such an exercise is Hall's (1989) report to the SCAQMD. This study estimates that the annual benefits of meeting federal ozone standards range from around $\$ 5$ billion to $\$ 20$ billion with a mid range estimate of $\$ 9.4$ billion. The SCAQMD study does not provide dollar values per ton of avoided emissions, however.

A second approach is to look for market evidence that would shed light on the economic value eliminating emissions. The external offsets program of the SCAQMD provides such a market. It has been examined by Hahn and Hester $(1989$, p. 121) who report 1985 market activity as 5 trades of NOx offsets and 42 trades in offsets for volatile organic compounds. They observed mean prices in 1985 at $\$ 5,000$ per ton of NOx and $\$ 2,500$ per ton of volatile organic compounds. There were only 3 trades for $C O$ with a mean price of $\$ 3,000$ per ton. But these prices are not necessarily reliable because:

While the increase in trading activity from 1983 to 1985 indicates that an active market in offsets may be developing in the (SCAQMD) area, the significant variations in price and number of trades indicate that this market has not reached an equilibrium. A second indication of this disequilibrium is the fact that only a very small proportion of the total emissions in the area are being traded.

$$
\text { (Hahn and Hester 1989, P. 122) }
$$

When market evidence is insufficient, some investigators turn to surveys designed to learn what people will pay to avoid emissions. The difficulty with surveys is setting the context so the individual has a realistic description of the emissions, a logical method of payment and a reasonable procedure for eliciting value. Contingent value methods are said to be a useful method of ensuring realism in "willingness to pay" surveys (Loomis 1987, Cummings 1986).

Many investigators distrust what people say they would do; they prefer to study individuals' actual economic behavior. By observing the extent to which individuals make concrete economic choices, economists may infer the dollar value associated with cleaner air. For example, the observed behavior might involve buying a more expensive house or traveling further on vacation (to avoid poor air quality). This approach is sometimes called "hedonic price estimation," since it is based on an underlying view of how individuals balance the pleasures and pains of life in a polluted world. Hedonic price estimation suffers from a lack of data at the proper level of aggregation (Kirlin 1990, p. 168). It also suffers from high variability in results with changes in estimation techniques (Graves 1988, p. 221). 
The final approach to be mentioned here is quite different. It focuses on the cost of controlling air pollution. This method is sometimes called the "revealed preference approach" if the particular control measure has been adopted by the appropriate governmental agency. The revealed preference approach is finding increasing application as utility planners incorporate environmental impacts in the "least cost planning process." It's been adopted in New York, Massachusetts and Nevada (Chernick and Caverhill 1991, p. 49): it is recommended for other states by the Tellus Institute (1990): and it has been adopted by the CEC in both the ER' 90 and ER' 92 processes. The revealed preference method, in its simplest form, is "based on the assumption that air districts, as rational decision makers, will adopt rules and regulations which require actions for which the marginal costs equal the marginal benefits" (CEC 1991B, p. 3)

Sheets $\$ 21-23$ use the monetary values (in 1989 \$) of avoided emissions in the South Coast recommended by the CEC staff for the ER' 92 process:
$16,600 \$ /$ ton of HC
$24,300 \$ / t$ on of NOX
$9,500 \$ /$ ton of $\mathrm{CO}$

The HC value was found by calculating the marginal cost associated with a collection of 43 measures in the SCAQMD plan to reduce emissions of reactive organic gasses (CEC 1991B, P. A-2). The NOx value was estimated in a similar manner from a collection of 24 SCAQMD measures plus two rules issued by the CARB. Estimating the value of $C O$ reduction was problematic, however. The collection of Co measures included only 11 SCAQMD rules and the CARB rule on reformulated gasoline. This small set led the CEC to the implausible conclusion that the average cost of co control is higher than the marginal cost. For the purposes of the ER'92, the CEC staff recommended that planning proceed with the average cost of the co control measures.

Sheets $21-23$ apply the CEC values to my EV calculations to obtain the following estimates of the monetary value (in 1989 ) of the avoided emissions from an EV sold in 1993:

$\$ 959$ from reduced HC emissions

$\$ 1,167$ from reduced NOx emissions, and

$\$ 6,394$ from reduced Co emissions.

The total value would be around $\$ 9,000$, quite a large value when one considers that the median sale price of a new car in 1990 was $\$ 13,400$ (MVMA 1990, p. 46).

Sheet \#24 repeats this calculation for EVs sold over the time interval from 1991 to 2005, and the results are displayed in Figure 21. Avoided emissions are valued at $\$ 9,000$ for EVs sold during the 1991-1993 years. The value falls to around $\$ 8,000$ after 1998 . Figure 21 shows that the avoided $C O$ emissicins dominate the tctal value. 


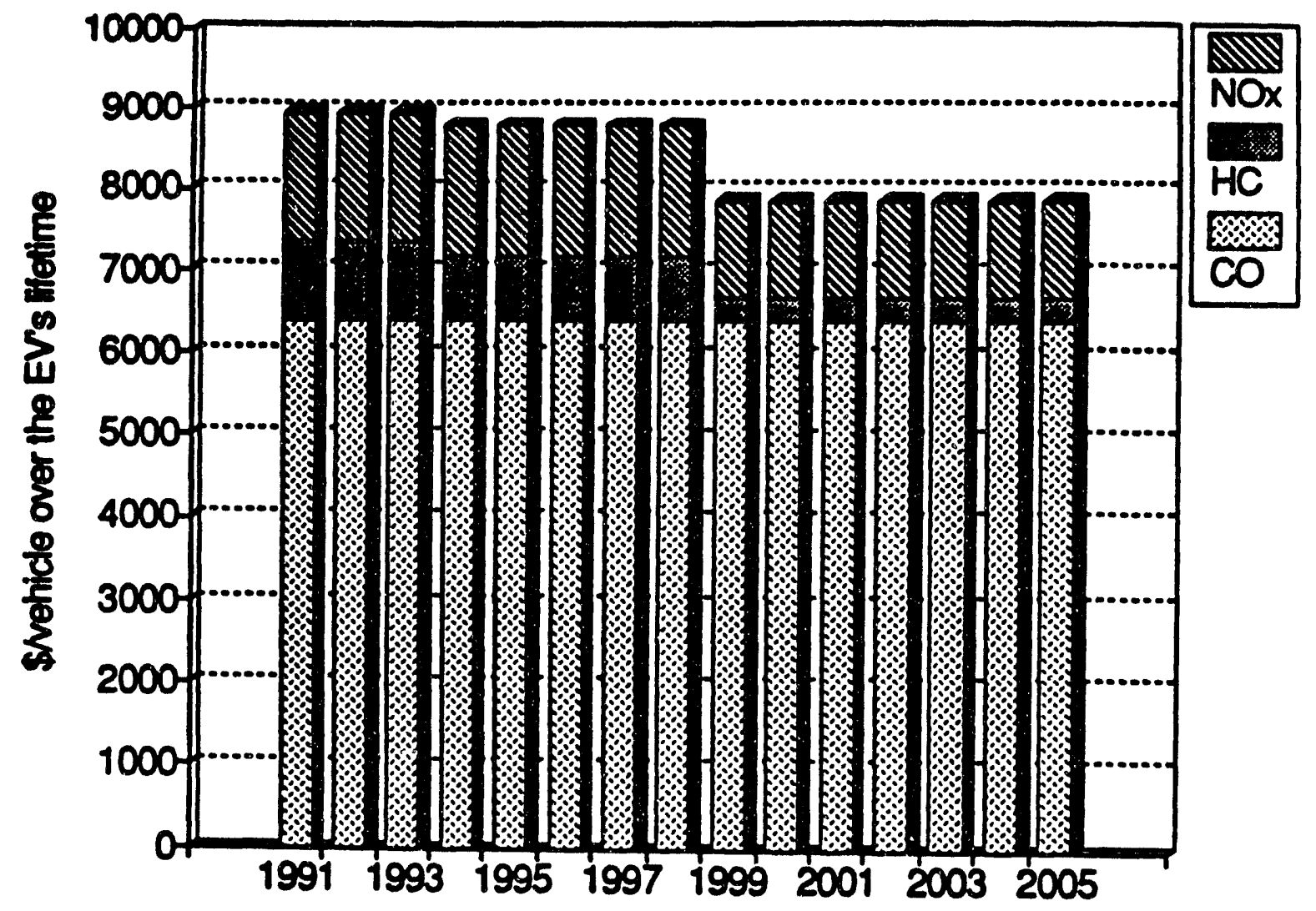

Figure 21. Monetary Value of Avoided Emissions from EVs (in 1989 \$) depending on the Year of Sale of the EV.

The dominant contribution of $c 0$ in Figure 21 leads one to revisit the CEC reasoning which led to $\$ 9,500$ per ton for avoiding Co emissions in the South coast. Had the CEC focused on the marginal cost (despite its low value), the key measure would be CARB's rule on reformulated gasoline. This rule is estimated to cost only 423 \$/ton of CO (CEC 1990B, p. A-3). The Tellus Institute has also examined the SCAOMD measures for reducing CO emissions. Their version of the revealed preference approach focuses on oxygenation of gasoline as the "revealing measure." Oxygenation is said to cost 820 \$/ton (in 1989 dollars), a value with Tellus suggests could be used across the U.S. as well as in southern California (1990, p. 23). Alternatively, one might take $3,000 \$ / t o n$ as indicative based on the limited market in co offsets (Hahn Hester 1989, p. 121). This wide range of estimates suggests that the Figure 21 results would be altered dramatically with a different, but plausible assignments of the value of reducing $C O$. If the co contribution were removed altogether, however, an EV would still provide significant value through the reduction in NOx and HC. The total value would be around $\$ 2,100$ for vehicles sold in 1991-1993 and fall to around $\$ 1,500$ for vehicles sold after the 1998 . 


\subsection{Discusaion of Opstream Effects}

The previous estimates of emission reduction are based on a simple comparison of vehicles. The analysis does not look upstream to the power plants that provide the electricity to fuel the EV or the refineries that fuel the CV. Useful information on upstream effects is given in the CEC scenarios project (CEC 1990A, Vol. II, Part D), in Wang's (1990) recent assessment of the "Emission Impacts of Electric Vehicles" and in the Claremont EV study (Hempel, p. 58). Hempel's observation on upstream effects is especially noteworthy:

What is interesting about the above comparison is that EV substitution and the resulting reduction in demand for the refining of gasoline and diesel highway fuels may result in a net emissions picture that is essentially a wash. This means that in the special context of the IA basin, emissions from power plants used in charging EV batteries probably should not be subtracted from the tail pipe emissions of gasoline and diesel powered vehicles in order to calculate net air quality benefits from EVs. It is more realistic to consider the full value of tail pipe emissions displaced as the net benefit of EV substitution.

$$
\text { (Hempel 1989, p. 70) }
$$

The purpose of this section is to discuss whether a consideration of upstream effects would lead to a major change in the overall emission benefit assigned to an EV.

I begin with HC emissions. Based on the simple vehicular comparison in sheet 21 , an EV sold in 1993 would reduce HC emissions by 115 pounds. The question now is whether the 115 pound estimate would increase or decrease when one looks upstream from the competing vehicles. The look upstream from the EV to power plants in the basin shows a negligible amount of HC emissions (Hempel 1989, p. 56). But the look upstream from the CV to refineries shows significant HC emissions. Hempel (1989, p. 58) notes, for example, that "all of the top five reactive organic gas emitters ... are associated with the production or fueling of gasoline vehicles." And wang (1990, p. 1279) reports emission factors for conventional autos which distinguish between the emissions at the tail pipe and emissions from evaporation, refueling and refining. His 1995 exhaust emission factors for light duty autos are:

0.290 grams/mile at the exhaust,

0.141 grams/mile for evaporation,

$0.024 \mathrm{grams} / \mathrm{mile}$ for refueling,

0.135 grams/mile for refining, which add up to

$0.590 \mathrm{grams} / \mathrm{mile}$. 
The total emissions factor is twice as large as the value assigned to the exhaust pipe of a CV. As far as hydro carbons are concerned, the upstream effects from CVs and EVs would substantially increase the 115 pound result.

Next, consider co emissions, the dominant source of value in Figure 21. When comparing the vehicles alone, sheet 23 suggest that an EV sold in 1993 would displace over 1,300 pounds of $C 0$ emissions. The look upstream from the EV to power plants in the basin shows a negligible amount of CO emissions (Hempel 1989, $p$. 56). And the look upstream from the $C V$ to refineries shows a similar result. Using Wang's (1990, p. 1270) exhaust emission factors and refinery emission factors as a guide, one would expect refinery operations to add only 28 to the $c 0$ emission expected from a CV. Thus, as far as carbon monoxide is concerned, looking upstream from CVs and EVs would not change the 1,300 pound benefit attributed to an EV.

The third comparison involves Nox. The simple vehicular comparison in sheet 22 suggests that an EV sold in 1993 would displace 133 pounds of NOx. The look upstream from the EV to power plants does reveal significant Nox emissions. I argue later in this section that a rough estimate of the NOx from natural gasfired generating stations in the South Coast is around 208 of the emissions from the displaced CV. But the look upstream from the CV also reveals significant Nox emissions. According to Wang's (1990, p. 1279) emission factors for 1995 conventional autos, the refineries' emissions would add 98 to the Nox emissions. This result is similar to the CEC's (1990A, Vol II, Part D, $p$. 14) emission factors for combustion, distribution, transportation, and refining. These combined upstream activities would increase Nox emissions by 8.48 . Thus, as far as nitrogen oxides are concerned, looking upstream from the CVs and EVs would tend to reduce the 133 pound benefit attributed to an EV by around 108 .

This brief look upstream from CVs and EVs suggests that Hempel is correct in arguing that power plant emissions should not be subtracted from tail pipe emissions in estimating the emission benefits of EVs. If planners are not in a position to complete a detailed analysis of the upstream impacts of BOTH CVs and EVs, the simple vehicular comparison would provide the next best indicator of the EV's value. Adding upstream effects will probably lead to no change the EV's Co benefit, a small decline in the Nox benefit and a substantial increase in the $\mathrm{HC}$ estimate. If one were to recalculate the total system-wide benefit of an $E V$, the values would probably be indistinguishable from the values plotted in Figure 21. 


\subsection{MOx Imiseions from the Two Milition IrVa}

An examination of the upstream impacts of CVs is outside the scope of this study. But I do look at the emissions from power plant operation in the different EV scenarios as these are included in the ELFIN simulations. Since Hempel $(1989, p .56)$ shows that power generation for EVs leads to negligible change in CO and HC emissions, I concentrate my attention on NOx. Total NOx emissions are tabulated in sheet 25 for each of the EV scenarios with two million EVs. Sheet 126 reports NOx emission factors (tons per GWh) for different generating units in the base case and in the first EV scenario.

Sheet 125 shows around 61 kilotons of NOx emissions in the year 2010 in the base case resource plan. Coal-fired power generation contributes around 43 kilotons or 708 of the total. QFs and self generators contribute around 6 kilotons, and economy purchases from the Pacific North West contribute around 4 kilotons. Gas-fired generation is responsible for 4.7 kilotons or only $8 \%$ of the total.

The four EV scenarios in sheet $\$ 25$ show around 66 kilotons of Nox emission. The overall effect is to increase Nox by 68. Gasfired units account for 518 of the extra NOx emissions in the lst and 2nd scenarios and 478 in the $4 \mathrm{th}$ scenario. But in the 3 rd scenario with smart control, gas burning units are responsible for only 298 of the extra NOx emissions. The 3rd scenario shows coal plants contributing 448 of the extra NOx emissions. This larger contribution arises from the greater use of these low cost units in the scenario with a flatter demand profile.

NOx emission factors may vary in the ELFIN simulations from unit to unit and in response to the simulated capacity factors for each unit. Sheet $\$ 26$ reports the emission factors in the base case and in the 1 st EV scenario to illustrate the relative change in emission factors to be attributed to EVs. This spread sheet shows that emission factors for coal plants, new and repowered gas units, QFs and Pacific North West units are not changed significantly by the extra demand from EVs. Existing gas burning units, taken as a group, show an increase from .263 to .290 tons/GWh. The largest relative change is projected for economy purchases from Pacific South west utilities. The lower section of sheet 26 illustrates how increased electricity generation can lead to qualitatively different effects on emissions factors. Unit 3 at the Alamitos power station is projected to deliver almost $50 \%$ more electricity in the EV scenario than in the base case. This greater usage leads to a $24 \%$ improvement in the emission factor (from 0.226 to 0.198 tons per GWh). But Unit 1 at the Ormond Beach power station is also used more extensively in the EV scenario. With this unit, however, greater usage leads to a 228 increase in the emission factor. 


\subsection{NOx Imissions Erom "In Basin Comparisons"}

Sheet 25 shows that the Nox emissions from power plant generation for EVs is composed of a different mix of gas-fired units in the basin, coal-fired units located outside the south Coast and economy purchases from utilities in the Pacific Northwest and Pacific southwest. The geographic distribution of these emissions adds an extra complication to deliberations on the policy implications of encouraging EVs as a way to combat air poliution in southern California.

Some studies side step the distributional question by evaluating the EV emission benefits on the assumption that ALI electricity generation would come from in basin resources. These "in basin comparisons" are not necessarily meant as a forecast of the most likely amount and distribution of emissions. They are meant to simplify the deliberations by confining the emissions reductions and emission increases in the same airshed. An example of an "in basin comparison is given in Hempel's (1989, p. 55, 56) estimates of NOx, $C O$ and $H C$ emissions from 1008 in basin charging of EVs. He shows that the Nox benefits of EVs would be reduced by around $20 \%$ if all the electric energy were produced from gas burning plants inside the basin. This particular result is positioned in Figure 22 as a five fold difference between the Nox emissions expected from a conventional vehicle (not counting up stream effects) and the Nox emissions from power plants confined to the basin. This result is labeled "HC" to stand for Hempel's stidy of "current conditions" in which the CV NOx standard is 1.46 grams/mile and the gas burning power plant's emission factor is around 0.5 tons/Gwh. Hempel repeats the "in basin comparison" with a more stringent CV NOx standard of 0.74 grams/mile and learns that NOx benefits from EVs are reduced by around $25 \%$ from power plants confined to the basin. This "HF" result (for future conditions) is position in Figure 22 as a 2.65 fold difference in the CV's NOx emissions relative to the emissions from power plants serving an EV. Hempel's calculations indicate the importance of the relative standards applied to new vehicles and power plants when performing "in basin comparisons." Four additional examples are located in Figure 22 to expand on his conclusions. These examples are taken from the analysis by researchers at RFF (1990, p. 2-5,2-28):

Example CV Nox (grams/mile)

\#1 base line: 0.4

\#2 1997 standard: 0.2

\#3 base line: 0.4

\#4 1997 standard 0.2
Power Plant NOx (tons/GWh)

uncontrolled: 0.56

uncontrolled: 0.56

controlled: 0.10

controlled: 0.10 


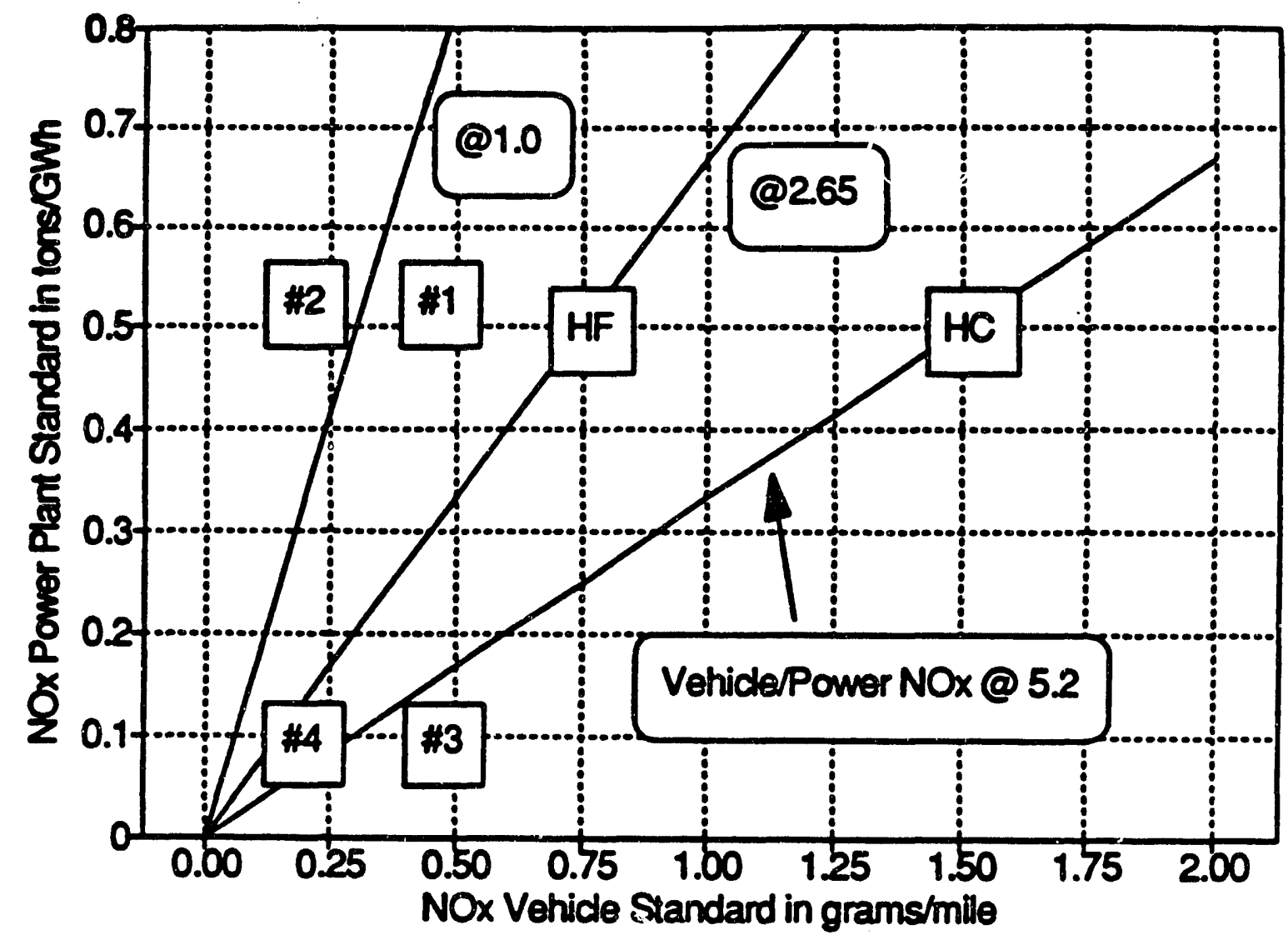

Figure 22. Ratio of the Nox Emissions from a Conventional Vehicle to the Nox Emissions from Power Generation for an Electric Vehicle with 1008 In Basin Generation.

The relative positions in Figure 22 show the wide variation in NOx impacts that can result from changes in the standards applied to CVs and power plants. In example 2 , the Nox emissions from a CV are reduced so dramatically that one would actually expect greater emissions from in basin power generation than from the displaced CV. In example 3, the NOx emissions would be similar to Hempel's result for "current conditions" - the CV's emissions would be over five times larger than the in basin power generation for an EV. 


\section{Chapter 8. Airshed Modeling and Peak Ozone Concentrations}

\subsection{Introduction}

Air pollution levels in the South Coast are well above state and federal standards set to p:otect public health. SCAQMD (1991, p. 2-4) reports that the ambient levels of ozone are, by far, the most serious problem. The SCAQMD reports that ozone levels at all of their 33 monitoring sites in the South Coast exceeded the state standard. SCACMD maps of the South Coast summarize the severity of the ozone problem with "violation contour lines" which link different parts of the region with the same number of days each year exceeding the one hour, state standard of 9 parts per hundred million (pphm). The contour lines (SCAOMD 1991, p. 2-6) show the highest concentration of ozone violations in the inland communities (ie, San Bernardino and Redlands, 125 days per year) and the San Gabriel mountain communities (ie, Azusa and Glendora, 125 days per year). Violations occur less frequently in the coastal cities (ie, Long Beach and Coasta Mesa, 25 days per year).

Ozone is formed by a photochemical reaction involving hydro carbons (HC) and nitrogen oxides (NOX). Since EVs can reduce the HC and NOx emissions in the South Coast, EVs can reduce the ambient ozone problem. Airshed models have been used by previous investigators to estimate this benefit. The claremont study (Hempel 1989 , P. 59) used the SAI urban airshed model, the first airshed model approved by the EPA, and the model used by the SCAQMD in preparing the 1988 Air Quality Management Plan. The RFF study used the airshed model developed at Carnegie Melion University and the California Institute of Technology (the CIT model) which is said to provide a more advanced description of deposition and a "complete description of atmospheric physics and chemistry to study pollution dynamics in an urban basin" (RFF 1990, p. 2-20). And the ozone concentrations reported in SCAQMD's 1991 draft plan were generated with the "Urban Airshed Model with the Carbon Bond Mechanism IV chemistry...recommended for ozone analysis by the EPA and the California ARB" (SCAQMD 1991, p. 5-12).

This chapter begins with a comparison of the findings from the airshed modeling by RFF, Claremont and the SCAQMD. I discuss the general pattern of findings from the many examples analyzed by the previous researchers. I conclude with recommendations of how one might estimate EV impacts on ozone concentrations by simple interpolation from the previous studies. 


\subsection{Summary of Profious Projections}

The results of 19 airshed modeling calculations are tabulated in spread sheet 27 . Sheet 28 rearranges the 19 projections in a more convenient form for graphing. Since the measure of ambient ozone used most consistently is peak ozone, peak ozone is shown along with the tons/day of HC and NOx emissions. The nineteen projections are arranged for comparison in Figure 23. Figure 24 shows a similar comparison, but it concentrates on the projections from the Claremont and the RFF studies. Figure 25 concentrates on the recent projections by the SCAQMD. Each of these figures reports the airshed model projection on the vertical axis. The key inputs to the model are summarized on the horizontal axis by the sum of tons/day of HC and tons/day of NOx emissions.

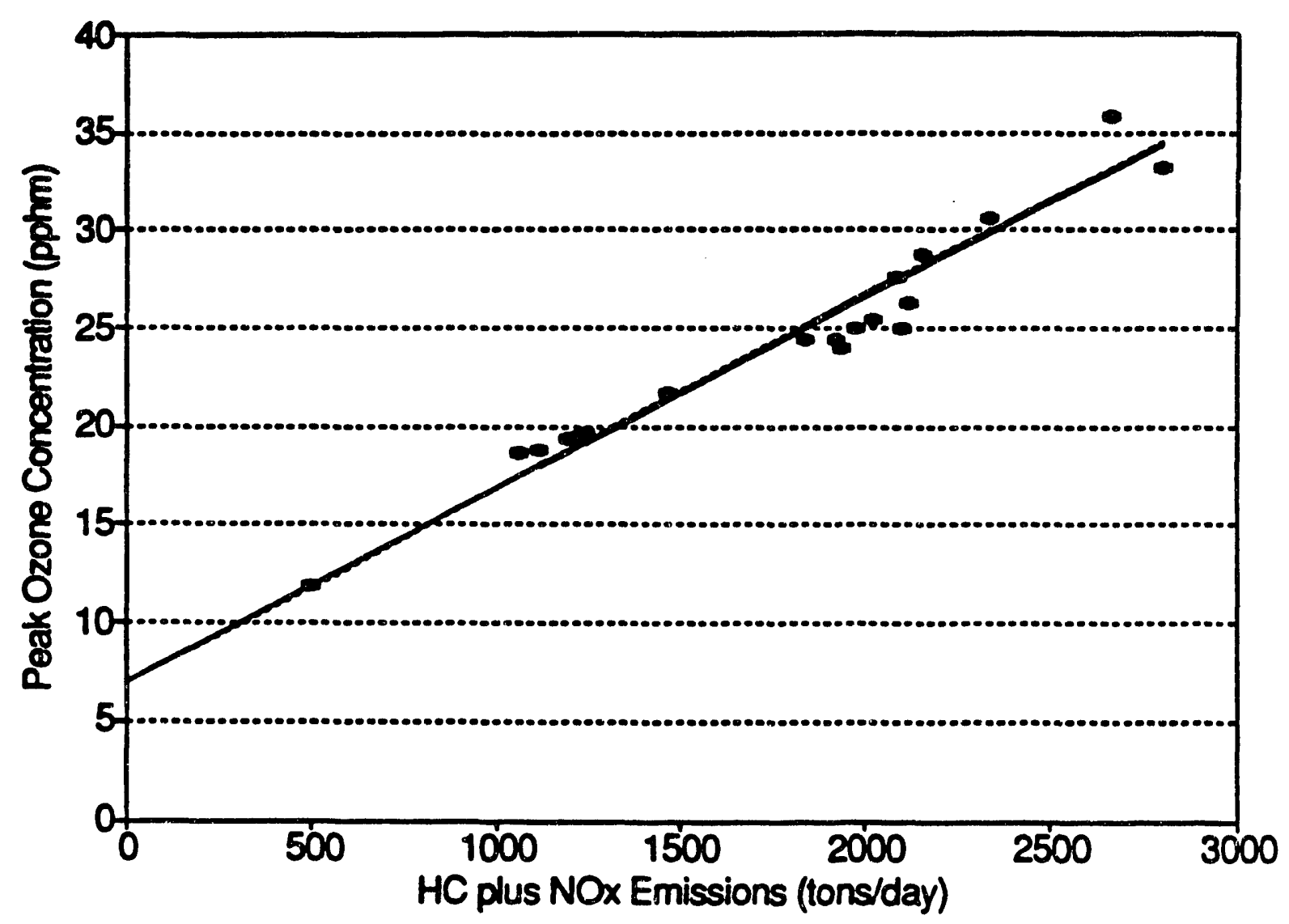

Figure 23. Comparison of Peak Ozone Projections from Studies by Claremont, RFF and the SCAQMD.

The example with the highest peak ozone is Hempel's "Base Case 1985" projection of $35.8 \mathrm{pphm}$. The key inputs to this projection are 1,530 tons/day of $\mathrm{HC}$ emissions and 1,132 tons/day of NOx emissions. Thus, Hempel's 1985 example is positioned at 2,662 tons/day on the horizontal axis in Figure 23. Looking to the 


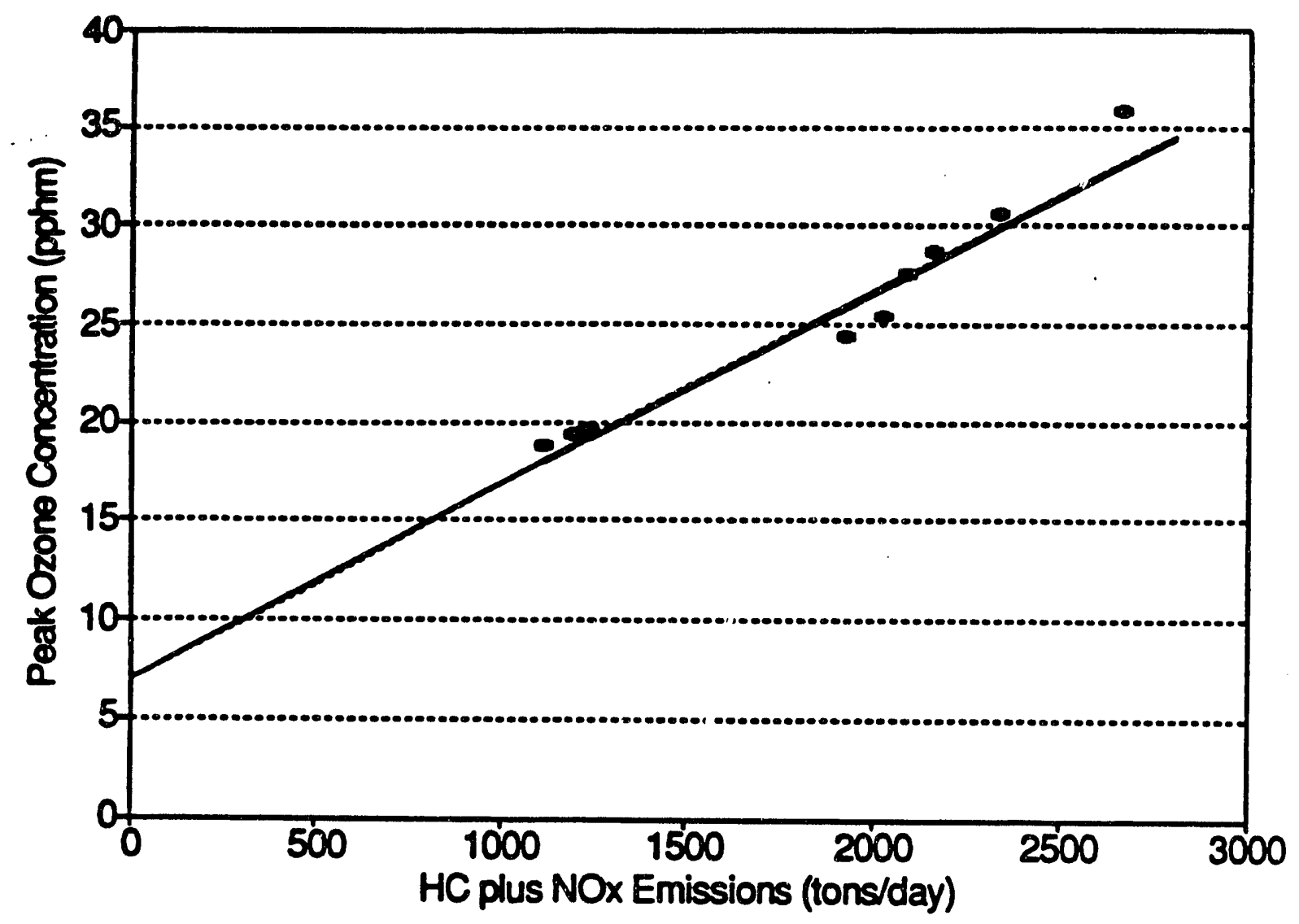

Figure 24. Comparison of Peak Ozone Projections in Studies by Claremont and RFF.

opposite end of the chart, the example with the lowest ozone is the SCAQMD's "2010 Control" scenario with a peak concentration of 11.9 pphm. This scenario assumes 171 tons/day of HC and 328 tons/day of Nox for a total of just about 500 tons/day. The "2010 Control" scenario is quite important as it shows the SCAQMD plan for eventually complying with the federal standard of 12 pphm on peak ozone.

Figure 24 reports 6 airshed projections from the claremont study and the 4 projections from RFF. Hempel's 6 examples involve much greater emissions, and the peak ozone projections lie in the range from 24 to $36 \mathrm{pphm}$. The 4 airshed projections from the RFF study lie in a tight cluster with peak ozone around 19 to 20 pphm. The greatest spread in simulated conditions appears in the nine examples from the SCAQMD study reported in Figure 25 . The district's projections span the range from a "1985 baseline" with peak ozone estimated at 33.1 pphm to the "2010 Control" example which comes in at $11.9 \mathrm{pphm}$, just under the federal standard of 12 pphm. 


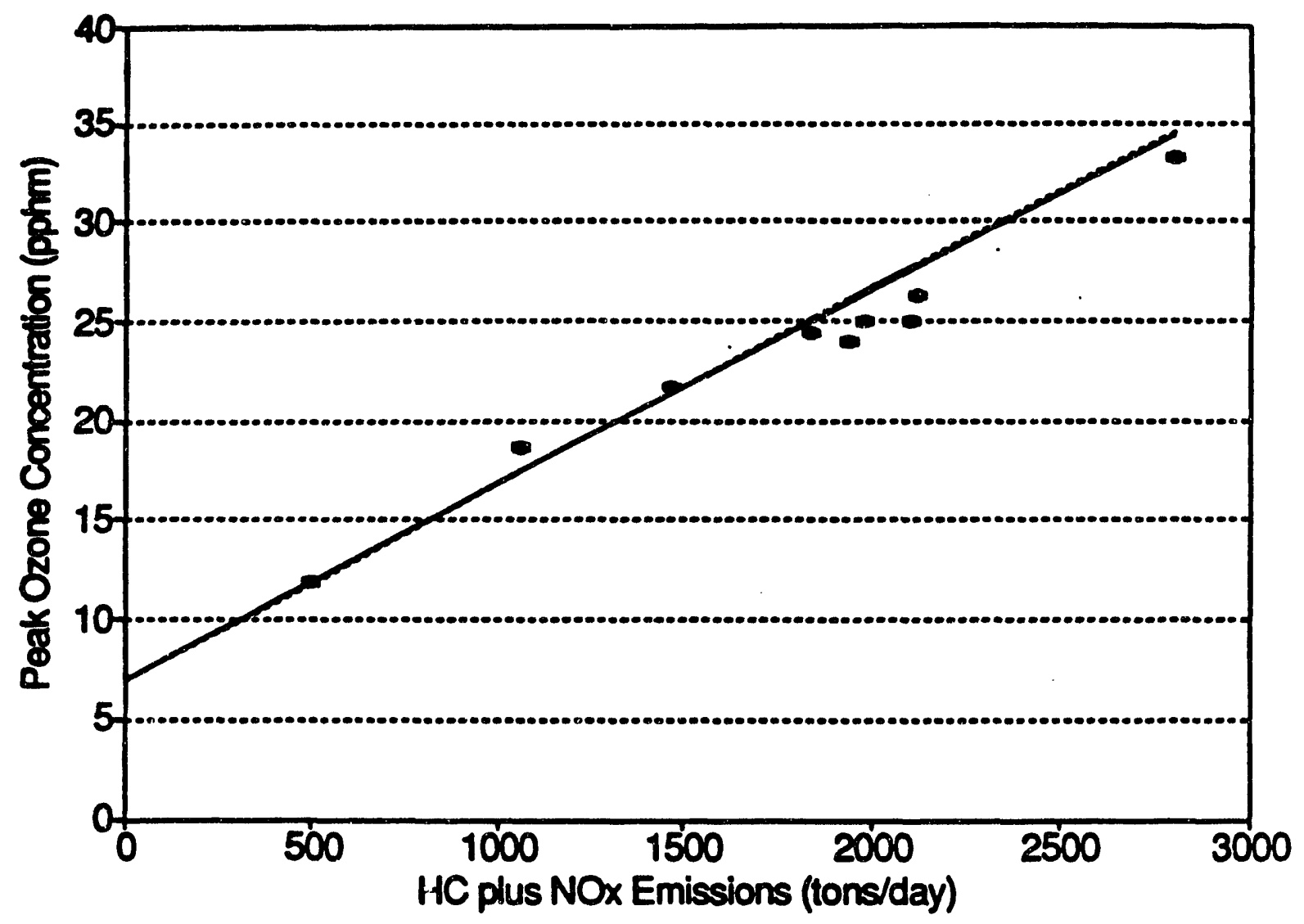

Figure 25. Comparison of Recent Ozone Projections by the SCAQMD.

The solid line appearing in Figures $23-25$ is drawn in linear fashion by simply assigning a high value of $33 \mathrm{pphm}$ to the example with the largest emissions and a low value of $7 \mathrm{pphm}$ if there were no emissions. This simple, linear relationship may be compared to all nineteen airshed projections in Figure 23 , to the projections from the RFF and Claremont studies in Figure 24 and to the SCAQMD projections in Figure 25. The comparisons show that this linear relationship provides a reasonable "fit" if one is looking for a simple means to interpolate from the previous studies.

\subsection{Discussion}

The problem with simple, linear interpolation is that the formation of ozone is not simple, and it's not linear. The complexity and the nonlinearity of airshed modeling is explained in the claremont study as follows: 
In calculating the effects of EVs on ambient air quality, it is necessary to distinguish between those pollutants that are emitted directly from a tailpipe or a smokestack, and those that are formed in the atmosphere through physical and chemical reactions of "precursors", e.g. chemical species such as NOx and hydrocarbons which combine under certain meteorological conditions to form ozone. Simply adding up the tons of individual pollutants emitted in a given year does not reveal much about their consequent risks to human health or to the environment. Before anything meaningful can be said about the relationship of emissions to air quality, one has to know precisely where and when the emissions occurred, the meteorological conditions present at the time, the various transport and surface removal processes operating, and the varying environmental exposure levels for each pollutant... In calculating the effects of EV substitution on ozone levels, it is not possible to use aggregate emissions data in order to arrive at a reliable estimate of air quality impacts. In the first place, the relationship between concentrations of ozone precursors and ozone air quality is nonlinear... The photochemistry of ozone formation is so complex, in fact, that achieving a clear scientific consensus on control measures may take many years to emerge.

$$
\text { (Hempel 1989, p. 58) }
$$

The complexity of ozone formation leaves one with three possibilities in assessing the benefit of EVs. The first possibility is to follow the approach used by RFF, claremont and the SCAQMD and use a complex, airshed model to estimate changes in ambient ozone. This approach is beyond the scope and resources of this study. The second possibility is simply to not discuss ozone impacts of EVs. With this approach, the air pollution benefits are usually summarized by the reduction in the emissions of key air pollutants as in Chapter 7. The third possibility is to interpolate from the findings from previous airshed studies. Interpolation may be useful in general assessments of EVs when the investigator does not have access to a credible airshed model.

Figure 23 is the simplest form of interpolation. The chart has only two dimensions with the combination of $H C$ and NOx emissions serving as the explanatory variable on the horizontal axis. The next logical step is to expand on this two dimensional picture by allowing NOx and $H C$ to serve as separate, explanatory variables. An illustrative, three dimensional portrayal is given in Figure 26. This diagram shows airshed modeling results reported in the SCE "Early Attainment Plan for Ozone" submitted as testimony" to the SCAQMD 1989 draft plan (SCE 1989). The results are reported relative to a base situation in the year 2010 in which peak ozone would be $30 \mathrm{pphm}$. Relative reductions in reactive organic gasses (ROG) and in NOx are used as the explanatory variables. Figure 26 
shows that a background value of $5 \mathrm{pphm}$ would be achieved if there were 1008 reduction in either ROG or NOx. I have labeled the 50/50 and $90 / 90$ results in Figure 26 to draw your attention to the examples where the precursors are reduced in equal proportions. (These conditions are of special interest because CVs emit large amounts of both NOX and HC.)

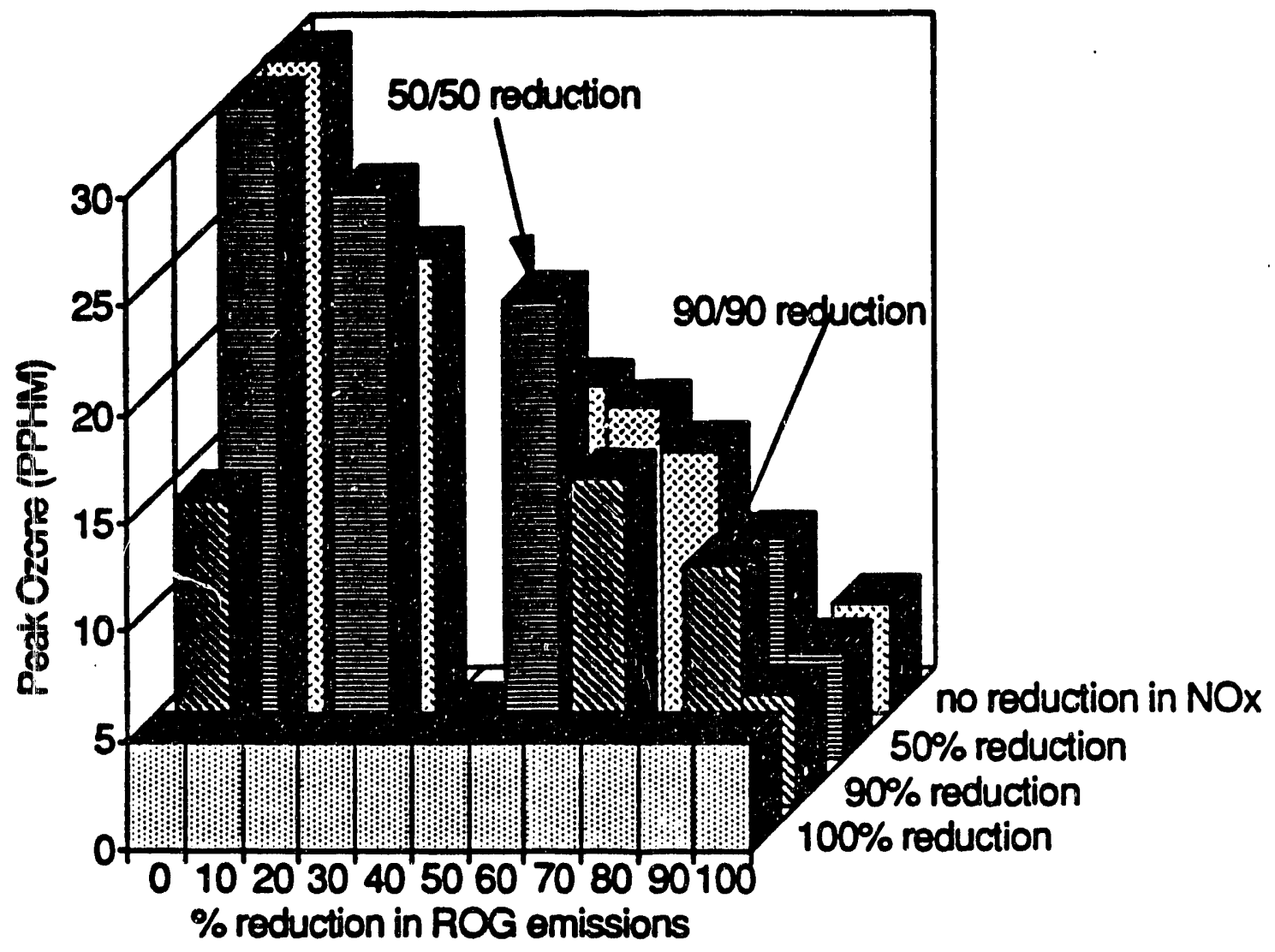

Figure 26. Peak Ozone Projections in Airshed Modeling Reported in SCE's "Early Attainment Plan for Ozone."

Figure 26 reveals some of the nonlinearities and unusual resilts from airshed modeling. Notice from the two examples with $30 \mathrm{kphm}$ at the top of the diagram, for example, that a 50\% redultion in NOx (with no reduction in ROG) does not reduce peak ozone. Looking at the back row of the chart, however, one sees that a 50 r reduction in ROG (with no reduction in NOX) reduces peak ozone to $15 \mathrm{pphm}$. If the $50 / 50$ and the $90 / 90$ results are compared to neighboring estimates, one sees that reductions in Nox can actually lead to higher ozone concentrations. At 50/50 reduction, peak ozone is expected to be 21 pphm. But if the Nox remains at the base value, peak ozone would be $15 \mathrm{pphm}$. A similar comparison occurs at the $90 / 90$ point in the chart. Peak ozone is projected 
to be 11 pphm with 908 reduction in both ROG and NOx. But if the Nox were only reduced by $50 \%$, peak ozone would be $10 \mathrm{pphm}$.

Three dimensional information like Figure 26 is often converted to two dimensional diagrams with ozone isopleths serving as "contour lines." The diagrams use EPA's "Empirical Kinectics Modeling Approach" and are called EKMA diagrams. These diagrams show the changes in either HC or NOx needed to reach a target ozone value. The EKMA diagrams reported by Kelly and Gunst (1990) in describing their smog chamber experiments in Los Angeles are particularly instructive. Kelly and Gunst conducted captive air experiments in downtown Los Angeles and Claremont by filling smog chambers with different mixtures of HC, NOx and clean air. They then developed empirical models of peak ozone formed in the chambers, and used EKMA diagrams to summarize their findings. When studying the impact of EVs, their findings from the "knee region" of the EKMA diagram are particularly relevant.

The knee region of an EKMA diagram covers a broad range of conditions where there are reductions in both HC and NOx emissions. (The middle of the region would correspond to the path from the base case to the $50 / 50$ case to the $90 / 90$ case shown in Figure 26.) Kelly and Gunst $(1990$, p. 2998, 3001) observe that. "between the NOx inhibition and HC saturation regions there is a highly curved region or 'knee' where neither the termination nor propagation reactions dominate. Ozone will respond to changes in HC and/Or NOx within the knee region... simultaneous reduction of $H C$ and NOx tends to keep the system in a HC/NOx region that is most resistant to changes in peak ozone. This partly explains why progress in attainting the ozone standard has been so difficult and slow." In their assessment of the ozone impacts of simultaneous reductions of HC and NOx, Kelly and Gunst note that simultaneous changes would cause the region to remain in the knee region, and the change in peak ozone is linear.

The linear result suggests that simple linear interpolation can be useful if the control strategies lead to roughly equal reductions in $\mathrm{HC}$ and NOx emissions. Sheet \#28 shows that many of the scenarios from previous studies show reductions in both HC and NOx. For example, the SCAQMD's "2010 Controls" scenario assumes 898 reduction. in $H C$ and 738 reductions in NOx. All the EV scenarios end up with some reduction in both HC and NOx (since conventional cars emit both of these pollutants). The RFF scenario with 1.5 million EVs comes closest to simultaneous reduction (HC is reduced by 98 , NOx by $11 \%$ ).

As a variation on the simple, linear interpolation in Figures 23-25, I have explored alternative ways to combine HC and NOx emissions into a single, explanatory variable. Based on the Kelly and Gunst $(1990$, P. 2997) empirical results, the best way to combine $\mathrm{HC}$ and $\mathrm{NOx}$ into a single explanatory variable is to take the square root of their product. The dashed line in Figures 23 
25 uses this nonlinear approach. (The dashed line is nearly identical to the solid line in these diagrams, so you must look closely to see that there are actually two lines.) The dashed line assumes the same starting point as the sold line (33 pphm with emissions at Hempel's 1985 base case). It also assumes the same end point ( 7 pphm with no emissions). But the dashed line follows a downward path based on the square root of the product of HC and Nox emissions. The estimated value of peak ozone would drop to 7 pphm if either HC or NOx emissions were eliminated. Figure 23 shows negligible differences between the linear and nonlinear methods of interpolating. (Indeed, the dashed line is barely visible in the three diagrams). The extremely small differences arise from the fact that the two methods adopt the same end points (33 pphm and $7 \mathrm{pphm}$ ) and that the nineteen scenarios from the previous studies end up with reductions in both NOx and $\mathrm{HC}$.

\subsection{EV' Impact on Peak 0zone: An Illustrative Interpolation}

Chapter 7 estimates emission reductions expected from one million EVs sold in the year 1993. A rough indication of the ambient benefits of the million EVs can be obtained by interpolating along the linear path shown in Figure 23. I consider an extreme example in which ONE MILLION EVs are sold in the year 1993. Assume, for the sake of the illustration, that air quality in the South Coast in 1993 is characterized by a peak ozone concentration of $28 \mathrm{pphm}$. Notice from sheet 28 , that this concentration is consistent with the emissions expected in 1994 in the baseline scenario examined in the SCAQMD 1991 Plan. Chapter 7 shows the emissions reductions from the one million EVs, and I focus on the "first year impacts" appearing in sheets $\$ 21 \& 22$. These sheets indicate that, by the end of their first year of operation, the one million EVs would reduce HC emissions by 9.2 tons/day and NOx emissions by 10.5 tons/day. Ignoring upstream effects and adding the two sources of emissions, the total reduction is nearly 20 tons/day. Notice from sheet $\$ 28$ that the SCAQMD "1994 baseline" has around 2,100 tons/day of combined HC \& NOx emissions. Thus, the first year's impact of the one million EVs is a 18 reduction in emissions. Using simple, linear interpolation, one would expect peak ozone to decline by around 1 i along the path from 28 pphm toward 7 pphm; the result would be around $27.8 \mathrm{pphm}$. The million EVs would lower peak ozone by only 0.78 .

This small improvement may surprise some readers, but it is consisteint with previous airshed studies in the South Coast (Hempel 1989, RFE1990). The small impact of one million EVs is not a sign that EVs are unimportant. It's an indication of the enormity of the southern California air pollution problem. 


\section{Chapter 9. Summary of Important Findings}

The important findings from my initial research are summarized in Question \& Answer format. The "Q A" summary will allow the reader to skip to the questions of most interest..

\section{What Are the Key rindings From Previous studies?}

Chapter 2 reviews the findings from previous EV studies with particular attention on six separate studies of EVs in southern California. These studies indicate that power generation to supply EVs would come largely from natural gas-fired units. The previous investigators conclude that EV demands would tend to improve the overall shape of the electricity demand and allow utilities to operate more efficiently. One study estimates that SCE could accommodate 0.6 million EVs with the existing resource plan, and these EVs would allow for a $3.5 \%$ reduction in SCE's average electric rate. Previous studies show that EVs would lead to significant reductions in emissions of important air pollutants. But they tend to show that large numbers of EVs, taken alone, do not lead to significant reductions in the peak ozone concentration in southern California.

This study does not contradict any of these findings. Rather, the thrust of this report is to confirm and extend the general findings from previous investigators.

\section{How Many EVs Might Appoar in Scenarios for SCE?}

Chapter 3 discusses the purpose of scenario analysis, and Chapter 4 describes scenarios in which 1 million or 2 million EVs might appear in the SCE area by the year 2010. The 1 million EV scenario is especially interesting because it happens to correspond closely with recent EV forecasts presented to the CEC. The forecasts assume that auto manufacturers will comply with CARB requirements for ZEVs and concentrate the sale of EVs in southern California. One million EVs in the SCE area would correspond to 1.7 million EVs in the South Coast--roughly $17 \%$ of the vehicle population expected by the year 2010. This level of penetration falls just within recent technical estimates of the potential market for EVs.

The 2 million EV scenario implies 3.3 million EVs in the south Coast--every third vehicle would be electric. These scenarios envision auto manufacturers moving well beyond the current CARB requirements for ZEVs. 


\section{Bow Would EV nffect the Peak Electric Ioad?}

Chapter 5 presents an extensive analysis of EV' impact on electricity demands for eight different scenarios. The examples show little impact on peak demand. The minimal impact is a logical consequence of the 250 mile range assumed for EVs with advanced batteries. The one exception to this pattern is a scenario in which EVs operate with less advanced batteries with a daily range of 150 miles. This example ends up with 158 of the EV energy provided by "opportunity charging" during day time hours. The peak load is estimated at $387 \mathrm{MW}$. The extra peak load would cause SCE's reserve margin to fall from around 238 to around 218.

\section{How Would IVs Affect the Off-Peak Electric Ioads?}

Chapter 5 demonstrates that EV demands tend to fall in the late evening hours when night time charging is left to the convenience of the customer. Little of the demand would land in the deep valley found in the hours from lam to $5 \mathrm{am}$. This pattern occurs because night time charging is limited to 3 hours or less. The short charging intervals, in turn, are the logical consequence of EVs with a $250 \mathrm{mile}$ range and a daily use of 40 miles. Chapter 5 also demonstrates that simple financial incentives to shift night time charging demands may lead to a worsening of the demand shape.

\section{Could Direct Control Systems Improve the Night Time Ioads?}

Chapter 5 examines the impact of "blind control" and "smart control" of night time charging. Blind control implies one way communication. The utility would send signals to start the Evs' night time charging cycle. But the control system could not receive information on the status of the EVs, so the signals would have to be sent without knowing the duration of the charging cycle. Chapter 5 demonstrates that this limitation would cripple the ability of a control system to improve the shape of the night time loads.

A "smart control" system implies two way communication. The utility can send signals to start charging, and information on the status of the EV can be monitored at the control center. With such a system, the control center can start the charging of EVs later in the morning hours and obtain a better blending of the EV loads with SCE's regular loads. Chapter 5 s. iows the relatively flat demand profiles that could be obtained, both for typical days in the summer months and the winter months. 
6. How Many rV could be Accommodated with the Existing Resource RIan?

Chapter 6 explains that 2 million EVs could be accommodated with SCE's existing long term plan, provided the vehicles are subject to smart control. The existing resource plan could accommodate 1 million EVs, regardless of whether their night time charging occurs at the customers' convenience or under smart control. These accommodacion levels are surprising high compared to results from previous studies. The unexpectedly high levels may be attributed to the (1) advanced batteries assumed for the EVs,

(2) use of smart control to shape the night time charging, and (3) higher level of reserves built into SCE's existing resource plan.

\section{What Generating Resources Would End Op Serving the EV Load?}

Chapter 6 confirms what previous research has found--roughly 908 of the extra electric energy will come from burning natural gas. A rough rule of thumb is that two-thirds of the gas-fired generation will occur in new or repowered units; the other third would be generated in SCE's existing units. The remaining 10 of the EV energy will be provided by a mix of coal-fired generation, economy purchases from utilities in the Pacific Northwest and economy purchases from utilities in the pacific southwest. SCE will be able to draw on the coal-fired units for a greater share of the EV energy in scenarios with smart control.

\section{How Would EVs Affect the Otility Operating Costs?}

Chapter 6 shows that 2 million EVs would increase the annual operating costs by around $\$ 1.9$ billion, an increase of 228 . Payments for natural gas would account for the majority of the cost increase.

Higher payments to QFs are second to natural gas in accounting for the higher operating costs. Even though QFs are not projected to supply any of the energy needed for EVs, total payments increase because of marginal cost contracts. Marginal costs are driven upward in EV scenarios, particularly if smart control permits the utilities to "remove coal plants from the margin." The QF's role in system operation is especially important in the two scenarios with one million EVs. Chapter 6 shows that around one-third of the extra operating costs would be attributed to QFs in the scenario with one million EVs subject to smart control Indeed, the QF payments are so large that SCE could be better off without a smart control system. This surprising result does not appear in the scenarios with two million EVs, however. 


\section{Bow Nould IVs Refect the Average Electric Rate?}

The impact on SCE's average electric rate is reported in Chapter 6 for each of the scenarios in which the EVs could be accommodated within the existing long term plan. The calculation assumes that EVs do not affect SCE's fixed costs, and it ignores utility spending on infrastructure, distribution systems or incentives. Two million EVs under smart control could lower SCE's long term average electric rate by 2.98 . The average electric rate would be reduced by 1.2-1.5\% in the scenarios with one million EVs.

These reductions are well below previous estimates. I attribute the smaller rate reductions to the pivotal role of QFs which is studied closely in Chapter 6. If payments to QFs were not affected by EVs, for example, the two million EVs would lead to a $4.6 \%$ reduction in the average electric rate.

\section{Do EVs Iead to Significant Reductions in Inmissions?}

Chapter 7 shows the reduction in emissions of key air pollutants when an EV displaces a conventional vehicle (CV). The calculations represent the longer life of the EV and the CARB requirements for CVs. An EV sold in 1993 would eliminate 115 pounds of HC, 133 pounds of NOx and over 1,300 pounds of CO. These reductions would change as the CARB rules become increasingly stringent over time.

Assigning monetary values to the avoided emissions is a slippery procedure, but it can shed light on the relative, environmental value of EVs. Chapter 7 shows an estimated value of around $\$ 9,000$ for EVs sold during the interval from 1993-1995. An EV's value would drop to around $\$ 8,000$ by the year 1999 due to improvements expected in CVs. The monetary value is dominated by the value assigned to reductions in CO emissions, and I alert the reader to the considerable variations in recent attempts to place a value on avoiding $C O$ emissions in the South Coast.

\section{Do Opstream Effects Alter the smission Benefits?}

Chapter 7 examines the emissions expected "upstream" from an EV and from a CV. The EV's upstream emissions are from power generation, both inside and outside the south Coast. The CV's upstream emissions include refining, transportation as well as emissions during the actual fueling of the vehicle. Inclusion of upstream effects will (1) greatly expand the EV's benefits in reducing HC emissions, (2) decrease the NOx benefit by around $10 \%$ and (3) not affect the estimate of co benefits. Because the $c 0$ benefits dominate the monetary calculations, one should expect that upstream effects will not lead to significant changes in the $\$ 9,000$ beneit estimated for an EV. 


\section{To What Ixtent Could IVs Reduce the South Const Ozone Problem?}

Chapter 8 discusses results from three different studies that employ sophisticated airshed models to simulate the formation of ozone in the South Coast. The discussion describes the rationale and conditions under which simple, linear interpolation may be used to gauge the impact of EVs on peak ozone. An illustrative example confirms what other researchers have found: EVS, when taken alone, do not lead to significant reductions in the peak ozone concentration. For example, Chapter 8 explains the likely impacts in the first year of operation if one million EVs were sold in 1993. These vehicles would reduce the amount of NOx and HC released in the South Coast by around 18. By simple interpolation, one would expect a 0.78 reduction in peak ozone. This small impact does not mean that EVs are unimportant; it means we have an enormous air pollution problem in southern California.

\section{What Are the Important Questions for Further Research?}

The final chapter raises important questions which were not addressed in the initial phase of the research. A particularly important question is whether the utility should actively promote the use of EVs. Utility options include:

(1) research and demonstration programs,

(2) provision of supporting infrastructure,

(3) offering low electric rates for night time charging, and

(4) provision of direct financial incentives to lower the initial purchase price of the vehicle.

During the next phase of the EV research, I will consider the extent to which SCE could commit its own financial resources to promote EVs during the early years of a scenario. The interesting question is whether SCE could provide significant incentives during the $1990 \mathrm{~s}$ and finance the incentive program from the improvements in system operation occurring past the year 2000 . The study will reveal if the utility could provide a significant boost to EV penetration without having to raise electric rates to its customers who do not own EVs.

This next line of research will consider issues reminiscent of the issues raised by Thomas Edison at the start of the 20 th century. His suggestion that utilities promote EV sales is relevant today. The promotional issues are especially relevant to SCE, a utilit" said to be on the "cusp of change" as it prepares to enter the 21 st century (Seligman 1991). 


\section{Chapter 10. Discussion and Further Research}

\subsection{Discussion}

I conclude this report with a short discussion of the following topics which were not addressed in the initial research:

1. Transferability of Results

2. Different Description of the EVs

2.1. Pure EVs vs. Hybrids

2.2. Swap Stations

3. Different Description of the Utility System

3.1. Operation of the Entire West Coast Electric System

3.2. Impacts on the Utility Distribution System

3.3. The Role of Renewable Generation

3.4. The Role of Load Management Programs

4. New Uncertainties for Utility Planners:

the example of Metal/Air Batteries

1. Transferability of Results

Many readers will wonder if the findings for the SCE system are transferable to other utilities. This question is of special interest, for example, to utilities in the rest of California, in Texas and in the Northeast. Utilities from across the state of California have joined with state agencies to develop "A California Plan for the Commercialization of Electric Vehicles" (CEVTF 1989). In the Northeast, air quality control agencies have formed NESCAUM - -Northeast States for Coordinated Air Use Management. NESCAUM is evaluating the suitability of the CARB requirements for $\mathrm{ZEVs}$ to conditions in the Northeast (Pechan, 1991; Tennis 1991). And in Texas, utilities and research organizations across a 5 state region have formed the South Central EV Consortium and released their plan for the commercialization of EVs (SCEVC 1991).

As a general rule, one should expect many of the findings from Chapters 5 and 6 to be transferable to other utilities. One would expect that the general conclusions about EVs impacts on electricity demands to be transferable. Also, some of the general conclusions about EVs! impact on operating costs and average electric rates would be transferable. But one should not expect the findings on the $\mathrm{mix}$ of generating resources used to fuel EVs to be transferable. Also one would expect the air pollution results from Chapters 7 and 8 to be limited to the unique situation in southern California. 
2.1. Pure EVs vs. Hybrids

This report considers only "pure EVs" whose sole source of power is a battery. Other vehicles with electric motors have not been addressed. These include electric-gasoline hybrid vehicles, fuel-cell vehicles and vehicles which draw power direct from an electrified roadway. The report concentrates on pure EVs because advanced, battery powered EVs are expected to be commercially available sooner (Deluchi 1989, p. 256).

A logical question concerns the transferability of the findings for pure EVs to other types of vehicles with electric motors. I posed this question with utility planners during project interviews, and I found general agreement that the direct impacts on the utility system are likely to be the same for a hybrid vehicle as a pure EV. If one were to compare a scenario with one million hybrid vehicles and a scenario with one million pure EVs, for example, the impacts on the utility's electric loads, system dispatch, and average system costs would probably be similar. If differences were to arise, they would probably involve the vehicle owner's decision on whether to use opportunity charging or gasoline when an extension in range is needed. Of course, the air pollution impacts of hybrids would be quite different from the impacts from pure EVs.

Many of the important findings for pure EVs are not likely to apply to electric vehicles that draw power from an electrified roadway. These vehicles would draw much of their power during peak periods, and their demands could lead to less efficient use of the generating units. Electrified roadway vehicles are under study at the SCAG (1991).

\subsection{Battery Swap Stations}

Battery swap stations are an interesting option to allow EV owners to extend their vehicles' range well beyond the limit of a single battery pack. The owner would simply drive into the swap station to have the discharged battery pack replaced by a fully charged battery pack. Deluchi (1989, p. 273) describes the main advantage of swap stations as extending the effective range of the EVs (which is especially important to single vehicle families). Deluchi suggests the batteries would probably be owned by the swap stations and leased to the EV owners. The high cost of batteries would not appear as part of the initial cost of the EV, and the risk of battery performance would be transferred to the swap stations. Recharging of the batteries would now involve decision making by thousands of swap station owners as well as millions of vehicle owners. If there were no problem storing batteries overnight, one would expect the swap station owners to recharge the hundreds of batteries at right to fully exploit the off peak rates offered by the utility company. But if swap station owners are 
pressed for space, they may end up charging batteries in the middle of the day to maintain a supply of recharged batteries for customers that drive in during the evening hours.

\subsection{Operation of the West Coast Electric System}

Economy purchases from utilities in the Pacific Northwest are projected to provide 58 of the extra energy for EVs in the third scenario. Pacific southwest purchases provide 28 (see sheet $\$ 5$ ). Somewhat similar results were obtained in Ducat's (1989) production cost calculations. He expected 108 of the EV energy to come from economy purchases, principally from the Pacific Southwest. These estimates suggest that there is not much of a role for economy purchases in serving the EV load.

To check further into the role of economy purchases, I asked colleagues from the Bonneville Power Administration (BPA) to help provide a "west coast perspective" on the results reported here. The agreed to conduct an exploratory analysis with PMDAM, the Power Marketing Decision Analysis Model. PMDAM is a computer model of the western U.S. bulk power market. It was designed to support the analysis of decisions to sell or purchase power, or acquire generating resources for the BPA. BPA staff used PMDAM to simulate how the utilities up and down the west coast might react to a scenario with 3.3 million EVs in southern California. We selected the EV scenario 1 from Table I and expanded the EVs and their loads to allow for a similar EV demands for the Los Angeles Department of water and Power. The simulations are quite different from the ELFIN results reported in Chapter 6 because the PMDAM calculations allow for fresh appraisal of the best mix of new generating resources in the EV scenarios (Phillips 1991).

The initial PMDAM results suggest that $85 \%$ of the SCE EV load would be satisfied by natural gas-fired units--a result similar to the findings reported in Chapter 6. As far as the long term expansion plans are concerned, the exploratory results indicate that the west coast system would acquire approximately the same total generating capacity with or without the EVs. But the mix of resource additions is likely to shift between resource categories and between different regions withir the entire west coast system. For example, BPA planners note a shift from single cycle combustion turbines to combined cycle combustion turbines and coal-fired stations. The regional shifts are most pronounced in southern California and in the Inland southwest. In southern California, BPA planners project that EVs would lead to less single cycle CTs, much more investment in combined cycle CTs and a slight reduction in wind and cogeneration. Utilities in the inland southwest are projected to cut back extensively on combined cycle CTs and to invest more heavily in coal-fired generation. Northern California utilities are projected to react to the southern California EVs by reduced investment in both single cycle and combined cycle CTs and 
to invest more heavily in wind and cogeneration. The Pacific Northwest utilities are projected to react in a minimal fashion; the model shows a small reduction in single cycle CTs and a small increase in nuclear generation.

At this stage, the results from the PMDAM analysis are strictly exploratory. But the general findings are probably indicative of what west coast planners are likely to discover over time. As EVs become more prominent, planners will increasingly explore how utilities' resource plans might be changed if large EV loads are expected. These future studies are likely to confirm the PMDAM finding that utilities will shift investment toward units that operate more efficiently in a "base load" fashion. These new, "EV induced, base load units" could well appear on the margin. If this were to happen, some of the interesting rate impacts appearing in Chapter 6 of this study might vanish from future studies.

\subsection{Impacts on the Utility Distribution system}

Distribution system impacts were not addressed in the EV studies reviewed in Chapter 2, and they are not considered in this report. But a recent assessment of $E V$ impacts suggests that distribution costs could become an important part of the impacts on an electric utility. For example, Fitzgerald (1992) estimates that transmission and distribution costs could amount to 30-45\% of EVs' impacts on investments by the Pacific Gas \& Electric Company.

Utility planners interviewed in this project feel that distribution system costs could become significant even though EV electricity demards appear small compared to total demand. They anticipate that EV sales will not be distributed uniformly over the utilities' service area. Rather, they expect EV sales to be concentrated in communities populated with affluent households or in communities with special incentives and charging infrastructure. Once EV sales "take off" in an individual community, further concentration of sales may be expected from the "word-of-mouth effect" and from the ensuing buildup of charging infrastructure.

EV's impact on the distribution system has been analyzed in a report to SCE by Arias (1982). He considered an EV scenario in which, "by the year 2000, there could be over 200,000 EVs in the total SCE service territory which could have combined electricity demands in excess of a thousand megawatts." (His EV scenario would fall between the $7 \mathrm{th}$ and $8 \mathrm{th}$ scenarios in Table I.) Arias argues that average impacts on the distribution system will probably be negligible, but he feels that localized problems could develop. Arias concludes that "in general, the impact of servicing a large EV population would be greatest in the affluent, smaller, and older service areas which would require accelerated maintenance of distribution system components and/or system upgrading, while little or no impact would be expected in the larger new service areas" (Arias, 1982, p. 2). 
A more recent study of the distribution system impacts of EVs was conducted by Detroit Edison (1987) for EPRI. They reported the results of a field test involving ten EVs. No adverse customer responses were reported. The field test did show that voltage harmonics were introduced which were capable of degrading reception of $A M$ and other radio signals. Voltage harmonics are currently under study at the University of Nevada at Las Vegas (Baghdouz 1991).

\subsection{The Role of Renewables and the Greenhouse Problem:}

Solar generating stations and other renewable generating technologies are often suggested as the ultimate answer to the carbon dioxide and other "greenhouse emissions" from vehicles. In her summary of "relative greenholie gas impacts", for example, Fisher (1991, p. iii) rates EVs/solar as far better than ten other vehicle/fuel combinations. But solar and other renewable generating technologies do not make an important contribution in the EV scenarios in this report because the primary source of energy for the EVs is natural gas. Deluchi (1989, p. 272) estimates that substituting EVs for CVs leads to only an $18 \%$ reduction in a composite measure of greenhouse gases when the EV's electricity comes from new natural gas plants. If, on the other hand, technological progress on solar and renewable technologies were to proceed at a high rate (ie, comparable to the progress envisioned for Na/S batteries), southern California utility companies may be investing in renewable generating resources after the turn of the century. Without such progress, however, the most attractive generating resource for southern California utilities appears to be combined cycle, gas burning units (Ducat 1989, $p$. 27).

\subsection{The Role of Load Management Programs:}

The production cost calculations in Chapter 6 do not attempt to find a different $\mathrm{mix}$ of resource additions in scenarios with extensive use of EVs. The ELFIN projections use the same mix of demand-side and supply-side resources that appear in the SCE long term resource plan. But the ELFIN results for SCE's pumped storage operation suggest that some demand-side programs may not be appropriate in a future with millions of EVs. With smart controlled EVs, for example, the cost effectiveness of the "valley filling" programs would probably decline since the night time valley is already being "filled" by EV loads.

4. New Uncertainties for Utility Planners:

the Example of Metal/Air Batteries

The introduction of EVs will bring many new sources of uncertainty that will complicate the utility planning process. Planners will face great uncertaint, in the growth of the EV 
population and their likely efficiency of operation. Planners will also face considerable uncertainty in the miles/day of travel and the extent of opportunity charging from the existing population of EVs. And finally, planners will face multiple uncertainties surrounding the indirect impacts of EV use and EV manufacturing.

As competing battery technologies improve, utility planners will confront uncertainty in battery decision making by both the vehicle manufacturers and the owners of existing vehicles. Depending on the lifetime of the battery technologies used in the current EV population, planners might have to prepare for the possibility of a rapid transition to an advanced battery that could dramatically alter the pattern of electric loads. Improved batteries might lead to improved efficiency of EV use (higher miles/kwh) and/or greater EV performance and use.

An especially interesting uncertainty involves the development of metal/air batteries. These batteries would have a metal anode made of aluminum (AI), zinc $(\mathrm{Zn})$ or iron (Fe). Their cathode uses atmospheric oxygen. The office of Technology Assessment describes metal/air batteries as an intriguing option:

For the longer term -- beyond the year 2000 - the
metal/air batteries are intriguing because they combine
high power density with mechanical rechargeability, that
is, they can be recharged rapidly by replacing the metal
anodes, adding water, and removing byproducts. These
batteries are also farthest from comercial readiness,
and their eventual practicality is far from assured;
important problems remain concerning their cost,
durability, the need for practical carbon dioxide
scrubbers, and their complexity.
(OTA 1990, p. 119)

The mechanical recharge may be contrasted with the electrical recharge envisioned for the $\mathrm{Na} / \mathrm{S}, \mathrm{Ni} / \mathrm{Fe}$ and $\mathrm{Pb} / \mathrm{acid}$ batteries considered in this report. With electrical recharge, charging requires either very large current flow (fast recharge) or very long charging time (night time charging). With metal/air batteries, the battery is recharged by simply replacing the consumed metal with a fresh anode. Deluchi (1989, p. 260) notes that, at present, the Al/air batteries are bulky, that the aluminum is expensive and that research is needed to develop better air electrodes. But if improvements make the Al/air batteries attractive, battery maintenance could be done at home and a "year's supply of aluminum would occupy only seven cubic feet."

From a utility planner's point of view, a transition from electrical to mechanical batteries would pose an interesting challenge. Imagine a scenario with millions EVs powered by a combination of lead acid, $\mathrm{Ni} / \mathrm{Fe}, \mathrm{Na} / \mathrm{S}$ and other electrically recharged batteries. If improvements in Al/air batteries were to 
bring the mechanical battery into a competitive position after the year 2000, EV owners might well replace their aging electrical batteries with the new, metal/air batteries. This replacement might take from 5-10 years depending on the attractiveness of the mechanical batteries and the operating life of the existing, electrical batteries. It is conceivable that the utility could see the demand for electric energy from EVs disappear within a single decade.

In such a scenario, the declining demand for EV electric energy might be replaced by a growing demand for electric energy used to smelt aluminum. And on the west coast, the aluminum industry is located in the Pacific Northwest where smelters purchase electric energy in huge quantities at wholesale rates from the BPA. If a scenario with massive shifts to Al/air batteries were to unfold after the turn of the century, planrers might see a rapidly declining demand for electric energy from EVs in southern California coupled with a rapidly increasing demand for electricity demand in the Pacific Northwest. The Northwest/Southwest transmission intertie would probably become quite important under this unusual scenario.

\subsection{Further Research}

The next phase of the EV research will provide an opportunity to examine utility impacts of EVs that are different from those reported here. It is important to study the utility impacts from hybrid EVs and from "pure EVs" which require a greater amount of day time charging. It will also be useful to reexamine the same type of EVs used in this report with variations in the assumption that night time charging will occur on a regular, daily cycle. And finally, there may be time to study the utility implications of extensive use of swap stations.

The major goal of the next phase is to consider the question of whether the utility company should adopt an active role to promote the widespread use of EVs. Promotional activities could involve demonstration programs, information sharing, provision of supporting infrastructure; attractive rates for off peak charging, battery leasing, and direct financial incentives to lower the purchase price of the EV. Utility company planners and state regulators are now discussing the role of utility promotional programs (CPUC 1991). The next phase of the EV research will consider the extent to which SCE could promote EV penetration before the cost of the promotional programs erases the benefits identified in chapter 6. Utility incentives will be examined in isolation and in combination with incentives that may be provided by auto manufacturers or by state agencies. 


\section{REFERTNCES}

Arias 1982

J. L. Arias, "Possible Impacts of Electric Vehicles on the scE Distribution System," prepared by Arias Research Associates, Inc. for the Research and Development Division of the Southern California Edison Company, August 1982 .

Baghdouz 1991

personal communication, Professor Yahia Baghdouz, Department of Electrical Engineering, University of Nevada at Las Vegas, June 1991.

Booth 1972

R. Booth, "Power System Simulation Model Based on Probability Analysis," IEEE Transactions on Power Apparatus and Systems, Vol. PAS-91, No. 1, 1972.

BPA 1988

Bonneville Power Administration, Office of Energy Resources "1987-1988 Scenario Planning Project: Sumary Report," September 1988.

Bernard 1990

M. J. Bernard III, M. K. Singh, and K. Heitner, "Three Scenarios for Electric and Hybrid Vehicle Commercialization," Argonne National Laboratory report ANL/ESD/TM-13, November 1990.

CARB 1985

California Aix Resources Board, "Electric Vehicle Systems: Overview of Current Technology and Emission Impacts in the South Coast Air Basin," February 1985.

CARB 1990

California Air Resources Board, "1990 Electric Vehicle systems Update," partial working draft dated April 12, 1990, cited with the permission of the CARB.

CEC 1986

California Energy Commission, 1986 Electricity Report, December 1986.

CEC $1990 \mathrm{~A}$

Michael Jaske, Patrick Mcauliffe, William Wood, and Albert Belostotsky, "Air Quality Scenario Project," report from the Energy Forecasting and Planning Division, California Energy Commission, November 1990.

CEC $1990 \mathrm{~B}$

California Energy Commission, 1990 Electricity Report, October 1990.

CEC 1991A

Gary Cullen, Tom Gorlin and Michael Jaske, "Demand Issues for the 1992 Electricity Report Proceedings," California Energy Commission, August 1991.

CEC $1991 B$

Richard Buell, Joe Diamond, Mike Ringer and Chris Tooker, "In-State Criteria Pollutant Emission Reduction Values and Modelling Assumptions," California Energy Commission, September 1991.

CEC $1991 C$

Michael Jaske, "System Operation Implications of EV Recharge Load: Southern California Edison," California Energy Commission, october 2, 1991.

CEC 1992

Staff Report, "Analysis of the Potential Electricity Demand, Electricity Supply and Emissions Impacts of Electric Vehicles," California Energy Commission,
February 10, 1992. 
CEVTE 1989

California Electric Vehicle Task Force, "A California plan for the Commercialization of Electric Vehicles," November 3, 1989.

Cheng 1991

personal communication, Margaret Cheng, Electric system Planning, Southern California Edison Company, November 1991.

Chernick and Caverhill 1991

Paul Chernick and Emily Caverhill, methods of Valuing Environmental Externalities," The Electricity Journal, Vol. 4, Nu. 2, March 1991.

CPUC 1991

California Public Utility Commission, "Fifth Report to the California Legislature on the Implementation of Assembly Bill 475: Investigation of Computer Models Used by California Energy and Telecomunications Utilities," July 1991.

CPUC 1991

California Public Utility Comission, "order. Instituting Investigation on the Commission's own motion to develop a policy governing utility involvement in the market for low-emission vehicles," october 23, 1991.

Cumings 1986

R. Cumnings, D. Brookshire, and W. Schulze, editors, Valuinq Environmental Goods: An Assessment of the Contingent Valuation Method, Rowman, Totowa, NJ, 1986.

Deluca 1990

W. Deluca, A. Tumbillo, J. Kulaga, C. Webster, K. Gillie and R. Hogrefe, "Performance Evaluation of Advanced Battery Technologies for Electric Vehicle Applications," presented at the 25th Intersociety Energy conversion Engineering Conference, Reno, Nevada, August, 1990.

Deluca 1991

personal communication, William Del.sa, Argonne National Laboratory, December 1991.

Deluchi 1989

Mark Deluchi, Quanlu Wang, and Daniel Sperling, "Electric Vehicles: Performance, Life Cycle Costs, Emissions, and Recharging Requirements," Transportation Research, Vol 23A, No 3, 1989 .

Ducat 1989

Glenn Ducat, "Electric Vehicle Deployment on the Southern California Edison System," Electric System Planning Division, Southern California Edison Company, March 15, 1989 .

EDF 1985

California Energy Comission Consultant Report, "Production Cost Modelling of the Southern California Edison System," Dec 1985.

EDF 1988

Environmental Defense Fund, "Elfin Dispatch Algorithms and Simulation Methods," March 1988 .

EDF 1990A

Environmental Defense Fund, "Elfin Algorithms Guide, Draft Nov. 1990.

EDF $1990 B$

Environmental Defense Fund, "User's Manual for ELFIN, Version 1.84" July 1990.

EPRI 1978

Electric Power Research Institute, "Technical Assessment Guide," June 1978. 
EPRI 1991

Electric Power Research Institute, "The Electric Smart House," EPRI Journal. June 1991 .

Eisher 1991

Diane Fisher, "Reducing Greenhouse Gas Emissions with Alternative Transportation Fuels," Environmental Defense Fund, April 1991.

Fitzgerald 1992

Daniel Fitzgerald, "Making EVs PGE's Business," presentation to the Electric Vehicle Policy and Technology Conference, Westwood Marquis Hotel, Los Angeles, California, March 5, 1992. Information on conference proceedings available from Joshua Newman and Associates, 3110 4th St, Santa Monica, CA 90405.

Ford 1991A

Andrew Ford, "The Stacker," Technical Memo usC/CIEE/1991-2, August 1991.

Ford $1991 \mathrm{~B}$

Andrew Ford, "Diurnal Electricity Demand Shapes for the Southern California Edison System," Technical Memo USC/CIEE/1991-1. March 1991.

Geinzer, Cranna and Ford 1991

Jay Geinzer, Mike Cranna and Andrew Ford, "1991 Scenario Analysis for the Pacific Northwest Electric System," Einal report to the BPA, January 1992.

Graves 1988

Phil Graves, James Murdoch, Mark Thayer and Don Waldman, "The Robustness of Hedonic Price Estimation: Urban Air Quality," hand Economics, August 1988.

Guy 1991

Jack Guy, Utility Representative, United States Advanced Battery Consortium, remarks at the California Energy Commission Workshop on Electric Vehicles, Sacramento, California, October 3, 1991.

Hadfield 1991

Peter Hadfield, "Corporate Strategies for a Changing Environment, Utilities Policy. October 1991.

Hahn and Hester 1989

R. Hahn and G. Hester, "Where Did All the Markets Go? An Analysis of EPA's Emissions Trading Program," Yale Journol on Requlation, Vol 6, Nu 1, Winter 1989 .

Hall 1989

Jane Hall, Principal Investigator, "Economic Assessment of the Health Benefits from Improvements in Air Quality in the South Coast Air Basin, "final report to the South Coast Air Quality Management District, Contract Nol 5685, June 1989 .

Hamilton 1980

W. F. Hamilton, Electric Automobiles, McGraw-Hill, New York, 1980.

Hamilton 1982

W. F. Hamilton, L. M. Morecroft, and W. M. Carriere, "Social and Environmental Impacts of Electric and Hybrid Vehicles," International Journal of Vehicle Design, Special Publication SP2, 1982.

Heirigs 1991

personal communication, Philip Heirigs, Mobile Sources Division, California Air Resources Board, December 1991.

Hempel 1989

Lamont Hempel, "Curbing Air Pollution in Southern California: The Role of Electric Vehicles," report from The Claremont Graduate School, April 1989. 
Janasik 1991

James Janasik, Project Manager, Transportation Program, Electric Power Research Institute, Remarks at the California Energy Commission Workshop on Electric Vehicles, Sacramento, California, October 3, 1991.

Kahn 1988

Edward Kahn, Electric Utility Planning \& Requlation, American Council for an Energy Efficient Economy, Washington DC, 1988 .

Kirlin 1990

John Kirlin, "Commands or Incentives to Improve Air Quality," california Policy Choices, Volume six, John Kirlin and Donald Winkler, Editors, University of Southern California, School of Public Administration, 1990

Kirshner 1991

personal communication, Dan Kirshner, Environmental Defense Fund, November 1991.

Kelly and Gunst 1990

Nelson Kelly and Richard Gunst, "Response of Ozone to Changes in Hydrocarbon and Nitrogen Oxide Concentrations in Outdoor Smog Chambers Filled with Los Angeles Air," Atmospheric Environment, Vol 24A, no 12, 1990.

Knight 1991

personal communication concerning April 1990 draft report to the CARB with Bob Knight, Bevilacqua-knight Inc, Oakland, California, August 1991.

Loomis 1987

John Loomis, "Balancing Public Trust Resources of Mono Lake and Los Angeles" Water Right: An Economic Approach," Water Resources Research, August 1987.

Mathtech 1978

Mathtech, Inc. "The Impact of Electric Passenger Automobiles on Utility System Loads, 1985-2000," Report EA-623 to the Llectric Power Research Institute, July
1978.

Meadows 1991

Donella Meadows, "Natural Resources Aren't Just Comodities," editorial in the Valley News, November 23, 1991.

Morales and Storper 1991

Rebecca Morales and Michael Storper, "Prospects for Alternative Fuel Vehicle Use and Production in Southern California," Lewis Center for Regional Policy Studies, Working Paper No. 2, May 1991, University of California at Los Angeles, 405 Hilgard Av, Los Angeles, California 90024-1467.

MVMA 1990 Motor Vehicles Manufacturers' Association, Eacts \& Eiqures '90, 7430 Second Ave,
Detroit, Michigan 48202 .

Nazemi 1991

Mike Nazemi, Planning Manager, office of Planning and Rules, South Coast Air Quality Management District, "Fuel Neutral," presentation to the California Energy Commission Workshop on Electric Vehicles, October 3, 1991.

Nesbitt 1991

Kevin Nesbitt, Kenneth Kurani, and Mark Deluchi, "Home Recharging and the Household Electric Vehicle Market: A Near-Term Constraints Analysis," submitted to the 1991 Annual Meeting of the Transportation Research Board, September 1991. 
NPTS 1986

Comsis Corp.. "Personal Travel in the U.S. 1983-1984: Nationwide Personal Transportation Study," prepared for the National Highway Traffic Safety Administration, August 1986.

OTA 1990

U.S. Congress, Office of Technology Assessment, Replacing Gasoline: Alternative Fuels for Light-Duty Vehicles, report OTA-E-364, September 1990.

Pechan 1991

E. H. Pechan A Associates. Inc "Adopting the California Low Emission Vehicle Program in the Northeast States: An Evaluation," July 1991.

Phillips 1991

personal communication with Dennis Phillips, Bonneville Power Administration, July 1991.

Puget 1989

Puget Sound Power and Iight Company, "Securing Future Opportunities 1990-1991," Demand and Resource Evaluation Project Report, December 1989.

RFE 1990

Hadi Dowlatabadi, Alan Krupnick and Armistead Russell, "Electric Vehicles and the Environment: Consequences for Emissions and Air Quality in Los Angeles and US Regions," Resources for the Future Discussion Paper QE91-01, 1991.

Santoro 1991

Sarah Santoro, Alternate Fuels Section, California Air Resources Board, Remarks at the California Energy Comission Workshop on Electric Vehicles, Sacramento, California, October 3, 1991.

Seligman 1991

Dan Seligman, "Special Report: sce on the Cusp of Change," The Electricity Journal, Vol. 4, Nu. 2, March 1991.

SCAQMD 1989

South Coast il Quality Management District and the Southern California Association of Governments, "Air Quality Management Plan," Final Report, March 1989.

SCAQMD 1991

South Coast Air Quality Management District and the Southern California Association of Governments, "1991 Air Quality Management Plan," Draft Final Report, May 1991.

SCAG 1991

Southern California Association of Governments, "Highway Electrification and Automation Regional Impacts Analysis Project,"

September 1991.

SCE 1988

Southern California Edison Company, System Planning \& Research, "Strategies for an Uncertain Future," March 1988.

SCE 1989

Southern California Edison testimony on the 1989 Draft Air Quality Management Plan, "Early Attainment Plan for Ozone: Approach and Results," January. 1989.

SCE 1990

Southern California Edison Company, "NetComm Matures as Advanced Communication and Metering System, Research Newsletter, Vol. 29, No. 4, 1990. 
SCEVC 1991

South Central Electric Vehicle Consortium, "Commercialization of Electric Vehicles in the South Central Region: Findings and Plan," February. 1991.

Sioshansi 1991

Fereidoon Sioshansi, "Electronic Metering and Two-Way Comnunications," Utilities Policy, July 1991.

Sperling 1988

Daniel Sperling, New Transportation Fuels, University of California Press, 1988.

Sperling 1990

Daniel Sperling, "An Incentive Based Transition to Alternative Transportation Fuels," Proceedings of a Conference on Energy and the Environment in the 21 st Century, Massachusetts Institute of Technology, March, 1990.

Stremel 1982

John Stremel, "Production Costing for Long-Range Generation Expansion Planning Studies," IEEE Iransactions on Power Apparatus and Systems, Vol. PAS-101, No. 3. March 1982 .

TBEA 1991

Theodore Barry Associates, "Electric Vehicles and Other Clean Fuel Alternatives - A Comparative Analysis," report prepared for the Southern California Edison Company, November 1991 .

Tellus 1990

Stephen Vernow and Donald Marron, "Valuation of Environmental Externalities for Energy Planning and Operations: May 1990 Update, " report of the Tellus Institute, Boston, Massachusetts, May 18, 1990.

Tennis 1991

Michael Tennis, "study of the Impact of Electric Battery Powered zero Emission Vehicles in the Northeast States," preliminary draft report prepared for NESCAUM, 85 Merrimac St, Boston, MA 03114, October 1991.

Turban 1988

Efraim Turban, Decision Support and Expert Systems, Macmillan Publishing Co., New York, 1988 .

Volti 1990

Rudi Volti, "Why Internal Combustion?" Invention f Technology, Vol 6, No 2, Fall, 1990.

Wack 1985

Peter Wack, "Scenarios: Uncharted Waters Ahead," Harvard Business Review, September-october 1985 .

Wang 1990

Quanlu Wang, Mark Deluchi and Daniel Sperling, "Emission Impacts of Electric Vehicles," Journal of Waste Management Association, Vol 40, No 9, September 1990.

Wang and DeLuchi 1991

Quanlu Wang and Mark Deluchi, "Comparison of Primary Energy Consumption by Gasoline Internal Combustion Engine Vehicles and Electric Vehicles," paper no. 910804 of the Transportation Research Board, 1991.

wiel 1991

Stephen Wiel, "The New Environmental Accounting: A Status Report," The Electricity Journal, November 1991. 


\section{RESEARCE NOTES}

The notes on my research are presented in 28 spread sheets. These sheets provide the detailed information needed for other researchers to verify the intermediate steps in my analysis.

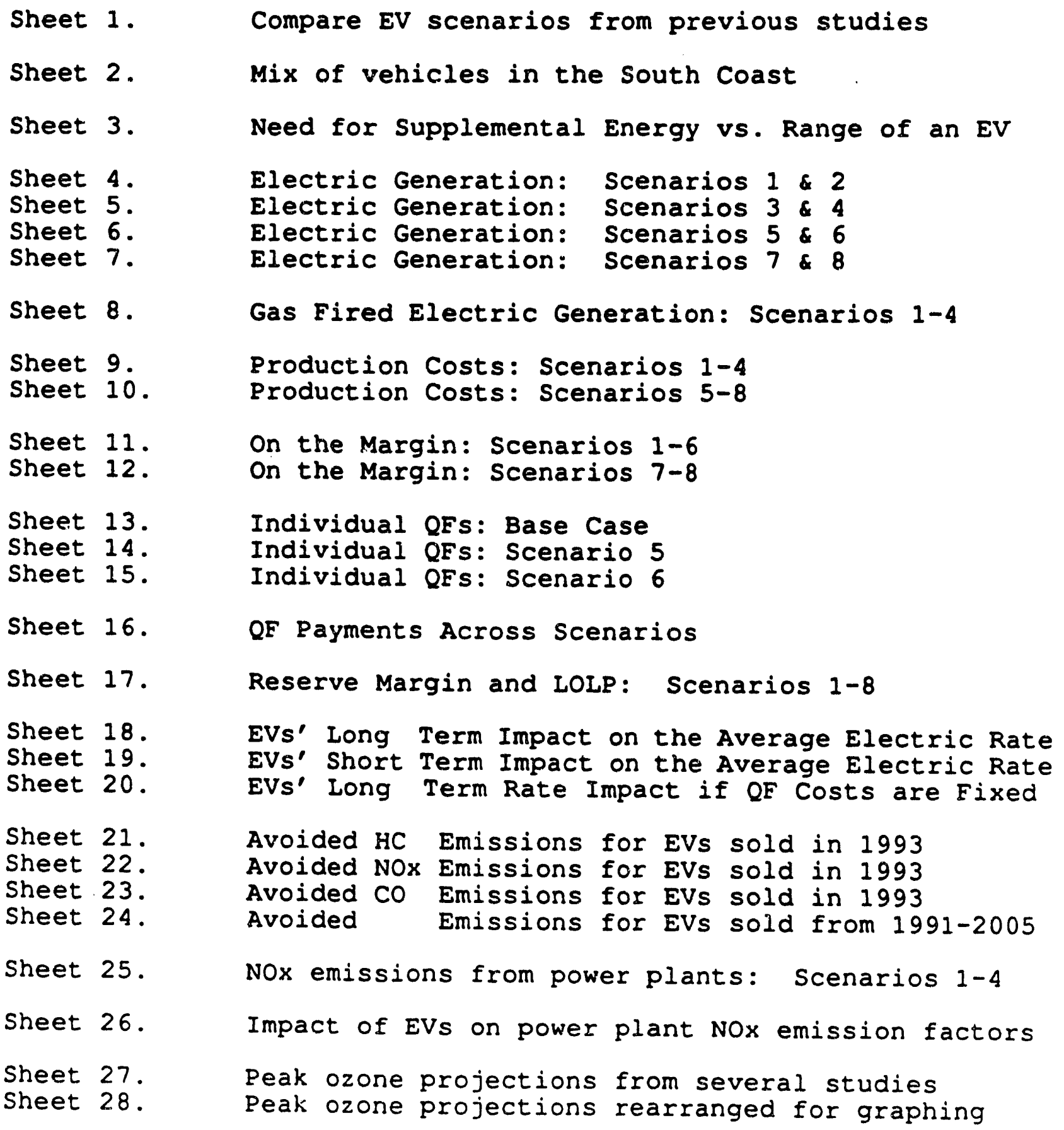


EVCOM1.WQ1: compare scenarios on EVs. Shaded entries are obtained directly (or with minor algebra) from the previous reports. Unshaded entries are calculated to fill out the comparison.

\begin{tabular}{|c|c|c|c|c|c|}
\hline $\begin{array}{l}\text { Study } \\
\text { Scenario } \\
\text { Hempel } 2010\end{array}$ & $\begin{array}{r}\text { EVs } \\
\text { (million) }\end{array}$ & $\begin{array}{l}\text { miles } \\
\text { per day }\end{array}$ & $\begin{array}{r}\text { miles } \\
\text { per kwh }\end{array}$ & $\begin{array}{r}\text { kwh } \\
\text { per day }\end{array}$ & $\begin{array}{l}\text { kwh/yr } \\
\text { (billion) }\end{array}$ \\
\hline $\begin{array}{l}\text { Breakthrough } \\
\text { Steady Advance }\end{array}$ & ? 137 & 38 & .1 .66 & $\begin{array}{l}19.9 \\
19.9\end{array}$ & $\begin{array}{l}36.8 \\
20.0\end{array}$ \\
\hline Ducat 2007 & & & & & \\
\hline $\begin{array}{l}\text { Deployment } \\
\text { CEC } 2010\end{array}$ & $\% 1 \% 10$ & 44 & 1.42 & 31.0 & 113 \\
\hline $\begin{array}{l}\text { High EV Impact } \\
\text { RFF } 2010\end{array}$ & 6.65 & 28 & 25 & 11.2 & 27.2 \\
\hline $\begin{array}{l}\text { Scenario II } \\
\text { Scenario III }\end{array}$ & 0.85 & 80 & $\frac{2114}{214}$ & $\begin{array}{l}37.4 \\
37.4\end{array}$ & $\begin{array}{l}6.82 \\
20.5\end{array}$ \\
\hline SCAQMD & & & & & \\
\hline $\begin{array}{l}\text { '89 Plan } \\
\text { '91 Revision }\end{array}$ & $\begin{array}{l}1.96 \\
1.69\end{array}$ & $\begin{array}{l}28 \\
28\end{array}$ & $=\frac{133}{23}$ & $\begin{array}{l}21.1 \\
11.2\end{array}$ & $\frac{15 \%}{69}$ \\
\hline Guide to Notes: & 1 & 2 & 3 & 4 & 5 \\
\hline
\end{tabular}

Notes on Hempel "2010" from Claremont April 1989 report.

1. 5.1 million EVs ( $p 40$ ) would be $46.5 \%$ of the vehicle fleet; and 2.8 million would be about $25 \%$ of the fleet.

2. Travel is 12,000 miles/yr (p. 57) or 33 miles/day.

3. 2 miles/kwhr with $83 \%$ efficiency (p. 57) is 1.66 miles/kwhr.

4.33 miles/day @ 1.66 miles/kwhr is $19.9 \mathrm{kwhr} /$ day.

5. 5.1 million EVs @ $19.9 \mathrm{kwhr} /$ day for 365 days is 37 billion kwhr/yr which is higher than the page 60 figure of 24.5 billion $\mathrm{kwhr} / \mathrm{yr}$. Also, the steady advance estimate of 20 billion $\mathrm{kwhr} / \mathrm{yr}$ is higher than the page 60 figure.

Notes on "Ducat 2007" from SCE March 1989 report.

1. 0.6 million EVs for SCE (p. 17) divided by $60 \%$ to get total for the basin.

2. Finding the assumed miles/day is not simple. Based on Ducat's assumed distribution of miles driven per weekday, I estimate an average of 51 miles/weekday. This estimate counts the effect of some opportunity recharging. Weekend driving is assumed to be half as much. So I would estimate that the EVs are traveling around $\mathbf{4 4}$ miles/day over the year.

3. If the EVs travel 44 miles/day and use $31 \mathrm{kwhr} / \mathrm{day}$, the miles/kwhr must be 1.42 .

4. If annual sales is 11.3 billion $\mathrm{kwhr}$, then average daily sales per $\mathrm{EV}$ is 31 .

5. The extra sales from EVs is 6.76 billion $\mathrm{kwhr} / \mathrm{yr}$ (p. 17). Divide this by $60 \%$.

Sheet $\# 1$, page 1 of 2 
Notes on CEC 2010 from Nov. 1990 "Scenarios Project" report.

1. Vol I, Part B, p. 18 lists 6.65 million EVs.

2. Vol II, Part A, p. 21 notes 10,200 miles/year as a "key assumption"

which was adopted to represent Tier I travel restrictions.

3. Vol II, Part B, p. 18 mentions a fleet average of $0.4 \mathrm{kwhr} / \mathrm{mile}$ for 2010 .

4.28 miles/day @ 2.5 miles $/ \mathrm{kwhr}$ gives $11.2 \mathrm{kwhr} /$ day.

5.6 .65 million EVs@ $11.2 \mathrm{kwhr} /$ day over 365 days gives 27.2 billion $\mathrm{kwwhr} / \mathrm{yr}$ which is slightly below the Vol I Summary report's extra load from EVs of 29.4 billion kwhr/yr in 2009 (see p. 3). The 29.4/27.2 difference is attributed to T\&D losses which add to the load to be served.

Notes on RFF 2010 from their 1990 discussion paper

1. Page xii shows 5 million and 1.5 million in Scenarios II and III.

2. Page 2-4 explains why EVs will be used so extensively.

3. Page 2-11 notes 2 miles $/ k w h r$ counting T\&D losses; I use 2.14 without losses

4.80 miles/day @ 2.14 miles/kwhr gives 37.4 kwhr/day.

5. for III, 1.5 million EVs @ 37.4 kwhr/day over 365 days gives 20.5

Notes on the SCAQMD 1989 Plan from Appendix IV-B "Energy Future", March 1989.

1. Appendix IV-B gives the number of EVs as a $\%$ of an unspecified number of vehicles. I estimate 1.96 million based on total electricity demand of 15 billion kwhr/yr (page 7-17) and each EV requiring 7,665 kwhr/year.

2. Appendix IV-B does not give the miles/day except to say that VMT is the same as the 2010 projection in the SCAG regional mobility plan. I adopted 28 miles/day based on the CEC Nov 1990 study (with the SCAQMD), vol II, Part A, p. 21.

3. the $1.33 \mathrm{miles} / \mathrm{kwhr}$ is based on $0.75 \mathrm{kwhr} / \mathrm{mile}$ (p. 4-8)

4. $21.1 \mathrm{kwhr} /$ day is 28 miles@ 1.33 miles $/ \mathrm{kwhr}$.

5. Page 7-17 gives the "rough estimate" of 15 billion kwhr/yr.

Notes on the SCAQMD 1991 Revision from their Dec. 1990 Draft Appendix IV-D

1. Page 8-2 gives the number of EVs as $20 \%$ of passenger cars and $14 \%$ of light trucks and 30 But the plan does not give the total number of these vehicles in use. If I were to adopt the vehicle in use assumptions from page E-2 of the CEC Nov. 1990 study, I estimate total EVs in use by 2010 at 1.69 million (not counting the busses).

2. The SCAQMD report does not explain the vehicle travel assumption, so I went forward with the 28 miles/day used in the CEC Nov. 1990 report.

3. Page 13-4 reports $.4 \mathrm{kwhr} / \mathrm{mile}$ or $2.5 \mathrm{miles} / \mathrm{kwhr}$.

4. $11.2 \mathrm{kwhr} /$ day is 28 miles/day @ 2.5 miles/kwhr.

5. 1.69 vehicles at $11.2 \mathrm{kwhr} / \mathrm{day}$ for 365 days is 6.91 billion $\mathrm{kwhr} / \mathrm{yr}$ which agrees with the SCAQMD reported value of electricty demand on page II-3-9.

Sheet 1 , page 2 of 2 
601

乙\# 7әәपร
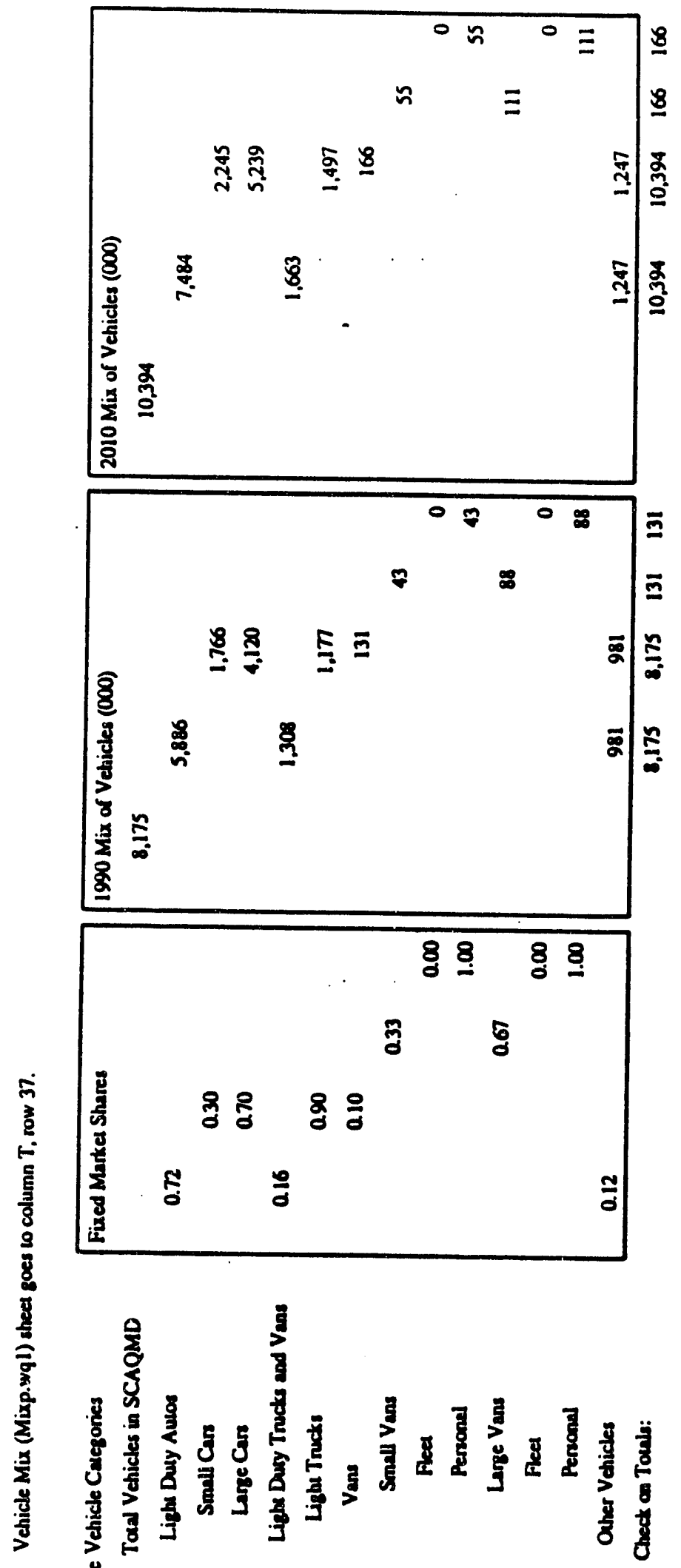

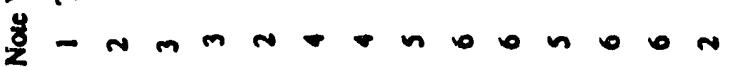

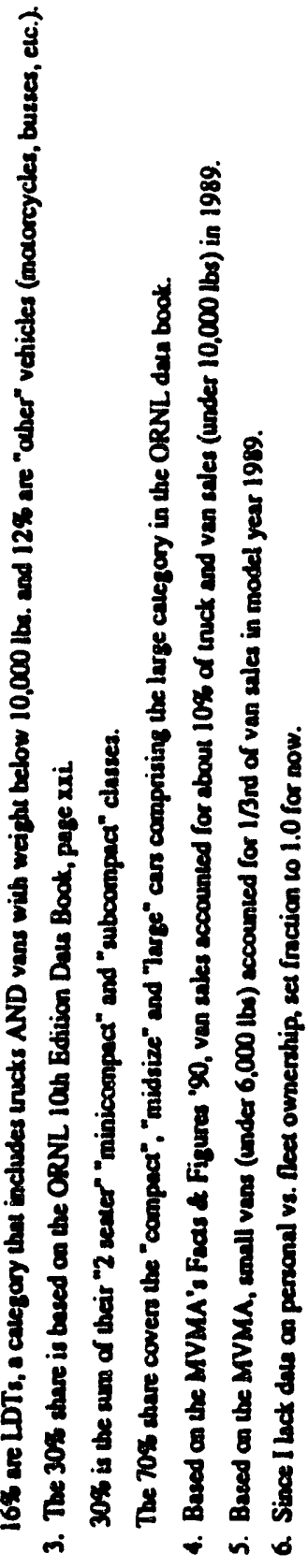




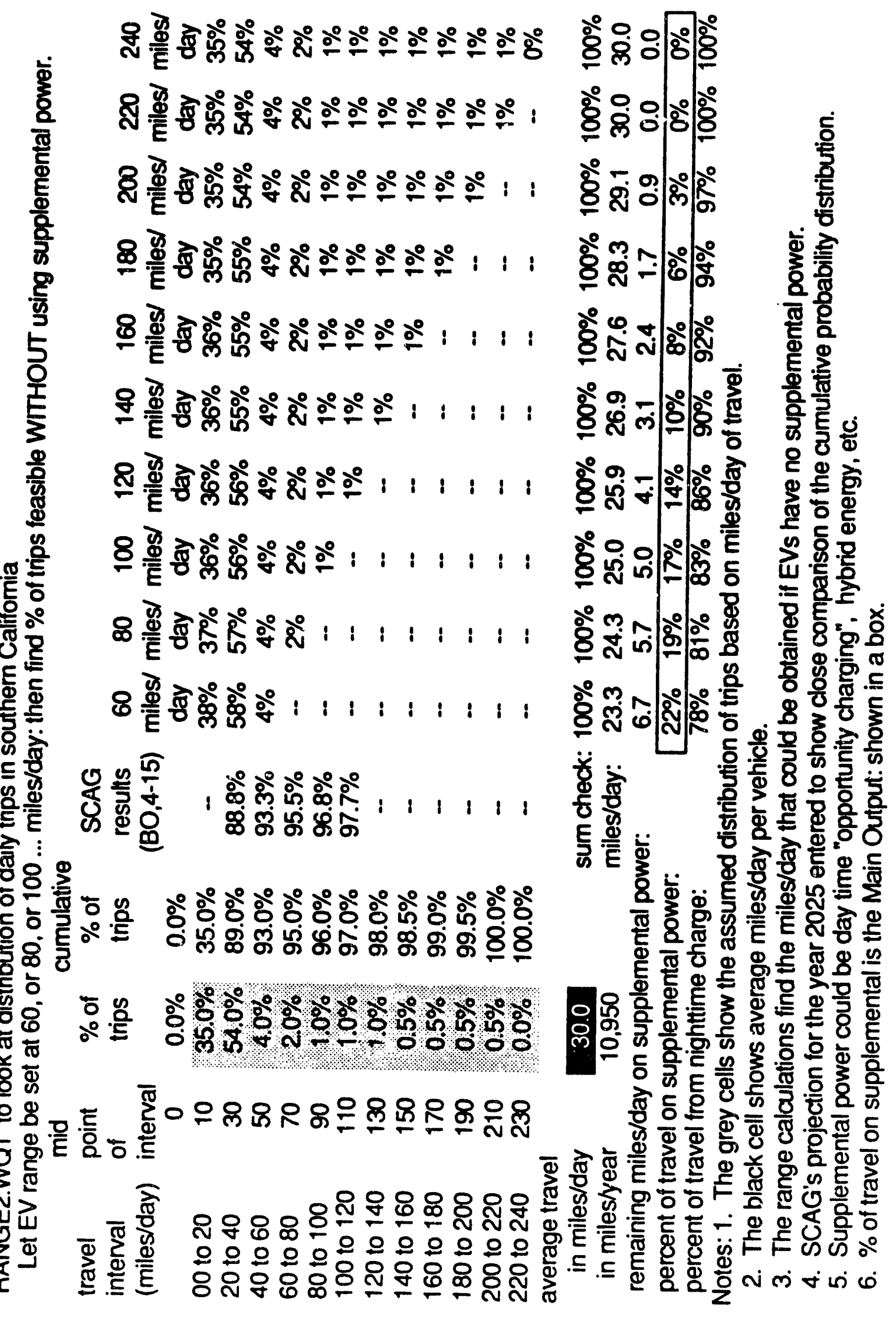

Sheet \#3 
Impact of EVs on Electric Generation in Scenarios 1-2, both of which have 2 million EVs

\begin{tabular}{|c|c|c|c|c|c|c|c|}
\hline & & $\begin{array}{l}\text { «Sscene } \\
\text { customer }\end{array}$ & $\begin{array}{l}\text { nio \# i is } \\
\text { conveni }\end{array}$ & $\begin{array}{l}\gg> \\
\text { ance }\end{array}$ & $\begin{array}{r}\ll \ll \text { Sce } \\
10 \text { pm inc }\end{array}$ & $\begin{array}{l}\text { nario \#2 >> } \\
\text { centive }\end{array}$ & $\gg \gg \gg \gg$ \\
\hline $\begin{array}{l}\text { Energy } \\
\text { (Gwhr/yr) }\end{array}$ & $\begin{array}{l}\text { Base } \\
\text { Case }\end{array}$ & $\begin{array}{l}\text { With } \\
\text { EVs }\end{array}$ & Impact & $\begin{array}{r}\text { Impact } \\
(\%)\end{array}$ & $\begin{array}{l}\text { With } \\
\text { Evs }\end{array}$ & $\begin{array}{l}\text { Impact } \\
\text { (Gwhr/yr) }\end{array}$ & $\begin{array}{r}\text { Impact } \\
(\%)\end{array}$ \\
\hline Nuclear & 14,673 & 14,673 & 0 & $0 \%$ & 14,673 & 0 & $0 \%$ \\
\hline Coal & 1,197 & 11,514 & 317 & $2 \%$ & 11,535 & 338 & $3 \%$ \\
\hline O/G Existing & 12,270 & 16,572 & 4,302 & $32 \%$ & 16,982 & 4,712 & $35 \%$ \\
\hline O/G new \& rep. & 18,585 & 26,376 & 7,791 & $58 \%$ & 25,407 & 6,822 & $51 \%$ \\
\hline QF \& Self & 46,714 & 46,763 & 49 & $0 \%$ & 46,769 & 55 & $0 \%$ \\
\hline $\begin{array}{l}\text { Hydro } \\
\text { PNW Economy }\end{array}$ & $\begin{array}{l}4,873 \\
6,102\end{array}$ & $\begin{array}{l}4,873 \\
6,569\end{array}$ & $\begin{array}{r}0 \\
467\end{array}$ & $\begin{array}{l}0 \% \\
4 \%\end{array}$ & $\begin{array}{l}4,873 \\
6,609\end{array}$ & $\begin{array}{r}0 \\
507\end{array}$ & $\begin{array}{l}0 \% \\
4 \%\end{array}$ \\
\hline PSW Economy & $\begin{array}{r}375 \\
5701\end{array}$ & 630 & 255 & $2 \%$ & 717 & 342 & $3 \%$ \\
\hline DSM Modifiers & 5,731 & $\begin{array}{r}5,753 \\
(632)\end{array}$ & 22 & $0 \%$ & 5,746 & 15 & $0 \%$ \\
\hline Other & $\begin{array}{c}(032) \\
3,986\end{array}$ & $\begin{array}{l}(632) \\
4,054\end{array}$ & 68 & $\begin{array}{l}0 \% \\
1 \%\end{array}$ & $\begin{array}{l}(632) \\
4,060\end{array}$ & $\begin{array}{r}0 \\
74\end{array}$ & $1 \%$ \\
\hline PS: down hill & $\begin{array}{r}138 \\
(230)\end{array}$ & $\begin{array}{r}73 \\
1201\end{array}$ & (65) & $-0 \%$ & 99 & (39) & $-0 \%$ \\
\hline Unserved & 0 & $\begin{array}{c}(122) \\
12\end{array}$ & 12 & $\begin{array}{l}1 \% \\
0 \%\end{array}$ & $\begin{array}{c}(166) \\
436\end{array}$ & $\begin{array}{r}64 \\
436\end{array}$ & $\begin{array}{l}0 \% \\
3 \%\end{array}$ \\
\hline EVs & 0 & $(13,332)$ & & & $(13,332)$ & & \\
\hline $\begin{array}{l}\text { Totals } \\
\text { O/G Total } \\
\text { Check on EVs: }\end{array}$ & $\begin{array}{r}123,782 \\
30,855\end{array}$ & $\begin{array}{r}123,776 \\
42,948\end{array}$ & $\begin{array}{l}13,326 \\
12,093\end{array}$ & $\begin{array}{l}100 \% \\
91 \%\end{array}$ & $\begin{array}{r}123,776 \\
42,389\end{array}$ & $\begin{array}{l}13,326 \\
11,534\end{array}$ & $\begin{array}{l}100 \% \\
87 \%\end{array}$ \\
\hline demand (GWh/d & day) & 33.816 & & & 33.816 & & \\
\hline in $\mathrm{kwh} /$ day per $\mathrm{E}$ & & 17.1 & & & 17.1 & & \\
\hline $\begin{array}{l}\text { in Gwhr/yr } \\
\text { Load in Gwhr/yr }\end{array}$ & & $\begin{array}{l}12,343 \\
13,330\end{array}$ & & & $\begin{array}{l}12,343 \\
13,330\end{array}$ & & \\
\hline
\end{tabular}


Impact of EVs on Electric Generation in Scenarios 3-4, both of which have 2 million EVs

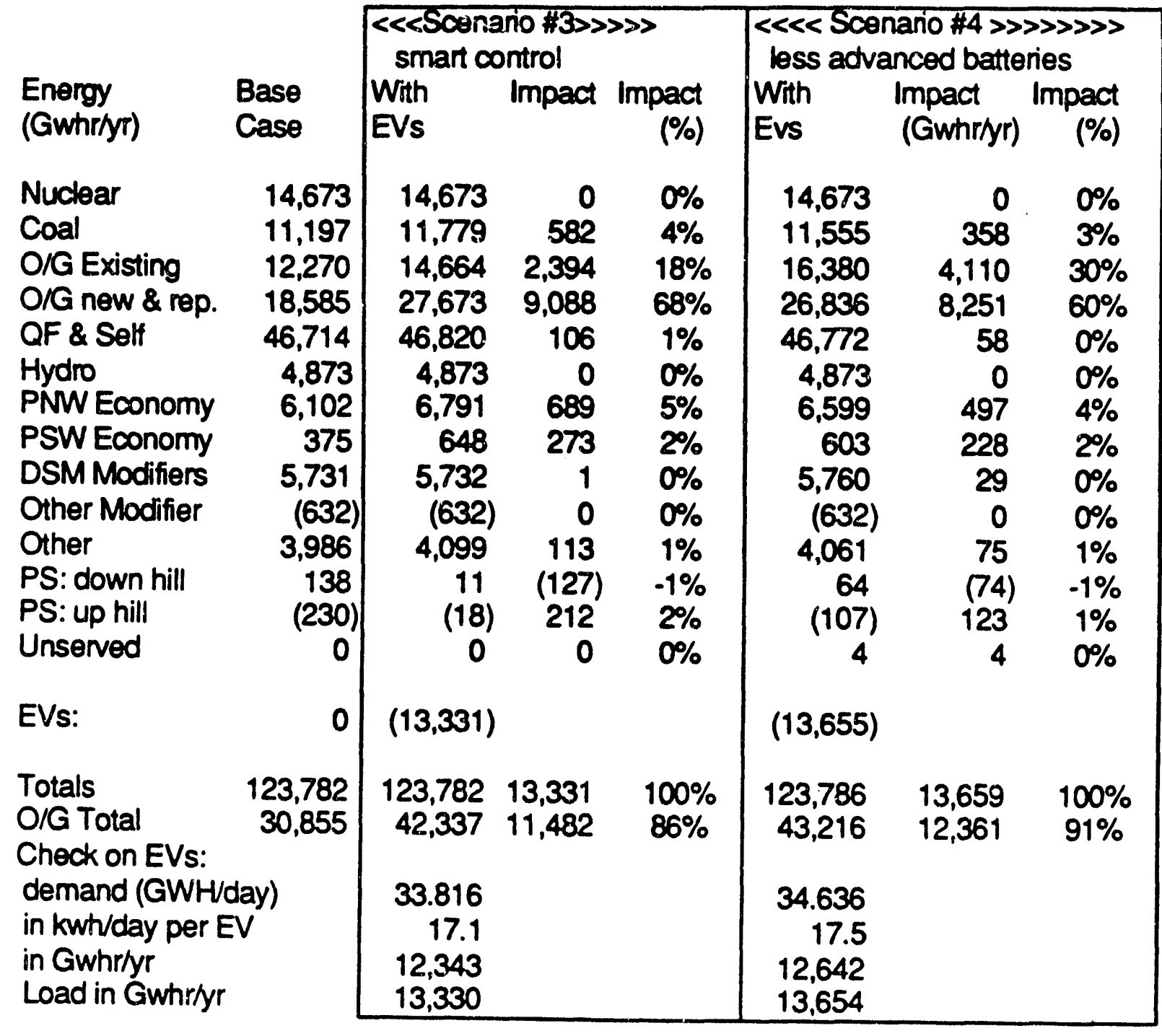

Sheet \#5 
Impact of EVs on Electric Generation in Scenarios 5-6, both of which have 1 million EVs

\begin{tabular}{|c|c|c|c|c|c|c|c|}
\hline \multirow[b]{2}{*}{$\begin{array}{l}\text { Energy } \\
\text { (Gwhrlyr) }\end{array}$} & \multirow[b]{2}{*}{$\begin{array}{l}\text { Base } \\
\text { Case }\end{array}$} & \multicolumn{3}{|c|}{ 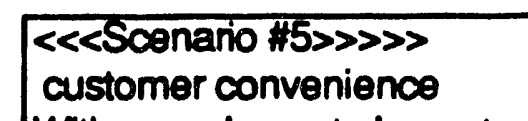 } & \multicolumn{3}{|c|}{ 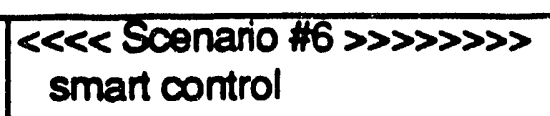 } \\
\hline & & $\begin{array}{l}\text { With } \\
\text { EVs }\end{array}$ & Impact & $\begin{array}{l}\text { Impact } \\
(\%)\end{array}$ & $\begin{array}{l}\text { With } \\
\text { Evs }\end{array}$ & $\begin{array}{l}\text { Impact } \\
\text { (Gwhr/yr) }\end{array}$ & $\begin{array}{r}\text { Impact } \\
(\%)\end{array}$ \\
\hline Nuclear & 14,673 & 14,673 & 0 & $0 \%$ & 14,673 & 0 & $0 \%$ \\
\hline Coal & 11,197 & 11,454 & 257 & $4 \%$ & 11,759 & 562 & $9 \%$ \\
\hline O/G Existing & 12,270 & 13,492 & 1,222 & $19 \%$ & 13,049 & 779 & $12 \%$ \\
\hline O/G new \& rep. & 18,585 & 22,946 & 4,361 & $68 \%$ & 22,663 & 4,078 & $63 \%$ \\
\hline QF \& Self & 46,714 & 46,754 & 40 & $1 \%$ & 46,817 & 103 & $2 \%$ \\
\hline $\begin{array}{l}\text { Hydro } \\
\text { PNW Economy }\end{array}$ & $\begin{array}{l}4,873 \\
6,102\end{array}$ & $\begin{array}{l}4,873 \\
6,449\end{array}$ & $\begin{array}{r}0 \\
347\end{array}$ & $\begin{array}{l}0 \% \\
5 \%\end{array}$ & $\begin{array}{l}4,873 \\
6,671\end{array}$ & $\begin{array}{r}0 \\
569\end{array}$ & $\begin{array}{l}0 \% \\
9 \%\end{array}$ \\
\hline PSW Economy & 375 & 483 & 108 & $2 \%$ & 523 & 148 & $2 \%$ \\
\hline $\begin{array}{l}\text { DSM Modifiers } \\
\text { Other Modifier }\end{array}$ & $\begin{array}{r}5,731 \\
(632)\end{array}$ & $\begin{array}{r}5,732 \\
(632)\end{array}$ & $\begin{array}{l}1 \\
0\end{array}$ & $\begin{array}{l}0 \% \\
0 \%\end{array}$ & $\begin{array}{r}5,731 \\
(632)\end{array}$ & $\begin{array}{l}0 \\
0\end{array}$ & $\begin{array}{l}0 \% \\
0 \%\end{array}$ \\
\hline Other & 3,986 & 4,043 & 57 & $1 \%$ & 4,095 & 109 & $2 \%$ \\
\hline PS: down hill & 138 & 83 & (55) & $-1 \%$ & 19 & (119) & $-2 \%$ \\
\hline $\begin{array}{l}\text { PS: up hill } \\
\text { Unserved }\end{array}$ & $\begin{array}{r}(230) \\
0\end{array}$ & $\begin{array}{c}(138) \\
0\end{array}$ & $\begin{array}{r}92 \\
0\end{array}$ & $\begin{array}{l}1 \% \\
0 \%\end{array}$ & $\begin{array}{c}(32) \\
0\end{array}$ & $\begin{array}{r}198 \\
0\end{array}$ & $\begin{array}{l}3 \% \\
0 \%\end{array}$ \\
\hline EVs: & 0 & $(6,434)$ & & & $(6,435)$ & & \\
\hline $\begin{array}{l}\text { Totals } \\
\text { O/G Total } \\
\text { Check on EVs: }\end{array}$ & $\begin{array}{r}123,782 \\
30,855\end{array}$ & $\begin{array}{r}123,778 \\
36,438\end{array}$ & $\begin{array}{l}6,430 \\
5,583\end{array}$ & $\begin{array}{l}100 \% \\
87 \%\end{array}$ & $\begin{array}{r}123,774 \\
35,712\end{array}$ & $\begin{array}{l}6,427 \\
4,857\end{array}$ & $\begin{array}{l}100 \% \\
75 \%\end{array}$ \\
\hline $\begin{array}{l}\text { demand (Gwhr/k } \\
\text { in kwh/day per } \\
\text { in Gwhr/yr } \\
\text { Load in Gwhr/yr }\end{array}$ & & $\begin{array}{r}16.319 \\
16.2 \\
5,956 \\
6,433\end{array}$ & & & $\begin{array}{r}16.319 \\
16.2 \\
5,956 \\
6,433\end{array}$ & & \\
\hline
\end{tabular}




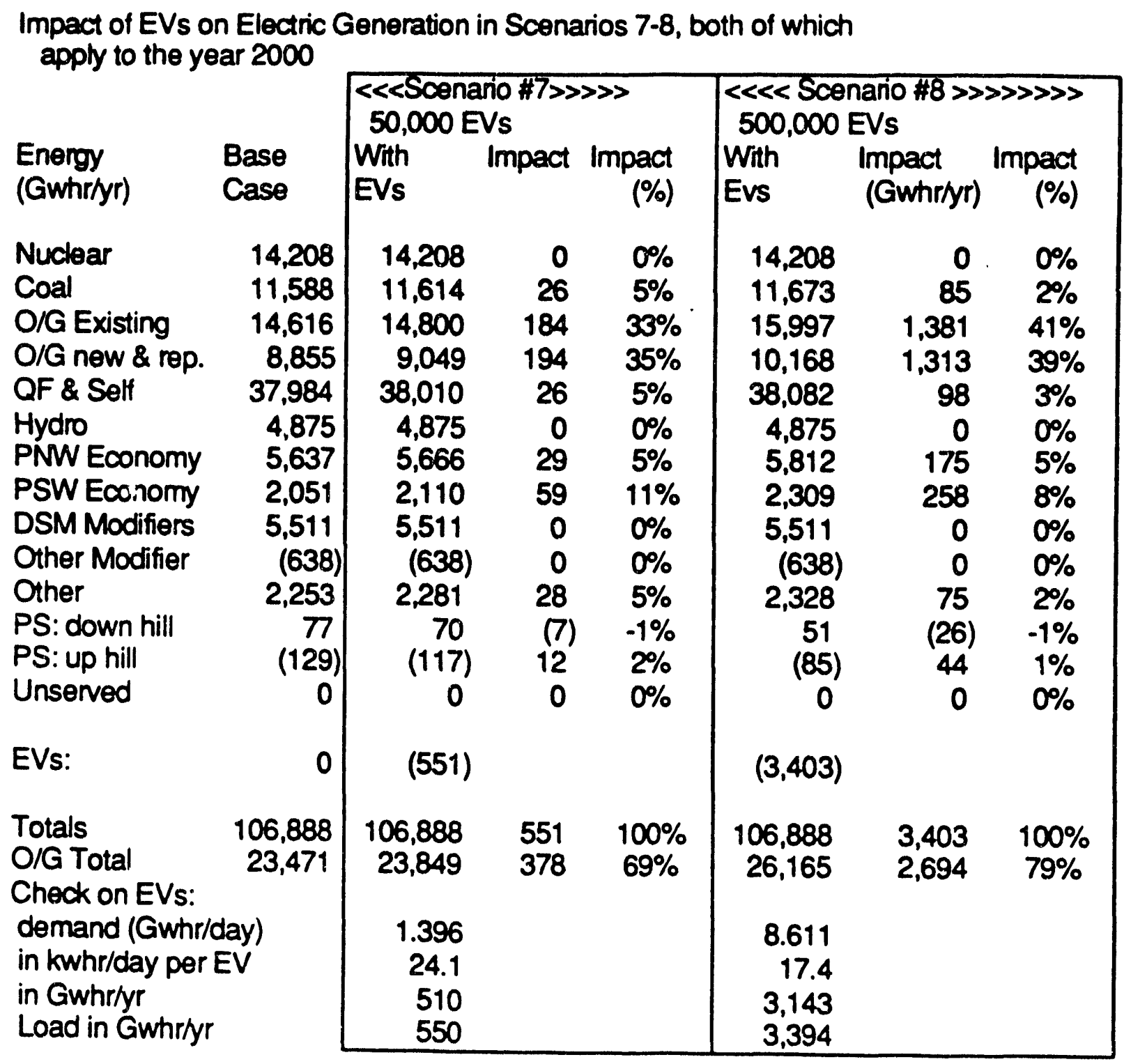


Natural Gas Fired Electric Generation in Scenarios 1-4

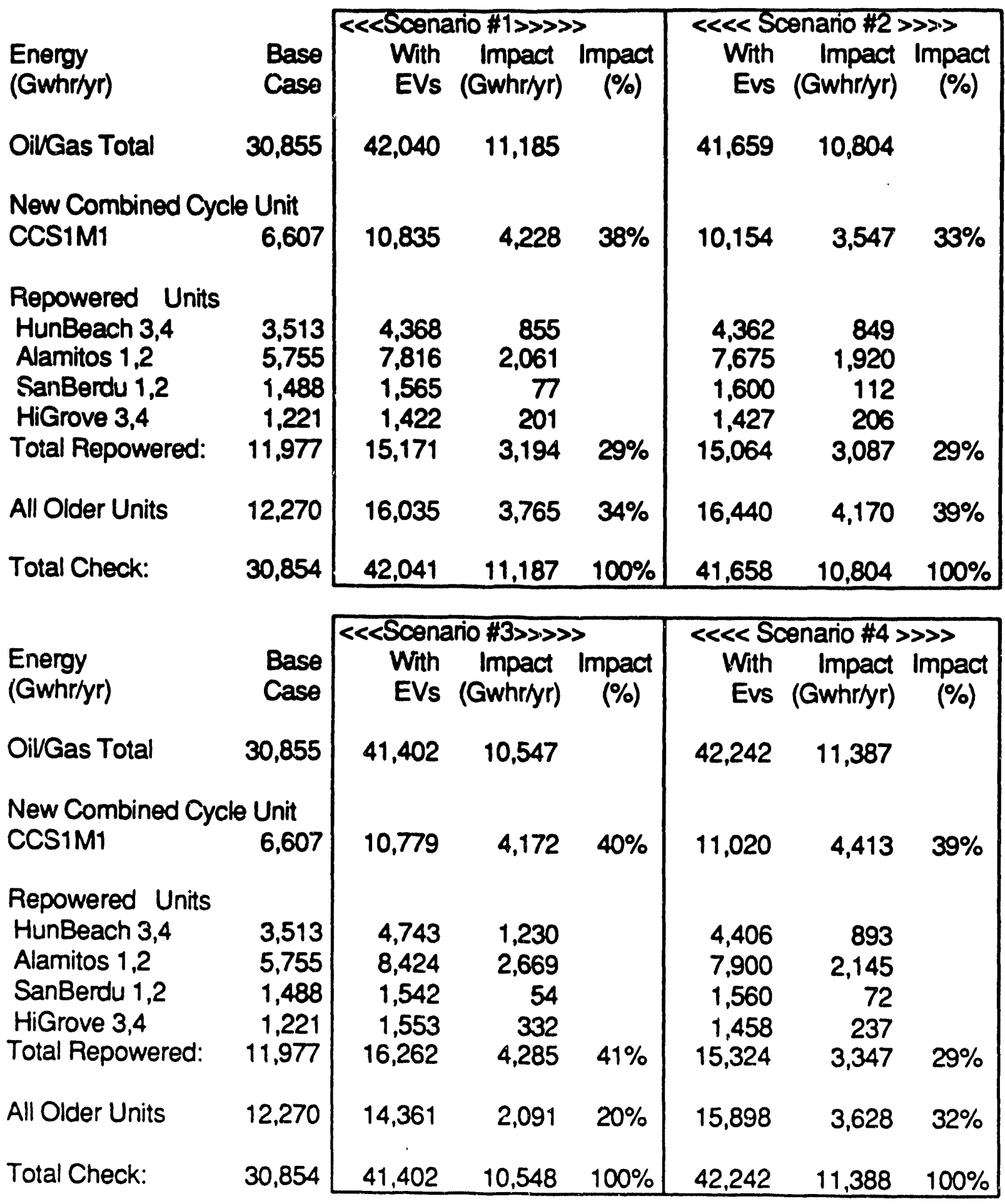


Impact of EVs on Production Costs in Scenarios 1-4, each of which has 2 million EVs

Production

Costs

(\$MYr)

Nuclear

Coal

O/G Existing

O/G new \& rep.

QF\&Self

Hydro

PNW Economy

PSW Economy

DSM Modifiers

Other Modifiers

Other

Pumped Stor.

Totals

Impact Check:

O/G Totals

\begin{tabular}{|c|c|c|c|c|c|c|}
\hline \multirow[b]{2}{*}{$\begin{array}{l}\text { Base } \\
\text { Case }\end{array}$} & \multicolumn{3}{|c|}{ 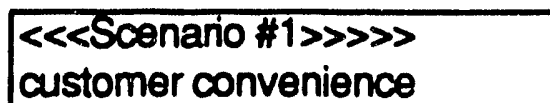 } & \multicolumn{3}{|c|}{$\begin{array}{l}\text { 《<< Scenario \#2 } \gg \gg \gg \gg \gg>> \\
\text { 10pm incentive }\end{array}$} \\
\hline & $\begin{array}{l}\text { With } \\
\text { EVs }\end{array}$ & $\begin{array}{l}\text { Impact } \\
\text { (\$MYyr) }\end{array}$ & $\begin{array}{l}\text { Impact } \\
(\%)\end{array}$ & $\begin{array}{l}\text { With } \\
\text { EVs }\end{array}$ & $\begin{array}{l}\text { Impact } \\
\text { (\$MYr) }\end{array}$ & $\begin{array}{r}\text { Impact } \\
(\%)\end{array}$ \\
\hline $\begin{array}{l}173 \\
433\end{array}$ & $\begin{array}{l}173 \\
445\end{array}$ & $\begin{array}{r}0 \\
12\end{array}$ & $\begin{array}{l}0 \% \\
1 \%\end{array}$ & $\begin{array}{l}173 \\
445\end{array}$ & $\begin{array}{r}0 \\
12\end{array}$ & $\begin{array}{l}0 \% \\
1 \%\end{array}$ \\
\hline 2,006 & 2,587 & 581 & $31 \%$ & 2,652 & 646 & $33 \%$ \\
\hline 2,226 & 3,132 & 906 & $48 \%$ & 3,018 & 792 & $40 \%$ \\
\hline 3,249 & 3,586 & 337 & $18 \%$ & 3,697 & 448 & $23 \%$ \\
\hline 0 & 0 & 0 & $0 \%$ & 0 & 0 & $0 \%$ \\
\hline 394 & 424 & 30 & $2 \%$ & 426 & 32 & $2 \%$ \\
\hline 26 & 50 & 24 & $1 \%$ & 61 & 35 & $2 \%$ \\
\hline 0 & 0 & 0 & $0 \%$ & 0 & 0 & $0 \%$ \\
\hline 11 & 11 & 0 & $0 \%$ & 11 & 0 & $0 \%$ \\
\hline 90 & 93 & 3 & $0 \%$ & 94 & 4 & $0 \%$ \\
\hline 0 & 0 & 0 & $0 \%$ & 0 & 0 & $0 \%$ \\
\hline 8,608 & 10,501 & 1,893 & 100 & 10,577 & & \\
\hline & & & & & & $100 \%$ \\
\hline & 5,719 & 1,487 & $79 \%$ & 5.670 & 1.438 & $73 \%$ \\
\hline
\end{tabular}

Production

Costs

(\$MYr)

Nuclear

Coal

O/G Existing

$O / G$ new \& rep.

QF\&Self

Hydro

PNW Economy

PSW Economy

DSM Modifiers

Other Modifiers

Other

Pumped Storag

Totals

Impact Check:

O/G Totals

\begin{tabular}{|c|c|c|c|c|c|c|}
\hline \multirow[b]{2}{*}{$\begin{array}{l}\text { Base } \\
\text { Case }\end{array}$} & \multicolumn{3}{|c|}{ 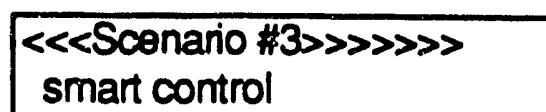 } & \multicolumn{3}{|c|}{$\begin{array}{l}\text { l<<< Scenario \#4 } \text { less advanced batteries } \\
\text { less }\end{array}$} \\
\hline & $\begin{array}{l}\text { With } \\
\text { EVs }\end{array}$ & $\begin{array}{l}\text { Impact } \\
\text { (\$MYyr) }\end{array}$ & $\begin{array}{l}\text { Impact } \\
(\%)\end{array}$ & $\begin{array}{l}\text { With } \\
\text { EVs }\end{array}$ & $\begin{array}{l}\text { Impact } \\
\text { (\$MYr) }\end{array}$ & $\begin{array}{r}\text { Impact } \\
(\%)\end{array}$ \\
\hline 173 & 173 & 0 & $0 \%$ & 173 & 0 & $0 \%$ \\
\hline 433 & 455 & 22 & $1 \%$ & 446 & 13 & $1 \%$ \\
\hline $\begin{array}{l}2,006 \\
2,226\end{array}$ & $\begin{array}{l}2,303 \\
3,282\end{array}$ & $\begin{array}{r}297 \\
1,056\end{array}$ & $\begin{array}{l}16 \% \\
58 \%\end{array}$ & $\begin{array}{l}2,561 \\
3,186\end{array}$ & $\begin{array}{l}555 \\
960\end{array}$ & $\begin{array}{l}29 \% \\
50 \%\end{array}$ \\
\hline 3,249 & 3,627 & 378 & $21 \%$ & 3,596 & 347 & $18 \%$ \\
\hline 0 & 0 & 0 & $0 \%$ & 0 & 0 & $0 \%$ \\
\hline 394 & 438 & 44 & $2 \%$ & 426 & 32 & $2 \%$ \\
\hline 26 & 50 & 24 & $1 \%$ & 47 & 21 & $1 \%$ \\
\hline 0 & 0 & 0 & $0 \%$ & 0 & 0 & $0 \%$ \\
\hline 11 & 11 & 0 & $0 \%$ & 11 & 0 & $0 \%$ \\
\hline 90 & 95 & 5 & $0 \%$ & 94 & 4 & $0 \%$ \\
\hline 0 & 0 & 0 & $0 \%$ & 0 & 0 & $0 \%$ \\
\hline 8,608 & 10,434 & 1,826 & $100 \%$ & 10,540 & 1,932 & $100 \%$ \\
\hline & & 1,826 & $100 \%$ & & 1,932 & $100 \%$ \\
\hline 4,232 & 5,585 & 1,353 & $74 \%$ & 5,747 & 1,515 & $78 \%$ \\
\hline
\end{tabular}

Sheet \#9 
Impact of EVs on Annual Production Costs, Scenarios 5-8

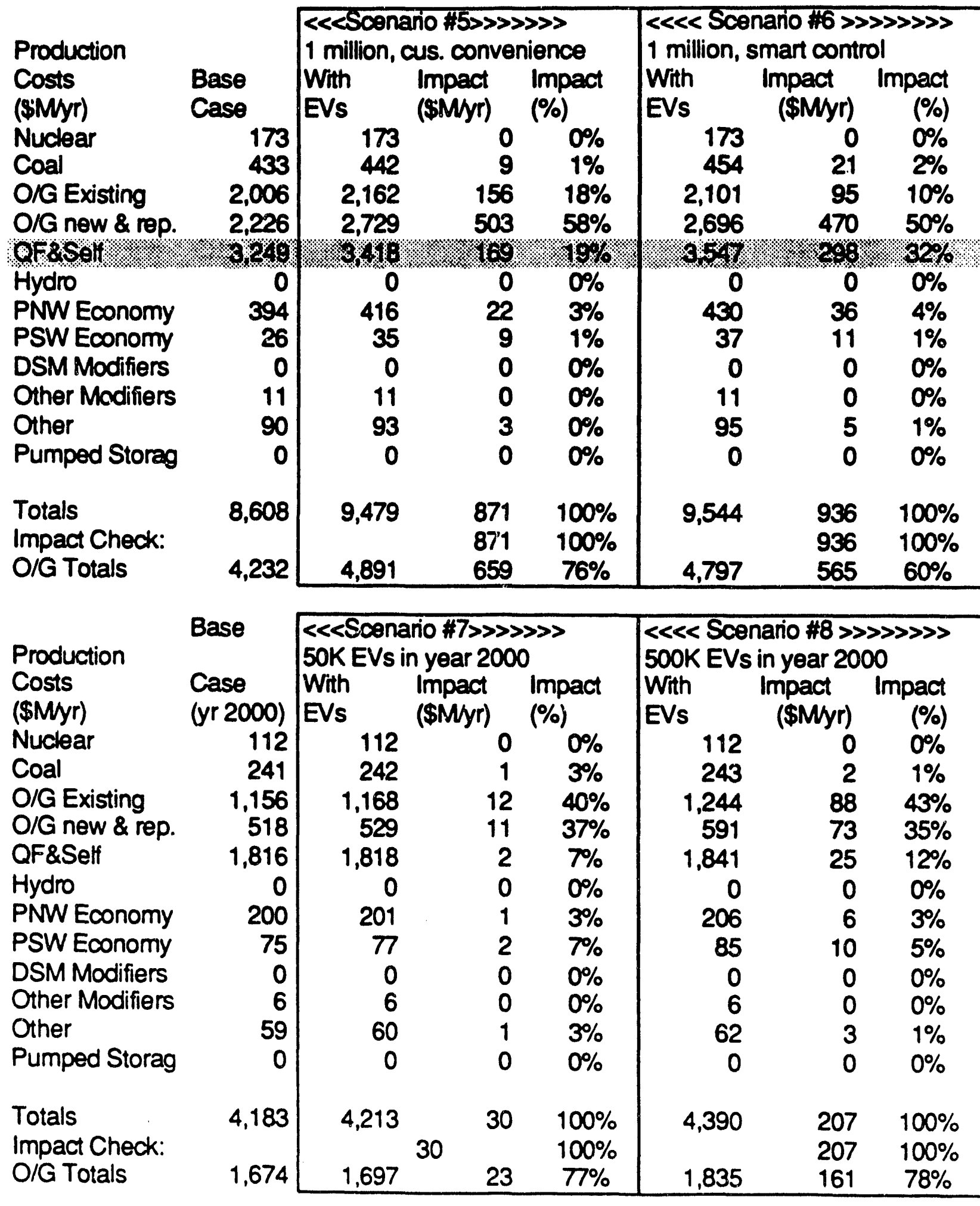

Sheet \#10 
Information on the Margin: Scenarios 1-6, all apply to the long term

\begin{tabular}{|c|c|c|c|c|c|c|c|}
\hline $\begin{array}{l}\text { MARGINAL COST in } \\
\text { mills/kwhr, nominal }\end{array}$ & $\begin{array}{r}\text { Base } \\
\text { Case } \\
\text { noEVs }\end{array}$ & $\begin{array}{r}\text { Scenario } \\
\# 1 \\
\ll \ll \ll<\text { two }\end{array}$ & $\begin{array}{r}\text { Sconario } \\
\# 2 \\
\text { million EVs }\end{array}$ & 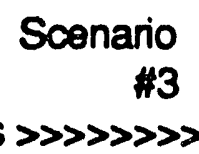 & $\begin{array}{r}\text { Scenario } \\
\# 4 \\
\# \gg \gg \gg \gg\end{array}$ & $\begin{array}{r}\text { Scenario } \\
\text { \#5 } \\
\text { <cone mill }\end{array}$ & $\begin{array}{r}\text { Scenario } \\
\# 6 \\
\text { \|lion EV } \\
\end{array}$ \\
\hline Nuclear & 0.0 & 0.0 & 0.0 & 0.0 & 0.0 & 0.0 & 0.0 \\
\hline $\begin{array}{l}\text { Coal } \\
\text { OivGas Existing }\end{array}$ & $\begin{array}{r}37.9 \\
1008\end{array}$ & $\begin{array}{r}37.9 \\
1076\end{array}$ & $\begin{array}{r}37.9 \\
108.3\end{array}$ & $\begin{array}{r}38.4 \\
100.3\end{array}$ & $\begin{array}{r}37.9 \\
1059\end{array}$ & $\begin{array}{r}37.9 \\
104 ?\end{array}$ & $\begin{array}{r}38.4 \\
102.9\end{array}$ \\
\hline OivGas new \& repower & 97.9 & 99.6 & 99.1 & 99.0 & 99.8 & 99.2 & 98.4 \\
\hline QF \& Self Generation & 62.3 & 82.3 & 80.4 & 97.1 & 86.1 & 73.6 & 93.6 \\
\hline Hyd & 96.8 & 105.5 & 102.9 & 102.4 & 105.8 & 97.8 & 98.6 \\
\hline PNW economy & 89.4 & 99.9 & 98.7 & 98.4 & 100.0 & 93.7 & 96.1 \\
\hline PSW economy & 72.8 & 90.2 & 98.1 & 96.8 & 88.6 & 80.2 & 78.5 \\
\hline DSM Programs & 443.9 & & 443.9 & 443.9 & 443.9 & 443.9 & 443.9 \\
\hline Other Modifiers & 0.0 & 0.0 & 0.0 & 0.0 & 0.0 & 0.0 & 0.0 \\
\hline Other & 89.9 & 100.5 & 98.3 & 101.5 & 101.9 & 93.5 & 96.8 \\
\hline Sumped Storage & 95.9 & 111.1 & 132.4 & 109.3 & 108.9 & 103.5 & 104.8 \\
\hline (pump & 58.8 & 67.4 & 83.4 & 66 & 66.7 & 62.2 & 62.8 \\
\hline Average Marginal cost. & 862 & $\% 979$ & $97 / 3$. & 99.6 & 984 & 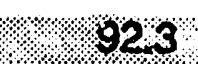 & 96.8 \\
\hline PERCENT OF TIME & Base & Sconario & Sconario & Scenario & Sconario & Scenario & Scenario \\
\hline MARGIN: & Case & $\# 1$ & $\# 2$ & $\# 3$ & & $\# 5$ & \#6 \\
\hline Nuclear & 0.0 & 0.0 & 0.0 & 0.0 & 0.0 & 0.0 & 0.0 \\
\hline $\operatorname{Cos}$ & 8.0 & 3.8 & 3.5 & 0.6 & 3.4 & 4.6 & 1.0 \\
\hline Oive & 8.9 & 20.3 & 19.0 & 13.5 & 18.2 & 11.2 & 10.2 \\
\hline repower & 25.8 & 30.5 & 28.6 & 28.4 & 30.4 & 30.3 & 29.0 \\
\hline seli Generation & 9.6 & 7.1 & 7.2 & 8.7 & 7.2 & 8.4 & 8.5 \\
\hline 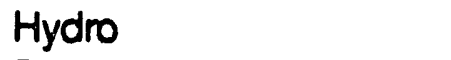 & 9.7 & 9.0 & 7.8 & 11.5 & 10.0 & 10.8 & 11.0 \\
\hline PNW econ & 22.9 & 16.9 & 17.8 & 24.6 & 18.0 & 20.5 & 28.0 \\
\hline & 1.2 & 1.3 & 1.5 & 0.8 & & 1.0 & 0.5 \\
\hline & 0.0 & 0.0 & 0.0 & 0.0 & 0.0 & 0.0 & 0.0 \\
\hline Other Modifiers & 0.0 & 0.0 & 0.0 & 0.0 & 0.0 & 0.0 & 0.0 \\
\hline Other & 10.9 & 8.9 & 8.5 & 11.4 & 9.7 & 11.2 & 11.0 \\
\hline Pumped Storage & 1.2 & 0.7 & 0.5 & 0.2 & 0.7 & 0.8 & 0.3 \\
\hline & 1.8 & 1.2 & 2.0 & 0.3 & 1.1 & 1.2 & 0.5 \\
\hline Sum Check: & 100.0 & 99.7 & 96.4 & 100.0 & 99.9 & 100.0 & 100.0 \\
\hline
\end{tabular}


Information on the Margin: Scenarios 7-8, both of which apply to the year 2000

$\begin{array}{lrrr}\text { MARGINAL COST in } & \begin{array}{r}\text { Base } \\ \text { mills/kwhr, nominal }\end{array} & \begin{array}{r}\text { Scenario } \\ \text { Case }\end{array} & \begin{array}{r}\text { Sconario } \\ \text { no EVs }\end{array} \\ & 50 K \text { EVs } & \text { 500K EVs } \\ \text { Nuclear } & 0.0 & 0.0 & 0.0 \\ \text { Coal } & 20.8 & 20.8 & 20.8 \\ \text { OiVGas Existing } & 47.5 & 47.6 & 47.9 \\ \text { OiVGas new \& repowered } & 43.7 & 43.8 & 44.2 \\ \text { QF \& Self Generation } & 41.2 & 41.3 & 42.5 \\ \text { Hydro } & 45.4 & 45.0 & 45.8 \\ \text { PNW economy } & 43.0 & 42.6 & 42.4 \\ \text { PSW economy } & 38.2 & 38.4 & 39.4 \\ \text { DSM Programs } & 202.0 & 202.0 & 202.0 \\ \text { Other Modifiers } & 0.0 & 0.0 & 0.0 \\ \text { Other } & 43.9 & 43.6 & 44.6 \\ \text { Pumped Storage } & 44.2 & 45.0 & 47.0 \\ \text { (pumping) } & 27.1 & 27.4 & 28.9\end{array}$

Averago Meinghroest:

\section{PERCENT OF TIME}

ON THE MARGIN:

Nuclear

Coal

OivGas existing

OivGas new \& repowered

QF \& Self Generation

Hydro

PNW economy

PSW economy

DSA programs

Other Modifiers

Other

Pumped Storage

(pumping)

Sum Check:
425

Base

Case

0.0

5.4

16.8

14.7

8.6

11.8

23.6

4.8

0.0

0.0

12.0

1.0

1.4

100.0
425

435

$\begin{array}{rr}\text { Scenario } & \text { Scenario } \\ \# 7 & \# 8 \\ 0.0 & 0.0 \\ 4.9 & 3.6 \\ 17.4 & 20.6 \\ 15.0 & 13.9 \\ 8.5 & 8.5 \\ 11.8 & 12.5 \\ 23.5 & 22.9 \\ 4.7 & 4.0 \\ 0.0 & 0.0 \\ 0.0 & 0.0 \\ 12.1 & 12.4 \\ 1.0 & 0.8 \\ 1.3 & 1.0 \\ 100.0 & 100.0\end{array}$


Closer look at the Qualitying Facilities (QFs). ELFIN base case results for the year 2009 are sorted by size of the sale

\begin{tabular}{|c|c|c|c|c|c|c|c|}
\hline QF BY NAME & $\begin{array}{l}\text { MC? } 1 \\
\text { is yes }\end{array}$ & $\begin{array}{l}\text { Cost } \\
\text { (\$M) }\end{array}$ & $\begin{array}{l}\text { Cost if } \\
M C\end{array}$ & $\begin{array}{c}\text { Cost if } \\
\text { fixed }\end{array}$ & $\begin{array}{l}\text { Energy } \\
\text { (Gwhr) }\end{array}$ & $\begin{array}{l}\text { Energy } \\
\text { if } M C\end{array}$ & $\begin{array}{l}\text { mills/ } \\
\text { kwh }\end{array}$ \\
\hline CGNVCP & 1 & 1,406 & 1,406 & 0 & 16,311 & 16,311 & 86.2 \\
\hline $\begin{array}{l}\text { GEOVCP } \\
\text { WHAYLE }\end{array}$ & $\begin{array}{l}1 \\
1\end{array}$ & $\begin{array}{l}481 \\
185\end{array}$ & 481 & 0 & 5,587 & 5,587 & 86.1 \\
\hline BIOVCP & 1 & $\begin{array}{l}185 \\
147\end{array}$ & $\begin{array}{l}185 \\
147\end{array}$ & $\begin{array}{l}0 \\
0\end{array}$ & $\begin{array}{l}2,081 \\
1,730\end{array}$ & $\begin{array}{l}2,081 . \\
1,730\end{array}$ & $\begin{array}{l}88.9 \\
85.0\end{array}$ \\
\hline SOLVCP & 1 & 109 & 109 & 0 & 1,202 & 1,202 & 90.7 \\
\hline GEOACN & 1 & 57 & 57 & 0 & 652 & 652 & 87.4 \\
\hline WNDVCP & 1 & 48 & 48 & 0 & 578 & 578 & 83.0 \\
\hline HYDVCP & 1 & 16 & 16 & 0 & 190 & 190 & 84.2 \\
\hline GEOTCM & 0 & 723 & 0 & 723 & 12,993 & 0 & 55.6 \\
\hline CGNHCP & 0 & 58 & 0 & 58 & 400 & 0 & 145.0 \\
\hline SOLFCP & 0 & 9 & 0 & 9 & 77 & 0 & 116.9 \\
\hline WNDFCP & 0 & 0 & 0 & 0 & 65 & 0 & 0.0 \\
\hline GEOFCP & 0 & 7 & 0 & 7 & 55 & 0 & 127.3 \\
\hline CGNFCP & 0 & 1 & 0 & 1 & 8 & 0 & 125.0 \\
\hline BIOFCP & 0 & 1 & 0 & 1 & 6 & 0 & 166.7 \\
\hline \multicolumn{2}{|c|}{$\begin{array}{l}\text { COGEN SELF GEN } \\
\text { BIO SELF GEN } \\
\text { BIO SELF GEN } \\
\text { ARGUS SELF GEN }\end{array}$} & $\begin{array}{l}0 \\
0 \\
0 \\
0\end{array}$ & & & $\begin{array}{r}3,986 \\
667 \\
71 \\
54\end{array}$ & & \\
\hline \multicolumn{2}{|c|}{$\begin{array}{l}\text { TOTAL via @sum } \\
\text { TOTAL from ELFIN's } \\
\text { summary printout }\end{array}$} & $\begin{array}{l}3,248 \\
3,249\end{array}$ & 2,449 & 799 & $\begin{array}{l}46,713 \\
46,714\end{array}$ & 28,331 & \\
\hline \multicolumn{2}{|c|}{$\begin{array}{l}\text { mills/kwh } \\
\text { average mar. cost } \\
\text { from ELFIN summan }\end{array}$} & 69.5 & $\begin{array}{l}86.4 \\
86.2\end{array}$ & & & & \\
\hline
\end{tabular}


Closer look at the Qualifying Facilities in EV Scenario \#5 with one million EVs and night time charging at customers' convenience.

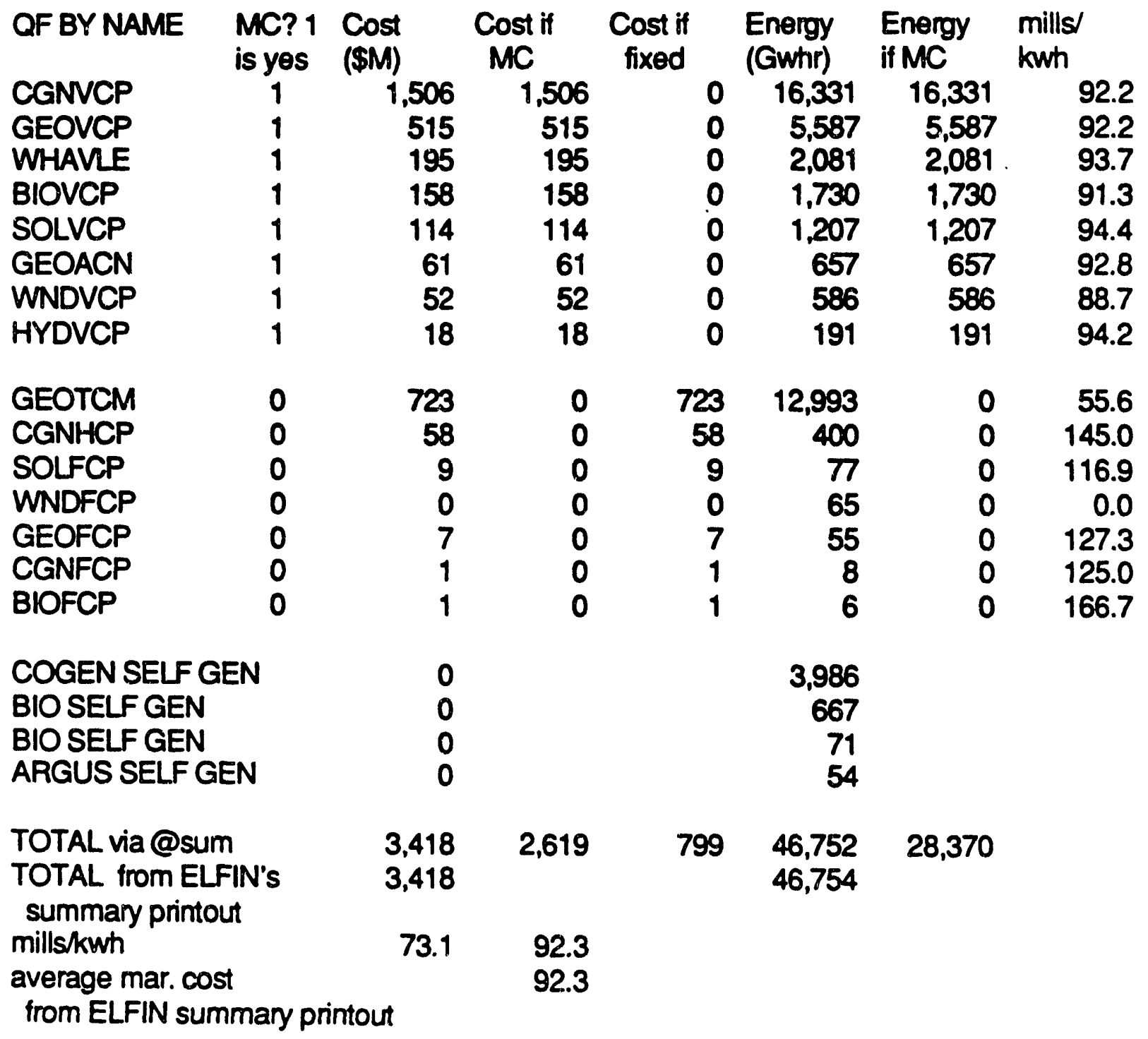


Closer look at the Qualifying Facilities in EV Scenario \#6 with one million EVs and night time charging subject to "smart control"

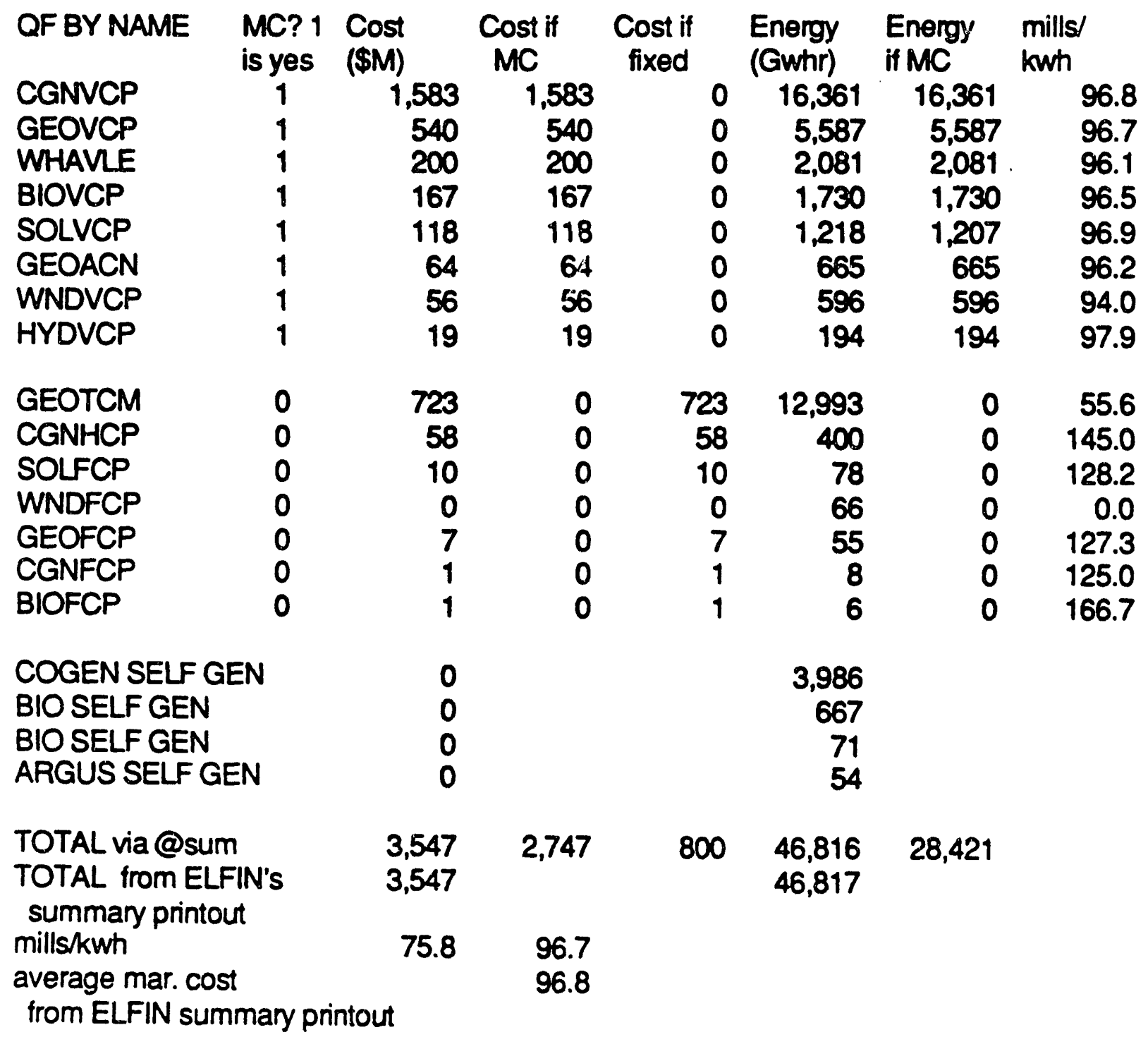


Information on QFs in the base case and in Scenarios 1-6

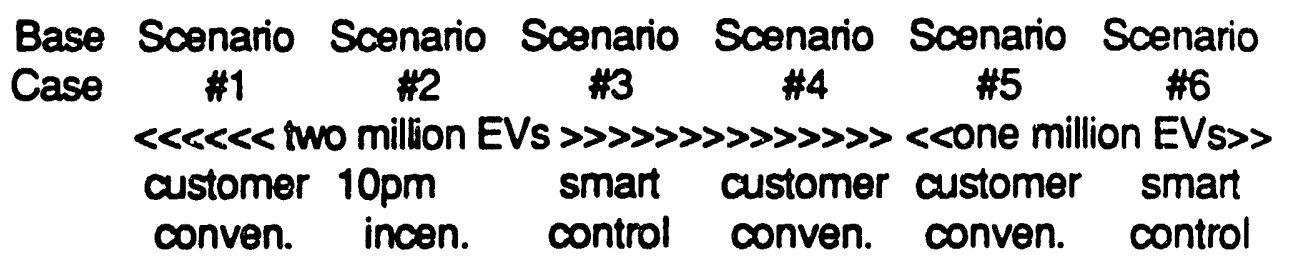

Case \#1 \#2 \#3 \#4 \#5 \#6

$\begin{array}{lrrrrrrr}\begin{array}{l}\text { Energy from QFs \& Self } \\ \text { Generators (GWhyr) }\end{array} & 46,714 & 46,763 & 46,769 & 46,820 & 46,772 & 46,754 & 46,817 \\ \begin{array}{l}\text { Annual Payments } \\ \text { to QFs (million) }\end{array} & \$ 3,249 & \$ 3,586 & \$ 3,697 & \$ 3,627 & \$ 3,596 & \$ 3,418 & \$ 3,547 \\ \begin{array}{l}\text { Unit Cost to SCE } \\ \text { (mills/kwhr) }\end{array} & 69.6 & 76.7 & 79.0 & 77.5 & 76.9 & 73.1 & 75.8 \\ \begin{array}{l}\text { Impact of EVs on unit cost: } \\ \begin{array}{l}\text { Annual Payments if no } \\ \text { change in unit cost: }\end{array}\end{array} \quad \$ 3,249 & \$ 3,252 & \$ 3,253 & \$ 3,256 & \$ 3,253 & \$ 3,252 & \$ 3,256 \\ \begin{array}{l}\text { Reduction in Annual } \\ \text { Payments in Sensitivity Test }\end{array} & \$ 334 & \$ 444 & \$ 371 & \$ 343 & \$ 166 & \$ 291 \\ \end{array}$






Sheet \#17 
AERlong.WQ1 Average Electric Rate Impacts in the Year 2009.

Consider scenarios 3, 5, and 6 which can be senved with LOLP under .05 days/year All $\$$ and mills are nominal in the year 2009 , the year of the study.

\begin{tabular}{|c|c|c|c|c|c|c|c|}
\hline \multirow[b]{2}{*}{$\begin{array}{l}\text { 1. ELFIN Projection of Annual } \\
\text { Costs for Fuel and Purchases } \\
\text { (million \$hyear) }\end{array}$} & \multirow{2}{*}{$\begin{array}{l}\text { Base } \\
\text { Case } \\
8,607\end{array}$} & \multicolumn{2}{|c|}{$\begin{array}{l}\text { Scenario \#3 } \\
\text { two million EVs } \\
\text { smart control }\end{array}$} & \multicolumn{2}{|c|}{$\begin{array}{l}\text { Scenario \#5 } \\
\text { one million EVs } \\
\text { customer conven. }\end{array}$} & \multicolumn{2}{|c|}{$\begin{array}{l}\text { Scenario \#6 } \\
\text { one million EVs } \\
\text { smart control }\end{array}$} \\
\hline & & 10,434 & $\begin{array}{l}1,827 \\
21.2 \%\end{array}$ & 9,479 & $\begin{array}{c}872 \\
10.1 \%\end{array}$ & 9,545 & $\begin{array}{c}938 \\
10.9 \%\end{array}$ \\
\hline $\begin{array}{l}\text { 2. Other Costs } \\
\text { (million \$lyear) }\end{array}$ & 10,141 & 10,141 & & 10,141 & & 10,141 & \\
\hline $\begin{array}{l}\text { 3. Total Revenue Requirement } \\
\text { (million Shear) }\end{array}$ & 18,748 & 20,575 & $\begin{array}{l}1,827 \\
9.7 \%\end{array}$ & 19,620 & $\begin{array}{r}872 \\
4.7 \%\end{array}$ & 19,686 & $\begin{array}{l}938 \\
5.0 \%\end{array}$ \\
\hline $\begin{array}{l}\text { 4. Electricity Sales with } \\
\text { no EVs (Gwhyear) }\end{array}$ & 95,104 & & & & & & \\
\hline $\begin{array}{l}\text { 5. EV Sales (Gwhlyear) } \\
\text { 6. Total Electricity Sales } \\
\text { (Gwhyear) }\end{array}$ & 95,104 & $\begin{array}{c}12,343 \\
107,44 ?\end{array}$ & $\begin{array}{l}12,343 \\
13.0 \%\end{array}$ & $\begin{array}{c}5,956 \\
101,060\end{array}$ & $\begin{array}{l}5,956 \\
6.3 \%\end{array}$ & $\begin{array}{c}5,956 \\
101,060\end{array}$ & $\begin{array}{l}5,956 \\
6.3 \%\end{array}$ \\
\hline $\begin{array}{l}\text { 7. Average Electric Rate } \\
\text { (mills/kwh) }\end{array}$ & 197.1 & 191.5 & -5.6 & 194.1 & -3.0 & 194.8 & -2.3 \\
\hline $\begin{array}{l}\text { EVs Impact on the } \\
\text { Average Electric Rate }\end{array}$ & & & $29 \%$ & & 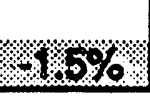 & & $-1.2 \%$ \\
\hline
\end{tabular}

NOTES:

1. ELFIN projections are given in Sheets 8,9

2. Other costs are considered fixed. EVs do not affect these costs since we do not add resources to the long term plan to serve the extra load. Also, we ignore utility spending (ie, smart control systems) to support or control EVs. These costs were provided by Jonathan Rubin of SCE on 11/1/91.

3. Total revenue requirements is the sum of the two previous costs.

4. SCE's regular electric sales were provided by Jonathan Rubin, SCE on 11/1/91. The sales include SCE's regular customers plus the resale agreements.

5. EV sales are shown in Sheets 4-7.

6. Total sales is regular SCE sales plus sales to EVs.

7. The average electric rate is defined as total revenue requirement spread over total sales. 
AERshort.WQ1 Average Electric Rate Impacts in the Year 2000 Both scenarios 7 and 8 can be served with LOLP under .05 dayshyear All $\$$ and mills are nominal in the year 2000 , the year of the study.

1. ELFIN Projection of Annual Costs from Fuel and Purchases (million \$year)

2. Other Costs (million \$year)

3. Total Revenue Requirement (million \$lyear)

4. Electricity Sales with no EVs (Gwhrs/year)

5. EV Sales (Gwhrshyear)

6. Total Electricity Sales (Gwhrs/year)

7. Average Electric Rate (mills/kwh)

EVs Impact on the Average Electric Rate

\begin{tabular}{|c|c|c|c|c|}
\hline $\begin{array}{l}\text { Base } \\
\text { Case }\end{array}$ & $\begin{array}{l}\text { Scenario } \\
\text { 50K EVs } \\
\text { customer c }\end{array}$ & nience & $\begin{array}{r}\text { Scenario } \\
500 \mathrm{~K} E \\
\text { customer c }\end{array}$ & enience \\
\hline 4,184 & 4,213 & $\begin{array}{c}29 \\
0.7 \%\end{array}$ & 4,391 & $\begin{array}{c}207 \\
4.9 \%\end{array}$ \\
\hline 6,802 & 6,802 & & 6,802 & \\
\hline $\begin{array}{l}10,986 \\
81,766\end{array}$ & 11,015 & $\begin{array}{c}29 \\
0.3 \%\end{array}$ & 11,193 & $\begin{array}{c}207 \\
1.9 \%\end{array}$ \\
\hline \multirow[t]{2}{*}{$\begin{array}{r}81,766 \\
134.4\end{array}$} & $\begin{array}{c}510 \\
82,276 \\
133.9\end{array}$ & $\begin{array}{c}510 \\
0.6 \% \\
-0.5\end{array}$ & $\begin{array}{r}3,143 \\
84,909 \\
131.8\end{array}$ & $\begin{array}{c}3,143 \\
3.8 \% \\
-2.5\end{array}$ \\
\hline & & $0.4 \%$ & & $1.9 \%$ \\
\hline
\end{tabular}

NOTES:

1. ELFIN projections are given in Sheet 10.

2. Other costs provided by Johathan Rubin of SCE on 11/1/91.

3. Total revenue requirements is the sum of the two previous costs.

4. SCE's sales were provided by Jonathan Rubin of SCE on 11/1/91.

5. EV sales are shown in Sheet 7.

6. Total sales is regular SCE sales plus sales to EVs.

7. The average electric rate is defined as total revenue requirement spread over total sales. 
AERqf.WQ1: Average Electric Rate Impacts Sensitivity Test:

This calculation is similar to AERlong. WQ1 expcept that the annual fuel and production costs are based on a fixed mills/kwh for QF payments

\begin{tabular}{|c|c|c|c|c|c|c|c|}
\hline \multirow[b]{2}{*}{$\begin{array}{l}\text { 1. ELFIN Projection of Annual } \\
\text { Costs for Fuel and Purchases } \\
\text { (million \$/year) }\end{array}$} & \multirow{2}{*}{$\begin{array}{l}\text { Base } \\
\text { Case } \\
8,607\end{array}$} & \multicolumn{2}{|c|}{$\begin{array}{l}\text { Sconario \#3 } \\
\text { two million EVs } \\
\text { smart control }\end{array}$} & \multicolumn{2}{|c|}{$\begin{array}{l}\text { Scenario \#5 } \\
\text { one million EVs } \\
\text { customer conven. }\end{array}$} & \multicolumn{2}{|c|}{$\begin{array}{l}\text { Scenario \#6 } \\
\text { one million EVs } \\
\text { smart control }\end{array}$} \\
\hline & & $\begin{array}{l}10,063 \\
\text { Note } 1\end{array}$ & $\begin{array}{r}1,456 \\
16.9 \%\end{array}$ & $\begin{array}{l}9,313 \\
\text { Note } 2\end{array}$ & $\begin{array}{l}706 \\
8.2 \%\end{array}$ & $\begin{array}{c}9,254 \\
\text { Note } 3\end{array}$ & $\begin{array}{l}647 \\
7.5 \%\end{array}$ \\
\hline $\begin{array}{l}\text { 2. Other Costs } \\
\text { (million \$/year) }\end{array}$ & 10,141 & 10,141 & & 10,141 & & 10,141 & \\
\hline $\begin{array}{l}\text { 3. Total Revenue Requirement } \\
\text { (million \$year) }\end{array}$ & 18,748 & 20,204 & $\begin{array}{l}1,456 \\
7.8 \%\end{array}$ & 19,454 & $\begin{array}{r}706 \\
3.8 \%\end{array}$ & 19,395 & $\begin{array}{c}647 \\
3.5 \%\end{array}$ \\
\hline $\begin{array}{l}\text { 4. Electricity Sales with } \\
\text { no EVs (Gwhyear) } \\
\text { 5. EV Sales (Gwhlyear) }\end{array}$ & 95,104 & 12,343 & & 5,956 & & 5,956 & \\
\hline $\begin{array}{l}\text { 6. Total Electricity Sales } \\
\text { (Gwh/year) }\end{array}$ & 95,104 & 107,447 & $\begin{array}{l}12,343 \\
13.0 \%\end{array}$ & 101,060 & $\begin{array}{l}5,956 \\
6.3 \%\end{array}$ & 101,060 & $\begin{array}{l}5,956 \\
6.3 \%\end{array}$ \\
\hline $\begin{array}{l}\text { 7. Average Electric Rate } \\
\text { (mills/kwh) } \\
\text { EVs Impact on the }\end{array}$ & 197.1 & 188.0 & -9.1 & 192.5 & -4.6 & 191.9 & -5.2 \\
\hline Average Electric Rate & & & $4.6 \%$ & & $-2.3 \%$ & & $2.6 \%$ \\
\hline
\end{tabular}

NOTES:

1. ELFIN projections from sheets 9,10 are reduced by amount shown in bottom row of sheet \#16. For EV \#3, for example, production costs would be $\$ 10,434$ million less $\$ 371$ million or $\$ 10,063$ million.

2. For EV \#5, production costs are $\$ 9,479$ million less $\$ 166$ million.

3. For EV \#6, production costs are $\$ 9,545$ million less $\$ 291$ million. 
HC2.wq1 to estimate hydrocarbon emissions that could be avoided when an EV displaces a CV.

HC (grams/mile), CV before 1994:

0.39

HC (grams/mile), CV 1994 to 1999:

0.25

HC (grams/mile), LEV 1999 and after:

0.075

These standards from CARB, 8-13-90 staff report, p.24, 29. They apply at 50,000 miles on the odometer. I ignore the mixing of vehicle types.

Number of EVs Sold:

Year of the Sale:

HC Standard (grams/mile) of displaced vehicle:

Year of the next Sale (10 yrs later):

HC Standard (grams/mile) for 2 nd displaced vehicle:

Average Travel (miles/day):

Conversion Factor (tons per million grams):

Odometer Emissions

$\begin{array}{rllrlrl}\text { Age of } & \text { Calendar } & \text { X } & \text { Travel } & \text { Travel } & \text { Reading } & \text { Age } \\ \text { the EV } & \text { Year } & \text { Axis } & \text { Factor } & \text { (miles/day) } & \text { (Kmiles) } & \text { Factor } \\ 1 & 1993 & 1993 & 130 & 39.0 & 14.2 & 0.55\end{array}$

$\begin{array}{lllll}1 & 1993 & 1993 & 1.30 & 39.0 \\ 2 & 1994 & & 1.20 & 36.0 \\ 3 & 1995 & 1995 & 1.00 & 30.0\end{array}$

$14.2 \quad 0.55$

$27.4 \quad 0.60$

$38.3 \quad 0.75$

$49.3 \quad 1.00$

$60.2 \quad 1.15$

$71.2 \quad 1.30$

$82.1 \quad 1.45$

$93.1 \quad 1.60$

$101.8 \quad 1.75$

$109.5 \quad 1.90$

Emissions Total

Rate Emissions

(gr/mile) (tons/day)

$0.215 \quad 9.2$

$0.234 \quad 9.3$

$0.293 \quad 9.7$

$0.390 \quad 12.9$

$0.449 \quad 14.9$

$0.507 \quad 16.8$

$\begin{array}{ll}0.566 & 18.7\end{array}$

$0.624 \quad 20.7$

$0.683 \quad 18.1$

$0.741 \quad 17.2$

$\begin{array}{lllll}11 & 2003 & 2003 & 1.30 & 39.0 \\ 12 & 2004 & & 1.20 & 36.0 \\ 13 & 2005 & 2005 & 1.00 & 30.0 \\ 14 & 2006 & & 1.00 & 30.0 \\ 15 & 2007 & 2007 & 1.00 & 30.0 \\ & & & \text { Average: } & 31.0\end{array}$

$14.2 \quad 0.55$

$27.4 \quad 0.60$

$38.3 \quad 0.75$

49.3

1.00

60.2

1.15

0.041

0.045

0.056

0.075

0.086

1.8

1.8

1.9

2.5

2.9

10.5

57,748

0.058

Total Emissions Avoided over 15 years (tons/vehicle):

115

If the \$/ton "value" of avoided emissions is (CEC p. 7 for ER92, 1989\$):

Then the "value" of the avoided emissions for each EV is:

$\$ 16,600$

$\$ 959$

Sheet \#21 
NOx2.wq1 to estimate nitrous oxide emissions that could be avoided when an EV displaces a CV.

NOx (grams/mile), CV before 1994:

0.4

NOx (grams/mile), CV 1994 to 1999:

0.4

NOx (grams/mile), LEV 1999 and after:

0.2

These standards from CARB, 8-13-90 staff report, p. 20, 29.

They apply at 50,000 miles on the odometer. I ignore mixing of vehicle types.

Number of EVs Sold:

$1,000,000$

Year of the Sale:

1993

NOx Standard (grams/mile) of displaced vehicle: $\quad 0.400$

Year of the next Sale (10 yrs later):

2003

NOx Standard (grams/mile) for 2 nd displaced vehicle:

Average Travel (miles/day):

0.200

Conversion Factor (tons per million grams):

\section{Odometer Emissions}

Age of Calendar $X$ Travel Travel

the EV Year Axis Factor (miles/day)

$11993 \quad 1993$

21994

31995

$4 \quad 1996$

$5 \quad 1997$

$6 \quad 1998$

$7 \quad 1999$

82000

92001

$10 \quad 2002$

1.30

1.20

39.0

36.0

30.0

30.0

30.0

30.0

30.0

30.0

24.0

21.0

0.70

Reading Age

(Kmiles) Factor

14.2

27.4

38.3

49.3

60.2

71.2

82.1

93.1

101.8

109.5

0.61

0.74

0.87

1.00

1.13

1.26

1.39

1.52

1.65

1.78

$14.2 \quad 0.61$

27.4

38.3

49.3

60.2

30.0

1.00

31.0

39.0
36.0
30.0
30.0
30.0
31.0

0.87

1.00

1.13

Average:

Total Emissions Avoided over 15 years (tons):

Total Emissions Avoided over 15 years (tons/vehicle):

Total Emissions Avoided over 15 years (pounds/vehicle):
.104

$\begin{array}{lc}\begin{array}{l}\text { Emissions } \\ \text { Rate }\end{array} & \begin{array}{c}\text { Total } \\ \text { Emissions } \\ \text { (gr/mile) }\end{array} \\ \text { (tons/day) } \\ 0.244 & 10.5 \\ 0.296 & 11.8 \\ 0.348 & 11.5 \\ 0.400 & 13.2 \\ 0.452 & 15.0 \\ 0.504 & 16.7 \\ 0.556 & 18.4 \\ 0.608 & 20.1 \\ 0.660 & 17.5 \\ 0.712 & 16.5\end{array}$

$\begin{array}{cc}0.122 & 5.3 \\ 0.148 & 5.9 \\ 0.174 & 5.8 \\ 0.200 & 6.6 \\ 0.226 & 7.5 \\ & 12.2 \\ & 66,525 \\ & 0.067 \\ & 133 \\ & \end{array}$

$\$ 24,300$

$\$ 1,617$

Sheet \#22 
Estimate carbon monoxide emissions that could be avoided when an EV displaces a CV.

CO (grams/mile), CV before 1994:

CO (grams/mile), CV 1994 to 1999:

CO (grams/mile), LEV 1999 and after:

These standards from CARB, 8-13-90 staff report, p. 20. They apply at 50,000 miles on the odometer. I ignore the mixing of vehicle types.

Number of EVs Sold:

Year of the Sale:

$1,000,000$

1993

3.400

2003

Year of the next Sale (10 yrs later):

3.400

Average Travel (miles/day):

Conversion Factor (tons per million grams):

Age of Calendar $X \quad$ Odometer Emissions the E

$\begin{array}{rl}\text { EV } & \text { Year } \\ 1 & 1993 \\ 2 & 1994 \\ 3 & 1995 \\ 4 & 1996 \\ 5 & 1997 \\ 6 & 1998 \\ 7 & 1999 \\ 8 & 2000 \\ 9 & 2001 \\ 10 & 2002\end{array}$

X Travel Travel Axis Factor (miles/day)

1993

1.30

1.20

1995

1.00

1.00

$1997 \quad 1.00$

1.00

1999

1.00

1.00

2001

0.80

0.70

39.0

36.0

30.0

30.0

30.0

30.0

30.0

30.0

24.0

21.0

Reading Age

(Kmiles) Factor

14.2

27.4

0.43

38.3

0.62

30

1.104

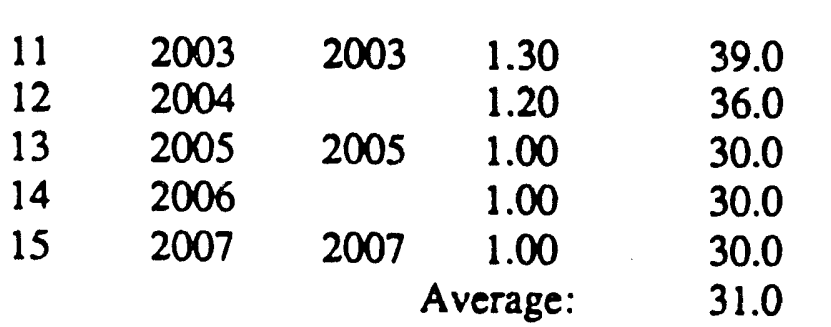

Total Emissions A voided over 15 years (tons):

$49.3 \quad 1.00$

60.2

71.2

82.1

93.1

101.8

109.5

1.19

1.38

1.57

1.76

1.95

2.14

14.20 .43

27.4

38.3

0.62

49.3

0.81

60.2

1.00

1.19

$\begin{array}{cc}\begin{array}{l}\text { Emissions } \\ \text { Rate } \\ \text { (gt/mile) }\end{array} & \begin{array}{c}\text { Total } \\ \text { Emissions } \\ \text { (tons/day) }\end{array} \\ 1.462 & 62.9 \\ 2.108 & 83.8 \\ 2.754 & 91.2 \\ 3.400 & 112.6 \\ 4.046 & 134.0 \\ 4.692 & 155.4 \\ 5.338 & 176.8 \\ 5.984 & 198.2 \\ 6.630 & 175.7 \\ 7.276 & 168.7 \\ & \\ 1.462 & 62.9 \\ 2.108 & 83.8 \\ 2.754 & 91.2 \\ 3.400 & 112.6 \\ 4.046 & 134.0 \\ & 122.9 \\ & 673.003 \\ & 0.673 \\ & 1,346\end{array}$

$\$ 9,500$

$\$ 6,394$

Sheet $\$ 23$ 
AVOID1.WQ1 to summarize emissions avoided by sale of an EV depending on the year in which the EV is sold.

Use previous sheets (ie, HC2.WQ1) and vary the entry for year of sale.

Let \$non be:

HC NOX CO

or:

\$6,603\% 24,600 \% $\$ 500$

$\$ 10,100 \quad \$ 10,100$

$\$ 2,200$

$\$ 17,200 \$ 18,600$

CEC. 9/5/91, p. 7, for the Bay Area

or:

$\$ 1,100$ CEC, 9/5/91, p. 7, for San Diego County

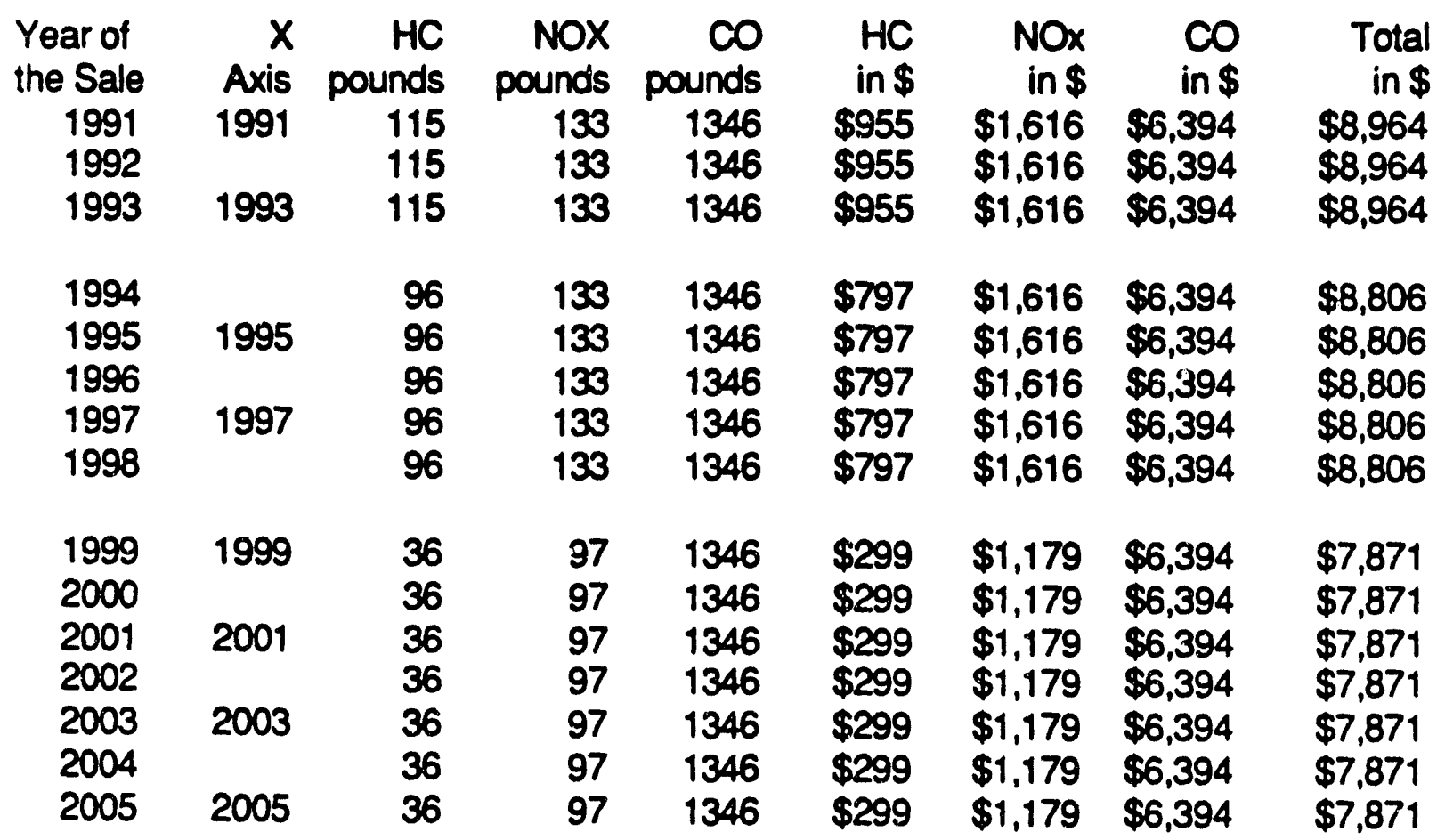


NOx Emissions from Power Plants in 4 scenarios with Two Million EVs

\begin{tabular}{|c|c|c|c|c|c|c|c|}
\hline \multirow[b]{2}{*}{$\begin{array}{l}\text { NOx Emissions } \\
\text { (tons/yr) }\end{array}$} & \multirow[b]{2}{*}{$\begin{array}{l}\text { Base } \\
\text { Case }\end{array}$} & \multicolumn{3}{|c|}{ 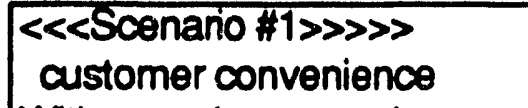 } & \multicolumn{3}{|c|}{$\begin{array}{l}\text { 《<< Scenario \#2 } \gg \gg \gg \gg \gg>>>> \\
\text { "10 pm incentive" }\end{array}$} \\
\hline & & $\begin{array}{l}\text { With } \\
\text { EVs }\end{array}$ & Impact & $\begin{array}{l}\text { Impact } \\
(\%)\end{array}$ & $\begin{array}{l}\text { With } \\
\text { Evs }\end{array}$ & Impact & $\begin{array}{l}\text { Impact } \\
(\%)\end{array}$ \\
\hline $\begin{array}{l}\text { Nuclear } \\
\text { Coal } \\
\text { O/G Existing } \\
\text { O/G new \& rep. } \\
\text { OF \& Self } \\
\text { Hydro } \\
\text { PNW Economy } \\
\text { PSW Economy } \\
\text { Other Modifier } \\
\text { Other }\end{array}$ & $\begin{array}{r}0 \\
42,686 \\
3,222 \\
1,470 \\
5,970 \\
0 \\
3,661 \\
500 \\
277 \\
3,552\end{array}$ & $\begin{array}{r}0 \\
43,734 \\
4,800 \\
2,068 \\
5,972 \\
0 \\
3,941 \\
1,172 \\
277 \\
3,630\end{array}$ & $\begin{array}{r}0 \\
1.048 \\
1.578 \\
598 \\
2 \\
0 \\
280 \\
672 \\
0 \\
78\end{array}$ & $\begin{array}{c}0 \% \\
25 \% \\
37 \% \\
14 \% \\
0 \% \\
0 \% \\
7 \% \\
16 \% \\
0 \% \\
2 \%\end{array}$ & $\begin{array}{r}0 \\
43,805 \\
5,285 \\
1,992 \\
5,973 \\
0 \\
3,965 \\
1,435 \\
277 \\
3,637\end{array}$ & $\begin{array}{r}0 \\
1,119 \\
2,063 \\
522 \\
3 \\
0 \\
304 \\
935 \\
0 \\
85\end{array}$ & $\begin{array}{l}0 \% \\
22 \% \\
41 \% \\
10 \% \\
0 \% \\
0 \% \\
6 \% \\
19 \% \\
0 \% \\
2 \%\end{array}$ \\
\hline \multirow[t]{2}{*}{$\begin{array}{l}\text { Totals } \\
\text { O/G Total }\end{array}$} & $\begin{array}{r}61,338 \\
4,692\end{array}$ & $\begin{array}{r}65,594 \\
6,868 \\
\end{array}$ & $\begin{array}{l}4,256 \\
2,176 \\
\end{array}$ & $\begin{array}{l}100 \% \\
51 \% \\
\end{array}$ & $\begin{array}{r}66,369 \\
7,277 \\
\end{array}$ & $\begin{array}{l}5,031 \\
2,585 \\
\end{array}$ & $\begin{array}{l}100 \% \\
51 \% \\
\end{array}$ \\
\hline & & \multicolumn{3}{|c|}{$\begin{array}{l}\text { «SSconario \#3 } 3 \gg \gg \gg> \\
\text { Smart Control }\end{array}$} & \multicolumn{3}{|c|}{$\begin{array}{l}\ll<<\text { Scenario \#4 } \gg \gg \gg \gg \gg \gg>>> \\
\text { customer convenience }\end{array}$} \\
\hline $\begin{array}{l}\text { NOx Emissions } \\
\text { (tons/yr) }\end{array}$ & $\begin{array}{l}\text { Base } \\
\text { Case }\end{array}$ & $\begin{array}{l}\text { With } \\
\text { EVs }\end{array}$ & Impact & $\begin{array}{l}\text { Impact } \\
(\%)\end{array}$ & $\begin{array}{l}\text { With } \\
\text { Evs }\end{array}$ & Irivpact & $\begin{array}{l}\text { Impact } \\
(\%)\end{array}$ \\
\hline Nuclear & & 0 & 0 & $0 \%$ & 0 & 0 & $0 \%$ \\
\hline $\begin{array}{l}\text { Coal } \\
\text { O/G Existing }\end{array}$ & $\begin{array}{r}42,686 \\
3,222\end{array}$ & $\begin{array}{r}44,619 \\
3,831\end{array}$ & $\begin{array}{r}1,933 \\
609\end{array}$ & $\begin{array}{l}44 \% \\
14 \%\end{array}$ & $\begin{array}{r}43,873 \\
4.502\end{array}$ & $\begin{array}{l}1,187 \\
1,280\end{array}$ & $\begin{array}{l}29 \% \\
32 \%\end{array}$ \\
\hline W \& rep. & 1,470 & 2,167 & 697 & $16 \%$ & 2,103 & 633 & $16 \%$ \\
\hline & & $\begin{array}{r}5,976 \\
0\end{array}$ & $\begin{array}{l}6 \\
0\end{array}$ & $\begin{array}{l}0 \% \\
0 \%\end{array}$ & 5,973 & 3 & \\
\hline Economy & 3,661 & 4,074 & 413 & $\begin{array}{l}0 \% \\
9 \%\end{array}$ & $\begin{array}{r}0 \\
3.959\end{array}$ & $\begin{array}{r}0 \\
298\end{array}$ & $\begin{array}{l}0 \% \\
7 \%\end{array}$ \\
\hline onomy & 500 & 1,131 & 631 & $14 \%$ & 1,071 & $\begin{array}{l}298 \\
571\end{array}$ & $14 \%$ \\
\hline odifier & 277 & 277 & 0 & $0 \%$ & 277 & 0 & $0 \%$ \\
\hline Other & 3,552 & 3,695 & 143 & $3 \%$ & 3,641 & 89 & $2 \%$ \\
\hline $\begin{array}{l}\text { Totals } \\
\text { O/G Total }\end{array}$ & $\begin{array}{r}61,338 \\
4,692\end{array}$ & $\begin{array}{r}65,770 \\
5,998 \\
\end{array}$ & $\begin{array}{l}4,432 \\
1,306 \\
\end{array}$ & $\begin{array}{l}100 \% \\
29 \% \\
\end{array}$ & $\begin{array}{r}65,399 \\
6,605 \\
\end{array}$ & $\begin{array}{l}4,061 \\
1,913 \\
\end{array}$ & $\begin{array}{l}100 \% \\
47 \% \\
\end{array}$ \\
\hline
\end{tabular}

Sheet \#25 
ELFEF.WQ1 looks at the NOx emissions factors

AVERAGE FACTORS

Coal

OivGas Existing

OiVGas new\&repowered

QF \& Sell Generation

Hydro

PNW economy

PSW economy

Other Modifiers

Other

INDMIUAL FACTORS

Combined Cycle 1 (new)

H. Beach 3,4 repowered

Alamitos 1,2 repowered

H. Beach 1 (old)

Alamitos 3 (old)

Ormond Beach 1 (old)

El Segundo 4 (old)

Four Comers 4 (coal)

Mojave 1 (coal)
《< Base Case Scenario 》»》>

NOx in Energy tons per

tons/yr GWhrshyr GWhr

\begin{tabular}{|c|c|c|c|c|c|}
\hline $\begin{array}{r}42,686 \\
3,222 \\
1,470 \\
5,970 \\
0 \\
3,661 \\
500 \\
277 \\
3,552\end{array}$ & $\begin{array}{r}11,197 \\
12,270 \\
18,585 \\
46,714 \\
4,873 \\
6,102 \\
375 \\
632 \\
3,986\end{array}$ & $\begin{array}{l}3.812 \\
0.263 \\
0.079 \\
0.128 \\
0.000 \\
0.600 \\
1.333 \\
0.438 \\
0.891\end{array}$ & $\begin{array}{r}43,734 \\
4,800 \\
2,068 \\
5,972 \\
0 \\
3,941 \\
1,172 \\
277 \\
3,630\end{array}$ & $\begin{array}{r}11,514 \\
16,572 \\
26,376 \\
46,763 \\
4,873 \\
6,569 \\
630 \\
632 \\
4,054\end{array}$ & $\begin{array}{l}3.798 \\
0.290 \\
0.078 \\
0.128 \\
0.000 \\
0.600 \\
1.860 \\
0.438 \\
0.895\end{array}$ \\
\hline
\end{tabular}

《< Scenario \#1 $\gg \gg>$

NOx in Energy tons per

tons/yr GWhrs/yr GWhr

\begin{tabular}{rrr|rrr|r|}
5418 & 6,607 & 0.078 & & 873 & 11,133 & 0.078 \\
272 & 3,513 & 0.077 & 337 & 4,388 & 0.077 \\
456 & 5,755 & 0.079 & 613 & 7,855 & 0.078 \\
& & & & & \\
21 & 113 & 0.182 & 21 & 114 & 0.181 \\
77 & 342 & 0.226 & 104 & 525 & 0.198 \\
396 & 1,702 & 0.233 & 564 & 1,982 & 0.285 \\
132 & 502 & 0.263 & 157 & 644 & 0.244 \\
& & & & & \\
0,489 & 2,098 & 4.999 & 10,654 & 2,131 & 5.000 \\
5,368 & 2,367 & 2.268 & 5,546 & 2,445 & 2.268 \\
\hline
\end{tabular}

Sheet \#26 
OZONE.WQ1 keeps track of various projections of HC \& NOx emissions as well as peak ozone concentration projected by models

$\begin{array}{lllll} & \text { HCorROG } & \text { NOx } & \text { HC plus Ozone } \\ \text { SCENARIO \& COMMENTS } & \text { Emis. } & \text { Emis. } & \begin{array}{l}\text { NOx is: } \\ \text { from model }\end{array} \\ & \text { (tons/day) } & \text { (tons/day) } & \text { (tons/day) } & \text { (pphm) }\end{array}$

Hempel's Report: emissions are on page 61; peak Ozone on p. 5:

$\begin{array}{llrll}\text { Base Case } 1985 \text { (for a "retrospective" benchmark) } & 1530 & 1132 & 2662 & 35.80 \\ \text { Base Case } 2010 \text { (sig. improve in auto controls) } & 1162 & 999 & 2161 & 28.80 \\ \text { Steady Adv. } 1985 \text { ("retrospective" impact) } & 1319 & 1016 & 2335 & 30.60 \\ \text { Steady Adv 2010 (impact relative to 2010 base) } & 1088 & 940 & 2028 & 25.40 \\ \text { Breakthrough 1985 ("retrospective" impact) } & 1163 & 928 & 2091 & 27.60 \\ \text { Breakthrough 2010 (impact relative to 2010 base) } & 1028 & 894 & 1922 & 24.40\end{array}$

RFF Report: all numbers referr to the year 2010

Emissions in $1000 \mathrm{lbs} /$ day on p. 3-22. Divide by 2 to get tons/day.

$\begin{array}{lllll}\text { Base Case for the year } 2010 \text { (counts Tier I controls) } & 646 & 595 & 1241 & 19.60 \\ \text { I base + } 0.5 \text { million Methanol vehicles } & 635 & 595 & 1230 & 19.51 \\ \text { II base }+0.5 \text { million Electric vehicles } & 625 & 569 & 1194 & 19.32 \\ \text { III base + } 1.5 \text { million Electric vehicles } & 589 & 530 & 1119 & 18.79\end{array}$

SCAQD 1991 draft plan (emissions for a specific episode).

Model estimate of Ozone on p. 5-14. Average daily emissions for 2010 on p. 3-13.

$\begin{array}{lrrrr}1985 \text { baseline } & 1605 & 1200 & 2805 & 33.10 \\ 1994 \text { baseline } & 1167 & 954 & 2121 & 26.20 \\ 1997 \text { baseline } & 1105 & 878 & 1983 & 24.90 \\ 2000 \text { baseline } & 1077 & 865 & 1942 & 24.00 \\ 2010 \text { baseline } & 1151 & 955 & 2106 & 25.00 \\ 1994 \text { control } & 991 & 855 & 1846 & 24.40 \\ 1997 \text { control } & 815 & 648 & 1463 & 21.70 \\ 2000 \text { control } & 523 & 543 & 1066 & 18.60 \\ 2010 \text { control } & 171 & 328 & 499 & 11.90 \\ 2010 \text { base line with average daily emissions } & 1128 & 872 & 2000 & -- \\ \text { ratio of episode day to average day (2010 baseline) } & 1.02 & 1.10 & 1.05 & \end{array}$

CEC Scenarios Nov 1990 (emissions but no Ozone projections)

$\begin{array}{lrrrr}\text { Vol II,A,p. } 14 \text { gives actual emissions for } 1987 & 1134 & 964 & 2098 & \ldots \\ \text { including both fuels and nonfuels } & & & & \\ \text { Baseline 2009 (Vol I,5) (Fuels only) } & 310 & 711 & 1021 & \ldots \\ \text { High EV 2009 (Vol I,5) (Fuels only) } & 204 & 573 & 777 & \ldots\end{array}$




\section{Sheet 28}

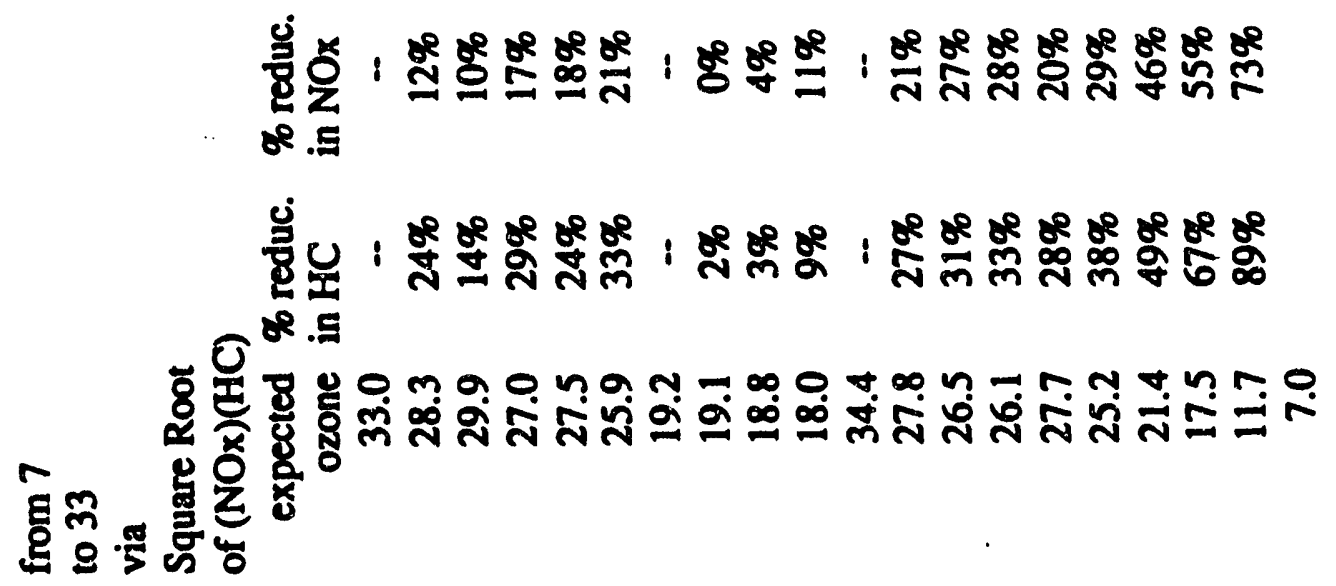

틀

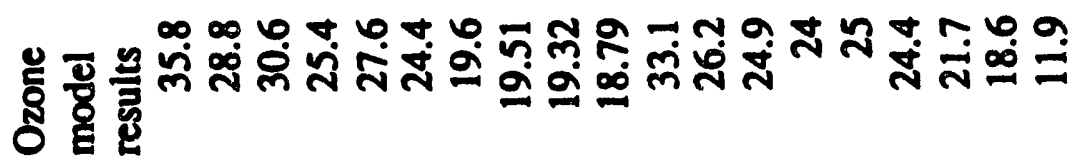

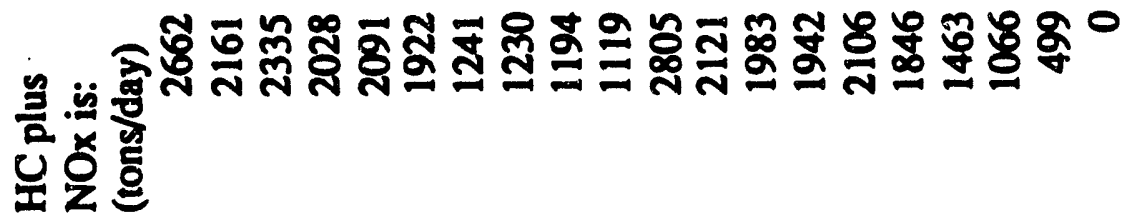

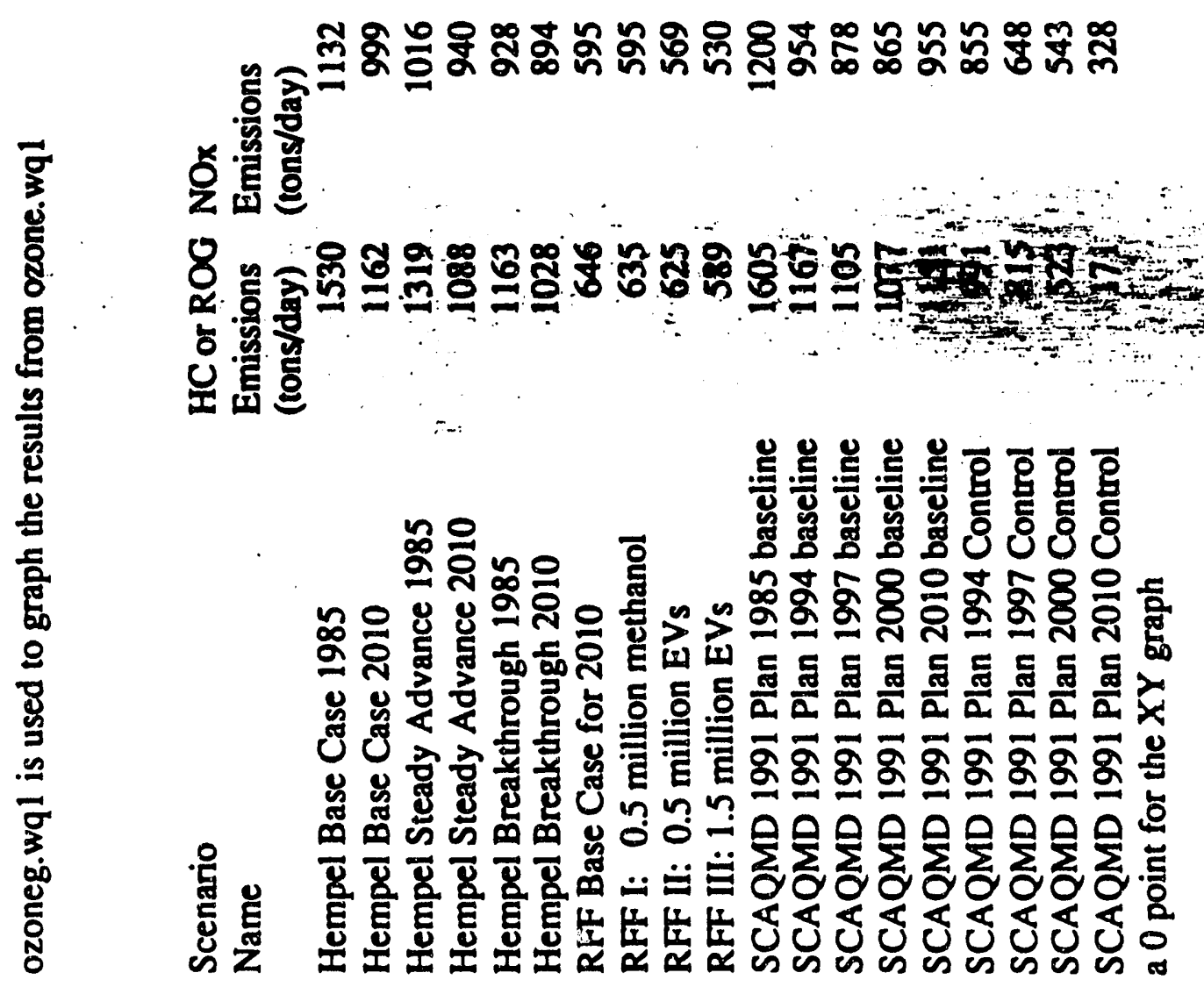



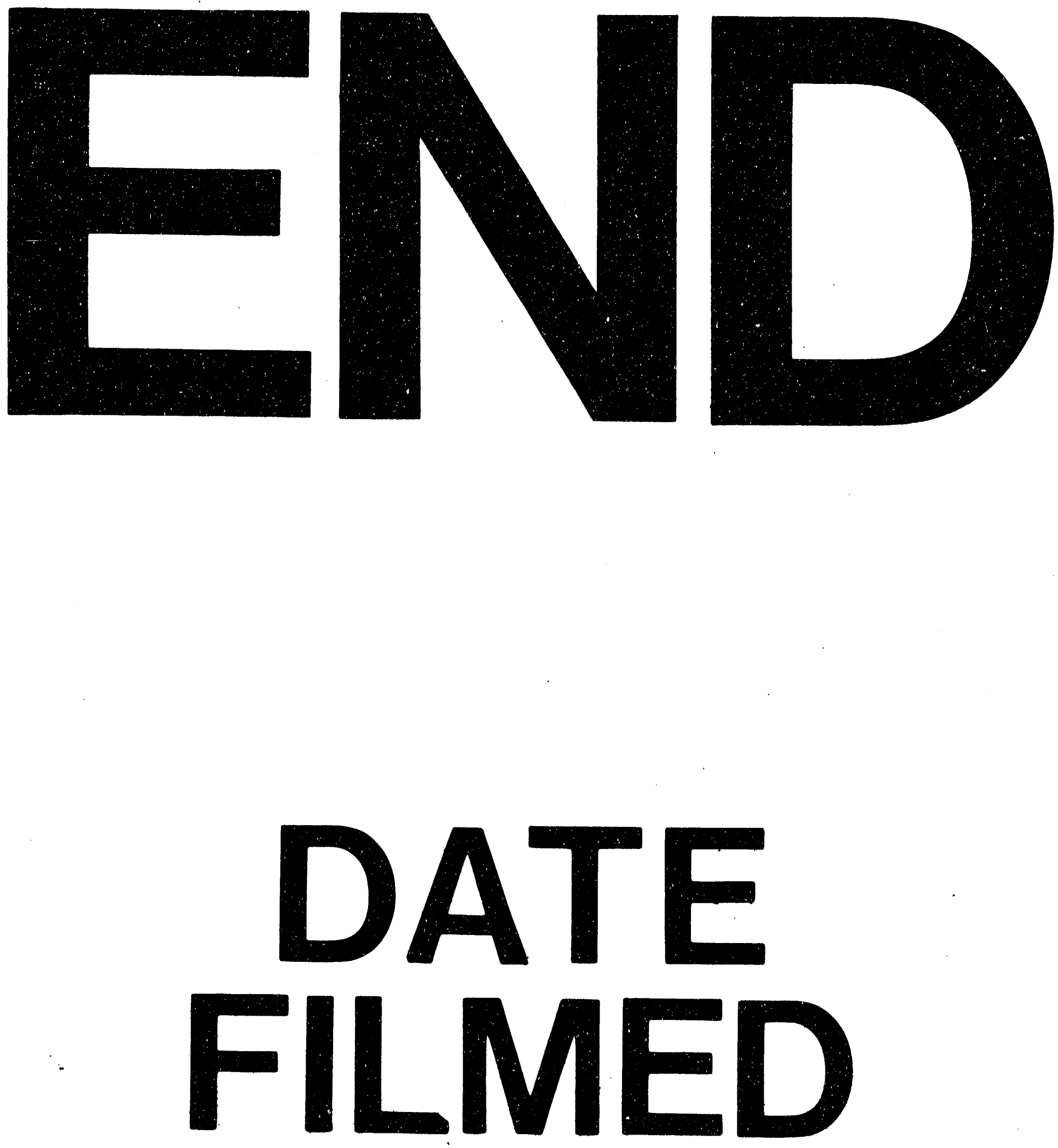

$p$

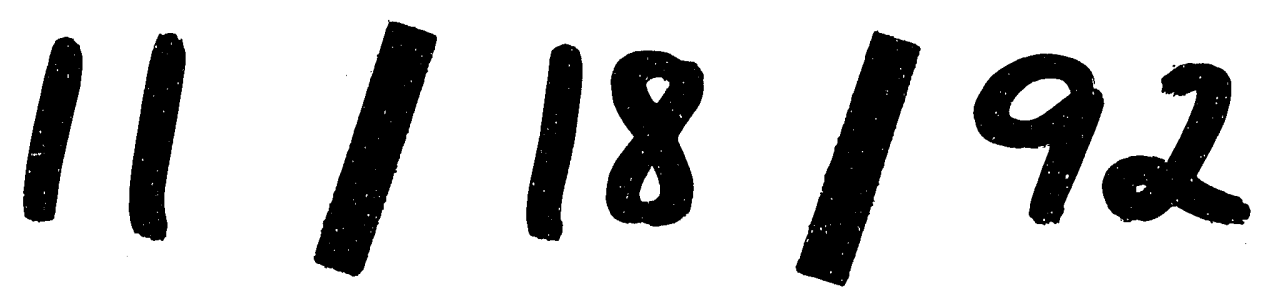


